S T A T E OF I L L I N O I S

Dwight H. Green, Governor

DEPARTMENT OF REGISTRATION AND EDUCATION

Frank G. 'Thompson, Director

NATURAL HISTORY SURVEY DIVISION

Theodore. H. Frison, Chief

\title{
Studies of
}

\section{North American Plecoptera}

With Special Reference to the Fauna of Illinois

$$
\text { T. H. F R I S ON }
$$




\section{STA I E OF I LILINOIS \\ Dwight H. Green, Governor \\ DEPARTMENT OF REGISTRATION AND FDUCATION \\ Frank G. Thompson, Direcior \\ BOARD OF NATURAL RESOURCES AND CONSERVATION \\ FrANK G. ThOMPSON, Chairman}

Millam Trelease, D.Sc., LL.D., Biology Arthur Cutts Willard, D.Eng., LL. D., Ezra J. Kraus, Ph.D., D.Sc., Forestry President of the University of Illinois

I. R. Howson, B.S.C.E., C.E., Engineering. Edson S. Bastrn, Ph.D., Geology Roger Adams, Ph.D., D.Sc., Chemistry

\section{NATURAL HISTORY SURVEY DIVISION Urbana, Illinois \\ SCIENTIFIC AND TECHNICAL STAFF \\ Theodore H. Frison, Ph.D., Chief}

\section{Section of Economic Entomology}

IV. P. FLINT, B.S., Chief Entomologist

C. C. Сомptos, Ph.D., Associale Entomologist

M. D. Farrar, Ph.D., Research Entomologist

J. H. Bigger, M.S., Associate Entomologist

S. C. Chandler, B.S., Southern Field Entomologist

James W. Apple, M.S., Northern Field Entomologist

B. G. Berger, M.A., Assistant Entomologist

H. B. Petry, Jr., B.A., Assistant, Entomology Extension

J. E. Porter, B.A., Enlomological Assistant

C. J. Weinman, Ph.D., Research Fellow in Entomology

George F. Ludvik, B.A., Research Fellow in Entomology

J. M. MAGNER, B.A., Funior Entomologist (U.S.B.E.P.2. and Commodity Credit Corporation, cooperating)

Section of Insect Survey

H. H. Ross, Ph.D., Systematic Entomologist

CARL O. Мohr, Ph.D., Associate Entomologist, Artist

B. D. Burks, Ph.D., Assistant Entomologist (On leave)

G. T. RIEGE L, M.S., Entomological Assistant

Kathryn M. Sommerman, M.S., Artist, Entomological Assistant

\section{Section of Forestry}

James E. Davis, M.F., Extension Forester L.ee E. Yeager, Ph.D., Foresier

Consultant: Herpetology, Howard Chicago Academy of Sciences

\section{Section of Aquatic Biology}

David H. Thompson, Ph.D., Zoologist

George W. BennetT, Ph.D., Limnologist

D. F. HANSEN, Ph.D., Assistant Zoologist

Bruno Limbach, M.S., Zoological Assistant

Section of Game Research and Management

R. E. Yeatter, Ph.D., Game Specialist

Section of Wildlife Experimental Areas

Arthur S. Hawkins, M.S., Game Technician (On leave)

F. C. Bellrose, Jr., B.S., Assistant Game Technician

J. B. Low, Ph.D., Assistant Game Technician

W. H. Elder, Ph.D., Assistant Game Technician

Cooperative Wildlife Restoration Program

(State Department of Conservation and U. S. Fish and Wildlife Service)

Harry G. Anderson, M.A., funior Biologist

L. G. Brown, B.S., Funior Biologist

R. E. Hesselschwerdt, B.A., funior Biologist

C. S. Spooner, Jr., M.F., Funior Biologist

Section of Applied Botany and Plant Pathology

L. R. TEHON, Ph.D., Botanist

D. B. CREAGER, Ph.D., Research Pathologist

J. C. Carter, Ph.D., Assistant Botanist

G. H. BoEWE, M.S., Field Botanist

Section of Publications

James S. Ayars, B.S., Technical Editor

This paper is a contribution from the Section of Insect Survey.

(22821-1200-4-42)

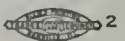


C O N'T N T S

Acknowledgments . . . . . . . . . . . . . . . . . . . . . . . . . 236

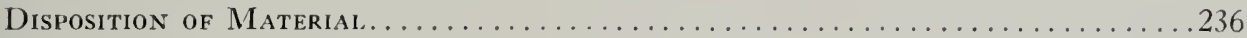

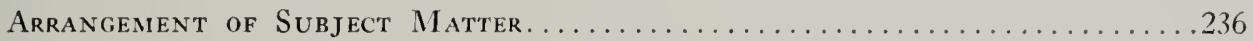

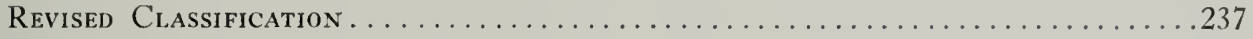

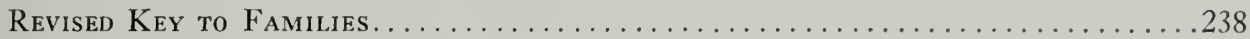

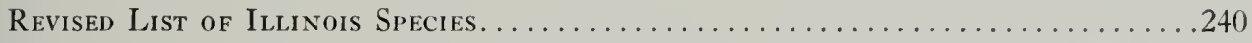

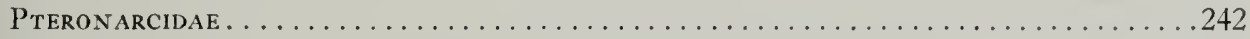

Peltoperlidae. . . . . . . . . . . . . . . . . . . . . . . . . . . . . . 245

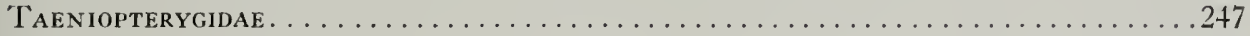

LeUCtridae. . . . . . . . . . . . . . . . . . . . . . . . . . . . 256

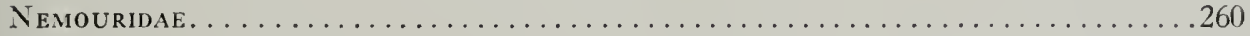

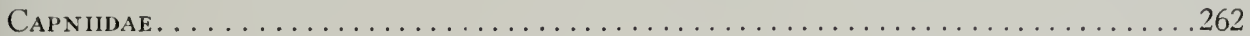

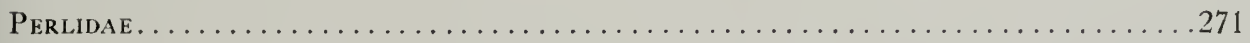

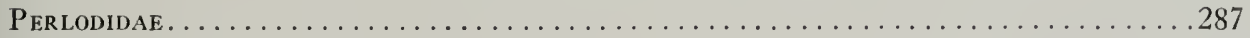

IsOPERLIDAE . . . . . . . . . . . . . . . . . . . . . . . . . . . . . 311

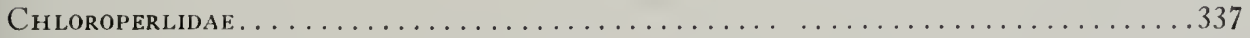

Literature Cited . . . . . . . . . . . . . . . . . . . . . . . . . . . . . . 348

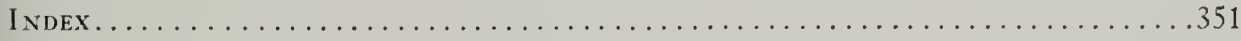




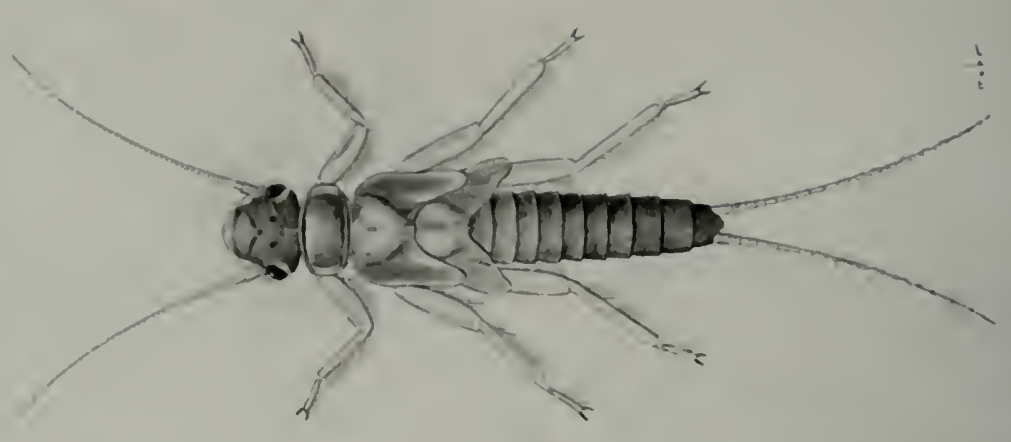

.
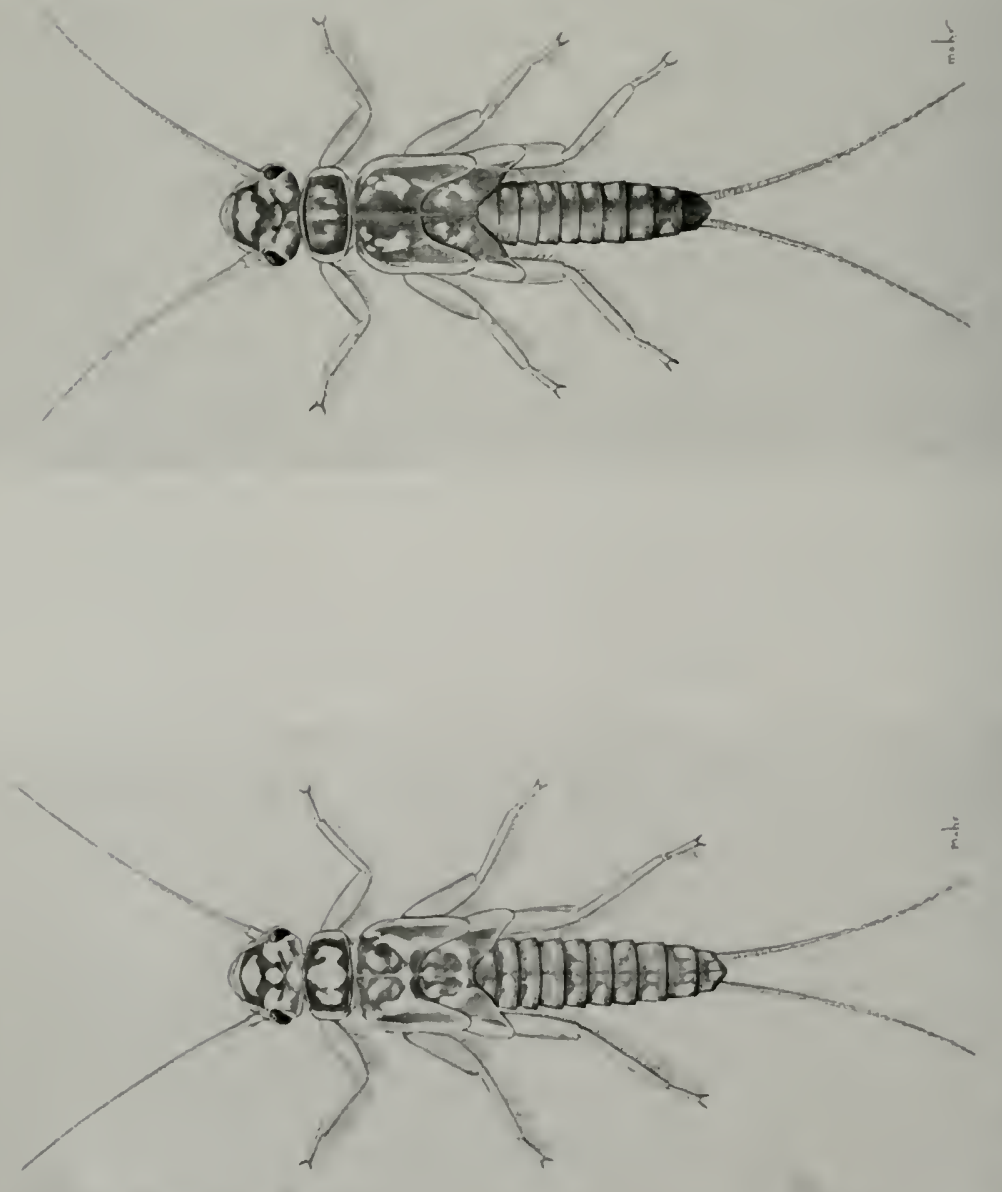


\title{
Studies of
}

\section{North American Plecoptera}

\author{
With Special Reference \\ to the Fauna of Illinois
}

\section{T. H. FR I SON}

$\mathrm{T}$

HIS paper is a result of the continuance of studies of the stonefly fauna of Illinois started in 1926 and expanded within more recent years to include the fauna of North America. Three previous papers of mine have dealt entirely or in part with Illinois material of these aquatic insects; the first dealing with the fall and winter species only (1929), the second with all the then known Illinois species (1935a) and the third with additional information and recordings of species (1937).

In 1937 the Illinois list of stoneflies stood at 38 species plus a questionable identification of a capniid female and the nymph of a species of Isoperla not placeahle to species. Studies of Illinois material since 1937 have revealed the identity of the capniid adult and the Isoperla nymph, and added nine additional species to the Illinois list.

Besides the study of Illinois Plecoptera, work has been in progress on the stonefly fauna of North America in general as a result of the availability of a large amount of adult and nymphal material submitted for identification by others or directly secured on collecting trips made by various members of the Illinois Natural History Survey staff. 'The Great Smoky Mountains National Park region and the states of $\mathrm{W}$ isconsin and Michigan have been particularly singled out for collecting trips because of their nearness to Urbana, Ill., and the occurrence in them of numerous species not found in Illinois which are fairly representative of more northern and eastern sections of the United States and Canada. Numerous other collecting trips producing much material, trips often coupled with vacations or other duties, have been made by various staff members to almost all parts of the United States, with the exception of the southwestern states, and to southern Canada. In addition to collection of adult and nymphal stonefly material in quantity, considerable attention always has been given on these trips to the taking of mating pairs and the rearing of adults from nymphs. Some of the rearing of adults from nymphs has been done at the point of collection by the use of special rearing cages and by working at night to secure adults emerging from nymphs. Other nymphal material has been transported to Urbana from distant localities and then reared.

Another phase of activity in connection with the Survey's study of the stonefly fauna of North America has been the careful examination of existing types. The collections of the Museum of Comparative Zoology, Cambridge, Mass., and of Cornell University, Ithaca, N. Y., in addition to the Illinois Natural History Survey collection, are particularly rich in typic specimens of Plecoptera, and all of the North. American types in these collections have been critically studied upon several occasions. The writer has also been privileged to study most of the other types of North American Plecoptera scattered here and there in various collections throughout the country.

The result of all this collecting, rearing, identification of material and study of types has naturally yielded much new information regarding the association of nymphs with adults, the distribution of 
numerous species, the synonymy of certain species with others and the discovery of new species. In the present paper are the most important of these findings, with special emphasis upon a complete account of the fauna of Illinois.

\section{Acknowledgments}

I :mm indebted to many individuals and institutions for the donation or loan of material upon which this paper in part is based. Specimens of special importance have been donated or loaned by the following: Nathan Banks and F. M. Carpenter, Museum of Comparative Zoology, Cambridge, Mass.; J. Chester Bradley, C. McC. Mottley, J. G. Needham and Henry Dietrich, Cornell University, Ithaca, N. Y.; Gordon B. Castle, Montana State University, Missoula, Mont.; A. C. Cole. Jr., University of 'Tennessee, Knoxville, 'Tenn.; E. 'T. Cresson, Jr., Academy of Natural Sciences of Philadelphia, Philadelphia, Pa.; K. C. Emerson, Oklahoma Agricultural and Mechanical College, Stillwater, Okla.; P. IV. Fattig, Emory University, Atlanta, Ga.; A. B. Gurney, U. S. Bureau of Entomology and Plant Quarantine, IVashington, D. C.; John F. Hanson, Massachusetts State College, Amherst, Mass.; P. H. Harden, University of Minnesota, St. Paul, Minn.; Thelma Howell, Wesleyan College, Macon, Ga.; P. J. Jennings, Brooklyn, N. Y.; Stanley G. Jewett, Jr., Portland, Ore.; D. E. Kinmins, British Museum, London, England; 'Trevor Kincaid and Melville H. Hatch, University of Washington, Seattle, Wash.; Willis King, National Park Service, Gatlinburg, Tenn.; G. F. Knowlton, Agricultural Experiment Station, Logan, Utah; Mitsuko Kohno, Wakamatsu, Japan; J. IV. Leonard, Institute for Fisheries Research, University of Michigan, Ann Arbor, Mich.; F. Earle Lyman, University of Michigan, Ann Arbor, Mich.; C. E. Mickel, University of Minnesota, St. Paul, Minn.; D. C. Mote and R. L. Post, Oregon State Agricultural College, Corvallis, Ore.; Ferris Neave, Pacific Biological Station, Nanaimo, B. C., Canada; A. Colin Nicol, University of IVestern Ontario, London, Ont., Canada; W. E. Ricker, Indiana University, Bloomington, Ind.; H. G. Rodeck, University of Colorado, Boulder,
Colo.; IV. M. Sprules, University of Toronto, Toronto, Ont., Canada; IV. C. Stehr, Ohio University, Athens, Ohio; M. C. Tanner, Ogden, Utah.

H. H. Ross, B. D. Burks, G. T. Riegel and K. M. Sommerman, all staff members of the Insect Survey Section of the Illinois Natural History Survey, have greatly aided the preparation of this report by the collection of material, sorting and labeling of material and in numerous other ways. J. S. Ayars, Editor of the Survey, has materially assisted with the funal reading, preparation and styling of this article.

I am particularly indebted, however, to C. O. Mohr, Associate Entomologist with the Survey, for almost all the splendid drawings which illustrate this article. Good drawings of the important structural details of the adult and nymphal stoneflies and dorsal views of the nymphs are, in certain respects, better for identification purposes than are word descriptions. Because of the excellent quality of these drawings, I have leaned heavily upon them in the writing of the descriptions.

\section{Disposition of Material}

All holotypes, allotypes and some of the paratypes of the species described as new in this article are deposited in the insect collection of the Illinois Natural History Survey at Urbana. Paratypes of some of the species are deposited elsewhere, as indicated in the typic records.

Much of the material listed in this paper is in the collection of the Illinois Natural History Survey. In some, but not all, instances in which material is in collections other than that of the Survey that fact is indicated, the following abbreviations being used for institutional collections.

M.C.Z.-Museum of Comparative Zoology of Harvard College, Cambridge, Mass.

C.U.-Cornell University, Ithaca, N. Y. A.N.S.-Academy of Natural Sciences of Philadelphia, Philadelphia, $\mathrm{Pa}$.

\section{Arrangement of Subject Matter}

In order to prevent treating various genera in two separate portions of this article, I have interwoven the subject 
matter pertaining especially to Illinois with that relating to the North American fauna as a whole. As in my paper dealing with the stoneflies of Illinois as a unit (1935a), I have followed a presentation order beginning with the Pteronarcidae and ending with Chloroperlidae.

\section{Revised Classification}

In my paper dealing with the stoneflies of Illinois (1935a), I gave a discussion of the classification then proposed for the Plecoptera of North America, together with an outline showing the relationships of the various groups as I then accepted them. As might be expected in the devel- opment of a classification of a neglected order of insects, the study of extensive material since 1935, particularly from western states, has caused some modifications of my former views.

My present ideas regarding the classification of the North American Plecoptera down to generic groups are represented by the outline below.

This outline represents changes in my 1935 classification as follows: (1) reduction of genera in the family Taeniopterygidae to Taenioptery $x$ and Brachyptera, (2) removal of Eucapnopsis from the Leuctridae and its placement in the Capniidae, (3) addition to the Capniidae of the recently described genera of Isocapnia

\section{REVISED CLASSIFICATION \\ OF THE PLECOPTERA OF NORTH AMERICA}

\begin{tabular}{|c|c|c|}
\hline & PTERONARCIDAE .... & $\begin{array}{l}\text { Pteronarcys } \\
\text { Pteronarcella }\end{array}$ \\
\hline & PELTOPERLIDAE .... & Peltoperla \\
\hline & TAENIOPTERYGIDAE & $\begin{array}{l}\text { Taeniopteryx } \\
\text { Brachyptera }\end{array}$ \\
\hline $\begin{array}{c}\text { HOLOGNATHA } \\
\text { or }\end{array}$ & NEMOURIDAE ........ & Nemoura \\
\hline FILIPALPIA & LEUC'TRIDAE. . & $\begin{array}{l}\text { Leuctra } \\
\text { Megaleuctra } \\
\text { Perlomyia }\end{array}$ \\
\hline & CAPNIIIAE. & $\begin{array}{l}\text { Capnia } \\
\text { Allocapnia } \\
\text { Capnura } \\
\text { Eucapnopsis } \\
\text { Isocapnia } \\
\text { Nemocapnia }\end{array}$ \\
\hline & PERLIDAE & $\begin{array}{l}\text { Atoperla } \\
\text { Perlinella } \\
\text { Neoperla } \\
\text { Perlesta } \\
\text { Acroneuria } \\
\text { Neophasganophora } \\
\text { Togoperla } \\
\text { Claassenia }\end{array}$ \\
\hline $\begin{array}{l}\text { SYSTELLOGNATHA, } \\
\text { SUBULIPALPIA } \\
\quad \text { or } \\
\text { SETIPALPIA }\end{array}$ & PERLODIDAE. & $\begin{array}{l}\text { Perlodes } \\
\text { Oroperla } \\
\text { Isogenus } \\
\text { Hydroperla } \\
\text { Dictyopterygella } \\
\text { Diploperla }\end{array}$ \\
\hline & ISOPERLIDAE. & Isoperla \\
\hline & CHLOROPERLIDAE & $\begin{array}{l}\text { Chloroperla } \\
\text { Hastaperla } \\
\text { Alloperla } \\
\text { Paraperla } \\
\text { Kathroperla }\end{array}$ \\
\hline
\end{tabular}


and Nemocapria, ( $t)$ addition of Clanssenia to the Perlidace, (5) addition of Dicsyoprerygella to the Perlodidae, (6) the recognition of Diploperla as the generic name for a group of species formerly for the most part placed in Perla (s.l.), and it: placement in the family of Perlodidae, (7) erection of a new family, the lsoperlidac, for the genus Isoperla, which I formerly placed in the Chloroperlidae, (S) recognition of Oroperla as a genus of Perludidae and (9) removal of Isoperla from Chloroperlidae and the addition to this family of Hastaperla.

Some of the now accepted genera represent rather homogeneous groups of species, whereas other genera are quite heterogeneous and may contain several more or less ininor complexes. Acceptance of these minor complexes within the larger generic units as subgenera will serve most nomenclatorial and classificatory needs. For instance, Brachyptera represents a genus containing several smaller complexes, most of which (Nephopteryx, Obipteryx, Oemopteryx, Rhabdiopteryx, Strophopteryx, etc.) have already been named and sometimes considered as genera. No phylogenetic relationships are lost or obscured by use of subgeneric names for such smaller complexes as Oemopteryx, for eximple, and the treatment of general entomological literature is often improved. The same applies to such genera as $\mathrm{Ne}$ monra and Perlodes. Isoperla (s.l.), as I now recognize it, contains several subgenera, some named and others unnamed. Almost any genus containing a number of species can be broken into finer subgeneric groups or complexes, but it is not the purpose of this article to go into detail concerning such classifications. Revisional papers dealing exhaustively with single families or genera are the best places for such lesser groupings to be defined and evaluated.

The groupings of the above species are subject to the personal factor in evaluation by individual specialists, and, like an accordion, the skeletal organizational scheme can be pulled out or contracted. Some students of stoneflies prefer to group the nemourids, leuctrids, capniids and taeniopterygids as subfamilies of a single large family, the Nemouridae. I prefer, however, at least for the present and until the world fauna is better known, to con- sider them as separate families. The actual problems of ready identification and keying remain the same regardless of which policy is followed. Future and broader studies of the world stonefly fauna will inevitably exert influences for some changes in existing classificatory systems.

\section{REVISED KEY 'TO FAMILIES}

of the Plecoptera of North America

(Figures illustrating almost all of the characters used in these keys may be found in Frison 1935a)

\section{Adults}

1. Anal area of forewings with two or more rows of crossveins; basal abdominal sternites with remnants of nymphal gills............Pteronarcidae

Anal area of forewings entirely without crossveins or with but one row; basal abdominal segments without remnants of nymphal gills.............. 2

2. Cerci short, not longer than greatest width of the pronotum.......... 3

Cerci long, much longer than greatest width of the pronotum.......... 7

3. Forewings with numerous costal crossveins; the pronotum, as viewed from the side, lies at a downward sloping angle to the otherwise general horizontal plane of the mesothorax and metathorax; some species with gill remnants at least on sides of mesothorax and metathorax above bases of legs...............Peltoperlidae

Forewings with no or few costal crossreins; the pronotum, as viewed from the side, lies in the same general horizontal plane as the mesorhorax and metathorax; without any gill remnants on sides of mesothorax and metathorax above bases of legs.............

t. Second tarsal segment about as long as other tarsal segments

Second tarsal segment much shorter than other tarsal segments.............

5. Cerci with five or six segments.

\section{Cerci one segmented}

Capniidae (Eucapnopsis only)

6. Apical marginal space beyond tip of subcosta with an oblique crossvein; some species with gill remnants in cervical region................. Nemouridae

Apical marginal space beyond tip of subcosta without oblique crossvein; no gill remnants ever present in cervical region................... Leuctridae

7. First tarsal segment long, about as long as the third tarsal segment; remnants of thoracic or submental gills never present; forewing with no or few median and cubital crossveins; females with a narrow or broad, pale, weakly sclerotized, median, longitudinal band on basal abdominal tergites distinctly contrasting with strongly sclerotized lateral margins; labium 
with paraglossae and glossae extending forward about the same distance and arranged alongside of one another in same horizontal plane (Filipalpia type)

Capniidae

First tarsal segment short, much shorter than third tarsal segment; remnants of thoracic or submental gills present or absent; forewing with from several to many median and cubital crossveins; females without a weakly sclerotized longitudinal band on basal abdominal tergites contrasting with strongly sclerotized lateral margins; labium with paraglossae extending forward beyond glossae and so dominating glossae that the latter are much reduced (Subulipalpia type).......

8. Remnants of branched filamentous gills on sides or venter of thorax, in position corresponding to location of branched filamentous gills in nymphs Perlidae

No remnants of nymphal branched filamentous gills on sides or venter of thorax, or if gill remnants are present they are single, not branched, fingerlike processes (some Perlodidae)

9. Remnant of finger-like gills located near each side of outer basal corner of submentum.

Perlodidae (Perlodes, Isogenus and IIydroperla)

No remnant of finger-like gills located near each side of outer basal corner of submentum.

10. Anal lobe of hindwing always present and large; anal lobe with 5 to 10 distinct veins, exclusive of first anal vein, reaching margin of wing; males with lobe on posterior margin of seventh or eighth, or sometimes both seventh and eighth, ventral abdominal segments except for Dictyopterygella

Anal lobe of lindwing usually present, but sometimes small and in IIastaperla lacking; anal lobe usually with but two to three distinct veins exclusive of first anal vein, except Kathroperla which may have six or seven, reaching margin of wing; males without a lobe on posterior margin of either seventh or eighth ventral abdominal segments

Chloroperlidae

11. Males with lobe on posterior margin of seventh abdominal sternite, except in Dictyopterygclla where all lobes are lacking and in Diploperla luctuosa which has lobe on eighth abdominal sternite; males with tenth abdominal tergite usually distinctly cleft, or if not distinctly cleft with subanal lobes projecting backward (Dictyopterygella) or with special terminal dorsal abdominal structures (Diploperla luctuosa, D. duplicata and D. bilobata); radial sector of forewing with from two to five branches, usually with three or more; subgenital plate of female usually well developed, large and frequently covering most of eighth abdominal sternite.

(Dictyopterygella and Diploperla)
Males without a lobe on posterior margin of seventh ventral abdominal segment but with such a lobe varying in size from small to large, always on eighth abdominal sternite; males with tenth abdominal tergite never distinctly cleft; radial sector of forewing with from two to four branches, but usually with two; subgenital plate of female sometimes not developed, and when present usually not covering most of the eighth abdominal sternite

Isoperlidae

\section{NYMPHS}

1. Gills present on some of the ventral basal abdominal segments.

Pteronarcidae

Gills absent on all ventral abdominal segments

2. Venter of thorax covered with large, overlapping, shieldlike plates

Peltoperlidae

Venter of thorax without distinct, large, overlapping, shieldlike plates.

3. Labium with paraglossae and glossae extending forward about the same distance and side by side in the same horizontal plane.

Labium with paraglossae extending forward much farther than the glossae, the latter deeply inset below and between the paraglossae so as to appear almost as basal segments of them... . 7

t. Second tarsal segment approximately as long as or longer than the first segment .............. Taeniopterygidae

Second tarsal segment shorter than the first.....................

5. Small and robust nymphs, hairy; hindwing pads extending considerably outward from the body at an angle; gills present or absent in ventral cervical region

Nemouridae

Small and slender nymphs; hairs few, fine or lacking; hindwing pads lying about parallel to longitudinal axis of body; no branched cervical gills.

6. Lateral margins of abdominal segments somewhat rounded, segments widest at posterior margin and narrower toward base; hindwing pads with anal lobe or area extending far beyond middle of wing pad; forewing pads of males sometimes entirely lacking; last abdominal segment in males sometimes with a conical projection

Capniidae

Lateral margins of abdominal segments almost straight, abdomen appearing more cylindrical; each hindwing pad with anal lobe or area small and not extending much beyond middle of wing pad; forewing pads of males always present; last abdominal segment in males without a conical projection

Leuctridae

7. Branched filamentous gills on sides and venter of thorax

Perlidae

Without branched filamentous gills on sides or venter of thorax.

8. With a small membranous finger-like 
gill locared near each side of outer basal angle of submentum Perlodidae (Perlodes, Isogenus and IIydroperla)

Withous such gill oll subinentum

9. Lateral margins of forewing pads ap. proximately straight or in line with longitudinal body axis: tip of lacinia with olle or more teeth; diameter of fourth segment of maxillary palpus Jut much greater than base of fifth segunent; nymphs frequemty with a cunspicuous color pattern on dorsum of ablomen.

L.ateral margins of forewing pads rounded: tip of lacinia never with more than one tooth; diameter of fourth segment of maxillary palpus often much greater than base of fifth segment; nymph without collspicuous color patiern on dorsum of abdomen (sometimes color pattern of adult ready to emerge is evident through Iy mphal skin) Chloroperlidae

111. Maxillae bujging out from sides of head in a very conspicuous manner; diameler of lacinia from base to apex tapers very rapidly, and it forms a long single claw or a long claw plus a -econdary une; color pattern of abdominal rergites suffused or with distinci trausverse markings

Perlodidae (Diploperla)*

Maxillae not or but slightly bulging out from sides of head; diameter of lacinia from base to apex less tapering, structure in general of more stocky form with smaller teeth or tooth at apex; color pattern of abdominal tergites suffused or with distinct longitudinal markings

Isoperlidae

\section{Revised List of Illinois Species}

"1\%he number of species of stoneflies now known to be found in Illinois represents a great increase over the numbers in all former lists. In briefly reviewing the growth of the Illinois faunal list it will suffice to quote from my papers of $1935 a$ and 1937.

In 1935 I wrote: "A revised tabulation of the species recorded by $\mathrm{W}$ alsh from the vicinity of Rock Island in 1862 gives us a present list of 15 species. In the tabulation of species by states as given by Needham and Claassen (1925), Illinois is credited with 14 species, but since two species of Pteronarcys are listed whereas all our evidence indicates but one, this list of 1925 includes only 13 species. If all the IValsh records had been placed by Needham and Claassen their list would have given 17 species for this state. Our studies to date give us a total of 36 species of stoneflies for Illinois plus at least two

\footnotetext{
- Nymph of Diclyopicryzella when found will probably
} bey o'st at this place. and possibly a third species as yet known only as nymphs and not placeable to species at the present time-a list more than double those of Walsh or Needham and Claassen.

"The status of two Acroneuria nymphs and another nymph which I am tentatively placing as Neophasganophora needs to be definitely established. 'Two of these, one Acromeuria and the Neophasganophora, are certainly species which are additions to our list. 'The second Acroneuria nymph now unnamed may represent a light phase of a species already reared and known, but there is also a possibility that it may be new to our list."

In 1937 I wrote: "These specific placements [assignment of specific names, based upon rearings, to two species known only from unidentifiable nymphs in 1935a] bring the total of Illinois stoneflies to 38 , with the certainty that two additional species will be added by future studies, one a questionable identification of a female Capnia as zernalis Newport and the other an Isoperla represented as yet by a single nymph not placeable to species."

'The rearing and collecting of Illinois material since 1937, together with the rearing and collecting of material from other states, have now expanded the Illinois faunal list to 49 species, which is greater than the number recorded for any other state except New York. The New York list of 1928 contained 59 recorded species, but at least two of these names are involved in the synonymy of other listed names. Additional species have been collected in New York since then, and the final list has possibilities of some 60 species.

'The Illinois list may eventually be augmented by a few additional species, but our field work has been so comprehensive that but few species can possibly be added. No Illinois nymphs are now known which cannot be placed to species. Of species known to occur in adjacent states, Acroneuria areta, Isoperla dicala and Isoperla namata, all described in this paper, may sometime be taken in Illinois. Acroneuria areta is found in the Ohio River basin, and specimens are a possibility at points along the boundary waters of the Ohio River in southern Illinois. Isoperla namain has been taken in two states, Indiana and Missouri, adjacent to southern Illinois and thus may eventually be found within 
our borders, but several streams which seemed to present possibilities of harboring this species have not thus far produced any specimens. Isoperla dicala has been taken in northern Indiana, and the upper parts of the Kankakee River basin in Illinois present possibilities for finding this species. Isoperla duplicata and Leuctra sara have been found in Indiana about 30 miles east of the border of central Illinois. 'Then the chance of finding some other species, not to be considered as a possibility based on present distributional records, can never be entirely excluded.

Of the North American families of stoneflies recognized by me, Illinois lacks representatives of but a single family, the Peltoperlidae. The nymphs of species belonging to this family are found in cold streams in mountainous or northern states, and it is unlikely that a species of this family will ever be found in Illinois.

\section{REVISED LIS'T' OF 'THE PLECOPTERA OF ILLINOIS}

'I'ogether With Illinois Literature Citations

\section{PTERONARCIDAE}

Pteronarcys Newman

Pteronarcys pictetii Hagen Frison 1935a, p. 336 (nobilis)

\section{TAENIOPTERYGIDAE}

Taeniopteryx Pictet

Taeniopieryx maura (Pictet) Frison $1935 a$, p. 341 (niralis)

Taeniopteryx parvula Banks Frison $1935 a$, p. 345

Taeniopteryx lita Frison Present paper, p. 249

Brachyptera Newport Brachyptera fasciata (Burmeister) Frison $1935 a$, p. 347

\section{NEMOURIDAE}

Nemoura Latreille

Nemoura venosa Banks Frison 1935a, p. 349

Nemoura trispinosa Claassen Present paper, p. 261

\section{LEUC'TRIDAE}

Leuctra Stephens

Leuctra claasseni Frison Frison $1935 a$, p. 354

Leuctra decepta Claassen Present paper, p. 257

Leuctra tenuis (Pictet)

Present paper, p. 258

\section{CAPNIIDAE}

Capnia Pictet Capnia opis (Newman) Present paper, p. 267
Nemocapnia Banks

Nemocapnia carolina Banks Frison 1935a, p. 356 (Capnia vernalis ?, 9 )

Allocapnia Claassen

Allocapnia forbesi Frison

Frison $1935 a$, p. 363

Allocapnia forbesi var. cornuta Frison Frison $1935 a$, p. 363

Allocapnia granulata (Claassen) Frison 1935a, p. $36 t$

Allocapnia illinoensis Frison Frison 1935a, p. 365

Allocapnia mystica Frison Frison $1935 a$, p. 366

Allocapnia pygmasa (Burmeister)

Present paper, p. 265

Allocapnia recta (Claassen)

Frison $1935 a$, p. 367

Allocapnia vivipara (Claassen)

Frison $1935 a, p .370$

Allocapnia rickeri Frison

Frison 1935a, p. 367 (pygmaca), ant present paper, p. 269

\section{PERLIDAE}

Atoperla Banks Atoperla ephyre (Newman) Frison 1935a, p. 377

Perlinella Banks

Perlinella drymo (Newman) Frison $1935 a$, p. 380

Neoperla Needham

Neoperla clymene (Newman) Frison $1935 a$, p. 381

Perlesta Banks

Perlesta placida (Hagen)

Frison $1935 a$, p. 386, and present paper. p. 271

Acroneuria Pictet

Acroneuria abnormis (Newman)

Frison, 1935a, p. 391

Acroneuria internata (Walker)

Frison 1935a, p. 401

Acroneuria ruralis (Hagen)

Frison 1935a, p. 403

Acroneuria evoluta Klapálek

Frison 1935a, p. 395 (arida), and present paper, p. 273

Acroneuria mela Frison

Frison 1935a, p. 405 (Acroaeuria sp. a), and 1937, p. 79 (evoluta)

Acroneuria perplexa Frison

Frison 1937, p. 79

Neophasganophora Lestage

Neophasganophora capitata (Pictet)

Frison $1935 a$, p. 409

Togoperla Klapálek

Togoperla media (Walker)

Frison 1935a, p. 412

Togoperla kansensis (Banks)

Frison 1937, p. 82, and 1935a, p. 414 (Togoperla sp. a)

PERLODIDAE

Hydroperla Frison

IIydroperla crosbyi (Needham \& Claassen)

Frison 1935a, p. 419

11 ydroperla harti Frison

Frison $1935 a$, p. 423

IIydroperla varians (WValsh)

Frison $1935 a$, p. 426 , and 1937, P. 82 


\section{CHI.OROPERL,HOA:}

Hastaperla Ricker
Ilastaperla breais (Banks)
Frison $1935 a, p .+31$ (cydippe), and
present paper, p. $3+0$
Alloperla Banks
Alloperla caudata Frison
Present paper, p. $3+2$
Hlloperla banksi Frison
Present paper, p. $3+3$

\section{ISOPIERLIIAE}

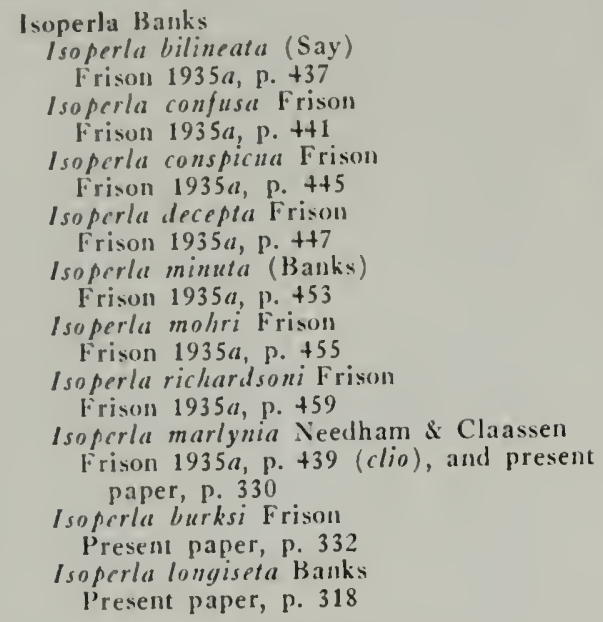

\section{PTERONARCIDAE}

Because of their large size for stoneflies, gill remnants on adults and general distribution, the species of Pteromarcys have long attracted the fancy of students of insect life. In spite of all the work done to date, however, there remain taxonomic problens and gaps in our knowledge which can be solved only, or best, by the rearing of series of specimens from numerous locallities.

One of the problems confronting the writer lias been the determination of the number of eastern North American species in the complex in which the nymphs lack the lateral lobes or hooks on the sides of the abdomen. 'This, in turn, has led to sume discoveries regarding existing nomenclaturial matters. My conclusions to date regarding these matters are presented under the headings of Pteronarcys dorsatn (Say) and pictetii Hagen.

The bibliograply and synonymy listed for dorsata and pictetii do not include all references to these two species in literature, but these listings do account for all references involving synonymy and nomen- clatorial problems. It is a fairly safe assumption that all American references since Smith (1917) for dorsata should now be associated with dorsatn and those for nobilis Hagen should now be associated with pictetii.

\section{Pteronarcys dorsata (Say)}

Sialis dorsata Say $(1823$, p. 164). Original description.

Pteronarcys regalis Newman (1838a, p. 176). Previous synonymy accepted.

Kollaria insignis Pictet (18+1, p. 123). Previous synonymy accepted.

Pteronarcys nobilis Hagen (1861, p. 15). New synonymy.

Pleronarcys proteus Hagen (1861, p. 1t). New synonymy.

Pteronarcys regalis Hagen (1873, p. 286). Previous synonymy accepted.

Pteronarcys nobilis Hagen (1873, p. 285). New synonymy.

Pteronarcys frigida Gerstaecker (1873, p.

65). Previous synonymy accepted.

Pteronarcys rectus Provancher (1876, p.

189). Previous synonymy accepted.

Pteronarcys flavicornis Provancher (1876, p. 191). Previous synonymy accepted.

Pteronarcys nobilis Klapálek (1907, p. 153). New synonymy.

Pteronarcys dorsata Needhain \& Claassen (1925, p. 35).

Picronarcys shelfordi Frison (1934, p. 25). Placed in synonymy of frigida by Ricker (1938, p. 130$)$.

In her revisional paper dealing with the North American species of Pteronarcinae and Perlodini, Smith (1917) established the association of the specific name of dorsata with a common northeastern species of Pteronarcy's which in the female has the posterior margin of the eighth abdominal sternite straight and in the male has the tips of the lobes of the tenth abdominal tergite bent upward. This concept of dorsata may or may not represent the species actually described by Say, but this interpretation of Say's species wats accepted by Needham \& Claassen (1925); there is no good reason for not following, and from the standpoint of stability of names there is good reason for favoring, the perpetuation of this earlier nomenclatorial decision.

lt is unfortunate, however, that, when adopting the use of the name dorsata, Smith (1917) did not correctly interpret nobilis Hagen (1861). The female of nobilis in the original description is characterized as having the " $\%$ antepenultimate one [ventral segment] truncated, orange, two short setiform appendages? 
(they cannot be clearly seen)." In view of this suggestive description, it is surprising that the name of nobilis was associated by Snith (1917) with a species which has the eighth abdominal sternite distinctly incised in the middle of its posterior margin. Needhain \& Claassen (1925) followed Snith, and, previous to a close study of the types of mobilis, this use of names was accepted by me (1935a).

In the Museum of Comparative $\mathrm{ZO}$ ology, there are two specimens, one male and one female, labeled as the types of nobilis and assigned the type number of "2+1." Upon two occasions I have studied these types in considerable detail, and upon another occasion had them independently studied for me by Dr. H. H. Ross of the Illinois Natural History Survey. The typic female specimen has associated with it on the insect pin the data, "P. nobilis Hagen-Winthem-Hagen," and the typic male the data, "New York-IVinthemHagen." Neither the typic male nor the typic female corresponds to the use of nobilis as defined by Smith (1917) and followed by Needham \& Claassen (1925) and subsequently by me (1935a). The typic female has the posterior margin of the eighth abdominal sternite straight and thus corresponds with the "truncated" part of Hagen's original description and the species dorsata as now accepted. The "two short setiform appendages" questionably mentioned by Hagen (1861) do not now show in the pinned specimen, and later Hagen (1873) states, "There are no appendages (as I described with a ? in my Synopsis)." Even if these appendages were present, as 1 shall show in a following paragraph, they would not preclude this typic female being placed in the synonymy of dorsata. The typic male, likewise, has the lobes of the tenth abdominal tergite slightly turned upwards as in shelfordi Frison and dorsata, and most certainly not downwards as in nobilis as used by Smith (1917). Since all evidence points to the male and female specimens labeled as types "No. 1+2" being the true types, it must follow that nobilis should be placed in the synonymy of dorsata.

Unaware of certain characters of frigida Gerstaecker (1873) from Labrador, previously sunk as a synonym of dorsata by Smith (1917), I described shelfordi in
$193+$ from Fort Churchill on Hudson's Bay. Ricker (1938), after a study of Gerstaecker's type, came to the conclusion that shelfordi was a synonym of frigida, and I now accept the view that these two are of the same species.

It is also now my view that shelfordi is the same as dorsata and that the differences originally used by me $(193 t)$ to

Fig. 1.-

Picronarcys

dorsata.

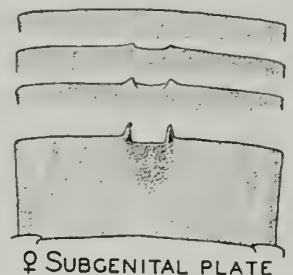

separate the two are attributable to variation. This view was gradually formed by the study of considerable adult Pteronaicy's material and by repeated attempts to separate to species the nymphs belonging to this same complex of species (lacking lateral hooks on sides of abdomen). My suspicions that shelfordi (= frigida) intergraded with dorsata were definitely confirmed by the rearing of a series of adults from nymphs found climbing out of the water in the Pere Marquette River near Baldwin, Mich., on May 19, 1940. Fig. 1 shows the posterior margins of the eighth abdominal sternites of adult females reared at this time. It can be seen from this figure that there is intergradation in the same locality between females of the dorsata and shelfordi types, and they should not be accepted as distinct species. When shelfordi was originally described I was not aware of the shape of the eighth abdominal sternite in the females of frigida, and as a result of Smith's (1917) paper I assumed that all the names placed in synonymy of dorsata referred to females having the posterior margin of the eighth abdominal sternite straight without small projections.

Distributional records do tend to indicate, however, that specimens of dorsata having the eighth abdominal sternite straight are more nearly confined to the southern part of the range of this species, and those with two small projections on the eighth sternite (frigida and shelfordi types) prevail in the northern part of its range. 
I am accepting Smith's (1917) placement of Kollaria insignis Pictet (1841), l'teronurcys regalis Newman (1S3S), $P$ '. rectus Provancher (1876), P. faricornis Provancher (1876) and P. frigida Gerstaecker (1873) as synonyms of dorsata. Klapilek (1907) has shown that insignis is the same as regalis, and regalis is a synonym of darsata, as a result of Smith's interpretation of Siy's species. Ricker (1938) further confirms synony'my of insignis with dorsata based upon study of the type of the former.

In 1939, I studied the specimens in the Provancher collection now in the Provincial Museum, Quebec, Canada, in hopes of definitely locating types of rectus and flaicurnis. In this collection I found one female and one male Pteronarcy's associated with the label of " $P$. regalis," and both are specimens of dorsata as I now recognize this species. Another female Pteronarcys standing associated with the name "rectus" may be a type, and it also is dorsata. All specimens of Pteronarcy's now in the Provancher collection tend to confirm the correctness of placing these names rectus and flaricornis in the synonymy of dorsata as done by Smith (1917).

It should be mentioned here that Hagen's 1861 record for proteus and his 1873 record for nobilis should be placed in the bibliography of dorsata since Hagen in 1873 states that the specimens recorded by him in 1861 as proteus are regalis (=dorsata). Smith (1917) thus erred in placing Hagen's (1861) reference to proteus under proteus when it should go under dorsata. Also, Klapálek's (1907) reference to nobilis should be placed in the synonymy of dorsata and not under pictetii (= nobilis) as done by Smith.

As mentioned in an earlier paragraph, I am placing regalis in the synonymy of dorsata because of reared females from the same locality which show all stages between having a straight posterior margin of the eighth abdominal sternite and having two conspicuous nipple-like processes. Hagen's (1873) report seems to be quite definite in regard to regalis having these nipple-like processes.

\section{Pteronarcys pictetii Hagen}

Pteronarcys pictetii Hagen (1873, p. 286). Original description, $\hat{o}, \hat{q}$.
Pteronarcys regalis Hagen (1861, p. 15). New synonymy for $\%$.

Pteronarcys nobilis Smith (1917, p. 48). New synonymy.

Pieronarcys nobilis Needham \& Claassen (1925, p. 36). New synonymy.

Pteronarcys nobilis Frison (1935a, p. 336). New synonymy.

Under the discussion of dorsata (Say) I have shown that nobilis Hagen is the species called dorsata by Sunith (1917), and that regalis Newman $(1838 a)$ is a variant of dorsata.

The types of pictetii are now in the Museum of Comparative Zoology, associated with the type number " $2+2$." The female has labels associated with it as follows: "Philadelphia - W W in them - Hagen." 'The male has associated with it the following data: "Meadville-Pa.-B. P. Mann." In view of the fact that the male type is the species dorsata, l hereby designate the female type as the lectotype to govern the use of the name pictetii.

A study of these types reveals that pictetii is the species called nobilis by Smith and was so synonymized by her. However, since Smith's concept of nobilis was in error, the name of pictetii, by selection of typic female as lectotype, is the first name available to be used for the species called nobilis by Smith (1917), Needham \& Claassen (1925) and Frison (1934 and 1935a).

Hagen's (1873) paper clearly corrected his earlier mistakes of 1861 regarding Pteronarcys, but he had no means of knowing that his nobilis and regalis would be found to intergrade and that dorsata would later be considered a species of Pteronarcys having name priority over both nobilis and regalis.

I have been unable thus far to find definite workable characters for separating the nymphs of dorsata and pictetii. At one time I thought that more distinctive striping of the nymphal abdomens indicated dorsata, but rearings have not confirmed this view, and the character of the water seems to have a marked influence upon the appearance of the nymphs. Mature female nymphs of pictetii can often be identified because of a strong indication of the incised posterior margin in the middle of the eighth abdominal sternite.

Ricker (1938), in his remarks regarding Pteronarcys pictetii, implies that the type of pictetii is a specimen called proteus 
by Pictet (1841) and is in the Zoological Museum, Berlin, Germany. Pictet's specimen may be in the Zoological Museum in Berlin, but the types of pictetii are in the Museum of Comparative Zoology, as already stated.

\section{Pteronarcys species}

In New Brunswick in 1939, a series of nymphs of Pteronarcys was taken which cannot be reliably assigned to any species known at this time. Since then a similar nymph has been collected in Connecticut. The nymph, fig. 2, because of lateral projections on the sides of the first eight abdominal segments, is suggestive of the nymph at present associated with the species biloba Newman and proteus Newman. Of these two species it most closely resembles the nymph now assigned to bilo$b a$ because of the more prominent lateral lobes and the more sharply angled anterior corners of the pronotum. It differs from

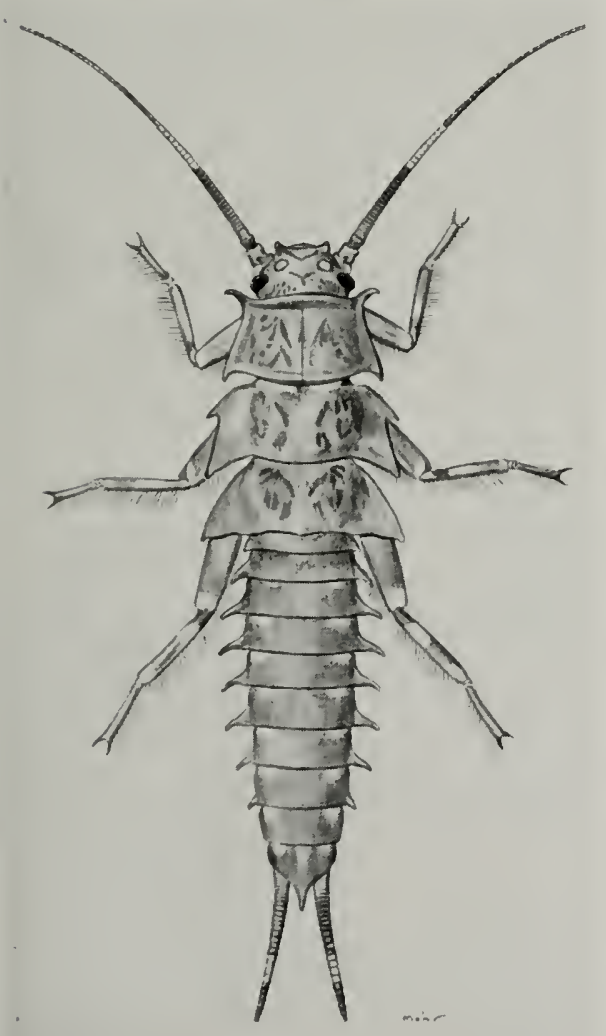

Fig. 2.-Nymph of Pteronarcys species. biloba, however, in that the lateral abdominal projections are much more developed except on the first and eighth segments, that there is a very prominent projection on each side of the mesonotal wing pad, and that the projections at the corner angles of the pronotum are abnormally prominent.

There is considerable question as yet regarding the true status of Pteronarcys comstocki Smith, and it is possible that the nymph now illustrated should be associated with this name. Reared material is needed to settle this and other points involved with the correct determination of several species of Pteronarcys.

Data associated with these specimens are as follows.

Connecticut.-Mount Carmel, Mill River, Sleeping Giant State Park: Oct. 14, 1941, K. M. Sommerman, 1 nymph.

New Brunswick.-PENobsquis, crawling on rocks in small clear stream: Aug. 20, 1939 . T. H. Frison \& T. H. Frison, Jr., 18 nymphs.

\section{PELTOPERLIDAE}

This family is exceedingly interesting to the student of stoneflies because of its many unique features, including the strikingly roachlike appearance of the nymphs.

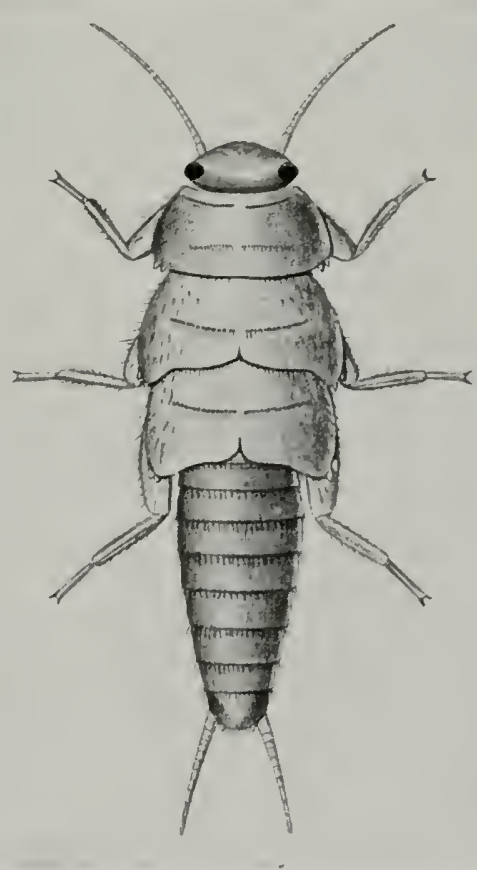

Fig. 3.-Nymph of Peltoperla brevis. 
Fen records of the various described species oceur in literature, and the general taxonomy of the group is far from satistactory because of the lack of reared ma-
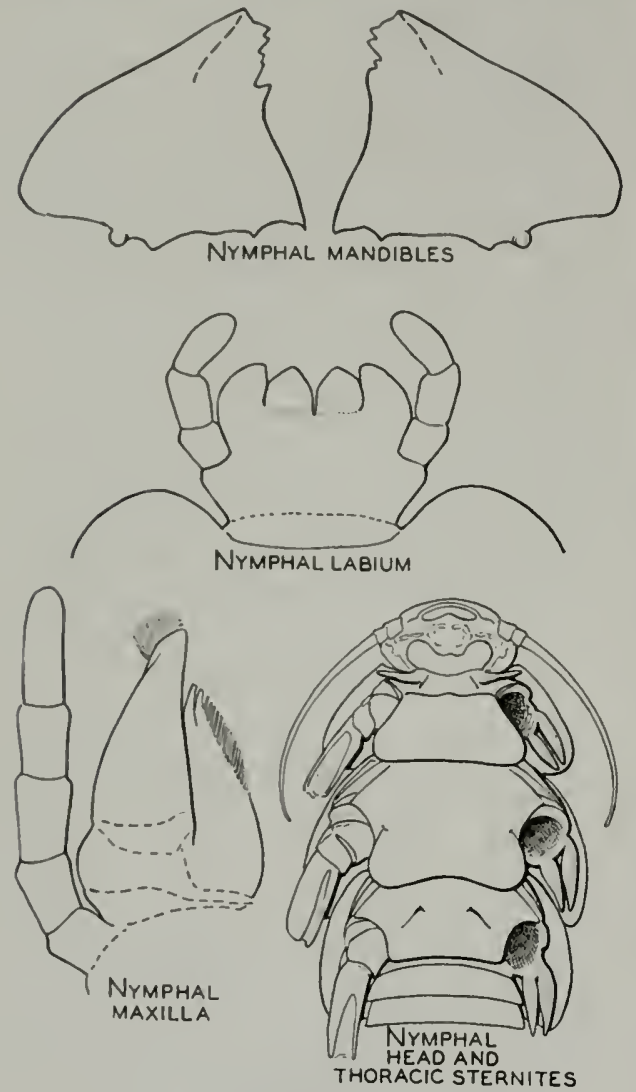

Fis. 4.-Peltoperla brevis.

terial and series of associated males and females, and because of certain weaknesses in existing specific descriptions.

'The character, number and location of the gills in the nymphs, and remnants of these in the adults, are certain to prove of great value in future work of identification. Claassen (1931) has given a good description of Peltoperla arcuata Needham nymphs hased upon reared material. This nymph has five pairs of filamentous gills, one pair each side near upper point of attachment of each mesothoracic leg, one pair each side near upper point of attachment of each metathoracic leg, and one pair on the underside of the metasternum. Nymphs in the Illinois Natural History Survey collection which certainly belong to $P$. brezis (Banks), fig. 3, have six pairs of gills, one pair near upper point of attachment of each leg and none beneath the metasternum, fig. 4. 'These differences in number and arrangement of gills indicate the taxonomic value of these characters, and they need to be carefully observed in all species. Dorsal view of the nymph is illustrated in fig. 3.

As in other adults whose nymphs have gills, the adults of Peltoperla show gill remnants when examined closely. I have noted, however, that adults of Peltoperla have membranous filaments on the dorsal thoracic segments which cannot be associated with gills in the nymphs. These false gill-like appendages appear to be remnants of membranous tissue, an appearance occasioned by the peculiar shieldlike thoracic segments of the nymphs.

\section{Peltoperla arcuata Needham}

Peltoperla arcuata Needham (1905, p. 108). Original description, $\$$.

Peltoperla arcuata Needham \& Claassen $(1925$, p. 170). Description, $\hat{o}$.

This species was originally described from a female; the description of the male appeared later. Since the description of the male of this species by Needham \& Claassen (1925) does not mention the peculiar shape of the anal cerci, I present three illustrations, fig. 5 , which show their shape. These illustrations are based upon a specimen from Ithaca, N. Y., in the Cornell University collection, recorded by Needham \& Claassen (1925). The figure presented by these authors for the male
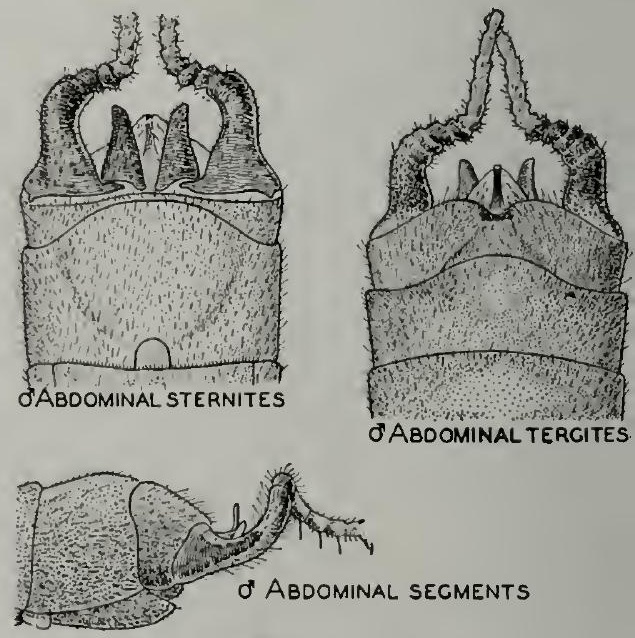

Fig. 5.-Peltoperla arcuata. 
gives but slight indication of the manner in which the anal cerci bend inward near their bases, and, without mention of this unusual character in the text, its significance is lost.

\section{Peltoperla zipha new species}

MALE.-Body, legs and cerci pale yellowish brown, with dorsum of head and thorax darker brown; with basal segments of antennae concolorous with head and with apical segments darker. Compound eyes and ocelli black and contrasting with head.

Head through compound eyes not so wide as anterior margin of pronotum, with posterior margin of compound eyes touching anterior margin of prothorax. Two lateral ocelli present, anterior or median ocellus lacking or not visible; lateral ocelli
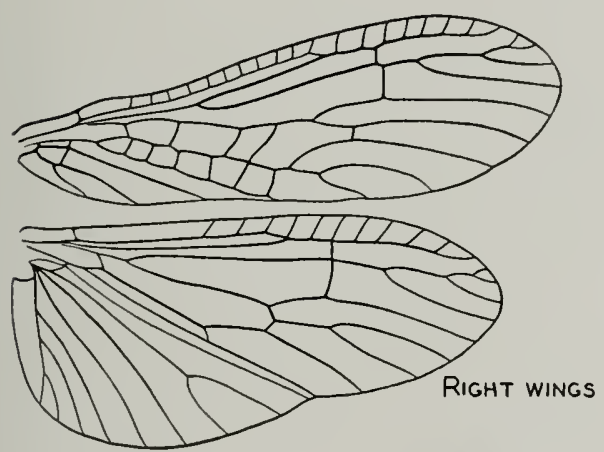

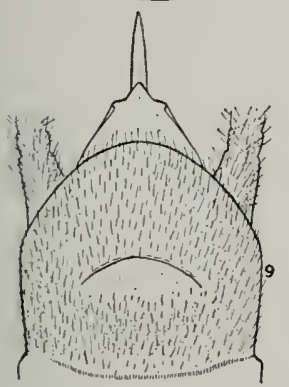

O' ABDOMINAL STERNITES

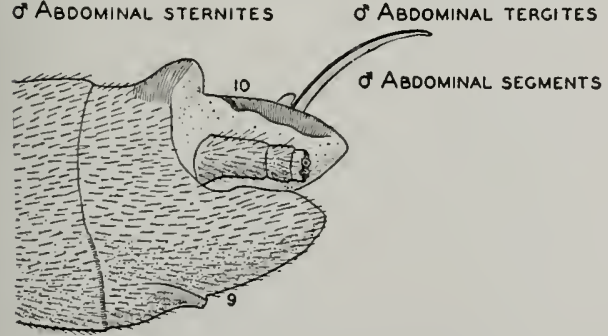

Fig. 6.-Peltoperla zipha. about twice as far apart as each is distant from adjacent compound eye.

Pronotum much wider than long, anterior corners angular and posterior corners much rounded, raised rugosities on posterior two-thirds of area. Legs with third tarsal segments much longer than second and first tarsal segments combined, the first segment slightly longer than the second.

Dorsum of abdomen without special structures through ninth tergite; tenth tergite with anterior part forming a strongly sclerotized upraised ridge attached to a cleft, more membranous area from which the long, slender, pointed supra-anal process arises, fig. 6; two minute membranous lobes are adjacent to place where supra-anal process projects; ninth abdominal sternite with a broad, slightly elevated, weakly developed lobe in middle. Cerci straight, with about 14 segments.

Wings extending far beyond tip of abdomen and with venation as illustrated in fig. 6 .

The gill remnants are difficult to locate but there appear to be one on each side of the mesosternum and metasternum near point of articulation with leg and certainly one or more on each side near upper point of attachment of each mesothoracic and metathoracic leg. False gills are evident, one on each side, on the mesonotum and on the metanotum.

Length to tip of wings $12 \mathrm{~mm}$.; length to tip of abdomen $8 \mathrm{~mm}$.

Holotype, male.-Tributary of Little River, Elkmont, Tenn.: May 14, 1939, T. H. Frison \& H. H. Ross.

This new species is quite different from any described species and is easily separated from arcuata Needham (Smith 1917) because it lacks the small lobe at base of the ninth abdominal sternite and has straight anal cerci. It differs markedly from the male of cornelia Needham \& Smith and related forms in the shape of its supraanal process.

\section{TAENIOPTER YGIDAE}

The generic classification of the Taeniopterygidae presents several problems which are impossible to elucidate thoroughly or unravel at this time. Studies of the North American species, adults and 
nymphs have indicated that the species separate into two fundamentally different gruups. These two groups were recognized in nly studies of the lllinois species (1929, 1935a) as the genera Tomisptery.x Pictet (18+1) (= Nephelopteryx Klapálek 1902) and Strophopteryx Frison (1929). Beginning with Klapalek, in 1902, numerous generic names hase been proposed for the reception of varius species in this family. Since the world species break up into many small units, and each new species seems to present a new combination of the characters used as the basis for these genera, I am following the course, at Peast for the present, of accepting these names as subgenera and holding to a generic division which presents more marked or fundamental differences in the nymphs as well as adults.

'The name of Taeniopteryx Pictet $(18+1)$ with its genotype of nebulosa (Limnaeus), as used by me in 1929, still holds for one of these basic genera, and the name Brachyptern Newport (1851) with its genotype of trifasciata (Pictet) is the first name available for the other. Sirophopteryx Frison (1929) belongs as one of the subgenera of Brachyptera. In Taenioptery $x$ belong the species like maura (Pictet), which have nymphs with coxal gills, adult males with one-segmented cerci and a ninth abdominal sternite reaching only to tip of abdomen, and adult females with the subgenital plate poorly developed. In Brachyptera belong the species like fasciata (Burmeister), which have nymphs lacking coxal gills, adult males with several-segmented cerci and a ninth abdominal sternite recurved up about the tip of the abdomen, and adult females with the subgenital plate much produced.

\section{KEY TO GLNERA}

\section{OF TAENIOPTERYGIIAE}

\section{Anul.TS}

Males with one-segmented anal cerci, ninth abilominal sternite reaching only to tip of abdomen and not abrupily recurved upwards about tip of abdomen, forewings always normal; fernales with subgenital plate not or scarcely produced; both sexes show coxal gill scars

Taeniopteryx

Males with several-segmented anal cerci, uinth abdominal sternite abruptly curved up about tip of the abdomelt, forewings sonetimes brachyplerous; females with a well-developed and protruding subgenital plate; both sexes without iraces of coxal gill scars.

lirachyptera

\section{Nympis}

Coxal gills present and terminal abdominal structures suggestive of characters of adulis

Taenioptery

Coxal gills absent and terminal abdominal struciures suggestive of characters of adults

Brachyptera

\section{Taeniopteryx maura (Pictet)}

Nemoura manra Pictet (1841, p. 361). Original description, ?.

Nemoura nivalis Fitch $(18+7$, p. $27+)$. New synonymy.

Taenioptryx nizalis Frison (1929 and 1935a, pp. 378 and $3+1$, respectively). Descriptions and records.

In my paper of 1929 I stated that "it is likely viralis and maura are the same species," and, again, in 1935 that "there is a strong probability that maura (Pictet) and mivalis (Fitch) are the same species ... in which case the former name would have priority."

Since these earlier papers I have had occasion to determine many hundreds of specimens from all parts of the distributional range of mizalis and maura, and I have come to the definite conclusion that nizalis should be regarded as a synonym of maura. In the past, manra and nivalis have been separable in the males only, and then on the basis of the presence or absence of a toothlike projection on the lower surface of each femur. As first pointed out in 1929, I find in the males from the same locality that some have this toothlike projection and others do not; in fact, specimens are not uncommon which have the tooth on one femur and lack it on the other. Another structural character of maura displaying great variation in size and shape is the lobe near the base of the ninth abdominal sternite. Coupled with the facts that two species of females cannot be detected and that differences in other characters known to be of great specific importance (such as the cerci, supra-anal process and subanal lobes) cannot be found, it no longer seems tenable to recognize maura and nizalis as two distinct species.

Whether the name of maura is being correctly used can never be definitely settled because, as Ricker (1938) records, only parts of the type remain, and they are not the parts most needed to make accurate determinations of species belonging to this family. No specimens of the typic 
series of nizalis are known to be in existence. It seems that the best interests of nomenclature and taxonomy will be served by using the name of maura for this species.

It has been interesting to find, in a large series of specimens from Oregon, adult and nrmphal specimens which I cannot satisfactorily separate from maura material taken in eastern North America (Frison 19+2). Slight differences in wing color seem to exist, but characters of this nature are apt to be variable. Taenioptery'x maura is common in parts of Minnesota, and no doubt it will be found eventually in states or Canadian provinces east of Oregon and west of Minnesota.

The species maura (= nir'alis and mau$\mathrm{ra}$ ) has been previously recorded from the District of Columbia, Illinois, Maine, Maryland, Massachusetts, New Hampshire, New York, North Carolina, Nova Scotia, Pennsylvania and Virginia. To this list I can now add the states of Connecticut, Florida, Georgia, Indiana, Iowa Kentucky, Michigan, Minnesota, Missouri, Ohio, Oklahoma, Oregon, Tennessee, IVest Virginia and IVisconsin.

\section{Taeniopteryx parvula Banks}

Taeniopteryx parqula Banks (1918, p. 7). Original description, $\delta$.

Taeniopteryx parvula Frison (1929, p. 383, and $1935 a$, p. $3+5)$. Additional descriptions and records.

The typic series of parvula consists of two males, No. 10,049, in the collection of the Museum of Comparative Zoology. One of these is from "IVashington, D. C.," and the other from "Peach Grove

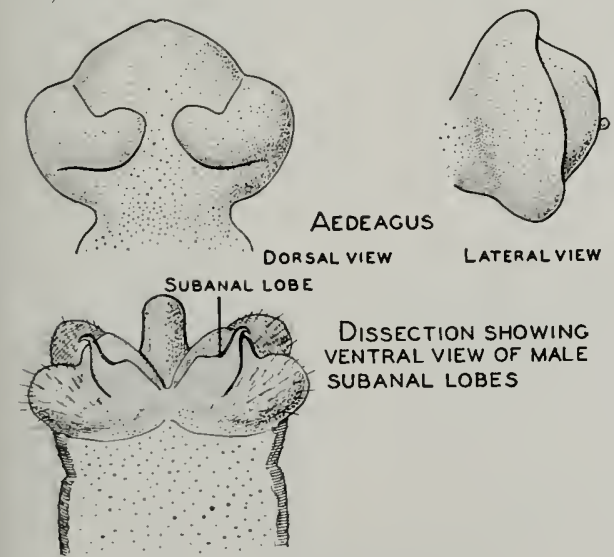

Fig. 7.-Tacniopteryx parrula.
Hill, Va., Feb. 21, 1915," and I am selecting the latter as the lectotype.

In view of the fact that there is another species of Taeniopieryx, described in this article as lita, very closely related to and apt to be confused with parz'ula, I wish to present drawings of the aedeagus, fig. 7 , and of the subanal lohes, not previously illustrated. Drawings of other aspects of partula are available for comparison in Frison 1935a (figs. 190, 21t and 223). It has been an interesting discovery to find that the aedeagus of parzula and of lita are very different, a discovery suggesting that this character merits study in the case of other species of this family.

\section{Taeniopteryx lita new species}

Male.-In general similar to parvula Banks as redescribed by Needham \& Claassen (1925). It differs from parzula as follows: The supra-anal process is much broader at tip, and the one-segmented cerci have a small finger-like process on upper surface, fig. 8 ; subanal lobes are prominent and lobate at tips, whereas in parrula these same lobes are less developed and terminate in a small pointed hook, fig. 7 ; ninth abdominal sternite with a membranous area on posterior median margin covered and surrounded with long, fine setae, fig. 8 ; aedeagus in various views as in fig. 8 .

Wing venation as in fig. 8 . Length to tip of wings $10 \mathrm{~mm}$.

Ferale.-Head, thorax, basal abdominal segments and appendages in general similar to those of male. Genital opening near middle of eighth abdominal sternite, not covered by a plate, sclerotized areas bordering opening larger, fig. 8, than in parzula (Frison 1935a, fig. 21t).

Holotype, male.-Elizabethtown, I1l.: March 7, 1928, T. H. Frison \& H. H. Ross.

Allotype, female.-Same data as for holotype.

Paratypes. - Illinols. - Elizabethtown: Same data as for holotype, $3 \delta$. GOLCONDA: March 17, 1932, H. H. Ross, $1 \delta$. Grayville, Wabash River: March 8, 1928, T. H. Frison \& H. H. Ross, $7 \delta$.

Arkansas.-Brasfield, Cache River: April 16, 1939, H. H. \& J. A. Ross, $1 \hat{o}$.

IndANA.-ST. Anthony: Feb. 13, 1938, T. H. Frison \& C. O. Mohr, $1 \hat{0}$. Rogers, White River: March 14, 1936. T. H. Frison \& H. H. Ross, $4 \hat{b}$. Winsiow, Patoka River: Feb. 1t, 1938, T. H. Frison \& C. O. Mohr, 28.

Maryland.-Priests Bridre: Feb. 25, 1938, B. D. Burks, $1 \hat{o}$. 

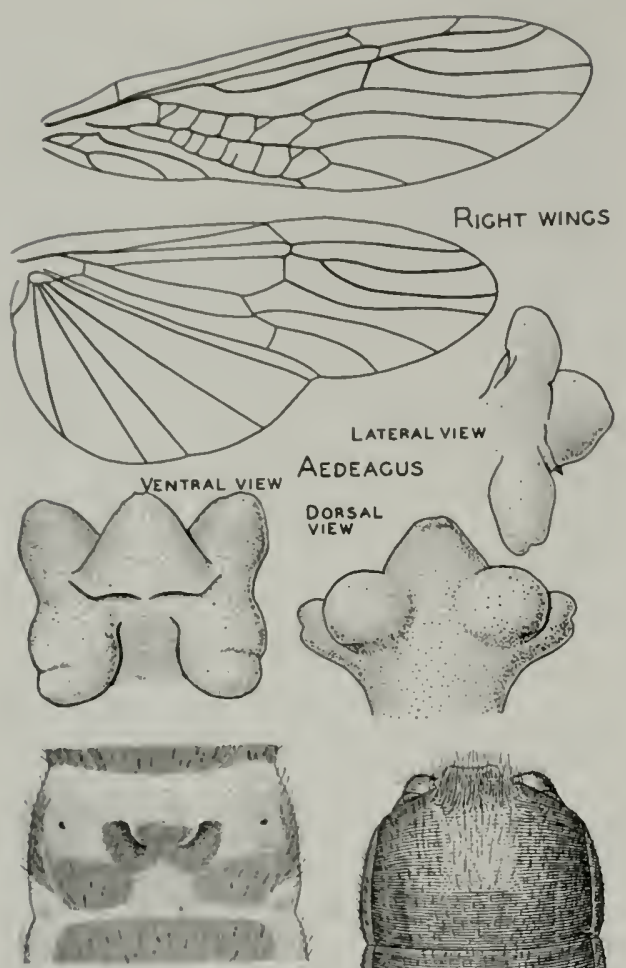

QSUBGENITAL PLATE
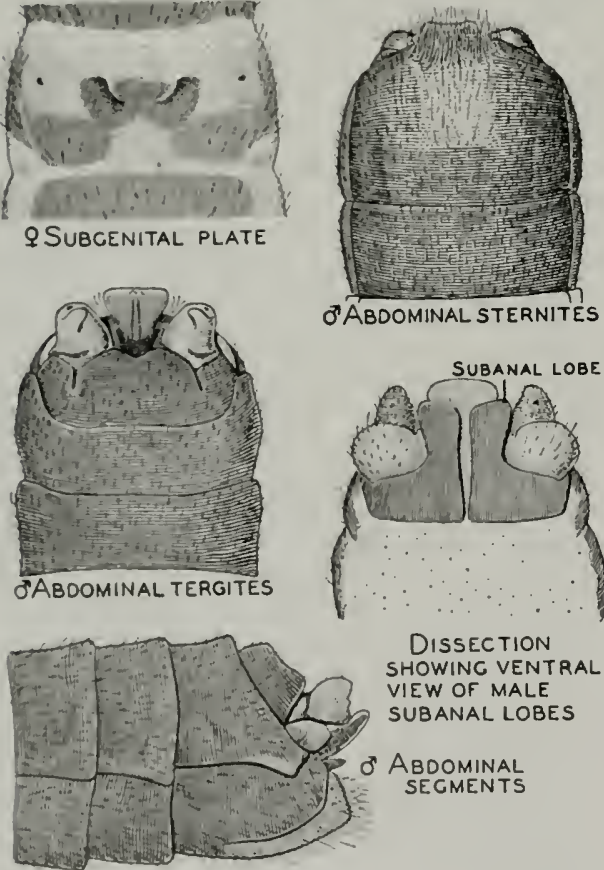

Fig. 8.-Taeniopteryx lita.

Mississippl.-Potts C.imp: Feb. 17, 19+1, T. 11. Frison, 10,2 .

'This is a species apparently with a more southern distribution than parrula and easily apt to be confused with it. It is not unlikely that some of the records of Needham \& Classen (1925) for parqula pertain to this new species. Illinois records of parrula from Elizabetitown (in part),

Golconda and Grayville (in part) recorded in my 1929 and 1935 a papers belong to this species.

\section{Brachyptera fasciata (Burmeister)}

Semblis fasciata Burmeister (1839, p. 875). Original description.

Strophopteryx fasciata Frison (1929 and $1935 a$, pp. $38 t$ and $3+7$, respeclively). Additional descriptions.

In 1929 I proposed the generic name of Strophopteryx for the inclusion of fasciata, because fasciata possessed some characters which did not fit the various genera then in use for the Taeniopterygidae. Also, I wished to emphasize the marked fundamental differences existing in both adults and nymphs between such Illinois stoneHlies as the species then known as Taeniopteryx nizalis (Fitch) and Semblis fasciata.

In my remarks in this article under the heading of Taeniopterygidae, I have stated my reasons for now recognizing but two genera in this family, Taenioptery $x$ and Brachyptera. This procedure reduces Strophoptery:x to subgeneric status along with such names as Rhabdiopteryx Klapálek and Oemopteryx Klapálek.

While determining large series of fasciata, $\mathrm{l}$ have observed instances of variation. The most noticeable involves the occurrence or non-occurrence of membranous

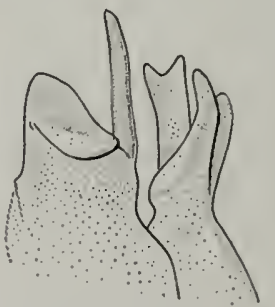

Subanal lobes

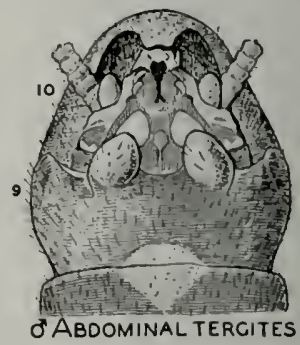

Fig. 9.-Brachyptera fasciata.

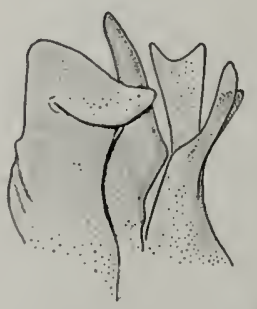

SUBANAL LOBES

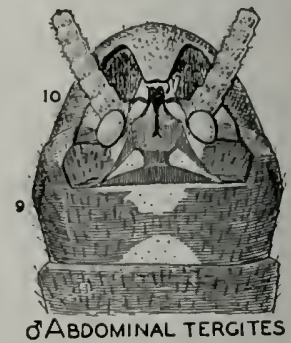

Fig. 10.-Brachyptera fasciata. 
lobes, one on each side, on the posterior margin of the ninth abdominal tergite in the males, fig. 9 ; in some males these lobes are present, whereas in many specimens they are lacking or relatively undeveloped, fig. 10. 'The subanal lobes of this species are asymmetrical, and in spite of their complexity 1 have failed to find marked differences in kind between these structures in males with and in males without the lobes on the ninth abdominal tergites, figs. 9 and 10. 'This latter fact, plus failure to find differences in the females and nymphs, has influenced my evaluation of the absence or presence of these lobes on ninth abdominal tergite as a non-specific character.

\section{Brachyptera glacialis (Newman)}

Nemonra (Brachyptera) glacialis Newman (1851, p. 451). Original description, $\hat{o}$, ㅇ․

Taeniopteryx (Ocmopteryx) alex Hanson (1938, p. 79). New synonymy.

Taeniopteryx glacialis Ricker (1938, p. 131). Notes regarding types.

In the collection of the Museum of Comparative Zoology, there is a male of glacialis from "Hudson's Bay" which is undoubtedly the typic male specimen mentioned by Ricker (1938) as having "been sent to the Museum of Comparative Zoology." Ricker (1938) selected lectotypic and lecto-allotypic specimens from the series of two male and three female types now in the British Museum. This species was entirely omitted by Needham \& Claassen (1925) in their Monograph.

I have studied in fluid the genitalic structures of the typic male in the $\mathrm{Mu}$ seum of Comparative Zoology, paratypic specimens of 'Taeniopteryx (Oemopteryx) alex and other specimens, and as a result I have come to the conclusion that alex is a synonym of glacialis. I can find no definite characters to separate them, and any differences observed can be ascribed to variation.

Hanson described alex from specimens collected at Wells, Hamilton County, N. Y. Records or specimens in the Illinois Natura] History Survey collection or specimens I have determined for others are as follows.

Connecticut,-Dinielson: March 24, 1937, H. H. Ross, $5 \hat{\delta}, 4$.

Minnesota.-LAke County, Stewart River: March 26, 1938, R. H. Daggy \& W. S. Chalgren, $5 \hat{\delta}$.

UтAH.-Mrton: March 16-19, 1940, R.A.Z., $3 \delta, 5$.

\section{Brachyptera oregonensis (Needham \& Claassen)}

Tacniopteryx oregonensis Needham \& Claassen $(1925$, p. 248). Original description, $\hat{o}$.

This species was originally described from males only, collected at Corvallis, Ore. Since the female has not been previously described it seems desirable here to

Fig. 11.-

Brachyptera

oregonensis.

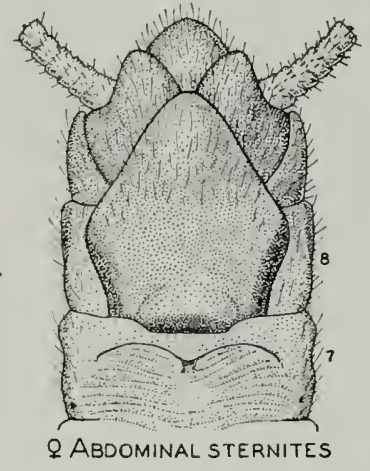

illustrate the important features of the terminal abdominal sternites of a female. fig. 11, based upon a specimen collected at Dixon Creek, Corvallis, Ore., March 10, 1935, by R. E. Dimick. Since all other characters are approximately the same as those in the male, this illustration showing the shape of the subgenital plate will suffice for a description of this sex, and the specimen is designated at the allotype.

A large number of specimens of orcyonensis are now in the Illinois Natural History Survey collection, and I have determined many specimens for others. These records are too numerous to be given in detail here but come from the following localities in Oregon: Benton County, Canyonville, Clackamas County, Clatskanie, Clatsop County, Columbia County, Corvallis, Crabtree, Forest Grove, Hillsboro, Lebanon, Lewisburg, Oak Creek, Philomath, Polk County, Portland, Salem, Seaside, Warren and Wren.

\section{Brachyptera pacifica (Banks)}

Taeniopteryx pacifica Banks (1900, p. 24+). Original description, $\delta$, + .

Taeniopteryx raynoria Frison (1942, p. 9). Recent synonymy.

Taeniopteryx kincaidi Frison (1942, p. 9). Recent synonymy.

In a recent publication (19+2), I treated raynoria Claassen (1937b) and kincaidi Hoppe (1938) as synonyms of pacifica. Additional comments regarding the types involved and the synonymy adopted are herewith presented. 
The topes of pacifun are in the collection of the Museum of Comparative Zoology and bear the type number "11,30t" and the locality of "Pulluman. Washington." In the typic series are three specimens, one male and two females. Through the kindness of Dr. Nathan Banks I was permitted to relax and study closely in Huid the genitalic charatcteristics of one male, and I herewith designate this male specimen as the lectotype.

The holotype, allotype and paratypes of kuncuidi were sent to me for study through the kindness of Professor Trevor Kincaid of the University of $W$ ashington, and the holotype and allotype of raynoria were studied through the courtesy of Professor J. Chester Bradley of Cornell University.

I synonymized raynoria and kincaidi with pacifica in my most recent stonefly paper $(19+2)$ hecause of my belief that all observable differences fall within the limits of specific variation and involve no marked differences in kind of structures. The differences observed included variation in the size and shape of the rearwardpointing appendages on the tenth abdominal tergite and the lobes protruding upward from the bases of the cerci, as well as differences in pigmentation of the abdominal segments. It may be that some of these differences predominate in certain geographical areas, and such names as raynorin and kincridi can be used in the future for geographical races or subspecies. For instance, the rearward-pointing lobes on the tenth abdominal tergite of the type of raynoria, which comes from "Yosemite, California," is larger than in many specimens I consider as pacifica in the Illinois Natural History Survey collection from Oregon, Washington and British Columbia.

Claassen (1937b) gave an illustration of the lateral view of the terminal ahdominal segments of his raynoria, and better to show its similarity with pacificn I include here a dorsal view of the terminal ahdominal segments of the holotypic male, fig. 12 , and a ventral view of the terminal abdominal segments of the allotypic female, fig. 12, which Claassen did not illustrate.

Taeniopteryx kincaidi, from several localities in Washington, was placed in the synonymy of pacifica (Frison 19+2) for the same general reasons as just given in the calse of raynoria. In her key involving the separation of the species of Taeniopteryx from Washington, Hoppe (1938) key's out pacifian from kincaidi on the hasis of the presence of two raised rearward-pointing appendages on the tenth abdominal tergite of the male in pacifica and their lack in kincaidi. No good specific characters for the separation of these

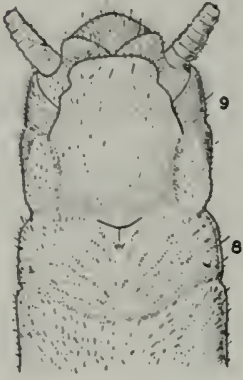

\&ABoominal steanites

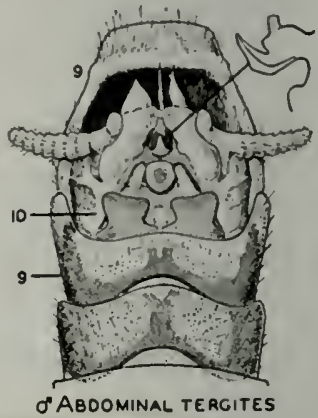

O'ABOOMINAL TERGITES
Fig. 12.-Brachyptera pacifica.

two species are given in the original description of kincaidi. An examination of the males in the typic series of kincaidi reveals the presence of these lobes exactly as in pacifica. The statements in the key regarding "Hind margin of the tenth tergite extended rearward" undoubtedly refer to the ninth tergite, and this particular structure seems to vary considerably in specimens of pacifica.

Taeniopteryx pallida (Banks 1902), described from "Little Beaver, Colo., July" 18,1898 ," is yet another species which must be considered in the final synonymy of the pacifica complex. Although at the present time I cannot certainly separate the typic female of pallida from other females of the pacifica complex, 1 have hesitated to sink this name in synonymy because of lack of males associated with females which may be considered as pallida. 'There is a possibility that the male when found might be distinct enough to warrant specific recognition. On the other hand if the male that goes with pallida falls within the pacifica complex, then the name pallida will be antedated only by pacifica.

It has been most interesting to discover that pacifica is not restricted to the western states and that it occurs in cold rapid streams in the mountainous parts of Maryland, New Hampshire, New York, North Carolina, 'Temnessee, Virginia, and no 
doubt other states. Critical comparative studies of eastern and western material have failed to reveal any significant characters for the separation of eastern specimens from western specimens. With respect to variation in the size of the lobes on the posterior margin of the tenth abdominal tergite, the eastern specimens are of the small type. A similar instance of a species of taeniopterygid occurring in both eastern and western parts of the United States has been recorded for Taenioptery.x maura (Pictet) under the name of nivalis (Fitch) by Frison (19+2).

Records for pacifica from eastern North America, based upon material in the Illinois Natural History Survey collection or examined by me, are as follows.

Maryland.-Piney Grove: April 19, 1938 , H. H. Ross, $1 \delta$.

New Hampshire.-Mount Washington: Brook near Pinkham Notch Camp, June 22, 1941, Frison \& Ross, $1 \hat{\delta}$, $q$ ?.

New York.-Mount Tremper, Esopus Creek: April 27, 1935, P. jemnings, 1 ․ Phoenecia: May 5, 19+0, P. Jennings, $1 \hat{o}$, 3 . S Schoharie: ex trout stomach, April, 1937, P. Jennings, 2 nymphs; May 5, 1937, P. Jennings, $1 \hat{\circ}$ : May 28, 1937, Flock, 1 ; April $16,1938, \mathrm{P}$. Jennings, $1 \hat{\delta}, 2$; ; ex trout stomach, April, 1940, P. Jennings, 1 o, 2 q, 2 nymphs.

North Carolina.-Blowing Rock: March 23, 1940, Frison, Mohr \& Hawkins, 1 ㅇ, 2 exuviae; near Grandfather Mountain, west of town, March 23, 1940, Frison, Mohr \& Hawkins, 3 nymphs. WiLlets: March 23, 1940, Frison, Mohr \& Hawkins, $1 \delta, 2$.

Tennessee.-Gatlinburg: March 24, $19+0$, Frison, Mohr \& Hawkins, $+\hat{\delta}, 5$ exuviae. Greenbrier Cove: March 15, 1938, 2,000 feet elevation, Smoky Mountains, A. C. Cole, 1 오.

VIRGINIA.-SPEEDWELL: March 22, $19+0$, Frison, Mohr \& Hawkins, 1 \&, 2 exuviae. SPERrYVILLE: March 17, 1940, Frison \& Mohr, 2 ㅇ.

\section{Brachyptera vanduzee (Claassen)}

Taeniopteryx vanduzee Claassen (1937b, p. 46). Original description, $\hat{o}$.

I have studied the type of this species in the collection of Cornell University, through the kindness of Professor J. Chester Bradley, and find z'anduzee to be a distinct and valid species. It differs from all other western species of the genus in the presence of a lobe on the ninth abdominal sternite. The genitalic structures are complicated, and, since the illustration given by Claassen (1937) is rather indistinct, 1 present fig. 13 of the type showing in greater detail important features of this species.
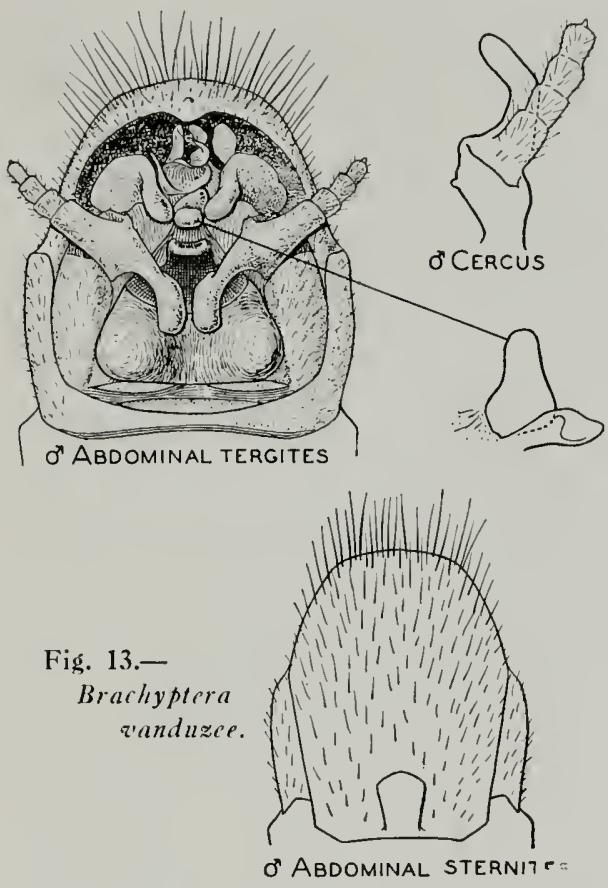

The type was collected at "Tahoe, California." Additional specimens of this species have not been seen or recorded by other entomologists.

\section{Brachyptera contorta}

\section{(Needham \& Claassen)}

Tacniopteryx contorta Needham \& Claassen $(1925$, p. $2+2)$. Original description, $\delta$.

This species has not been recorded in literature since it was described from a single male from "Jaffery, N. H., March 18 , C. IV. Johnson" in the collection of Cornell University. Since the female and nymph have not been described, I present brief descriptions of their most important characters as follows.

Fenale.-In general similar to the male as described by Needham \& Claassen (1925). Coxae without small, round, membranous areas on ventral surfaces (evidence of lack of tracheal coxal gills in nymph). Venation of wings as in fig. 14. Ninth abdominal sternite produced into broad, rounded plate shaped as in fig. $1+$.

Allotype, female.-East Hampton, Lyman's Brook, Conn.: March 24, 1937, H. H. Ross. Taken at same time and place as males of the same species. 
Nimph.-In general similar to the mymph of fusciata (Bumeister), as described by Frison (1929, p. 385). Differs

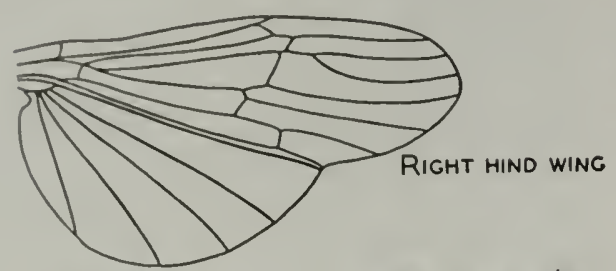

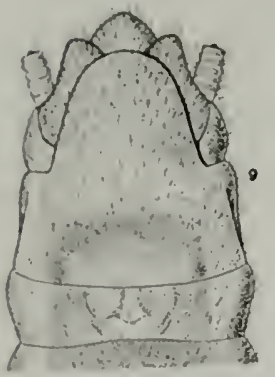

O. ABDOMINAL STERNITES

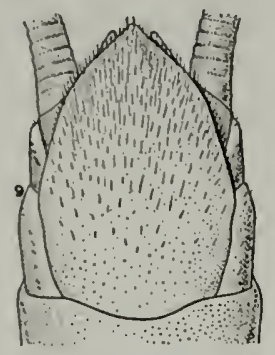

NYMPHAL ABDOMINAL STERNITES
Fig. 14.-Brachyptera contorta.

chiefly in that ninth abdominal sternite has a broad, platelike projection extending about to tip of abdomen, fig. 14, instead of a narrow, platelike projection.

Nymphal specimens from same locality as allotype.

Illinois Natural History Survey collection records are as follows.

CoNNecticut.-EAST Hampton: Same data as for allotype, $2 \delta, 19,16$ nymphs.

Virginla.-Stindardóvilie: March 21, 1940, T. H. Frison, C. O. Mohr \& A. S. Hawkins, 13,79 . Sperryville: March 17, 19+0, T. H. Frison, et al., 7 \} , 3 9,3 nymphs.

\section{Brachyptera rossi new species}

MALE.-General hahitus similar to that of other species of Brachyptera. Head, thorax and abdomen mostly black with portions suffused with reddish brown. Antennae black, the segments longer than broad throughout length. Legs with tarsi, tibiae and apical third of each of the femora black; basal two-thirds of each of the femora yellowish brown. No traces of membranous gill scars on coxae. Wings with veins black and membrane smoky, venation as in fig. 15.

Apical abdominal segments intricately modified and presenting the distinctive characters, fig. 15, for this new species as follows: Ninth abdominal sternite greatly prolonged into a plate which extends back beyond the tip of abdomen, then bends upwards and is club headed at tip as riewed from the side, with a stout, sickleshaped structure at tip as viewed from above, and near its base there is a prominent lobe; tenth abdominal tergite bears two slender, pointed projections, directed backwards, on middle of posterior margin ; cercus 5 or 6 segmented, with a platelike lobe at its base above; supra-anal process a short, stout, pointed lobe; subanal lobes complicated, asymmetrical and, viewed from above, as in fig. 15. Length to tip of wings, $13 \mathrm{~mm}$.

Holotype, male. - Near Woodstock, Bog Brook, N. H.: June 21, 1941, T. H. Frison \& H. H. Ross.

I take great pleasure in naming this species for Dr. H. H. Ross, of the Illinois Natural History Survey staff, who has greatly assisted in many ways my studies of the North American Plecoptera.

Five Brachyptera exuviae were found under a bridge near the place where the
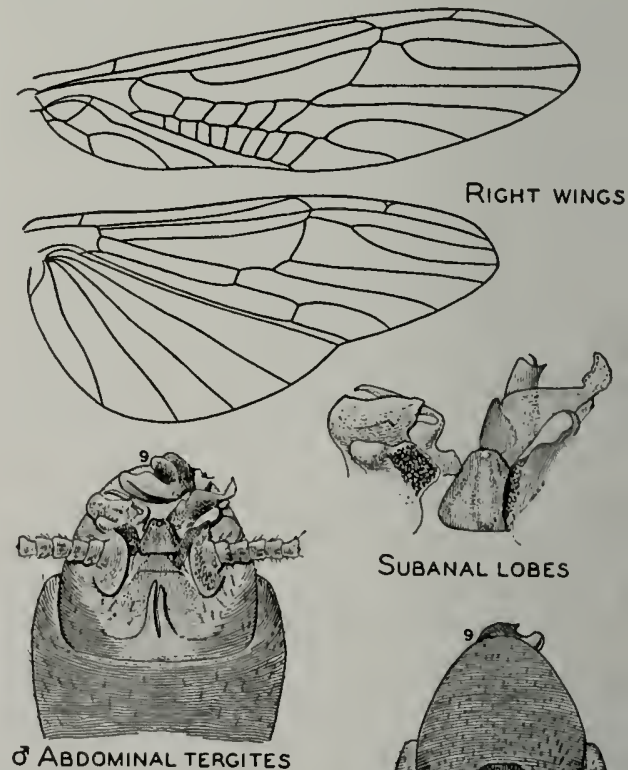

SUBANAL LOBES
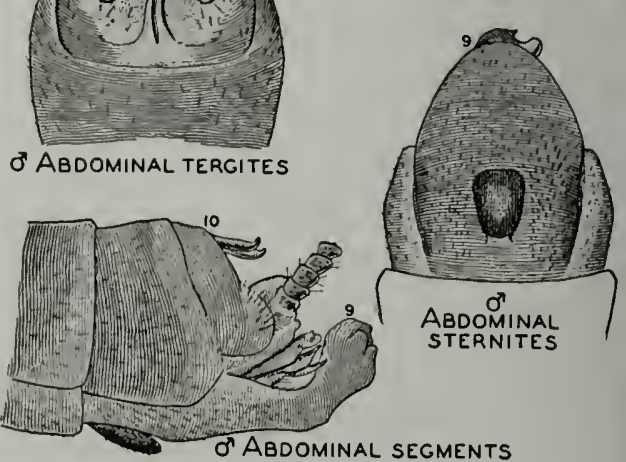

Fig. 15.-Brachyptera rossi. 
holotype was collected. The exuviae represent both males and females, are very dark, lack a longitudinal pale stripe on abdominal tergites, lack coxal gills and, from shape of apical abdominal segments, undoubtedly should be associated with rossi.

The peculiar, pointed projections on the tenth abdominal tergite, combined with the lobe on the ninth abdominal sternite, readily separate the adult of this new species from adults of all previously described species.

\section{Brachyptera limata new species}

Male.-General habitus similar to that of other species of Brachyptera. Head, thorax and abdomen mostly yellowish
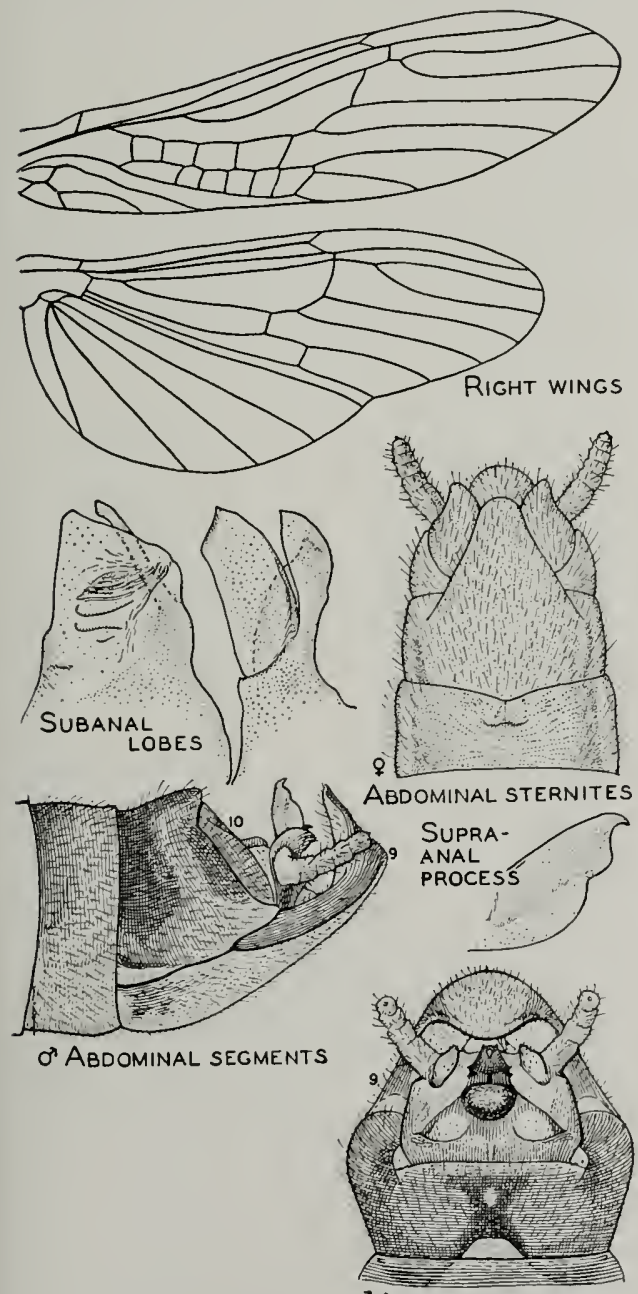

OAABDOMINAL TERGITES

Fig. 16.-Brachyptera limata.

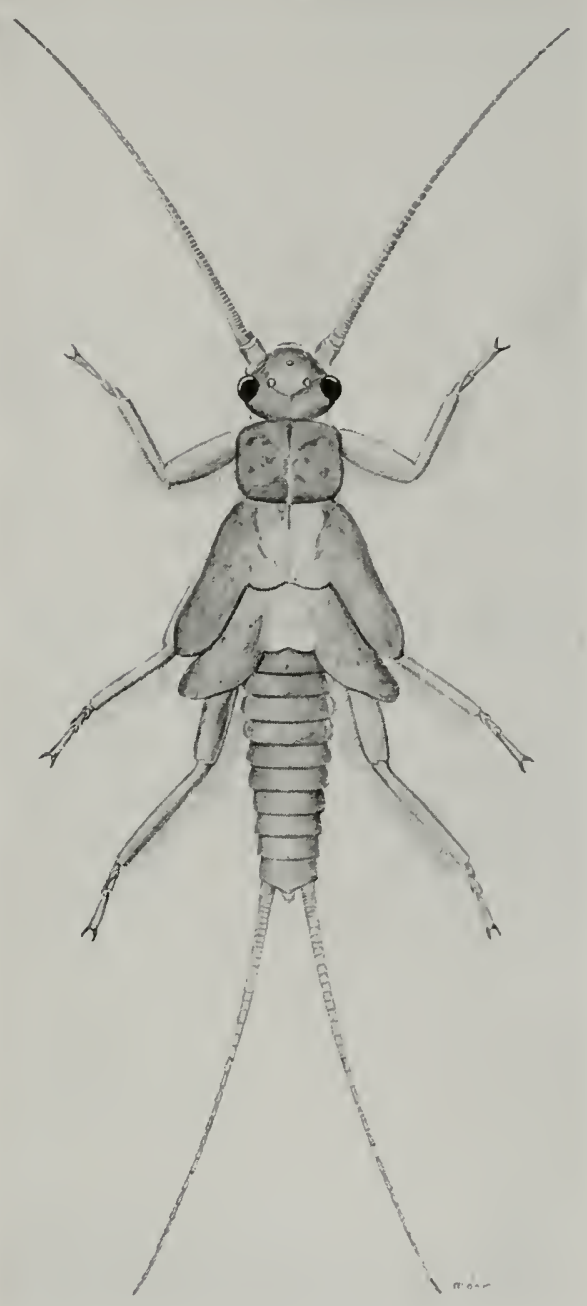

Fig. 17.-Nymph of Brachyptera limata.

brown, antennae and parts of thorax dark brown. No traces of membranous gill scars on coxae. Wings stained with brown, venation as in fig. 16.

Apical abdominal segments intricately modified and presenting the most distinctive characters for this new species, fig. 16, as follows: Ninth abdominal sternite greatly prolonged into a plate which extends back beyond tip of abdomen, then bends upward, but becomes considerably narrowed at tip, without a lobe near base; tenth abdominal tergite without any projections near basse; cerci several segmented, with a small globose lobe above base; supra-anal process short, somewhat re- 
curved up and forward with tip forming a point; subanal lohes complicated, asymmetrical and, as viewed from ahove, are ats in tig. 16.

Length to tip of wings $10 \mathrm{~mm}$.

Finda. - Head, thorax, basal abdominal segments and appendages in general similar to those of male. Genital opening near middle of eighth abdominal sternite not covered by a plate. Ninth abdominal sternite prolonged to form plate reaching nearly to tip of abdomen and rounded at tip, fig. 16.

Holotype, male--Newfound Gap near Gatlinburg, Little Pigeon River, Tenn.: May 1t, 1939. T. H. Frison \& H. H. Ross.

Allotype, female.-Saine data as for holoype.

Paratypes.-Tensessee. - Newfouxd Gap: Same data as for holotype, $226 \hat{6}, 78 q$.

Nyupu.-In general similar to the nymph of fasciata (Burmeister), as described by Frison (1929, p. 385). No longitudinal pale stripe on abdominal tergites, fig. 17. Platelike projection of ninth abdominal sternite somewhat broader than in fasciata, and abdominal tergites uniformly brownish.

Nymphal and exuvial specimens with same data as for holotype.

This new species presents many structures which place it close to the western Brachyptera nigripennis (Banks), from which it differs, however, in shape of supra-anal process, in shape of lobes at base of each cercus, and by the much-narrowed tip of the ninth abdominal sternite. It differs from B. pacifica (Banks), another western species, in lacking lobes at base of tenth abdominal tergite, by the much-narrowed tip of ninth abdominal sternite, and other characters.

\section{I.EUCTRIDAE}

\section{Leuctra Stephens}

At the time of the publication of The Stomeflies, or Plecoptern, of Illinois (Frison 1935a), claasseni firison (1929) was the only species of Leuctra known to occur in Illinois. Since then, intensive field work in exceedingly local, small and segregated habitats has revealed the presence of two additional species. It becomes desirable, therefore, to record these new alditions to the lllinois list, to illustrate the characters most useful in recognizing the three lllinois species and to present a key for identifying them.

\section{KES TO ILLINOIS SPECIES OF I.EUCTR.A ADULTS}

\section{MAl.ES}

1. Ninth abdominal tergite with a prominent, sharply oullined, deep, longitudiwal cleft, fig. 18 claasseni

Ninth abdominal tergite without such a cleft

2. Seventh abdominal tergite with a conspicuous, rearward-pointing process, fig. 20 tenuis

Seventh abdominal tergite without a special process, fig. 19.

decepta

\section{FEMALES}

1. Eighth abdominal sternite about as long as seventh, with posterior margin in middle indented so that sternite is bilobed.

Eighth abdominal sternite much shorter than seventh, posterior margin not bilobed; three small, separated, humplike areas on anterior margin, tig. 18

claasseni

2. Seventh and eighth abdominal sternites conspicuously fused; cleft between lobes of posterior margin of eighth sternite wide and deep, sides and tips of lobes formed by a cleft more strongly and darkly sclerotized than rest of sternite, fig. 20 .

tenuis

Seventh and eighth abdominal sternites indistinctly or weakly fused; cleft between lobes of posterior margin of eighth sternite narrow, sternite almost uniformly sclerotized, fig. 19... decepta

Hanson (19+1) in a recent paper has separated Leuctra as previously used by cther North American workers into two genera, Leuctra Stephens and Paraleuctra Hanson. It is obvious to anyone who has closely studied a series of species of Leuctra (s.l.) that this genus contains some smaller complexes. Paraleuctra may be of generic rank, but, for the time being, pending a thorough revisional study of the Leuctridae, 1 prefer to recognize Paraleuctra as a subgenus. If Paraleuctra is a valid genus, it is probable that other additional generic names will be necessary. Paraleuctra is represented in lllinois by clanssini Firison.

\section{Leuctra claasseni Frison}

Lesuctra claasseni Frison (1929, p. 40t). Original description, 3 .

Lenctra claasseni Frison (1935a, p. 355). Description and new records, $q$.

The original description of this species was based solely upon Illinois specimens, 
and additional records of specimens from Missouri and Oklahoma were added in 1935. Since the Missouri record was based upon a nymph whose identity was assumed hecause of the presence of claasseni in similar and adjacent territory in Illinois, a doubtful procedure in this genus where nymphs are of homogeneous appearance, I an pleased to confirm the Missouri record from adult specimens and to add additional distributional records as follows.

Indiana.-Turkey Run State Park, Newby Gulch: May 12, 1933, T. H. Frison \& C. O. Mohr, 1 nymph. Tributary of Sugar Creek, east of TURKEY RUN STATE PARK: Apri] 9, $19+0$, T. H. Frison \& H. H. Ross, $11 \delta, 5 q$, 1 nomph.

Missouri.-Southeast of ElisinOre: March 8, 1939, T. H. Frison \& C. O. Mohr, $1 \hat{\delta}$ (reared), 1 \%, 2 nymphs.

Ohio.-Ash Cave: March 6, 1938, T. H. Frison, 1$\}$.

New illustrations of the important male and female structures, fig. 18 , are presented to aid with the separation from other Illinois species. Both the male and the female of this species are markedly different from decepta Claassen and tenuis (Pictet), the other two Illinois species of

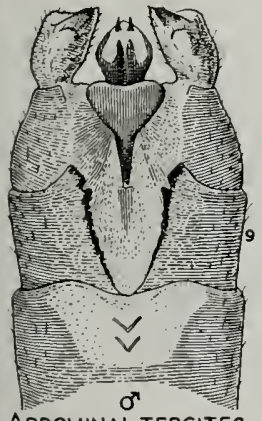

ABDOMINAL TERGITES
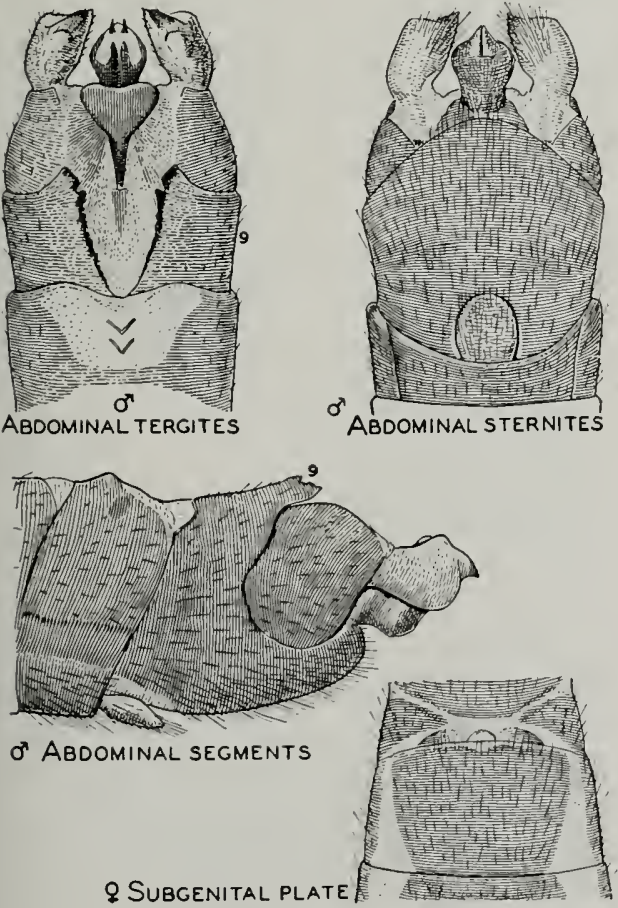

Tis. 13.-Lenctra claasseni
Leuctra; in fact, claasseni is so distinctive that it represents a subgroup or division among North American species of the genus, which Hanson (19+1) has named Paraleuctra.

\section{Leuctra decepta Claassen}

Leuctra decepta Claassen (1923, p. 260). Original description, $\delta$, $q$.

Leuctra dccepta Needham \& Claassen (1925, p. 227). Additional record.

Leuctra decepta Claassen (1931, p. 99). Nymphal description.

Leuctra decepta was described from New York specimens and, since the original description was published, this species

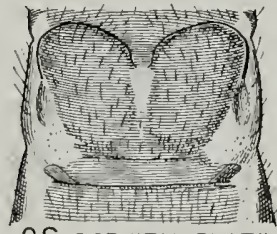

Q SUBGENITAL PLATE

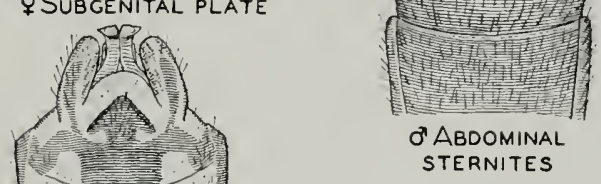

STERNITES

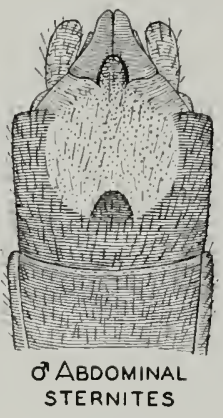

ơ Aboominal tergites

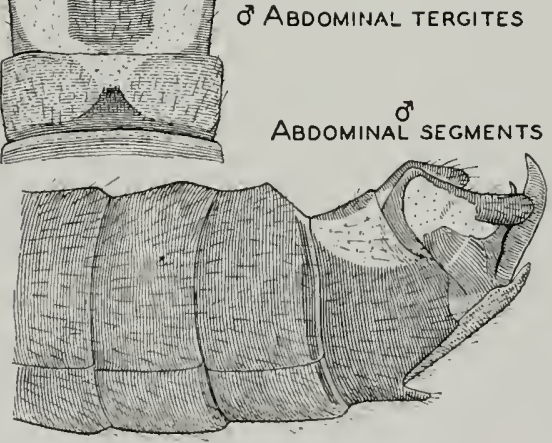

Fig. 19.-Leuctra decepta.

has not heen recorded from other states. The recent finding of this species in southern Illinois and other places indicates it is widely distributed in eastern North America.

Since this species was not known to occur in Illinois when my report on the Illinois stonefly fauna was published in 1935, I am presenting illustrations, fig. 19 , to aid with its recognition. The structural features of both male and female show decepta to be much more closely re- 
lated to tenuis (Pictet) than to claasseni Frisoll.

New locality records are as follows.

II.1.No)s. - Heron, spring tributary to Gibhons Creek: May 2t, 1940, C. (). Mohr \& B. D. Burks, 3 \& (2 reared), 39,7 nymphs; May 29 , 1939 . B. 1). Burks \& (;. T. Riegel, 2 o, 1 uymph: May 30, 1940, B. I). Burks, + nymphs. EDmvill., Lusk Creek: May 2t, 1940, C. O. Mohr \& B. D. Burks, $20,29,5$ nymphs; June 1, 1940, B. D). Burks, $10,29,1$ nymph.

Floridil-Leon County, 12 miles west of Thlollassen: Nov. 30, 1939, L. Bermer, 26.

Georais-RABU: County, small creek Howing into Lake Burton: June 22, 1940, H. H. Hubbs, 10 .

MMNE-NEW LiMerick, Hunter Brook: Aug. 25, 1937, '. H. Frison \& T. H. Frison, Jr., $2 \delta$.

Miñesota - LAKE Countr, Encampment River: Aug. 5, 1939, B. T. Peters \& R. 11 . Daggy, 5 ; ; July 4, 1938, H. Knutson, $1 \delta$.

New Brunswick. - Anagance: Aug. 21, 1939, T. H. Frison \& T. H. Frison, Jr., $1 \delta$.

NEW YORK,-COLD BROOK: June 22 and 30 , $19+0$, II. Dietrich, $\delta \delta$, $q$ \% . Caroline, Wild Flower Reserve: Aug. 16, 1928, T. H. Frison, $+\delta$.

North Carolisa.-Newfound Gap: June 13, 1935, H. H. Ross, $2 \%$.

Novi ScotiA.-Moser River, Goldmine Brook cascades: July 19, 1939, J. A. C. Nicol, 8 ô. SPRINGHil, Junction: Aug. 21, 1939, T. H. Frison \& ' 1 . H. Frison, Jr., $3 \delta$. MoOse River: Aug. 21, 1939, T. H. Frison \& T. H. Frison, Jr., 1 $\delta$. INGRIMPORT: Aug. 22, 1939, T. H. Frison \& T. H. Frison, Jr., $1 \delta$.

Untario.-Algonquix PArk, Costello Lake: various dates, June, July, August and Septemh?r, 1938 and 1939, W. M. Sprules, o $\delta$, $q$.

TeNinessee, - Ginthinburg: June 13, 1940, T. H. Frison ot al., $5 \delta$; Sept. 4, 1940, B. D. Burks, $+\delta, 9$.

Virgisia.-Mountain LakE, Hunters Branch, 3,500 feet elevation: July 28, 1941, A. C. Cole, $1 \delta, 2$.

Several nymplaal specimens show anal gills as first illustrated for claasseni (Frison 1935a). Since tenuis (Pictet) nymphs also show these anal gills, all three of the Illinois species of Leuctra possess them. 'These anal gills are so delicate, however, that they are easily lost by the nymphs or overlooked in specimens.

\section{Leuctra tenuis (Pictet)}

Nemoura tenuis Pictet (18+1, p. 375). Original description.

As in the case of decepta Claassen, the finding of tenuis in a segregated relic hathitat in Illinois adds another species to the Illinois stonefly faunal list. Its finding is additional evidence that each locality, stream and other habitat, no matter how restricted, must be searched repeatedl) at various seasons of the year if state faunal lists of stoneflies are to approach completeness. Diagnostic structures of the adult insects of tenuis are illustrated in fig. 20.

The type of tenuis came from Pennsylvania, and Needham \& Claassen (1925) have added the additional state record of New York. The geographical range of this species will undoubtedly be greatly expanded with future collecting, as the following new records for its occurrence indicate.

Illixols.-Etcrs, Botanical Gardens: Sept. 19,1939, H. H. Ross \& C. O. Mohr, $9 \hat{\delta}, 4+$.

MaINE.-NEW LIMERICK, Hunter Brook: Aug. 25,1939 , T. H. Frison \& T. H. Frison, Jr. 36 .

Míchigan.-Otsego County, west branch Sturgeon River: June 24, 1936, J. W. Leonard, $2 \delta, 29$; July 9, 1937, F. E. Lyman, $1 \hat{\delta}, 1$.

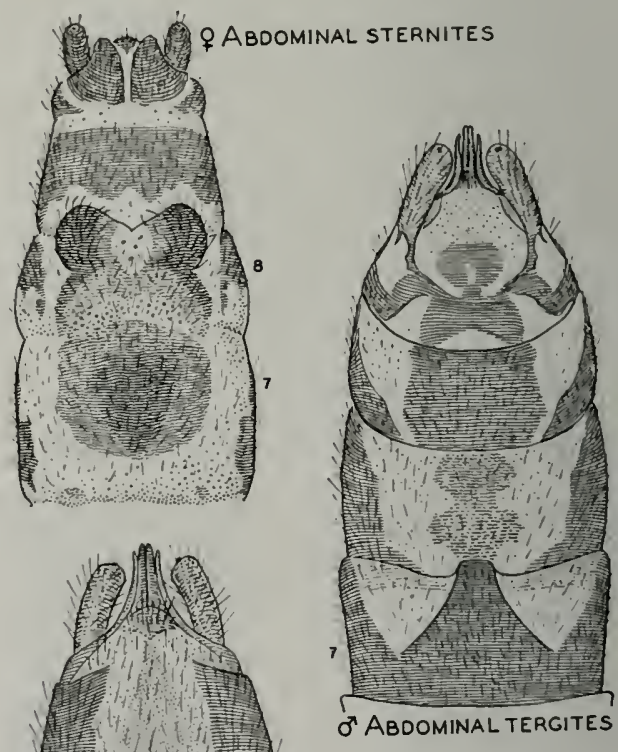

O ABDOMINAL STERNITES
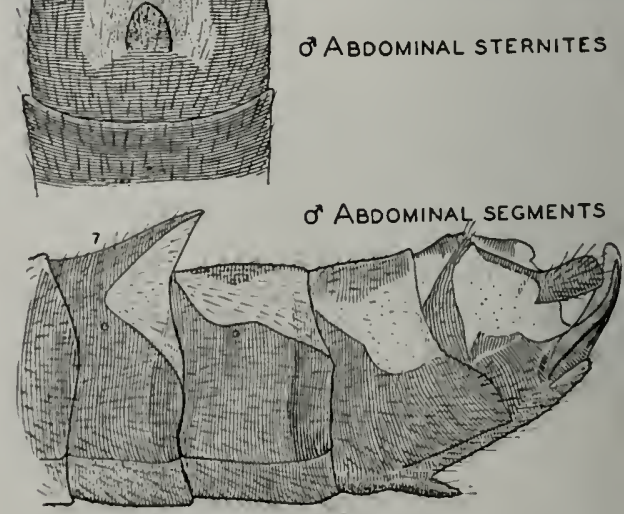

Fig. 20.-Leuctra tenuis. 
Cheboygan County, west branch Sturgeon River: July 3, 1938, J. W. Leonard, $2 \hat{\sigma}, 2$ 오. Montmorency County, Hunt Creek: Aug. 30Sept. 3, 19+0, J. W. Leonard, $3 \hat{\delta}, 1$ ㅇ․

Missourl.-Greer Spring: June 7, 1937, H.

H. Ross, $2 \hat{o}, 2$ 오.

New Brunswick. - Peticodiac: Aug. 21, 1939, T. H. Frison \& T. H. Frison, Jr., $10 \hat{\text { ô. }}$. Anagance: Aug. 21, 1939, T. H. Frison \& T. H. Frison, Jr., 26,5 o .

New YORK.-CAROLINE, Wild Flower Reserve: Aug. 16, 1928, T. H. Frison, $1 \hat{o}$. STRATFORD, Trammel Creek: July 19, 1934, H. $\mathrm{K}$. Townes, $1 \hat{\delta}, 2$ ㅇ.

Novi Scoti1. - Moser River, Goldmine Brook: July 29, 1939, J. A. C. Nicol, $2 \hat{o}, 2$ 오. Chester Basin: Aug. 23, 1939, T. H. Frison $\&$ T. H. Frison, Jr., to, 79,5 nymphs. INGRAMPORT: Aug. 22, 1939, T. H. Frison \& T. H. Frison, Jr., 1 . .

Ontario.-Algonquin Park, Costello Lake: June and July, 1938, and June, July and August, 1939, W. M. Sprules, of of, $q$ ㅇ.

TEnNessee. - Chim NeYs CAMP Grounds, Great Smoky Mountains National Park: July 21, 1939, A. C. Cole, 1 ó.

Several nymphs show remnants of anal gills as first recorded for claasseni (Frison 1935a) and also as noted for nymphs of decepta Claassen in this paper. Evidently such anal gills are to be expected in many if not all nymphs of Leuctra. They are very easily overlooked because of their delicate nature and are probably usually lost in handling.

\section{Leuctra occidentalis Banks (1907) \\ Leuctra purcellana Neave (193t) \\ Leuctra forcipata Frison (1937) \\ Leuctra sara Claassen (1937b)}

The study of a large series of specimens of any stonefly species is almost certain to show that slight variations of some structures in most species, and more in others, are to be expected. The genus Leuctra presents a group of species with very conspicuous morphological differences in most of the males named to date and less distinctive differences in the females.

One of the first described and a common western species of this genus is occidentalis Banks (1907). 'The male of this species is one of several having the anal cerci strongly sclerotized and peculiarly shaped. A taxonomic problem arises in determining which departures in shape of this structure from the typic occidentalis should be considered, at least for the time being, as species and which as simply variants. Fig. $21 A, B$ and $C$ shows the character of this structure in specimens from three different states, Oregon, Montana and California, respectively. A study of series of specimens indicates that the observable differences in these specimens is of the variant order.
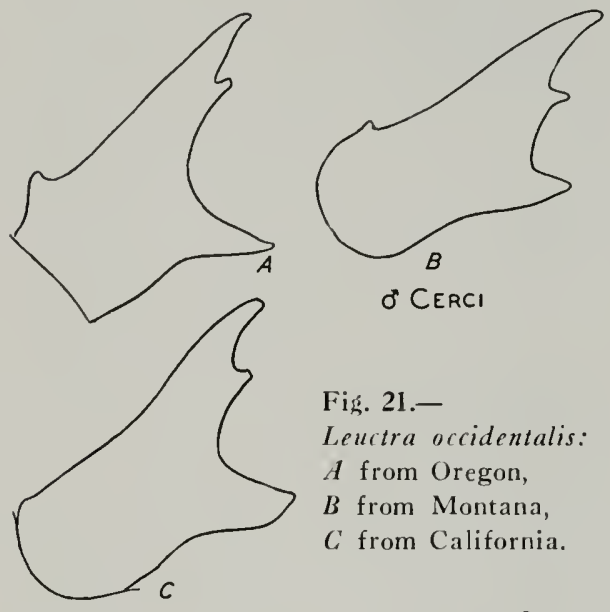

Fis. 21.-

Leuctra occidentalis:

$A$ from Oregon,

$B$ from Montana,

$C$ from California.

Fig. 22.-Leuctra purcellana from Prairie Hills,

British Columbia.
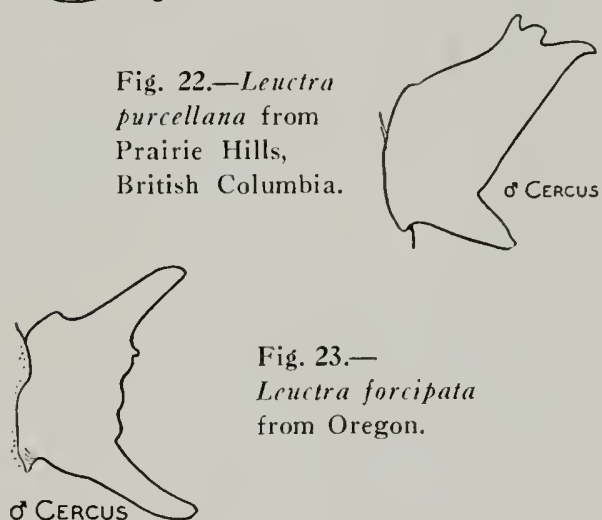

Fig. 23.-

Leuctra forcipata from Oregon.

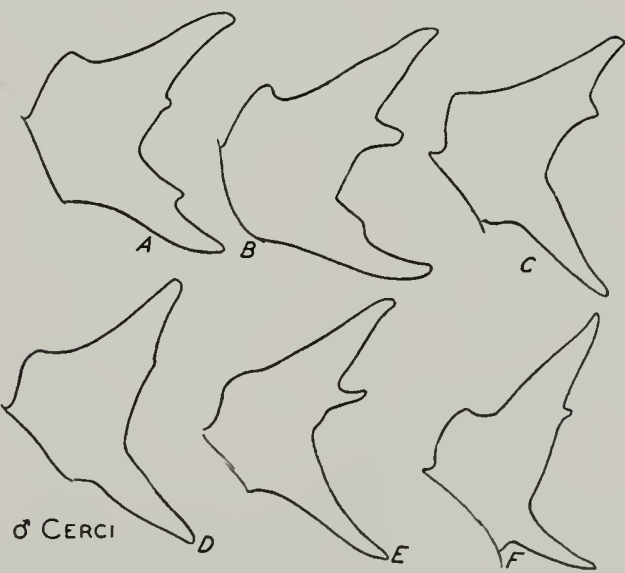

Fig. 24.-Leuctra sara: A from Massachusetts, $B$ from Indiana, $C-F$ from Tennessee. 
Since gividenulis was described, three additional specific names of elosely related forms have been pruposed. Fig. 22 shows the modified anal cercus uf a male specimen from "Prairie Hills, B. C.. July 19. 1908," in the collection of the American Entomulogical Society of Philadelphia, which agrees very well with purellana Veave (193t) described from British Columbia. Fig. 23 shows the modified anal cercus as it exists in specimens from Oregron that I described (1937) under the name of forcipata.

Classen (1937b) proposed the name uf sarn for a species of this genus from New York which very clusely resembles the western occidentalis and the related forcipata and purcellana. Fig. $2+A$ shows the character of the variation observed in the modified anal cercus from a Massachusetts specimen; fig. $2+B$ from an Indiana specimen: $2+C-F$ from 'Tennessee specimens. I am strongly of the opinion that all of these eastern specimens are of the same species, and the differences are due merely to variations in local populations.

The differences between sara and occidentalis are certainly slight, and there is reason to suspect that collecting in northern states and southern Canada will show that sara is specifically the same as occidentalis. The same fate in synonymy may be in store for the more divergent forms decribed as forcipata and purcellana. Until further evidence to this effect is prodused, however, it seems the safest procedure to hold occidentalis, forcipata, purcellana and sara as distinct species, recognizing that certain specimens are merely variants (no names necessary) of these more widely separated units. The recognition, for the time being at least, of these four major types as species causes the to propose another specific name for an even more divergent form. Certainly, this new form deserves specific status if sara (eastern states) is held as distinct from ocridentalis (western states), because it is quite different from the other related forms.

\section{Leuctra projecta new species}

Mals.-Similar in most morphological festures to occidentalis Banks (1907). Differs in the shape of the modified anal cercus as illustrated in fig. 25 .
FEası:-Unkmown but probably very similar to the female of occidentalis.

Holotype, male.-Rocky Mountain National Park, Wild Basin, Colo.: June 13, 1937.

Paratype. - Oregon - Columbia Countr, Scappoose Creek: Feb. 19, 1939, S. G. Jewett, Jr., 13 .

'The moditied anal cerci of the paratype. fig. 25B, differ from those of the holotype, fig. 25. , as shown by comparing the two

Fig. 25.-

Leuctra

projerta.

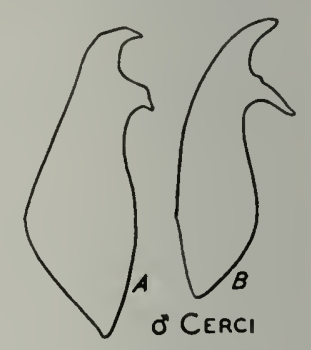

drawings. I am considering the two specimens, however, to be of the same species because of the features in common which are very different from those of the other described species. Lenctra projecta will fall in the group of species for which $\mathrm{Han}$ son $(19+1)$ proposed the generic name of Paraleucira and which, at least for the present, 1 am considering as of subgeneric siatus.

\section{NEMOURIDAE}

\section{Nemoura Latreille}

As in the case of the genus Lenctra, cnly one species of Nemoura was known to occur in Illinois when my paper (1935a) on the Illinois stonefly fauna was published. Recently, a second species of this genus has been found in northeastern Illinois, thereby necessitating the following keys for the separation of the Illinois species of Nemonra.

\section{KEY TO ILLINOIS SPECIES OF NEMOURA}

\section{MALES}

(iill remnants in cervical region; forward recurved part of supra-anal process narrow and elongate; anal cerci small, membranous and without special structures, fig. 26 .

Without gill remnants in cervical region; supra-anal process broad, somewhat knoblike, fig. 27; anal cerci elongate, strongly sclerotized and with projecting points at tip. 
FEMALES

Gill remuants in cervical region; eighth abdominal sternite forming a shelflike plate that is distinctly indented in middle and that protrudes from under the backward projecting posterior margin of seventh sternite, fig. 26 venosa

Without gill remnants in cervical region: eighth abdominal sternite not with small lobes on posterior margin showing under backward protruding posterior margin of seventh sternite, fig. 27

trispinosa, p. 261
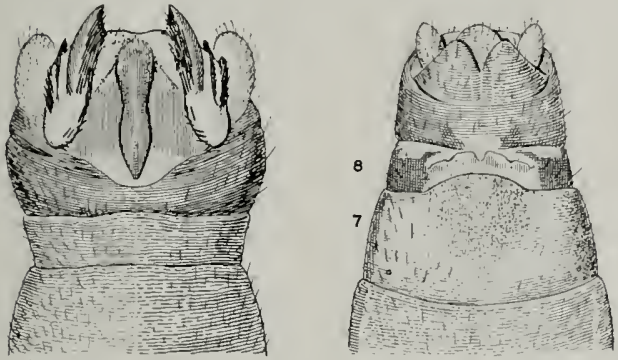

¿ABDOMINAL TERGITES

OABDOMINAL STERNITES

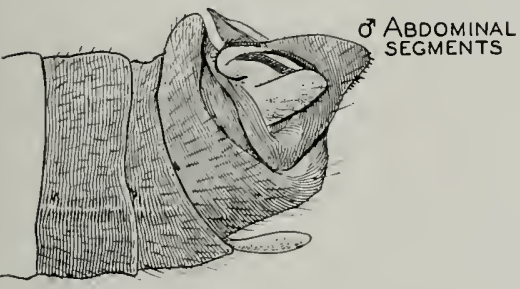

Fig. 26.-Nemoura venosa.

NyMPHS

Gills in cervical region (Frison 1935a, fig. 26t) . . . . . . . . . . . . . . venosa Without gills in cervical region, fig. 27

trispinosa, p. 261

\section{Nemoura trispinosa Claassen}

Nemoura trispinosa Claassen (1923, p. 289). Original description, ô, + .

This species was originally described from New York specimens and subsequently recorded by Needham \& Claassen (1925) from Quebec.

The finding of this species in a small, isolated relic habitat in northern Illinois, the same locality which produced the interesting record for Leuctra tenuis (Pictet), adds a second species of Nemoura to the Illinois list. It is desirable, therefore, to present an illustration, fig. 27 , of the important characters used for identifying the sexes.

New records for this species are as follows.
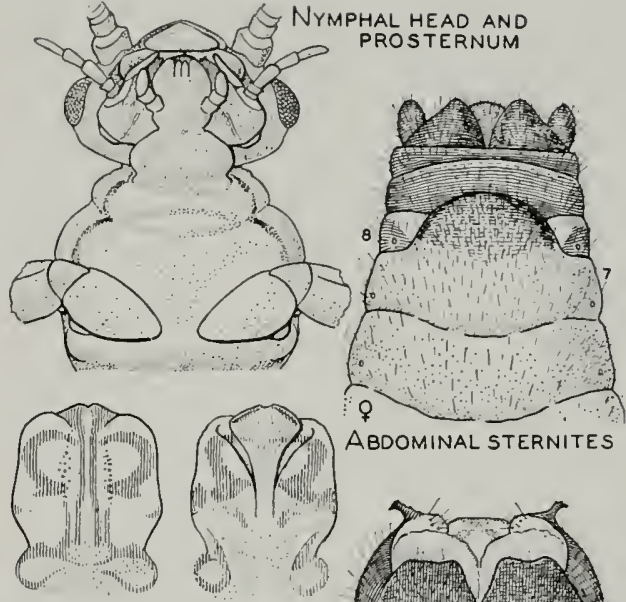

A - SURFACE - B

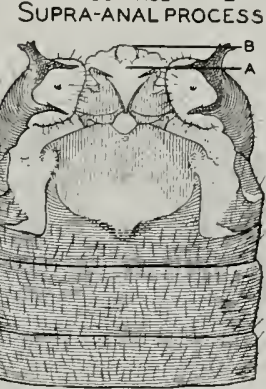

OABD OMINAL TERGITES

ABDOMINAL STERNITES

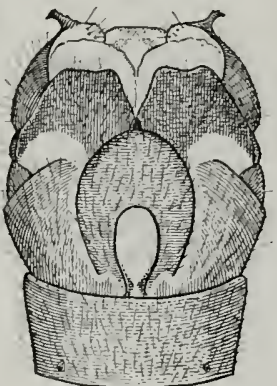

o A ADOMINAL STERnites

$\sigma^{x}$ ABDOMINAL
SEGMENTS

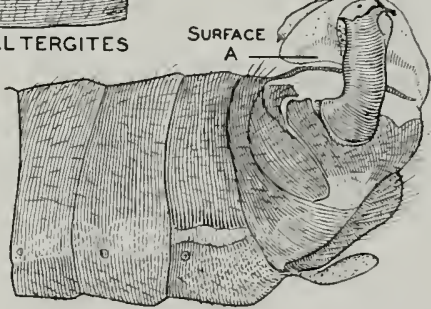

Fig. 27.-Nemoura trispinosa.

Illinols.-Elgin, Botanical Gardens: June 13, 1939, T. H. Frison \& H. H. Ross, + $\delta, 10$ 옹 13 nymphs; May 9, 1939, H. H. Ross \& B. D. Burks, 17 nymphs.

NeW York.-Essex County, Artists Brook: June 23, 1940, H. Dietrich, $1 \hat{\delta}$.

\section{Nemoura californica Claassen}

Nemoura californica Claassen (1923, p. $28+$ ). Original description, $6, q$.

Nemoura lobata Frison (1936, p. 260). Original description, $\delta$. New synonymy.

When lobata was described by me in 1936, I mentioned that it was "very suggestive of $\mathrm{N}$. californica Claassen." Since then 1 have seen additional western material and during a recent visit to the California Academy of Sciences had the 
opportunit!, through the courtesy of Dr. l. S. Ross, to study the holotypic male in the collection there. It is now my opinion that lobata is specifically identical with inlifornica and therefore should be relegited to sinomymy. Allowance must he male for sliglat variations in complicated genitalic structures of the character represented by this and other stonefly species.

The allotypic female as well as male and female paratypic specimens of californica are in the collection of Cornell University, and material in the lllinois Natural Histury Survey collection has been complared with these specimens.

\section{CAPNIIDAE}

In my 1935a paper on Illinois stoneHies, I presented a key for the separation of the genera of Capniidae occurring in Illinois. 'This key included the genera Allocapnia and Capnia. Under the discussion of Nemocapnia corolina Banks in the present paper, I show that my questionable record of a single Illinois specimen of Capuia (zerualis Newport?), a female (1929 and 1935a), belongs to the yenus Nemocapria and not to Capnin. However, in 1940, specimens of Capnia opis (Newman) were taken in northeastern Illinois, and it is desirable, therefore, to present a new key to the Illinois genera of Capniidae to replace the one of $1935 a$.

\section{KEI TO ILLINOIS SPECIES OF CAPNIIDAE}

\section{ADULTS}

1. lighth abdominal tergite of male with a rajsed process or tubercle-like structure; wings sometimes absent or abbreviated; anal field or lobe of hindwing, when wing is present, large and extending nearly out to tip of wing

Alloeapnia, p. 265

lighth abdominal tergite of male without a raised process or tubercle-like structure

2. Wings normally developed; radial vein llear point of origin with radial sector straight; no oblique crossvein beyond end of subcosta in forewing; posterior margin of large, darkly sclerotized medial area (mesobasisternite) of mesosternum but slightly produced backwarel, fig. 28 Nemocapnia, p. 262

Wings normally developed, absent or abbreviated; radial vein near point of origin with radial sector slightly but distinctly beut forward; usually an ob- lique crossvein beyond enel of sutcosta in forewing; posterior margin of large, larkly sclerotized medial area (mesobasisternite) of mesosterum strongly produced backward, fig. 28

Capnia, p. 264

\section{Nrmplis}

(Nymphs homogelleous with respect 10 good key characters; mature nymphs frequently reveal characters used in adult key.)

Wing parls present in most species, but ab. sent or rudimentary in a few species; anal field or lobe of hindwing, when pad is present, large and extending out nearly to length of wing; mesobasisternite of mesosternum, when boundary limits are visible, saine as for adults, fig. 28

Allocapnia, p. 265

Wing parls always present; anal field or lobs of hindwing reduced and extending about to middle of wing length; mesobasisteruite of mesosternum, when boundary limits are visible, same as for adults, fig. $28 \ldots \ldots \ldots \ldots \ldots \ldots$ Nemocapnia, p. 262

Wing pads present, absent or rudimentary; anal field or lobe of hindwing, when pad is present, reduced and extending about to middle of wing length; mesobasisternite of mesosternum, when boundary limits are visible, same as for adults, fig. 28

Capnia, p. 264

\section{Nemocapnia carolina Banks}

Nomocapnia carolina Banks (1938, p. 74). Original description, $\hat{o}, \underline{q}$.

Capnia sp. Frison (1929, p. 407). Erroneous generic assignment.

Capnia (vernalis Newport?) Frison (1935a, p. 356). Erroneous generic assignment.

In my paper on the Fall and Winter Stoneflies, or Plecoptera, of Illinois (1929), I questionably recorded a female specimen of a capniid from Grayville, Ill., March 8, 1928 (collected by T. H. Frison \& H. H. Ross) as "Capria sp." and in commenting concerning this specimen sug-
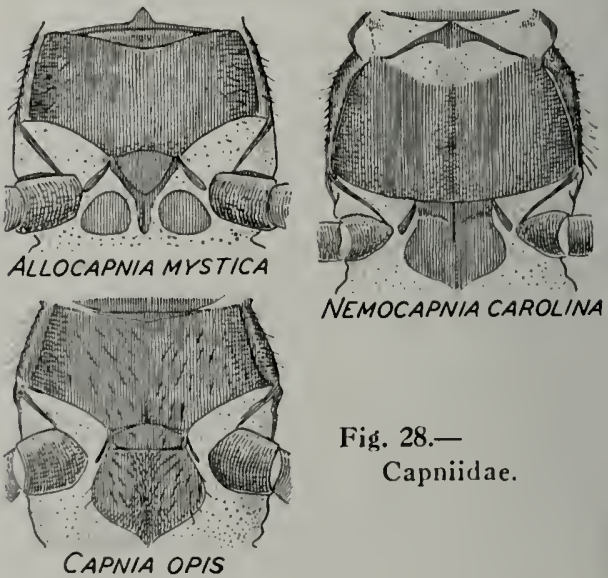

Fig. 28.-

Capniidae. 
gested it might be the female of Capnia zernalis Newport. Additional material of this species was not in hand in 1935 and so in my later and more comprehensive report of the Illinois stoneflies (1935a) I again cited this Illinois record and its questionable assignment to r'ernalis.

On the basis of several old specimens from "Morgantown, N. Car. (Morrison)" in the collection of the Museum of Comparative Zoology, Banks (1938) described a new genus, Nemocapnia, includ-
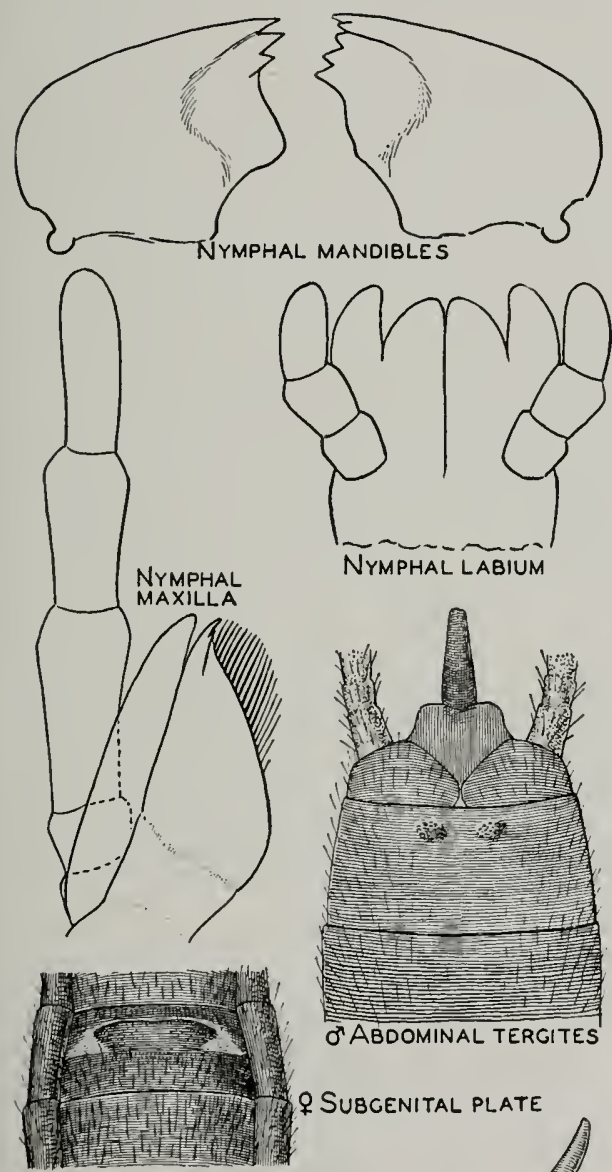

q SUBGENITAL PLATE

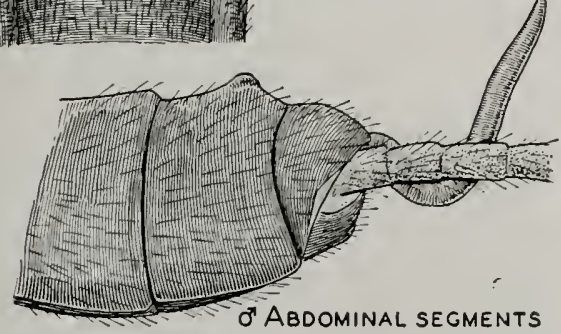

Fig. 29.-Nemocapnia carolina from North Carolina. ing in it a single species described as new under the name carolina. After seeing the typic specimens in 1939 , I realized that the female Illinois specimen questionably recorded as Capnia vernalis in my papers of 1929 and $1935 a$ was $N$. carolina Banks and not the female of a species of Capnia. Both males and females are easily recognized because of the characters of the wings. Although no seasonal data are associated with the typic specimens, the date of capture of the Grayville, Ill., specimen on March 8, 1928, and collection of other specimens in other states, places this species in the winter faunal list.

To facilitate recognition of this species, I present figs. 28, 29 and 30, which illustrate the important structural characters of the adult males and females, as well as the nymphal mouthparts. The dorsal view of a nymph is shown in fig. 31. Fig. 29 represents a specimen from North Carolina; fig. 30 represents specimens from Illinois and Indiana. The structure of the nymph confirms its placement in the Capniidae.

In addition to assigning correctly now the Grayville, Ill., March 8, 1928, female specimen to the species Nemocapnia carolina, thereby adding another genus and species to the Illinois list, I wish to add the following new records for the distribution of this recently described species.

Arkansas.-Benton, Salt Creek: April 15, 1939, H. H. \& J. A. Ross, $1 \hat{\delta}$.

INDIANA.-Rogers, White River: April 17,

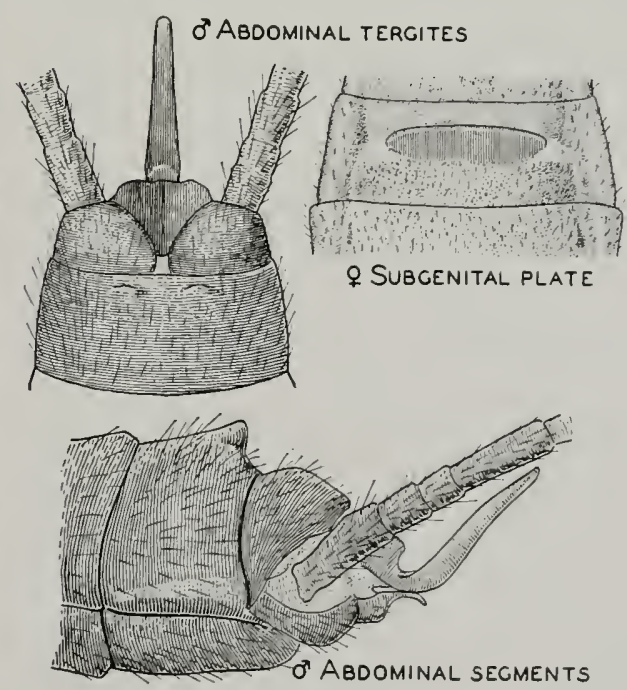

Fig. 30.-Nemocapnia carolina from Illinois and Indiana. 


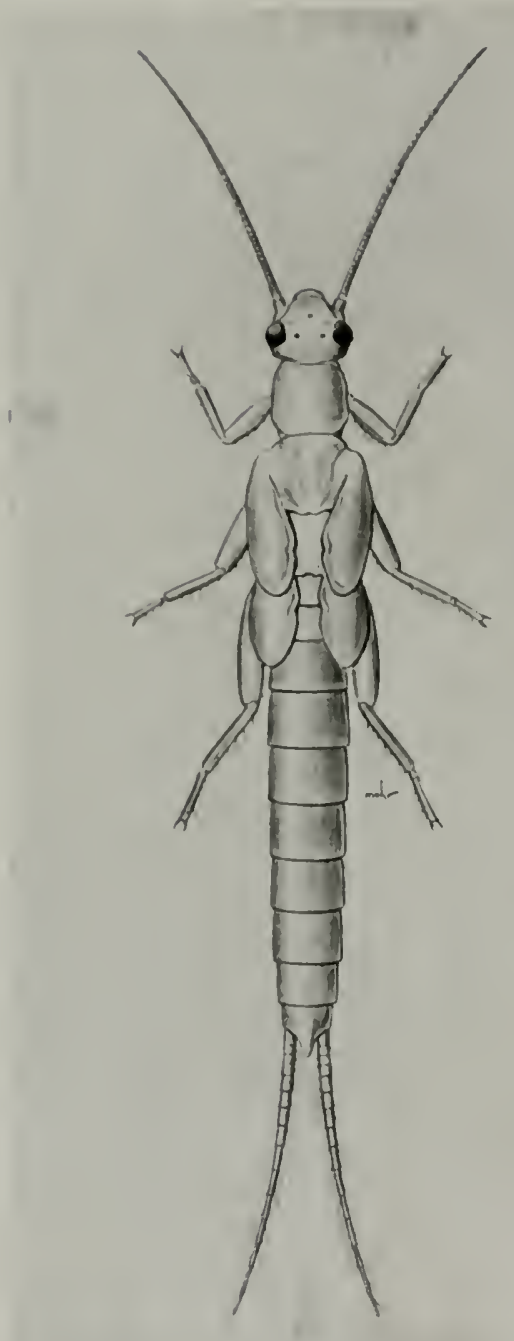

Fig. 31.-Nymph of Nemocapnia carolina.

1940, C. O. Mohr \& B. D. Burks, 1 ; ; April 16, 1936, H. H. Ross \& C. O. Mohr, $1 \hat{o}$; April 21, 1936, T. H. Frison \& C. O. Mohr, 1 ; April 14, 1940, C. O. Mohr \& B. D. Burks, 2 ㅇ․ SiloAls, White River: April 5, 1940, C. O. Mohr \& B. I). Burks, 1 ㅇ․

VIRGINIA.-SoUti HiLl, Roanoke River: Feb. 16, 1937, ô ồ, $q$ o . Remington, Rappaliannock River: March 21, 1940, T. H. Frison

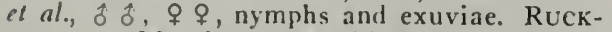
ERSVILLE: March 21, 1940, 'I. H. Frison et al., 1 ô. Lyxchrurg, Elk Creek: March 22, 1940, T. H. Frison et al., 8s, 69 . RichmoND, Robert F. Lee Bridge: 1 ㅇ.

\section{Capnia opis (Newman)}

Chloroperla opis Newman (1839, p. 89). Original description, $\hat{o}, q$.
Capnia rernalis Needham \& Claassen (1925, p. 256). Misidentification.

Capnin opis Ricker (1938, p. 134). Proper symonymy revealed.

Ricker (1938) has shown that opis is the same species as that redescribed and recorded by Needham \& Claassen (1925) as z'ermalis Newport (1851). Reference to the specific name of opis by Needham \& Claassen (1925) and by Claassen (1928) is entirely omitted.

Ricker (1938) further states that v'erualis is not a synonym of opis but a distinct species. Thus far, among the numerous specimens of Capnia that I have examined from North America, I have been unable to recognize more than one species, opis (= rermalis in the sense of Needham \& Claassen), of Capnia from eastern North America. If zermalis is a distinct species, as Ricker states, I am unfamiliar with it, and it must have a much different general distributional range than opis. Experience with long series of specimens unquestionably of the same species has shown me that slight variations in structural characters are to be expected, and it is probable that specimens I consider within the limits of variation of opis are comparable to the specimens which Ricker (1938) considered a separate species by the name of

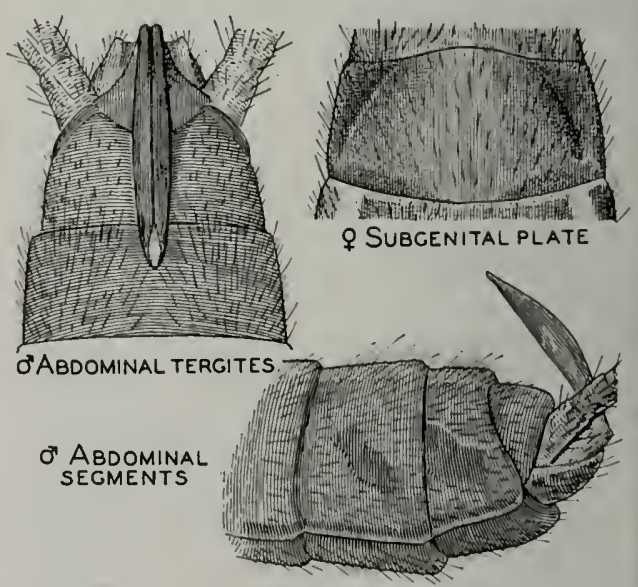

Fig. 32.-Capnia opis.

iernalis. Fig. 32 shows structural characters of specimens of opis taken from lllinois.

Capnia opis was originally described from specimens collected in Newfoundland, and Needham \& Claassen (1925) have added records, under the name of vernalis, from New 
York and Michigan. Additional records for this species are as follows.

Ililinois.-Elgin : Botanical Gardens, March 20, 1940, B. D. Burks, 1 exuvia; Trout Springs, March 7, 1940, Mohr \& Burks, $2 \hat{o}, 1$ ㅇ, 2 nymphs, 2 exuviae.

Connecticut.-Danielson: March 24, 1937, H. H. Ross, $2 \hat{b}, 3$ ㅇ․

Maryland.-Keyser Ridge: April 19, 1938, H. H. Ross, 4\% ; Dec. 30, 1934, T. H. Frison \& H. H. Ross, 12 nymphs.

Michigan.-Ontonagon County, Shore of Lake Superior between Silver City and Ontonagon: May 15, 1935, J. W. Leonard, $\hat{o} \hat{o}$, 우. Crawford County, Au Sable River: March 20, 21 and 23, 1936, J. W. Leonard, $3 \hat{\delta}, 8 \%$.

NeW York.-Clinton: March 25, 1903, 3 ô. Pompey Center: April 11, 1937, H. H. Ross, 1․ EAst Winfield: April 11, 1937, H. H. Ross, 1 . . Deansburg: April 11, 1937, H. H. Ross, $3 \hat{o}$.

North Carolina.-Near Grandfather Mountain, west of Blowing Rock: March 23, 1940, T. H. Frison et al., $3 \hat{\delta}, 2$ ㅇ․

OHIO.-BLACKLICK: Nov, 5, 1936, L. S. Roach, 4 nymphs. Hocking County: March 22,1938, D. J. \& J. N. Knull, 1 9.

Ontario.-Glen Major: April 7, 1934, F. P. Ide, $1 \hat{o}, 1$ ㅇ.

Pennsylvania. - Ebensburg: March 23, 1937, H. H. Ross, 1 \%, 6 nymphs. Riverside: March 22-28, 1937, H. H. Ross, $3 \hat{\jmath}, 3$ ㅇ.

Quebec. - Laurentides National Park, Long Lake: June 20, 1938, C. Gauthier, 1 오․

Tennessee.-Great Smoky Mountains National Park, Greenbrier Cove: March 15, 1938, A. C. Cole, 2 ㅇ.

VIRGINIA.-GORE: March 17, 1940, T. H. Frison et al., 3 오. STANDARDSville: March 21, 1940, T. H. Frison et al., 1 ㅇ. SPERRYville: March 17, 19+0, T. H. Frison et al., $9 \hat{\delta}, 5$ ․․ Elkton, Elk Run: March 21, 1940, T. H.

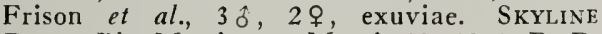
Drive, Big Meadows: March 18, 1941, B. D. Burks, $7 \hat{o}, 2$ ㅇ.

West Virginia.-ERWin, Wolf Creek and tributary of Cheat River: $\hat{\delta} \hat{\delta}$, $q$ ㅇ. KANETown: $2 \hat{\delta}, 1$ ㅇ. Augusta, Little Cacapon River: $1 \hat{\delta}, 3$ ‥ Evansville: $\hat{o} \hat{\delta}$, 우우. MAComber, Cheat River: $\hat{\delta} \hat{o}$, $q$ ㅇ, exuviae. Fellowsville: $\hat{\sigma} \hat{\sigma}, \hat{q} q, 1$ nymph. All collected March 16 and 17, 1940, by T. H. Frison et al.

Wisconsin, - SPOONER, Namakagon River: April 29, 1939, T. H. Frison \& B. D. Burks, $1 \hat{o}, 2$ ㅇ․

\section{Allocapnia Claassen}

Since my paper on Illinois stoneflies (1935a), another species of this genus has been found in Illinois, and the study of previously overlooked typic specimens makes necessary some nomenclatorial changes. These changes and additional notes, new descriptions and comments are included in the following discussions of various species of Allocapnia.

\section{Allocapnia vivipara (Claassen)}

Capnella vivipara Claassen (1924, p. 46). Original description, $\hat{o}, \hat{q}$.

Capnia minima? Walsh (1862, p. 367). New synonymy.

Discovery of a specimen of Allocapnia in the collection of the Academy of Natural Sciences of Philadelphia unquestionably labeled as "Capnia minima ? Newport" by Walsh (1862) confirms my supposition (1935a) that this record referred to a species of Allocapnia. The tip of the abdomen of this specimen is missing so that it cannot be named to species, but since IValsh referred to a species with rudimentary wings, my original placement (1935a) of this record under rivipara now seems conclusive.

To date, vivipara has been recorded from the states of Illinois, Missouri, New York and Ohio (Frison 1935a). I now have many additional records of this species from the states of Indiana, Iowa, Kansas, Kentucky, Oklahoma, Pennsylvania, Tennessee, Virginia and West Virginia. Evidently this species is widely distributed throughout eastern and central North America.

\section{Allocapnia pygmaea (Burmeister)}

Semblis pygmaea Burmeister (1839, p. 874). Original description.

Perla nivicola Fitch (18+7, p. 278). Original description, $\hat{\sigma}$, $ᄋ$. In part.

Capnella pygmaca Needham \& Claassen (1925, p. 277). Redescribed.

Allocapnia torontonensis Ricker (1935l, p. 257). New synonymy.

In two of my papers dealing with Illinois stoneflies (1929 and 1935a), one species of Allocapnia, very abundant in southern Illinois, has been referred to under the name of pygmaea (Burmeister), and its identification as this species was at one time checked by Claassen. Since then it has become quite evident to me that two species have been confused under the name pygmaea and that, due to the erroneous assignment of certain Illinois material to pygmaea, Ricker (1935b) was wrongly influenced by me to describe some Ontario specimens of Allocapria as a new species by the name of torontonensis.

A restudy of material identified as $p y g$ maea by Claassen and the redescription of this species by Needham \& Claassen (1925) convince me that pygmaea, a species with a long-headed supra-anal process, fig. 33, is identical with torontonensis. The Needham \& Claassen (1925) concept 
2, 1939, Frison \& Burks, ôे ô, 1 $q$. Midmount : Jan. 1, 1939, Frison \& Burks, 10 . RuckersvIr.LE, Rapidan River: March 21, 19+0, Frison, Mohr \& Hawkins, 39 . SuELBY, Rapidan River: Jan, 1, 1939, Frison \& Burks, mating pair, $\delta$, 9 \%. SPERrYill.LE: March 17, 19+0, $\mathrm{T}$. H. Frison el al., $6 \hat{\delta}$, $q$. Winchester, Hogue Creek: March 17, 19+0, T. H. Frison el al., $5 \delta,+$ t

West Virginia.-Augusta, Little Cacapon River: March 17, 1940, T. H. Frison et al., $\delta \hat{\delta}$, 우 (2o, 2 , mating pairs). CAPON B3RIDGE, Cacapon River: March 17, 19+0, $T$.

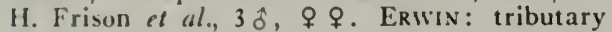
of Cheat River, March 16, 19+0, T. H. Frison et al. 50, 5\%; Wolf Creek, March 16, 1940, T. H. Frison el al., 5 \%. Evansville: March 16, 1940, T. H. Frison ot al., 5ô, 5 o. Felbowsville: March 16, 19+0, T. H. Frison et al., 1 of, 2 9. IAEGER, Horse Creek: Jan. 1, 1936, John Addair, 8 $\hat{\delta}, 1 \%$; Feb. 2, 1936, John Addair, $10 \hat{\delta}, 8 \%$. Kinetown: March 16, $1940, T$. H. Frison et al., $5 \delta, 6 \%$. MACOMBER, Cheat River: March 17, 19+0, T. H. Frison et al., of $\hat{\delta}, 9$ \%. ROMNEY: March 17, 19+0,

T. H. Frison et al., ô ô, 8 \&.

Wisconsin. - Whitcomb: April 8, 1937, Frison \& Mohr, 2\%. WittenberG: April 8, 1937, Frison \& Mohr, $1 \hat{o}, 1$.

\section{Allocapnia curiosa new species}

MALE.-Body and appendages mostly dark brown to black with pale, membranous areas. No gill remnants.

Head through compound eyes wider than pronotum. Ocelli arranged to form an isosceles triangle; the anterior ocellus situated well forward on the front, the lateral ocelli almost three times as far apart as distance from each lateral ocellus to inner margin of compound eye. Maxillary palpi less than thickness of basal flagellar segments.

Pronotum quadrangular, surface with a narrow, median, longitudinal, depressed stripe and indistinct, raised rugosities. IVings somewhat abbreviated, forewings extending to sixth tergite, hyaline with veins dark brown.

Abdomen with tergites seven and beyond, fig. 3t, darker and more heavily sclerotized than those preceding; first four to five tergites with a narrow, median, pale, longitudinal, membranous-like stripe; seventh tergite with a tubercle in middle of anterior half and with its tip slightly directed rearwards; eighth tergite with a small anterior tubercle in middle area and a tall, transverse one on posterior margin, which is notched in middle to form two points, ninth tergite slightly cleft for reception of supra-anal process; recurved supra-anal process shaped as in fig. 34 ; ninth sternite without a lobe at the base.

FeMale.-Similar in most morphological features to the male. IVings not abbreviated and extending to or beyond tip of abdomen ; a wide, median, dorsal, longitudinal stripe extending from base of abdomen to hind margin of eighth tergite,
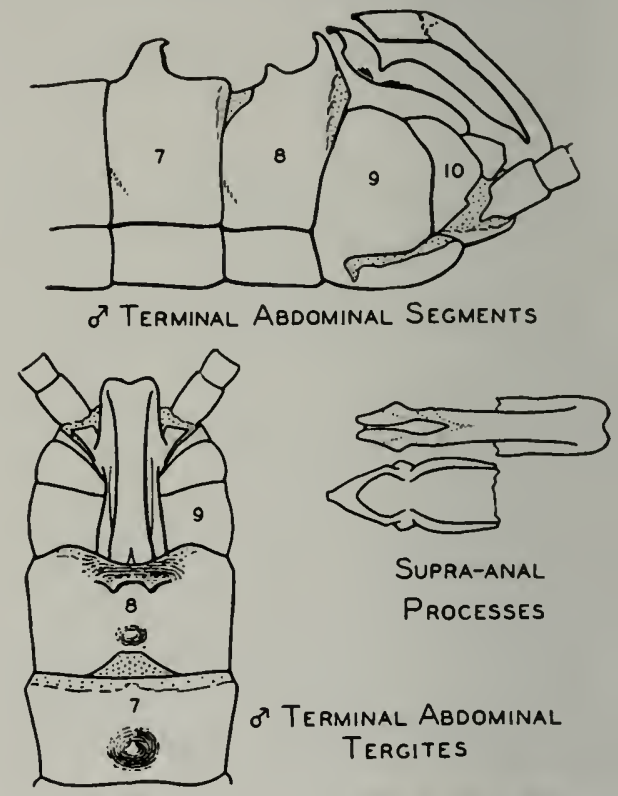

SUPRA-ANAL

Processes

Terminal Abdominal TERGITES

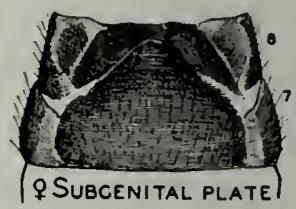

Fig. 34.-Allocapnia curiosa.

last two tergites entirely and darkly sclerotized; seventh abdominal sternite, fig. $3 t$, convexly swollen, with posterior median margin produced lobelike backwards over eighth sternite, posterior margin of seventh beneath lobelike projection and anterior margin of eighth sternite apparently fused at certain points of contact; eighth sternite with posterior margin straight, without any special structure, but somewhat recessed.

Holotype, male. - Kanetown, WV. Va.: March 16, 19+0, T. H. Frison et al.

Allotype, female.-Same data as for holotype.

Paratypes. - West Virginia, - Kanetown: Same data as for holotype, $20 \hat{\delta}, 2 \%$, including 
a mating pair. RoMEY: March 17, 1940, T. H. Frison et al., $3 \hat{\delta}, 3$ ㅇ. IAEger, Horse Creek: Feb. 2, 1936, J. Addair, $1 \hat{\delta}$.

Maryland.-Grantsville, Shade Run: Feb. 13, 1938, R. E. Yeatter, $1 \hat{o}$.

This species is easily distinguished from all other species of Allocapria. The males, in having a tubercle on the seventh abdominal tergite, suggest forbesi Frison and illinoensis Frison, but the shape and general arrangement of all tubercles is quite different. The females are unique because of the pronounced lobelike projection of the posterior margin of the seventh sternite. The seventh and eighth sternites are slightly fused beneath the lobelike projection of the seventh sternite, but this attachment is readily broken so that a membranous transverse strip may seem to be present between these sternites beneath the lobe.

\section{Allocapnia virginiana new species}

Male.-Similar in general features to curiosa Frison. Differs from this and other species of the genus as follows. Abdomen with first seven tergites without tubercles, a narrow, median, pale, longitudinal, membranous-like stripe on first four basal tergites; eighth tergite, fig. 35, with a large, odd-shaped, robust tubercle which in turn has a small, pointed tubercle on anterior face or margin; recurved supra-anal process very short, broad and shaped as in fig. 35 ; ninth and tenth tergites broadly cleft for reception of supraanal process.

Fenale.-Similar in most morphological features to the male. Wings extending to tip of abdomen; a wide, median, dorsal, longitudinal stripe extending from base of abdomen to hind margin of eighth tergite, last two tergites entirely and darkly sclerotized; seventh abdominal sternite similar to those preceding; eighth abdominal sternite with a darkly sclerotized subgenital plate shaped as in fig. 35 .

Holotype, male. - Shelby, Rapidan River, Va.: Jan. 1, 1939, T. H. Frison \& B. D. Burks.

Allotype, female.-Same data as for holotype.

Paratypes.-VIRGINIA.-ShELBY: Same data as for holotype, $2 \hat{\alpha},+q$. MADison: Jan. 1, 1939, T. H. Frison \& B. D. Burks, 1 ô, 6 o. Remington, Rappahannock River: Dec. 31, 1938, T. H. Frison \& B. D. Burks, $2 \hat{o}, 2$ ㅇ․

The shape of the supra-anal process and structures on the eighth abdominal tergite separate the male of this species from males of all other known species of Allocapnia. The female of this new species

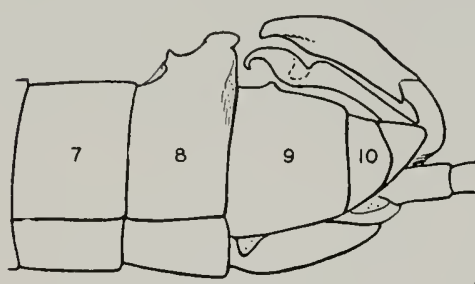

or Terminal Abdominal SEGMENTS

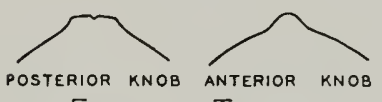

EIGHTH TERGITE.

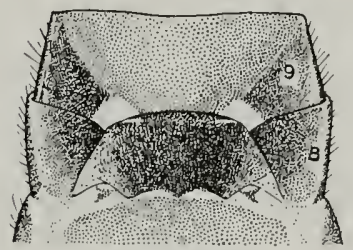

\& Subgenital Plate.
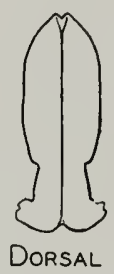

SUPRA-ANAL PROCESS

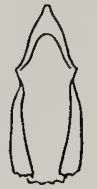

VENTRAL

SUPRA-ANAL PROCESS
Fig. 35.-Allocapnia virginiana.

belongs to the group of species having only the last two dorsal abdominal tergites darkly sclerotized and with a pale, membranous, transverse stripe between the seventh and eighth abdominal sternites; it differs, however, in shape of subgenital plate. The male and female are associated on the basis of their collection together at the same time at three different localities.

\section{Allocapnia rickeri new species}

Allocapnia pygmaea Frison (1929, p. 396). Misidentification.

Allacapnia pygmaea Frison (1935a, p. 367). Misidentification.

As mentioned in the discussion under pygmaea (Burmeister), certain Illinois specimens of Allocapnia once recorded by me (1929 and 1935a) as pygmaea, and also many similar specimens in the Illinois Natural History Survey collection from other localities, require a new specific name. I propose, therefore, for this species of Allocapnia the name of rickeri in honor of Dr. William E. Ricker, who 
2. 1939, Frison \& Burks, oै ô, 19. Midmount: Jan, 1, 1939, Frison \& Burks, 1 ô. RuckersVll.LE, Rapidan River: March 21, 19+0, Frison, Mohr \& llawkins, 3 \%. Suelny, Rapidan River: Jan. 1, 1939, Frison \& Burks, mating pair, of 9 . 9 . SPERrYille: March 17, 19+0, T. II. Frisoll el al., $6 \delta$, $q$ \% WINCHESTER, Hogue Creek: March 17, 1940, T. H. Frison et al. $5 \delta^{\circ},+$ +.

Wrst Virginia.-Augusta, Little Cacapon River: March 17, 1940, T. H. Frison ot al., $\delta \delta$, $q$ (28, 2 , mating pairs). CAPON BRIDGE, Cacapon River: March 17, 1940, T. H. Frison el al, $3 \hat{\delta}$, $q$ \%. ERwin: tributary of Cheat River, March 16, 1940, T. H. Frison et al., 58, 5\%; Wolf Creek, March 16, 1940, 1. H. Frison at al, 5 . Evansville: March 16, 1940, T. H. Frison et al., 5o, 5\%. FE1. l.owsVille: March 16,1940, T. H. Frison et al., 10 , 2 오. IAEGER, Horse Creek: Jan. 1, 1936, John Addair, 8fo, $1 \%$; Feb. 2, 1936, John Addair, $10 \hat{0}, 8 \%$. Kinetown: March 16, 1940, T. H. Frison et al., 5o, 6q. MACOMBER, Cheat River: March 17, 19+0, T. H. Frison et al., ôे $\hat{\delta}$, 9 . Romser: March 17, 1940, T. H. Frison at al., ô ô, 8 ㅇ.

Wisconsin. - Wiltcomb: April 8, 1937, Frison \& Mohr, 2o. Wittenberc: April 8, 1937, Frison \& Mohr, 1 o, 1 ㅇ.

\section{Allocapnia curiosa new species}

MALE.-Body and appendages mostly dark brown to black with pale, membranous areas. No gill remnants.

Head through compound eyes wider than pronotum. Ocelli arranged to form an isosceles triangle; the anterior ocellus situated well forward on the front, the lateral ocelli almost three times as far apart as distance from each lateral ocellus to inner margin of compound eye. Maxillary palpi less than thickness of basal flagellar segments.

Pronotum quadrangular, surface with a narrow, median, longitudinal, depressed stripe and indistinct, raised rugosities. Wings somewhat abbreviated, forewings extending to sixth tergite, hyaline with veins dark brown.

Abdomen with tergites seven and beyond, fig. 34 , darker and more heavily sclerotized than those preceding; first four to five tergites with a narrow, median, pale, longitudinal, membranous-like stripe; seventh tergite with a tubercle in middle of anterior half and with its tip slightly directed rearwards; eighth tergite with a small anterior tubercle in middle area and a tall, transverse one on posterior margin, which is notched in middle to form two points, ninth tergite slightly cleft for reception of supra-anal process; recurved supra-anal process shaped as in fig. 34 ; ninth sternite without a lobe at the base.

Female. - Similar in most morphological features to the male. WVings not abbreviated and extending to or beyond tip of abdomen ; a wide, median, dorsal, longitudinal stripe extending from base of abdomen to hind margin of eighth tergite,

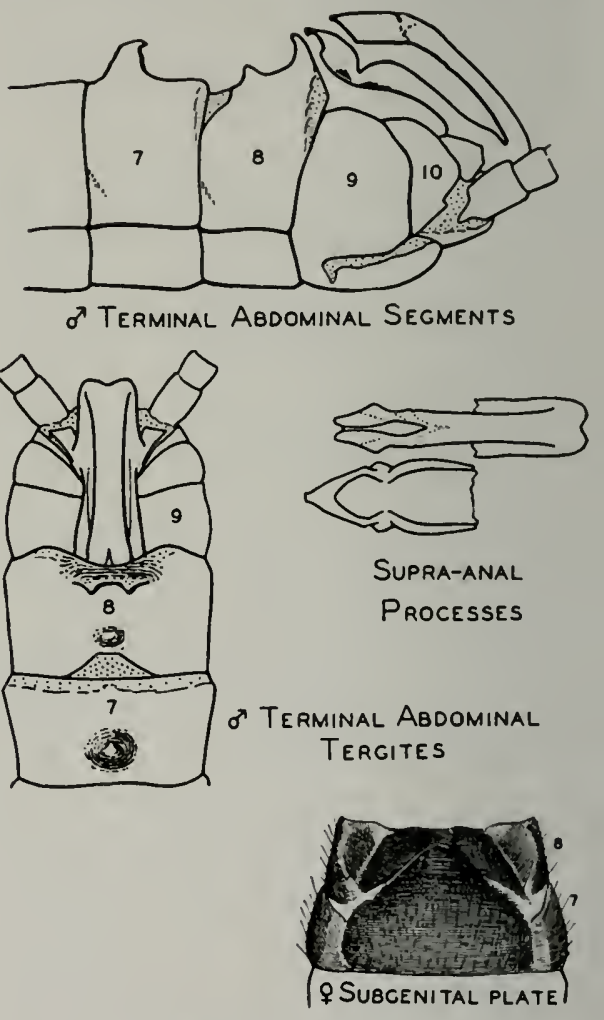

Fig. 34.-Allocapnia curiosa.

last two tergites entirely and darkly sclerotized; seventh abdominal sternite, fig. $3+$, convexly swollen, with posterior median margin produced lobelike backwards over eighth sternite, posterior margin of seventh beneath lobelike projection and anterior margin of eighth sternite apparently fused at certain points of contact; eighth sternite with posterior margin straight, without any special structure, but somewhat recessed.

Holotype, male. - Kanetown, W. Va.: March 16, 1940, T. H. Frison et al.

Allotype, female.-Same data as for holotype.

Paratypes. - IVEST Virginia. - Kanetown: Same data as for holotype, $20 \hat{\delta}, 2 \%$, including 
a mating pair. RomeY: March 17, 1940, T. H. Frison et al., $3 \hat{\delta}, 3$ o. IAEgER, Horse Creek: Feb. 2, 1936, J. Addair, 10 .

Maryland.-Grantsville, Shade Run: Feb. 13, 1938, R. E. Yeatter, $1 \hat{\delta}$.

This species is easily distinguished from all other species of Allocapnia. The males, in having a tubercle on the seventh abdominal tergite, suggest forbesi Frison and illinoensis Frison, but the shape and general arrangement of all tubercles is quite different. The females are unique because of the pronounced lobelike projection of the posterior margin of the seventh sternite. The seventh and eighth sternites are slightly fused beneath the lobelike projection of the seventh sternite, but this attachment is readily broken so that a memhranous transverse strip may seem to be present between these sternites beneath the lobe.

\section{Allocapnia virginiana new species}

MALE.-Similar in general features to curiosa Frison. Differs from this and other species of the genus as follows. Abdomen with first seven tergites without tubercles, a narrow, median, pale, longitudinal, membranous-like stripe on first four basal tergites; eighth tergite, fig. 35, with a large, odd-shaped, robust tubercle which in turn has a small, pointed tubercle on anterior face or margin; recurved supra-anal process very short, broad and shaped as in fig. 35 ; ninth and tenth tergites broadly cleft for reception of supraanal process.

FENALE.-Similar in most morphological features to the male. Wings extending to tip of abdomen; a wide, median, dorsal, longitudinal stripe extending from base of abdomen to hind margin of eighth tergite, last two tergites entirely and darkly sclerotized; seventh abdominal sternite similar to those preceding; eighth abdominal sternite with a darkly sclerotized subgenital plate shaped as in fig. 35 .

Holotype, male. - Shelby, Rapidan River, Va.: Jan. 1, 1939, T. H. Frison \& B. D. Burks. type.

Allotype, female.-Same data as for holo-

Paratypes.-ViRGIN1A.-SHELBY: Same data as for holotype, $2 \hat{\delta}, 4+q$. MADison: Jan. 1, 1939, T. H. Frison \& B. D. Burks, $1 \delta$, 69 . Remington, Rappahannock River: Dec. 31 , 1938, T. H. Frison \& B. D. Burks, $2 \hat{o}, 2$ ㅇ.

The shape of the supra-anal process and structures on the eighth abdominal tergite separate the male of this species from males of all other known species of Allocapnia. The female of this new species

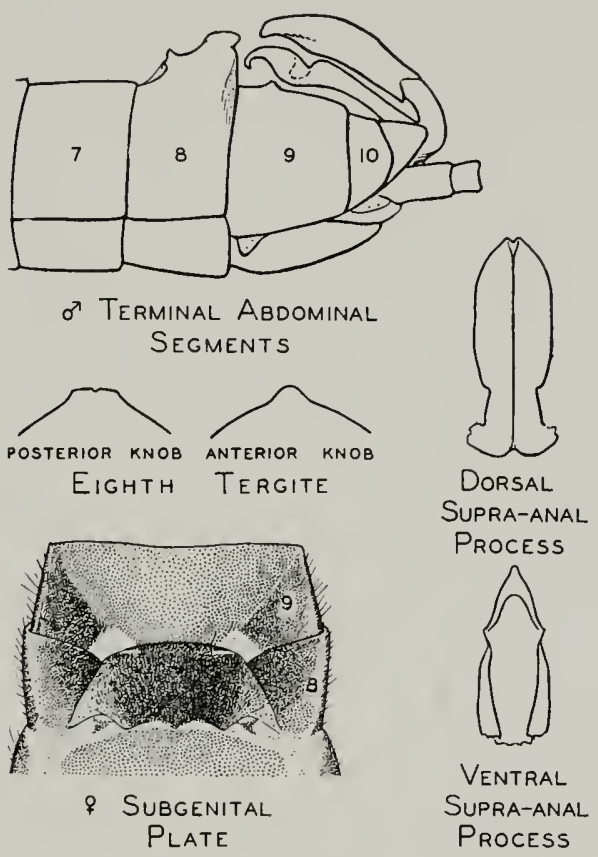

Fig. 35.-Allocapnia virginiana.

belongs to the group of species having only the last two dorsal abdominal tergites darkly sclerotized and with a pale, membranous, transverse stripe between the seventh and eighth abdominal sternites; it differs, however, in shape of subgenital plate. The male and female are associated on the basis of their collection together at the same time at three different localities.

\section{Allocapnia rickeri new species}

Allocapnia pygmaca Frison (1929, p. 396). Misidentification.

Allocapnia pygmaea Frison (1935a, p. 367). Misidentification.

As mentioned in the discussion under pygmaen (Burmeister), certain Illinois specimens of Allocapnia once recorded by me (1929 and 1935a) as pygmaea, and also many similar specimens in the Illinois Natural History Survey collection from other localities, require a new specific name. I propose, therefore, for this species of Allocapnia the name of rickeri in honor of Dr. William E. Ricker, who 
has considerably contributed to our knowledge of North American stoneflies.

The morphological characters of rickeri, excepting those in which it differs from the true pygmaea, have been fairly well covered in $111 y-1929$ and $1935 a$ papers under the name of pygmaen. It seems necessary

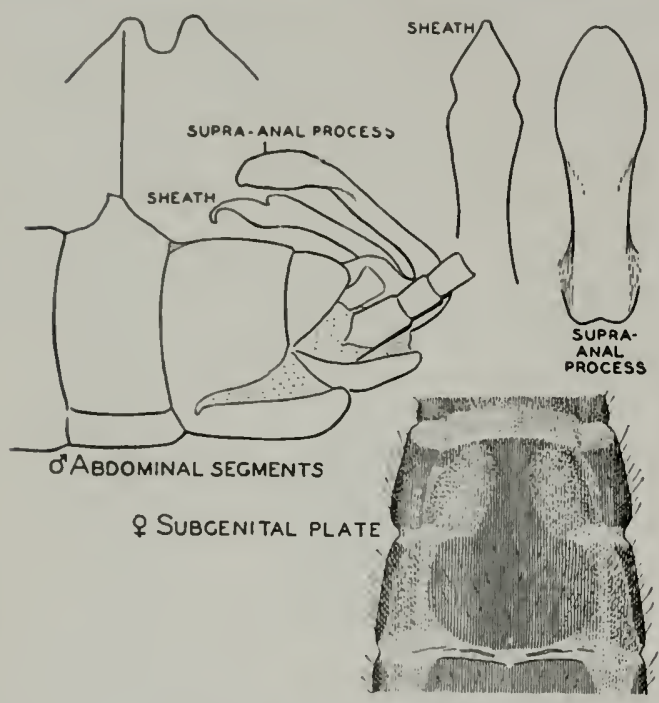

Fig. 36.-Allocapnia rickeri.

to present here, therefore, only a brief review of the most salient characters needed for recognition of rickeri and new illustrations for comparison with those of the true pygmaea.

MAtE.-Similar in general features to curiosa Frison as described in this paper. Certain characters peculiar to rickeri and separating it from other species are as follows: Wings short and usually extending about half the length of abdomen; seventh abdominal tergite without suggestion of any tubercle, eighth tergite with two rather low and definitely separated tubercles, ninth and tenth tergites with middle area depressed and membranous for reception of supra-anal process; supraanal process, fig. 36 , with a short head.

Feviale.- Similar in most morphological features to the male. Wings reaching about to or slightly beyond tip of abdomen; a wide, median, dorsal, longitudinal stripe extending from base of dorsum of abdomen to hind margin of eighth tergite, last two tergites entirely and darkly sclerotized; seventh and eighth abdominal sternites fused in middle and without transverse membranous strip between them; subgenital plate shaped as in fig. 36.

Holotype, male.-Golconda, Big Grand Pierre River, Ill.: March 7, 1928, T. H. Frison \& H. H. Ross.

Allotype, female.-Same data as for holotype.

Holotype and allotype represent a mating pair.

Paratypes,-Il.Linols.-Apple River, northwest of APPLE RIVER CANYON STATE PARK: March 2, 1938, Ross \& Mohr, $112 \hat{\text { f }, ~} 27$ ㅇ. BLOOMFIELD: March 7, 1928, on concrete foundation of bridge, Frison \& Ross, $13 \hat{\alpha}$, 2 ㅇ. Dixon SPRINGs: Feb. 2, 1934, Frison \& Mohr, $5+\hat{\delta}, 20,1$ mating pair. EICHORN: March 6, 1928, Frison \& Ross, 42 $\hat{\delta}, 8$ ? ; Buck Creek, on bridge, Frison \& Koss, $21 \hat{\delta}, 11$ \% . Golconds, Big Grand Pierre River, on and near bridge: March 7, 1928, Frison \& Ross, $75 \hat{o}, 32 \%$, + mating pairs. Gorham: Feb. 3, 1934, Frison \& Mohr, 1ô, 1 ‥ Herod: Gibbons Creek, under bark of tree hanging over stream, March 6, 1928, Frison \& Ross, $3 \hat{o}$; Gibbons Creek, on stones and debris in and near margin of stream, $47 \hat{\delta}, 30 \%, 1$ mating pair; April 19, 1937, Ross \& Mohr, 1 ; Rose Creek, foundation of concrete bridge, March 6, 1928, Frison \& Ross, 1 mating pair; Big Grand Pierre River, foundation of concrete bridge, March 6, 1928, Frison \& Ross, 1 \% . Herod-El,1ZABEThtown, Hicks Branch Creek: March 6, 1938, Frison \& Ross, 3 ô. JonesBoro: Feb. 3, 1934, Frison \& Mohr, 50 ô, 4 9. NEw Columbia, Clifty Creek: Dec. 26, 1932, Harper, $+\hat{\delta}$. Thebes: Feb. 3, 1934, Frison \& Mohr,

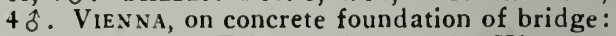
March 7, 1928, Frison \& Ross, $1 \hat{\delta}$. WARREN, tributary of Apple River: March 2, 1938, Ross $\&$ Mohr, $111 \hat{\delta}, 8$ \%

Other specimens of this species examined, but not included in paratypic series, are as follows.

Illinors.-Golconda, Big Grand Pierre River: March 7, 1928, Frison \& Ross, many nymphs.

District of Columbia.-IVashington, Potomac River: Feb. 5, 1938, Gurney \& Burks, $1 \hat{\delta}$.

INDIANA.-BACON: creek southwest of town, Feb. 14, 1938, Frison \& Mohr, of $\hat{\delta}$, $\uparrow q, 3$ mating pairs; Patoka River northwest of town, Feb. 14, 1938, Frison \& Mohr, of $\hat{o}$, $q$. . ENGLISH, creek north of town: Feb. 14, 1938, Frison \& Mohr, $\hat{o} \hat{o}$, $q$ q 9,1 mating pair. McCormick Creek State Park: March 14,1936 , Frison \& Ross, ôt ô, $q$ q. Marengo, creek west of town: Feb. 14, 1938, Frison \& Mohr, $\hat{\delta} \delta, 2 q$. MEDora, creek northwest of town: Feb. 14, 1938, Frison \& Mohr, $2 \hat{\delta}$. MII.LTOWN, creek west of town: Feb. 1t, 1938, Frison \& Mohr, $8 \hat{\delta}, 1+$. NeEDMORE, creek near town: March 14, 1936, Frison \& Ross, $\hat{o} \hat{o}, q+3$ mating pairs. Palmyra, Blue River north of town: Feb. 1t, 1938, Frison \& Mohr, $\hat{\delta} \hat{\delta}, q q$. PAoli, south of town: Feb. $1+, 1938$, Frison \& Mohr, $\hat{o} \hat{o}, \hat{q} q$, many mating pairs. SALEM, river south of town: 
Feb. 14, 1938, Frison \& Mohr, 6ô, 4 오. SPRINGVille: Feb. 14, 1938, Frison \& Mohr, $\hat{o} \hat{\delta}, q q$. Turkey Run State Park: March 18, 1933, Frison \& Mohr, 1 우 ; Sugar Creek, April 19, 1933, Frison \& Mohr, 2 . W Wllow VALLeY: March 1+, 1936, Frison \& Ross, ôे ô, 1 ㅇ․

Kentucky.-Trenton: Jan. 5, 1939, Frison

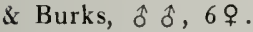

Maryland. - EMmitsburg: Feb. 14, 1937, 8 ô, 3 ㅇ. Indian Springs: Feb. 2, 1936, Frison \& Ross, $1 \hat{\delta}, 3$ \%.

New YORK.-ITHACA: March 15, 1922, $2 \hat{\delta}$, 2 우 ; Beebe Lake, March 18, 1935, 1 ㅇ‥ NORTH Collins: April 13, 1937, H. H. Ross, $1 \hat{\delta}$.

Ohio.-Little Hocking, White Run Creek: March 16, 1940, T. H. Frison et al., $3 \hat{o}, 1 q$.

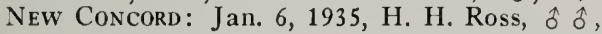
39.

Pennsylvania.-Amity Hall, on Route U. S. 22: Feb. 17, 1938, R. E. Yeatter, of of, 69. Claysville, 5 miles east on U. S. 40: Feb. 13, 1938, R. E. Yeatter, 1 ㅇ․ EMERICKVILle, 11/2 miles east of town: Feb. 18, 1938, R. E. Yeatter, $\hat{\delta} \delta$, $q$ ㅇ. Grampian, Kratzer Run: Feb. 18,1938 , R. E. Yeatter, $1 \hat{0}$. NorthumberLAND: March 23, 1937, H. H. Ross, ô $\hat{\delta}, 4$ 우. VAN, East Sandy Creek: Feb. 18, 1938, R. E. Yeatter, $\hat{o} \hat{\delta}$, $+q$.

Tennessee.-Bristol: Jan. 2, 1939, Frison

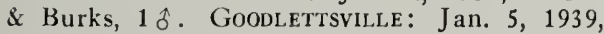
Frison \& Burks, 16,1 . Johnson City: Jan. 2, 1939, Frison \& Burks, ồ $\hat{o}, 4$. . McDonald: Jan. 4, 1939, Frison \& Burks, ô $\hat{\delta}, 1$ \& , 2 mating pairs. SPRINGField, Sulphur Fork Creek: Jan. 5, 1939, Frison \& Burks, ô $\hat{o}$, 우우.

Virginia.-AFTON: March 22, 1940, Frison Mohr \& Hawkins, $\hat{\delta} \hat{\delta}, 2$ 오. Bull Run, Bull Run Creek: March 21, 1940, Frison, Mohr \& Hawkins, $1 \delta$. Cedarville: March 17, 19+0, T. H. Frison et al., $3 \hat{\delta}$. CUlpePer, Gaines Run Creek: March 21, 1940, Frison, Mohr \& Hawkins, $1 \hat{0}, 1$ ‥ ElKToN, Elk Run: March 21, 1940, Frison, Mohr \& Hawkins, $\hat{\delta} \delta, 3$ ㅇ. Elliston, Roanoke River: Jan. 2, 1939, Frison \& Burks, $1 \hat{\delta}, 1$ ㅇ. FAIRFAx: Jan. 2, 1935, T. H. Frison, 20ิ; Dec. 31, 1938, Frison \& Burks, 3 mating pairs; March 21, 19+0, Frison, Mohr \& Hawkins, $1 \hat{o}$. FAIRFIELD: Jan. 1, 1939, Frison \& Burks, ô ô, ㅇ․ Fort CHISwEll: Jan. 2, 1939, Frison \& Burks, $1 \hat{\delta}, 1$. . GORE: March 17, 19+0, T. H. Frison et al., $9 \hat{o}, 4 \hat{q}, 3$ mating pairs. Greenville, Christian Creek: Jan. 1, 1939, Frison \& Burks, $\hat{\delta} \hat{o}, 1$ mating pair. GrorTOEs, Mill Creek: Jan. 1, 1939, Frison \& Burks, $\delta \hat{\delta}$, 오 우, 6 mating pairs. HUNTER: Jan. 30 , 1938, Gurney \& Burks, 9 ô, 2 ㅇ. MARION, Holston River: Jan. 2, 1939, Frison \& Burks, 1 ㅇ․ Port Republic: North River, Jan. 1, 1939 , Frison \& Burks, 20, 1 우 ; March 21, 1940 , Frison, Mohr \& Hawkins, $\hat{\delta} \hat{\delta}, 1$ ㅇ, 1 mating pair. RADFORD: Plum Creek, Jan. 2, 1939, Frison \& Burks, $\hat{\delta} \hat{o}, 6 q, 1$ mating pair; March 22, 19+0, Frison, Mohr \& Hawkins, 3 \%. Riverton: March 17, 1940, T. H. Frison et al., 2 ô, 1 ‥ RoAnOKE, Mud Lick Creek: Jan. 2, 1939, Frison \& Burks, 2 ㅇ. Shawsville: Jan. 2, 1939, Frison \& Burks, $3 \hat{\delta}$. VIENNA, Indian Run Creek: Feb. 13, 1938, B. D. Burks, ô ô, 6 ․ Warrenton: March 21, 1940, Frison, Mohr \& Hawkins, $3 \hat{o}, 2$ ㅇ. Winchester,
Hogue Creek: March 17, 1940, T. H. Frison st al., toे, 1ㅇ, 1 mating pair.

West Virginia. - Evansville: March 16, 19+0, T. H. Frison et al., $4 \hat{o},+o$. PruntYTown: March 16, 1940, T. H. Frison et al., 1 $\hat{\delta}$. Shaffenaker: March 17, 1940, T. H. Frison et al., 10. SmithbuRG: March 16, 1940, T. H. Frison et al., $2 \hat{\delta}$. Volcano: March 16, 19+0, T. H. Frison et al., $\hat{o} \hat{\delta}$, 우 우.

\section{PERLIDAE}

\section{Perlesta placida (Hagen)}

Perla placida Hagen (1861, p. 28). Original description, $\hat{\delta}, \hat{q}$.

Perlesta placida is one of the most widely distributed species of stoneflies in North America, and large series of specimens from various localities reveal considerable variation. It is not my intention to go into detail in this paper con-

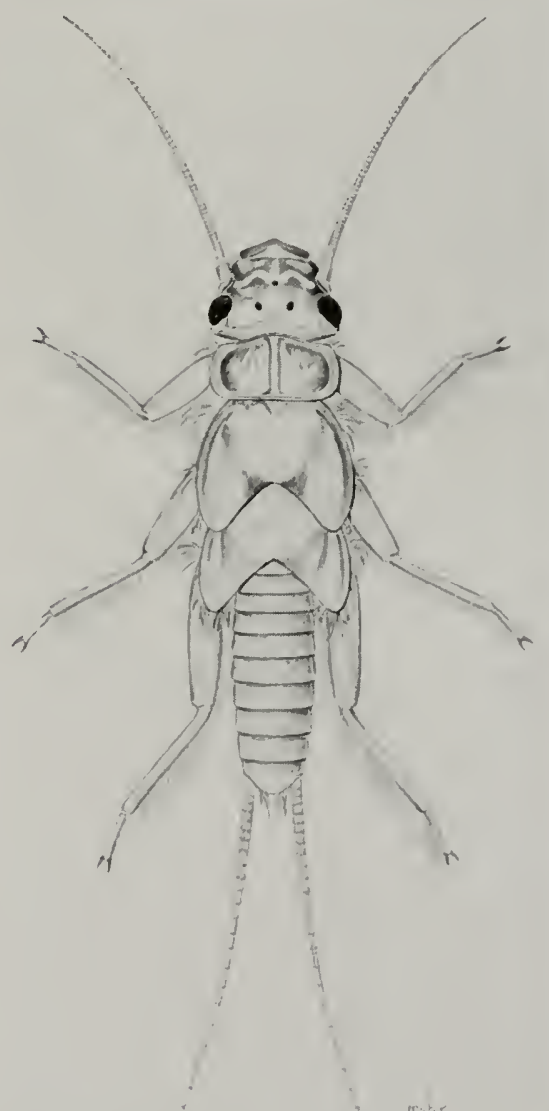

Fig. 37.-Nymph of Perlesta placida. 
cerning the ramifications of this variation. However, it seems desirable to illustrate a form which is commonly encountered in the Great Smoky Mountains National Park near Gathinburg. 'Tenn., hecause its identity might be overlooked. 'The nymph uf this variant is shown in fig. 37 .

Fig. 38.1 is a dorsal view of the head and pronotum of this variant, and fig. $38 \mathrm{~B}$

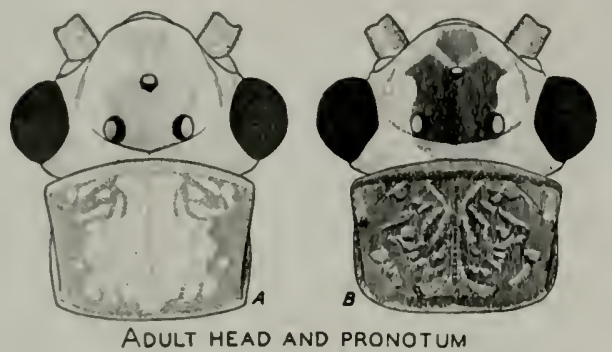

Fis. 38.-Perlesta placida: $A$ from Great Smoky Mountains National Park, $B$ from lower altitudes.

is the same view of more nearly typical specimens taken at lower elevations. The difference in color pattern is quite noticeable even in old pinned specimens. The nymph of this variant, fig. 37 , differs from typical specimens from elsewhere in its generally lighter color and in the comparative absence of numerous short, stout setae which usually give the nymphs a freckled appearance (Frison 1935a, figs. 307 and 308).

\section{Acroneuria arida (Hagen)}

Perla arida Hagen (1861, p. 18). Original description, $\hat{\delta}, \mathfrak{q}$.

Perla qalida Banks (1906a, p. 32). Original description, $q$. Previously correctly synonymized by Needham \& Claassen (1922).

Acroneuria arida Needham \& Claassen (1925, p. 185). In part.

Acroneuria arida Claassen (1940, p. 172). Catalogue-in part.

'Ihrough the courtesy of Dr. Nathan Banks, I have had the privilege of studying in considerable detail the types of Perla arida Hagen (1 female, No. 14,386) and $P$. ralida Banks (1 female, No. 11, $315)$, both in the collection of the Museum of Comparative Zoology. Because of the importance of establishing the presence or absence of anal gill remnants on the subanal lobes, the apical abdominal segments of the typic female of arida from "Philadelphia_IVinthem" were clipped from the abdomen, softened in potassium hydroxide and studied in fluid. The typic female of ralida is from "Waynesville, $\mathbf{N}$. C., July, 1901, F. Sherman, Jr."

Needham \& Claassen (1922) were correct in placing ralida as a synonym of arida, but in 1925 they confused another species with arida which led me (1935a) to an erroneous assignment of certain Illinois specimens to this species. These Illinois specimens belong to a species which wats described later by Claassen (1937b), on the basis of a single adult female, as prolonga, which in turn is a synonym of ezoluta Klapálek, as I am now using this name.

Studies of the types involved, the rearing of evoluta (= arida Frison 1935a) and comparisons of extensive material in the Illinois Natural History Survey collection all have established that evoluta is a species with anal abdominal gills in the nymph and subanal gill remnants in the adult, and that arida (= valida) lacks such structures in the adult, and, of course, this means that the nymph when discovered will not possess anal abdominal gills.

A fundamental character for the separation of arida from evoluta, as now recognized, having been established, the differences previously observed in the shape of the subgenital plate of the females become understandable as specific differences. In arida, the subgenital plate is much constricted at its base, fig. 39 , so that the end portion is much broader than its base, whereas in equluta the base is not, or but slightly, constricted (Frison 1935a, figs. 2+2-3).

Although Klapálek (1909) records three males and one female of ralida from "North Carol. Morr." in the Selys Longchamps collection, no description or illustration is given of the male, and it is possible that these specimens, particularly the males, are not arida. Klapálek failed to recognize arida as a valid species and erroneously placed it in the synonymy of arenosa (Pictet).

Since the male of arida has not been previously described (Needham $\&$ Claassen 1925 description is undoubtedly male of eqoluta), I present fig. 39 and the following brief description.

MALE.-General habitus the same as for other species of Acroneuria from North America. Dorsum of head yellow 
with pattern of dark brown markings as in fig. 39. Pronotum with raised rugosities and a narrow, yellow, longitudinal median line. Terminal abdominal tergites with groups of small spinulae arranged as
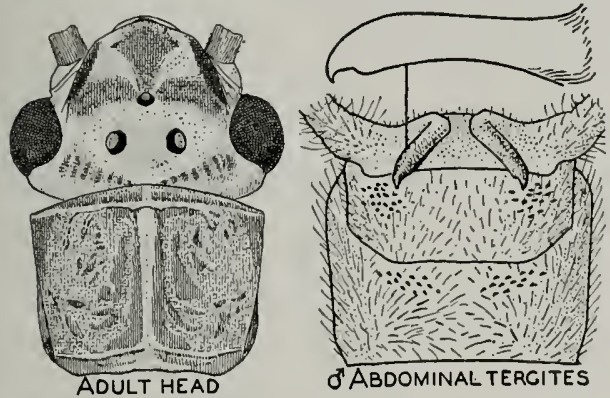

AND PRONOTUM

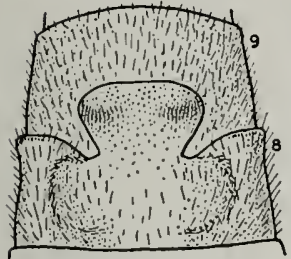

\& SUBCENITAL PLATE

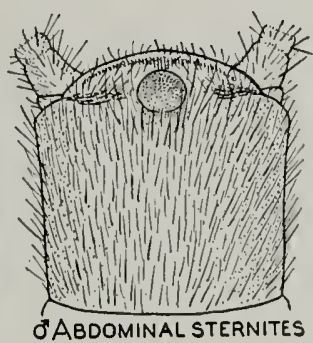

Fig. 39.-Acroneuria arida.

in fig. 39. Genital hooks or modified subanal lobes of the finger-like type with a distinct notch on inner margin at tip. Ninth sternite with a small, nearly round, padlike disk. Subanal lobes show no trace of gill remnants.

Allotype, male.-Knoxville, Tenn.: June 21, 1939, A. C. Cole.

The subgenital plate of the female of arida was figured by Banks at the time of the original description of ralida, but to aid recognition of this species another illustration of this structure, fig. 39, is presented.

The nymph of this species has not as yet been discovered.

In addition to the records from North Carolina and Philadelphia (Pennsylvania) given in the original descriptions, I can now add the following.

Georgia.-Summerville: June 9, 1937, P. W. Fattig, $5 \hat{o}, 7 \hat{\circ}$. RingGold, Chickamauga Creek: June 1t, 1939, P. W. Fattig, $5 \delta, 6 \%$. Ball Ground: June 27, 1932, P. W. Fattig, 1ㅇ․ Ellaville, Cedar Creek, 10.7 miles north: May 26, 1939, P. W. Fattig, 2 ․

TENNESSEe.-KNoxville: April 24, 1936, C. B. Huffaker, 19 ; May 26, 1936, C. B. Huffaker, $1 \hat{o}$; June 1, 1936, D. A. Johnson, $1 \hat{o}$;
June 6, 1936, D. A. Johnson, $1 \hat{\delta}$; May 22, 1939, A. C. Cole, 2 우 ; June 14,1939 , A. C. Cole, 1 우 ; June 21, 1939, A. C. Cole, $2 \hat{o}, 4$ 오. Seviervilie: June 11, 1938, at light, T. H. Frison \& T. H. Frison, Jr., 1 ․ GREenbrier Cove, Smoky Mountains: June-July, 1940, A. C. Cole, $1 \hat{o}, 1 \uparrow$. Monteagle: A. C. Richards, 2 .

\section{Acroneuria evoluta Klapálek}

Acroneuria evoluta Klapálek (1909, p. 245). Original description, ㅇ.

Larva No. 1-Garman (1912, p. 59, fig. 47). Nymphal description.

Acroneuria arida Needham \& Claassen (1925, p. 185). In part.

Acroneuria evoluta Clark (193t, p. 121)

Acroneuria arida Frison (1935a, p. 395). Misidentification.

Acroneuria prolonga Claassen (1937b, p. 42). New synonymy.

Acroneuria evoluta Ricker (1938, p. 138) Notes on type.

Acroneuria arida Claassen (1940, p. 172). Catalogue-in part

In my remarks concerning the synonymy of arida (Hagen), I have called attention to the fact that Needham \& Claassen (1925) confused two species under the name of arida. One of these species, arida (Hagen) $=$ valida (Banks), lacks gill remnants on the subanal lobes of the adults and hence lias nymphs lacking anal abdominal gills. The second of these species has anal abdominal gills in the nymphs and shows gill remnants on the subanal lobes of the adults (erioluta = arida as used in the sense of Frison 1935a).

Due to the confusion of species in literature at the time of publication of my 1935 a paper, the Illinois records of arida reported by me at that time apply to the species here called eqoluta. It is obvious from this situation that my placement then of evoluta as a synonym of arida does not hold, and evoluta becomes available as the name for this Illinois (1935a) material.

Ricker's (1938) notes on the type of eroluta are the basis for my use now of the name eroluta for the Illinois material recorded (1935a) as arida. Ricker states that his study of evoluta "indicates that it is synonymous with arida Hagen, as earlier suggested by Frison." It should be pointed out that at the time of Ricker's article the arida in the sense of Frison is not equivalent to the true arida (Hagen) but to a species for which the first name available now appears to be er'oluta.

In 1937, I adopted the use of the name 
eioluta for an lllinois species heretofore confused with arida as used in the sense of Prison 1935a. "The transfer now of the name ezoluta to my arida material of 1935a leaves the species called eqoluta in 1937 "without a name," as Ricker (1938) has earlier suggested.

Part of the material listed by Needham S. Claassen (1925) as arida belongs to the species I an now recognizing as arida (= ralida) and part belongs to the species I am here recognizing as eroluta. Clark's (193t) record of ez'oluta from Put-in-Bay, Ohio, mentioned as belonging to arida in my 1935 a paper, again becomes part of the bibliography of eqoluta as here recognized. Since Garman's (1912) description of "Larva No. 1" and his fig. 47 are equivalent to arida in the sense of Frison 1935a, it also must be included in the bibliography of ez'oluta as now accepted.

Aroneuria prolonga Claassen (1937b) was described on the basis of a single female from "Bridger Mountains, Montana, June 19, 1914." I have studied this type in the collection of Cornell University and consider it to be the same as my arida material of $1935 a$, which I am now calling eqoluta as a result of Ricker's remarks concerning the type. Any differences which might be observed between the subgenital plates of eroluta, as now accepted, and prolonga are certainly slight and I believe well within the range of individual variation.

For the convenience of other students and the bibliographic record, 1 have given the complete bibliography of eqoluta to date. My only question is whether the name of equlutu is even now being correctly used, a matter impossible to investigate further at this time.

\section{Acroneuria mela new species}

Acronenria rooluta Needham \& Claassen $(1925$, p. 186). At least in part.

Acronenria arida Claassen (1931, p. 81, figs. 202 and 207). Nymph.

Acroneuria sp. a Frison (1935a, p. 405). Nymphal description.

Acroneuria evoluta Frison (1937, p. 79). Additional descriptive material and associaion of nymph.

Acroncuria equluta Claassen (1940, p. 173). C'atalogur.

As already mentioned in connection with evoluta Klapálek, it is necessary at this time to give a new specific name to the species illustrated and mentioned by me (1937) under the name of evoluta. In my article of 1937, I mentioned the possibility that my use of the name of evoluta for certain Illinois material, following its use "hy Needham \& Claassen (1925) for

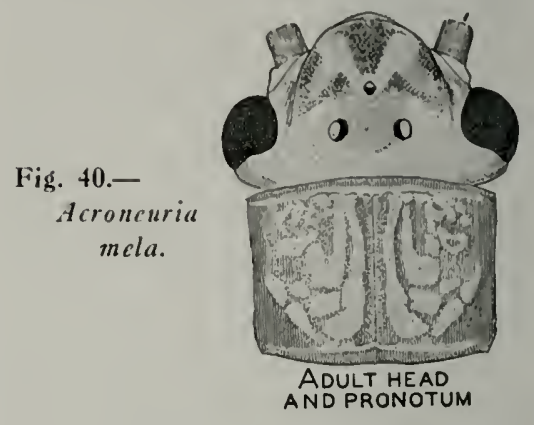

similar specimens from Kansas," was somewhat dubious. Ricker (1938) has made a recent study of the typic female of eroluta in the collection of the Vienna Museum, and he states that it is not the same as the eroluta of Frison 1937 but "synonymous with arida Hagen [sense of Frison], as earlier suggested by Frison (1935:95)." IVhen Ricker made his study of the type of evoluta he had available the published illustrations and descriptions (Frison $1935,1937)$ to separate the two Illinois species at one time lumped as arida, but was not aware that the true arida (Hagen) $=$ r'alida (Banks) was yet another species. This explains his statement of "synonymous with arida Hagen."

Claassen's (1931) reference in his key to the nymph of arida, and his drawing (fig. 202) and photograph (fig. 227) of this nymph, should now be assigned to the bibliography of this new species since they are the same as my species $a$ of $1935 a$ and equluta of 1937.

Since this species has been confused in literature, and since, except for notes and illustrations in my stonefly paper of 1937 , no single description certainly applies altogether to this species, I consider it advisable to treat it as a new species rather than to propose a new name as an appendage to previously mixed literature.

MALE.-General habitus the same as for other species of Acroneuria from North America. I)orsum of head yellow with a pattern of dark brown markings as in fig. 40. Pronotum with raised rugosi- 
ties and a longitudinal, median depressed line. Terminal abdominal tergites with groups or patches of small spinulae arranged as in fig. $6+$ of Frison 1937. Genital hooks or modified subanal lobes tapering to a point which is curved inwards at tip (fig. 64, Frison 1937). Subanal lobes show gill remnants.

FEMALE.- Head, thorax, basal abdominal segments and appendages in general similar to those of male, but slightly larger in size. Important differences are as follows: eighth abdominal sternite modified into a subgenital plate extending partly over ninth sternite and shaped as in fig. $6+$ of Frison 1937.

Holotype, female.-Petersburg, Ind.: reared from nymph from White River, June 11, 1936, T. H. Frison \& C. O. Mohr.

Allotype, male.-Same data as for holotype except reared June 9, 1936.

Paratypes. - Indiana.-Petersburg: Same data as for holotype and allotype with rearing dates as follows: June 3,18 ; June 4,3 ; June $8,1 \hat{o}$; June $9,2 \hat{o}, 3 q$; June 10, 2 ; ; June 13, 3ㅇ; J June 15, 5 q; June 22, 1 ; ; July 6,1 ㅇ․

The female, instead of the male, has been selected as the holotype because it is easier to separate from other species of Acroneuria than is the male. The type series has been based upon Indiana specimens only because it is a reared series.

Records for this species in the Illinois Natural History Survey collection not recorded by me (1937) under the name evoluta are as follows.

ILLINOIS.-OAKWOOD: June 24, 1937, T. H. Frison, Jr., 1 ㅇ․ Urbana: July 3, 1938, G. T. Riegel, 1 ㅇ. Eddyville, Lusk Creek: June 1, $19+0$, B. D. Burks, 1 ㅇ․

Georgia.-Summerville: June 9, 1937, P. IV. Fattig, 1 ㅇ. Ringgold, Chick amauga Creek: June 14, 1930, P. W. Fattig, $1 \hat{o}, 6$ o. DALTON : June 14, 1939, P. W. Fattig, 3 \%.

Kansas.-Lawrence: June 30, 1921, P.IV.C., 1 우 (previously determined by Claassen as equoluta).

Ohio.-Adams County: June 4, 1930, J. S Hine, 1 오.

OKI,AHOMA.-ARDMORE: June 8, 1939, Kaiser \& Nailon, 1․ Broken Bow: June 13, 1939, Kaiser \& Nailon, $1 \hat{o}, 1$ ㅇ․

TennesseE.-SPARTA: May 31, 1934, T. H. Frison, 1 .

\section{Acroneuria filicis new species}

In my paper on the stoneflies of Illinois $(1935 a)$, I commented at some length regarding the confusion in literature and determinations of species under the name pennsylzanica (Rambur). Ricker (1938) gives considerable information regarding specimens determined by Klapálek as pennsylianica, and one of the specimens he studied at Prague may be the missing type of pennsylzanica. Ricker comes to the conclusion that pennsylranica (Rambur $18+2$ ) is identical with arenosa (Pictet 18+1) [not clara Klapálek (1917) = arenosa sense of Klápalek (1909)]. Accepting the synonymy indicated by Ricker, and I know of no valid reason to oppose his conclusion in this particular case, leaves an eastern North American species sometimes determined as pennsylianica (Needham \& Claassen 1922, 1925, at least in part) without a specific name.
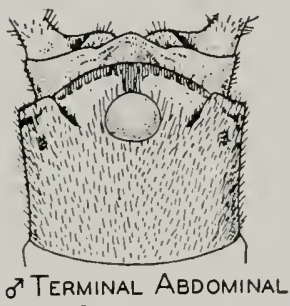
STERNITES

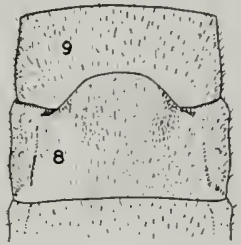

\& Subgenital

Plate

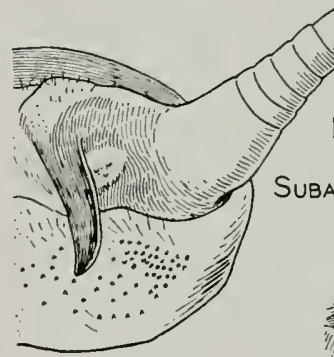

$\sigma^{7}$ GILL

REMNANTS AND Subanal HoOK

9 Gll Remnants AND

Subanal Lobe
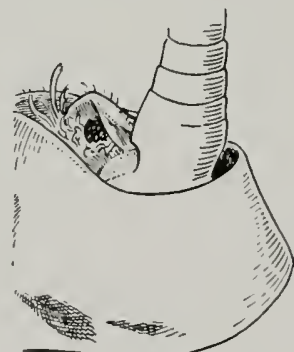

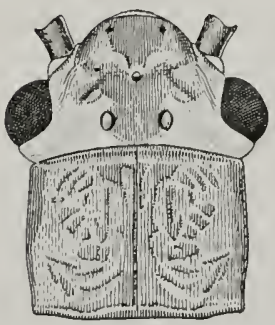

\& HEAD AND PRONOTUM

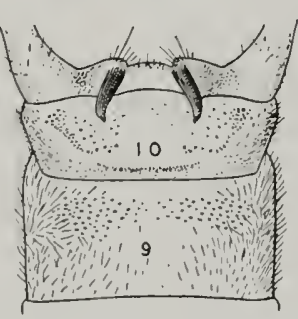

o TERMINAL ABdominal TERGITES
Fig. 41.-Acroneuria filicis. 
Since the records and descriptions in existing literature in most, if not all, cases represent mixed series when penusylianica is referred to, I helieve the best interests of nomenclature and taxonomy in this instance are served by considering the species of Acroneurin involved as a new species and by not merely proposing a new name.

Malr-General habitus the same as for other species of Acroneurin from North America. Dorsum of head yellow

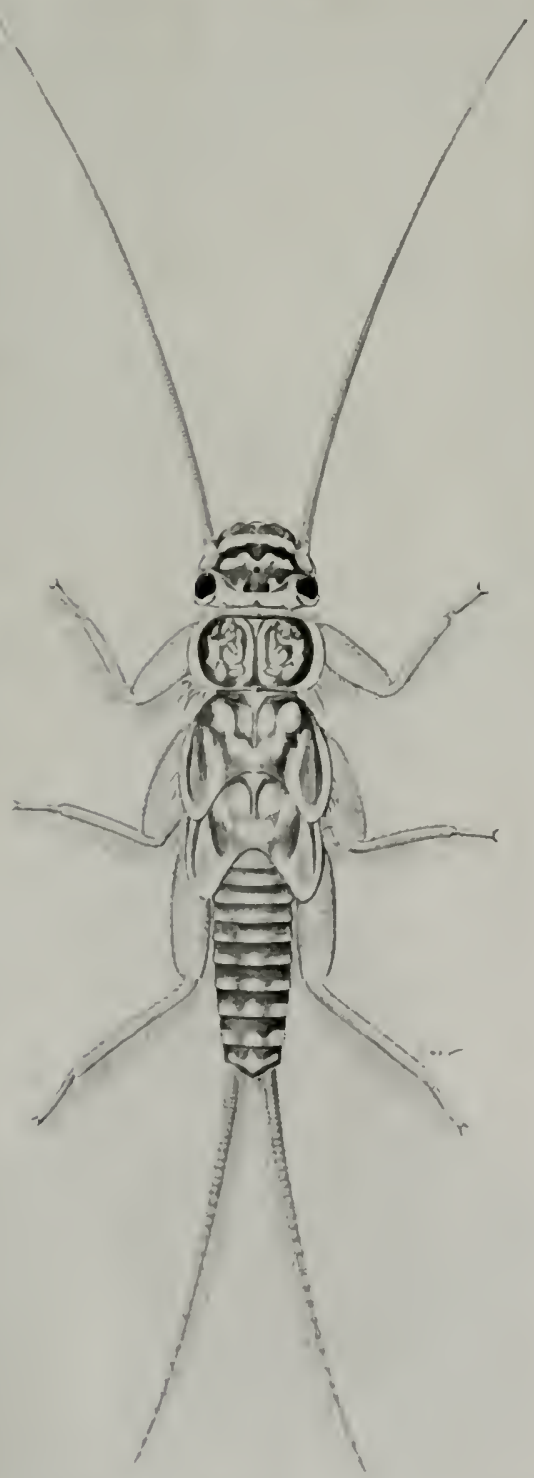

Fig. 42.-Nymph of Acroneuria filicis. with a pattern of dark brown markings as in fig. 41 . Pronotum brown with raised rugosities and a longitudinal, median depressed line, this line not lighter colored as in some other species. 'Terminal abdominal tergites with groups or patches of small spinulae arranged as in fig. 41 . Genital hooks or modified subanal lobes tapering to a point and slightly curved inwards at tip. Subanal lobes show gill remnants.

Fexale.-Head, thorax, basal abdominal segments and appendages in general similar to those of male but slightly larger in size. Important differences are as follows: eighth abdominal sternite modified into a subgenital plate slightly extending over ninth sternite and with posterior margin rounded as in fig. 41 .

Holotype, female.-Pineville, Ky.: at light, June 24,1938 , T. H. Frison \& T. H. Frison, Jr.

Allotype, male.-Same data as for holotype. Paratypes. - Kentucky.-PINevil.Le: Same data as for holotype and allotype, $12 \hat{\delta}, 46 \hat{q}$. Cumberland Falls: June 12, 19+0, T. H. Frison et al., 1 오.

TenNesseE. - Chimneys Camp Grounds, Great SMoky Mountains National Park, 2,900 feet elevation: Aug. 4, 1939, Rehn \& Rehn, 2ô, 39 ; July 9, 1939, at light, A. C. Cole, 2 \% ; July 12, 1939, A. C. Cole, 2 \%. GatLINBURG: June $18,19+0$, reared from nymph, T. H. Frison $t$ al., $1 \hat{\delta}$.

Ohio.-Athens or Athens County: April 25,1931, W. C. Stehr, 1 우 ; June 14, 1938, W. C. Stehr, 1 ; ; June 11-27, 1939, W. C. Stehr, $2 \hat{\delta}, 4 q$; June 20-22, 19+1, W. C. Stehr, $5 \hat{\text {, }}$ 2 ; J June $21-J u l y ~ 6,1941$, at light, J. Walker, 4 .

I am naming this new species in honor of my son, T. H. Frison, Jr., who has accompanied me on many collecting trips for aquatic insects in various parts of the country and who assisted me in the collection of the material from Pineville.

NYMPH.-A brief description of the more important characters of the heretofore unknown nymph is as follows: Body and appendages pale yellowish brown with a very distinct pattern of dark brown or dusky markings on dorsum, fig. 42; Wshaped, pale yellowish mark anterior to median ocellus is broad throughout and dark pattern tends to fill space between lateral ocelli and inner margins of compound eyes; abdominal tergites dominantly dark brown or dusky with pale yellowish on posterior margins, the yellowish part expanding along median line and on some segments tending to be segregated to 
three spots on posterior margin. Head without a transverse occipital ridge on posterior margin between compound eyes.
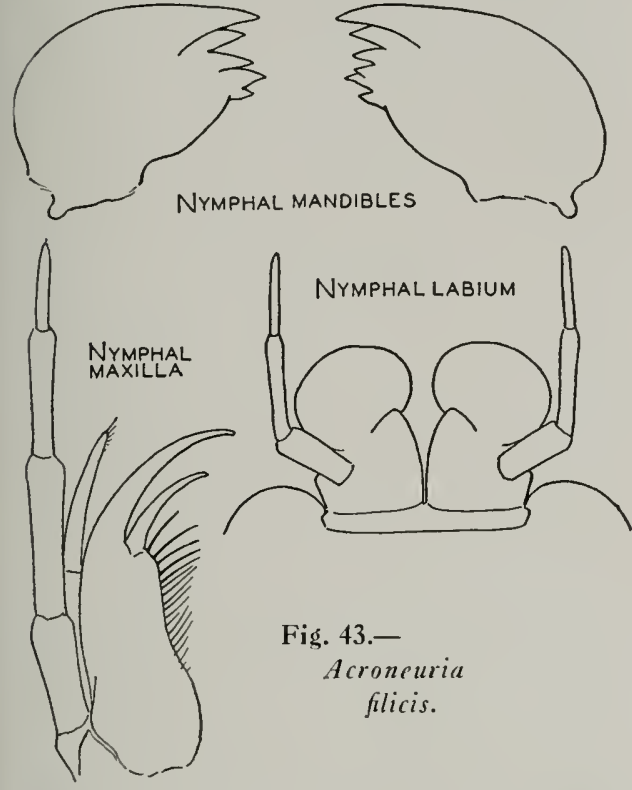

Maxilla, labium and mandibles as in fig. 43. Anal gills present at apex of abdomen. Approximately full grown female nymph $25 \mathrm{~mm}$. and male somewhat smaller.

This nymph in general resembles the nymphs of evoluta Klapálek (= arida of Frison 1935a), perplexa Frison and mela Frison, having in common with them anal gills. Differences in color pattern which seem to have taxonomic significance are as follows: (1) In eroluta (Frison 1935a, fig. 313 ) the pale yellow color of the head behind the ocelli tends to invade the space between the ocelli and compound eyes; the transverse dark hands of the abdominal tergites are usually confined to the anterior half of each tergite; and the transverse band on head anterior to median ocellus is more bandlike and less $W$ shaped. (2) In mela (Frison 1935a, fig. $316)$ the abdominal tergites are almost entirely dark, and three light spots, instead of a $W$-shaped transverse band, are present on the head anterior to the median ocellus. (3) In perplexa (Frison 1937, fig. 66) the dark markings on the abdominal tergites are mostly on the anterior half of each tergite and decrease in width near lateral margins, and the $W$-shaped mark on the head is less broad throughout. ows.

Nymphal and exuvial records are as fol-

NorTh CAROLINA.-East fork of Tuckaseegee River, Jackson County: June 19, 1939, T. Howell, 1 nymph. Blowing Rock Mountain: March 23, 19+0, T. H. Frison, C. O. Mohr \& A. S. Hawkins, 1 nymph.

Tennessee.-Ozone: June 11, 1935, H. H. Ross, 1 exuvia. Gatlinburg, Le Conte Creek: June 13, 1938, T. H. Frison \& T. H. Frison, Jr., 2 nymphs; June 18, 1938, T. H. Frison \& T. H. Frison, Jr., 1 exuvia; June 14, 1940, T. H. Frison et al., 2 exuviae (adult ô reared from 1 exuvia).

\section{Acroneuria xanthenes (Newman)}

Perla xanthenes Newman (1838a, p. 178). Original description, $\hat{\delta}, \hat{q}$.

Acroneuria brevicauda Klapálek (1909, p. $2+5$ ). Original description, of (at least in part). Synonym.

Acroneuria xanthenes Needham \& Claassen (1925, p. 19t). Female suggested as type without definite lectotypic designation.

Acroneuria xanthenes Ricker (1938, p. 140). Accepts female as lectotype and erroneously records typic male as Togoperla kansensis (Banks).

Eccoptura xanthenes Klapálek (1923a, p. $63)$. Notes on types.

Although few records have been given for this species in literature, it has acquired a rather snarled and complicated bibliography. It is clearly evident from Klapálek's (1923a) illustrations of the two specimens, male and female, in the British $\mathrm{Mu}$ seum, accepted as the types, and Ricker's (1938) notes, that the male and female of the typic series represent two different species. This fact was first pointed out by Needham \& Claassen (1925), and they suggested that the female be considered as the type because of its unique character, and that less confusion would then result. Ricker (1938) considers that Needham \& Claassen (1925) designated the female as a "lectotype," but since no definite designation of a single type was made in this connection by Needham \& Claassen, I herewith definitely designate the female of Newman's typic series of a male and female as the lectotype, and I select the female for the same reasons as those advanced by Needham \& Claassen.

Ricker (1938) makes the additional statement that "Dr. Claassen identified the $\hat{o}$ as Togoperla kansensis Banks." I cannot accept this placement of the typic male because Klapálek (1923a) clearly recognized kansensis as a distinct species, gave figures of kansensis which differ radically from the typic male he figured as 
santhenes, and erected a separate genus called banksiella for the reception of the single species, kansensis. Since Klapálek stated he saw the typic male and female of xanthenes, and figured them as well as kansensis, I do not believe he could have firiled to observe that the typic male of xumthenes was the same as kansensis, if such were the case. It is, however, certain from Klapilek's figure of the male which he accepted as xanthenes that this male is not the male of xanthenes, as Needham $\mathbb{S}$ Claassen state, and that it is not an Acrou'uria as used in the sense of Needham \& Claassen and all later North American students of this group. At the present time, unfortunately, 1 am unable to assign to any North American species the male figured and considered by Klapálek to be one of Newman's two typic specimens of xanthenes. Klapálek states that the two types are from "Georgia," but Newman did not indicate the locality in his original description, as he did with other new species described in the same article, and he did not insert the locality in his only other reference to xanthenes in 1839 . Ricker (1938) repeats the statement that the male and female cotypes are "from Georgia" and evidently this locality record is now associated with the types.

Another annoying item in the bibliography and synonymy of xanthenes is the placement of brezicauda. The original description is based upon "1 $\hat{o} \mathrm{~N}$. Carol. Morr. (Coll. de Selys)," and, judged by Klapálek's remarks concerning color-no good structural details are given or figured -this specimen is the male of xanthenes. Ricker (1938) states that the "type" is in the Prague Museum (the Selys Longchamps collection is, or was, in Brussels) and resembles a small " $z A$. arida Hagen" and that a "paratype ('Cotypus') is a $\hat{o}$ A. xamhenes" and that both are labeled "North Carolina, Morrison." If the type now is in the Prague Museum, the second specimen has been added to the typic series since the original description. Apparently, in any case, bresicauda falls into synonymy since the original description indicates a single specimen of xauthenes, and at least one of the specimens purporting to belong to the typic series of brezicauda at Prague is xamthenes. In case there are two typic specimens of breqicauda at Prague, as Ricker states, and there is no single type in the Selys collection at Brussels as Klapálek states, 1 herewith designate the male specimen at Prague stated by Ricker to be xanthenes ats the lectotype of bres $i$ cauda. This procedure will insure the future placement of breqicauda in the synonymy of xanthenes, where the original description indicates it belongs.

Arrangements made with the officials of the Great Smoky Mountains National Park, Gatlinburg, 'lenn., in $19+0$, enabled me to rear adult male and female specimens of xanthenes from nymphs and thereby confirm an association of adults and nymphs which, as a result of repeated 1llinois Natural History Survey collecting trips to this region, had seemed evident for some time. Besides establishing the correct association of nymphs with adults, these rearings definitely proved the associ-

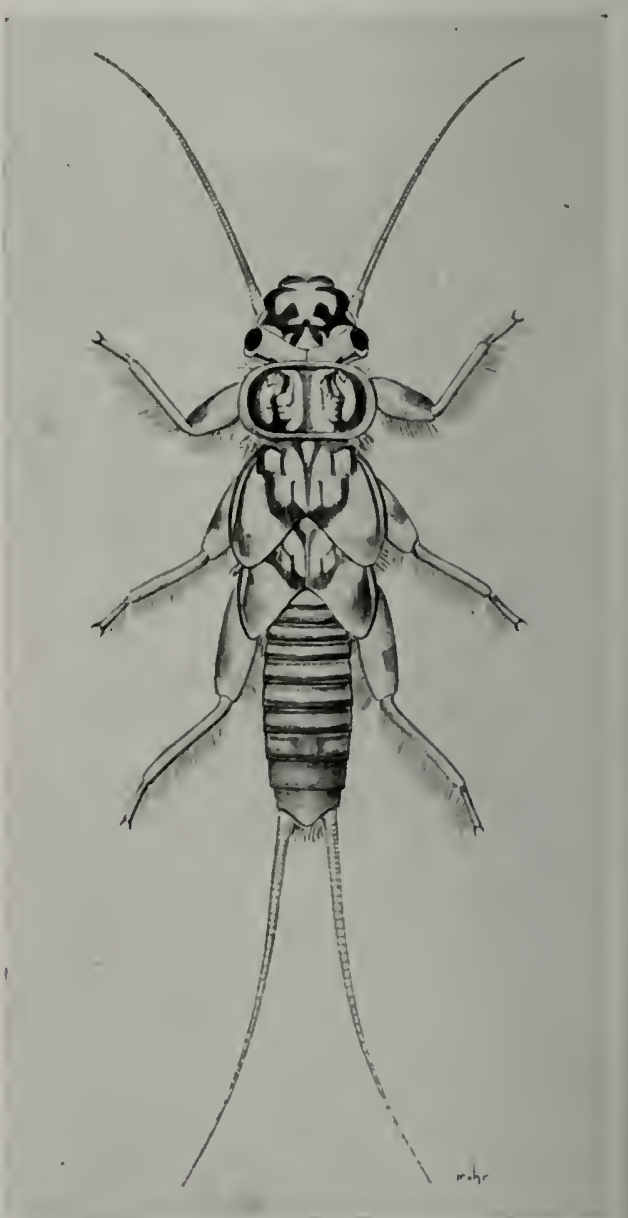

Fig. 44.-Nymph of Acroneuria xanthenes. 
ation of males with females as given by Needham \& Claassen (1925).

NYMPH.-A brief description of the important characters of the nymph is as follows: General morphological features similar to those of other described nymphs

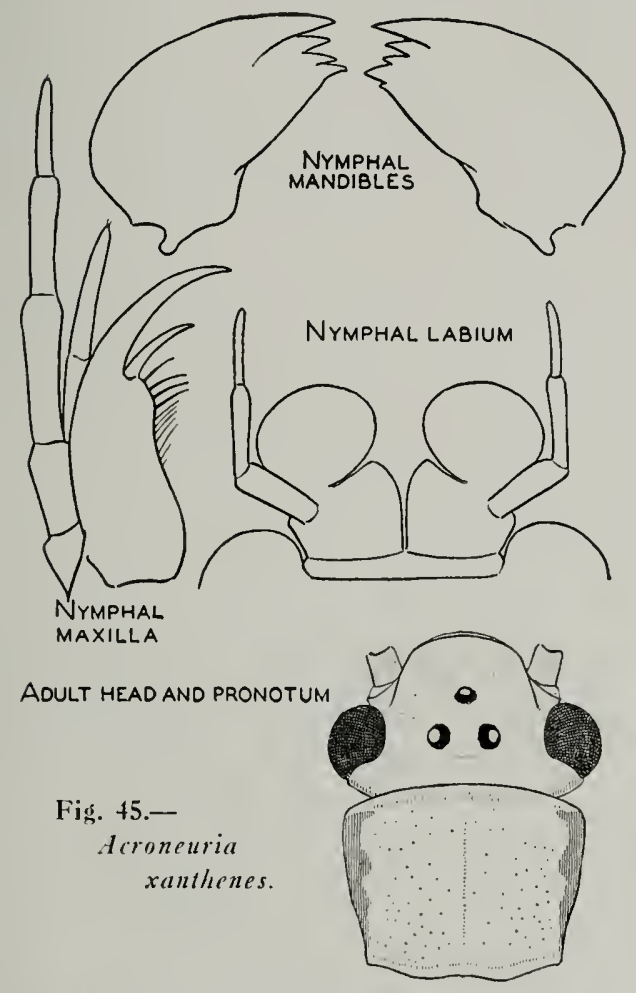

ct Alcroneuria (Frison 1935a). Body and appendages yellow with a very distinctive pattern of dark brown or dusky markings on dorsum, fig. 44; large open area anterior to ocelli is particularly distinctive; dorsal abdominal tergites with narrow, dark, transverse bands on anterior and posterior margins, these bands usually becoming fused in part on apical segments. Head without a transverse occipital ridge on posterior margin between compound eyes. Maxilla, labium and mandibles as in fig. 45. Anal gills present at apex of abdomen. Approximately full grown nymph with a length of $20 \mathrm{~mm}$.

The most important structural characters of the adult do not need to be redescribed since the female subgenital plate has been well illustrated by Klapálek (1923a) and Needham \& Claassen (1925), and the male by the latter authors. 'To aid with its determination,
1 now add an illustration, fig. 45 , showing the dorsal color pattern of the head and pronotum. This pattern is especially distinctive among Acroneuria because of the dusky lateral margins on the pronotum. In fresh material, these margins contrast with the rest of the surface, which is entirely yellow or yellowish, except for black ocelli and compound eyes.

Acroncuria xanthenes has been previously recorded only from Georgia and North Carolina. Supplementary and new state distributional records are as follows.

Florida.-Liberty County: Camp Torreya, April 12, 1930, 5 nymphs; Torreya State Park' Dec. 10, 1937, L. Berner, + nymphs.

Georgia.-Atranta: May 30, 1937, P. W. Fattig, $1 \delta$. Jones County, 10 miles north of Macon: April 30, 1938, L. Berner, 1 nymph.

North Carolina. - Montreat, Orlando Park: June 21, 1929, 1 of. Cherokee: June 26, 1938, W. Stehr, 1 o Marion: April 2t, 1938, Ross \& Burks, 1 nymph. SMOKEMONT: June 17, 1935, H. H. Ross, 2 exuviae. JAckSON County: Chattooga River, Aug. 28, 1938, T. Howell, 1 nymph; Norton Mill Creek, Aug. 8, 1938, T. Howell, 1 nymph. HoT SPRINGS, French Broad River: June 15, 1935, H. H. Ross, 1 exuvia. Newfound GaP, 2,560 feet elevation: May 28, 193t, T. H. Frison, 2 nymphs. Macon County: Edward's Creek, Aug. 26, 1938, T. Howell, 1 nymph; Nantahala River, May 30, 1939, 'T. Howell, 1 nymph. Swain County, Smoky Park, Forney Creek: Aug. 13, 1939, T. Howell, 1 nymph. Jacksox COUnTY: east fork of Tuckaseegee River, June 13, 1939, T. Howell, + nymphs; Slicken Creek, June 14, 1939, T. Howell, 2 nymphs; Knob Creek, July 20, 1939, T. Howell, 1 nymph; west fork of Tuckaseegee River, July 20, 1939, 1 nymph.

Ohio.-Waterloo Township, Athens CounTY, branch of Grass Run: May 15, 1941, J. D. Walker, 3 nymphs.

Pennsylvania. - Jenkintown, Montgomery County: Aug. 15, 1939, A. M. Laessle, 1 nymph.

Tennessee.-Great SMoky Mountains National. Park: Grassy Patch, July 22, 1939, A. C. Cole, 79 ; Chimneys Camp Grounds, July 12, 1939, A. C. Cole, 1 o , 6 ; ; Chimneys Camp Grounds, at light, July 16, 1939, A. C. Cole, $2 \delta, 10 \propto$; Chimneys Camp Grounds, July 20-2t, 1939, A. C. Cole, 5 o ; Chimneys Camp Grounds, at light, July 3-9, 1939, A. C. Cole, 10 \%; Chimneys Camp Grounds, 2,700 feet, June 17,1939, A. C. Cole, $1 \delta$; Greenbrier Cove, 2,400 feet, July 19, 1939, A. C. Cole, 19 . Smoky Mountains: June-July, 1940, A. C. Cole, 19. Elkmont, Little River: June 17, 1938, T. H. Frison \& T. H. Frison, Jr., + exuviae. Ozone: June 11, 1935, H. H. Ross, 2 exuviae. Gatlinburg: June $15,19+0, T$. H. Frison ct al., 1 q , exuvia (reared); Fighting Creek (branch of Little Pigeon River), May 27, 193t, T. H. Frison, + nymphs; Le Conte Creek, June 13, 1938, T. H. Frison \& T. H. Frison, Jr., 1 exuvia; Le Conte Creek, June 16, 1938, T. H. Frison \& T. H. Frison, Jr., 
1 usmph, 6 exuriae; Pigeon River, June 1t, $19+0$, Frison et al., 6 nymphs, 1 exuvia; June 16-17, 19t0, Frison of al., 2o, exuviae (reared); June 20, 1940, Frison of al., 19 , exuvia (reared); June 27, 1940, Frison at al. 19, exuvia (reared); Le C'onte Creek, June 14, 19+0. Frison et al., + exuriae; Little Pigeon River, June 12, 1935, 11. H. Ross, 9 nymphs.

Virginja. - Curley's Neck Bringe: April 19, 1938, M. L.. Davis \& D. T. Ries, 1 nymph. Grear Fulls: April 3, 1938, B. D. Burks, 1 IIImph. Bir Mrabows, Skyline Drive: Jan. 1, 1939. Frison \& Burks, 1 nymph. Criglersville, Rapidan River: March 27, 1938, B. D. Burks, 1 llimph. FilRFix: Dec. 31, 1938, Frison \& Burks, 5 myimphs. Madisos, Crooked Run Creek: Jan. 1, 1939, Frison \& Burks, 13 minphs. SPEEwELl: March 22, 1940, Frison, Mohr \& Hawkins, 1 nymph. Falls CHurcu: June 11, 1 \& (collection of $\mathrm{N}$. Banks) ; April 2. $19+1,13$. I). Burks, 1 nymph.

\section{Acroneuria georgiana (Banks)}

Perla georgiana Banks (1914, p. 608). Origis al description, $q$.

Since this species was first described from a single female from Clayton, Ga., June, 1909, Type No. 11,328, Museum of Comparative Zoology, it has been recorded again only from "Tallulah Falls, Jume 17, Georgia," and from "North Carolina," hoth records hy Needham \& Claassen (1925).

lllinois Natural History Survey field work in the Great Smoky Mountains National Park over a period of years revealed the presence there of a small Acroneuria nymph which was suspected of being the nymph of georgiana. In $19+0$, male adults of georginma were reared from this nymph, thereby defunitely establishing this relationship.

Since the nymph has not been previously recognized, a brief description of its most important characters is given here. General morphological features similar to other described nymphs of Acroneuria (Frison 1935a). Body and appendages mostly uniformly yellowish brown, without a prominent, contrasting, dusky or dark color pattern, except on dorsum of head, fig. t6. Head with a distinct transverse occipital ridge on posterior margin between compound eyes. Maxilla, labium and mandibles as in fig. 47. Anal gills present at apex of abdomen. Approximately full grown nymph with length of $15 \mathrm{~mm}$.

Needham \& Clatissen (1925) have figured the most important characters of the male and female. It should be added to their description that in fresh material the adult males are very pale colored and the dark brown or dusky markings on the dorsum of the head form a very distinctive pattern, fig. 47 .

Records for this species in the collection of the Illinois Natural History Survey are as follows.

North Carolix. - Smokemont: June 14, 1935, H. H. Ross, 1 nymph. Rainow GAp: April 24, 1938, H. H. Ross \& B. I). Burks, 1 nymph. Montreat, Lookout Cove: July 2, 1928, O. Park, 6 $\delta$. Craybeard Mountain near Montreat, west fork of Flat Creek Cove: July 7, 1928, O. Park, $1 \hat{\delta}$.

TenNessee.-Gatindinurg: June 17 and 26 , $19+0$, T. H. Frison et al., $2 \hat{\delta}$, reared; Fighting Creek Gap, May 15, 1939, 'T. H. Frison

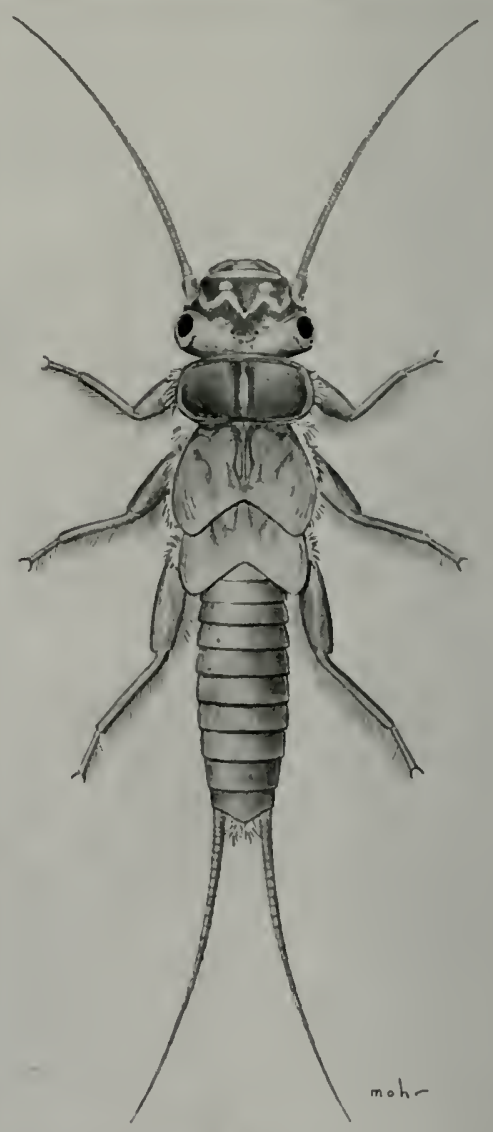

Fig. 46.-Nymph of Acroncuria georgiana.

\& H. H. Ross, 2 nymphs; Fighting Creek Gap, May 27, 193t, 'I. H. Frison, 6 nymphs; Little Pigeon River near Alum Cave Trail, June 17, 1938, I'. H. Frison \& T. H. Frison, Jr., 1 nymph; Le Conte Creek, June 18, 1938, 5 
exuviae, and June 16, 1938, 1 nymph, T. H. Frison \& T. H. Frison, Jr.; Little Pigeon River, June 17, 1938, T. H. Frison \& T. H.

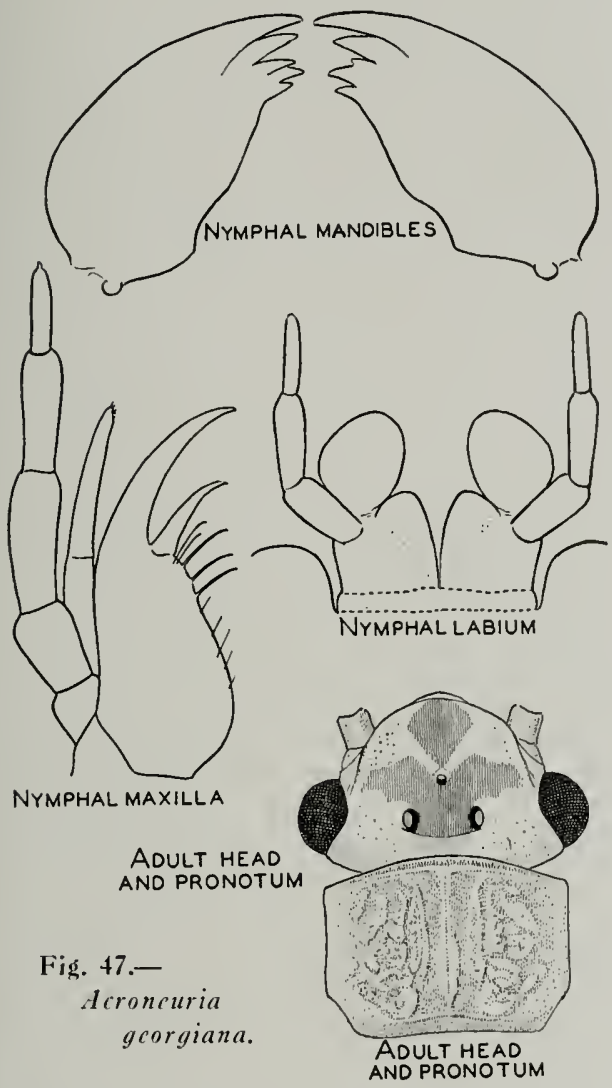

Frison, Jr., 1 nymph. MARYville: May, 1923, + nymphs. Elkmont, Little River: June 17, 1938, T. H. Frison \& T. H. Frison, Jr., 1 nymph, 3 exuviae. Great SMOKY Mountains National, Park, Chimneys Camp Grounds: July 3-9, 1939, A. C. Cole, 1 ô.

\section{Acroneuria carolinensis (Banks)}

Perla carolinensis Banks (1905, p. 215). Original description, $\hat{\delta}$, $\$$.

Acroneuria lycorias Claassen (1931, p. 87). Nymph-new synonymy.

Acroneuria lycorias Frison (1937, p. 97). Erroneous synonymy of cucstae Ricker.

This is another species of Acroneuria which has been infrequently recorded in literature and confused with other species. Reared specimens of both carolinensis and lycorias (Newman) prove that Claassen (1931) erroneously associated the nymph of carolinensis with the species lycorias and failed to recognize the nymph of lycorias (= perbranchiata Neave).
Illinois Natural History Survey rearings and collections in various states where both carolinensis and lycorias occur have led to the discovery that the nymphs of the former have no anal abdominal gills, whereas such gills are present in lycorias. A corollary of this, of course, is that the subanal lobes of the adults in both sexes iri lycorias possess anal gill remnants, whereas these remnants are lacking in carolinensis. Such an easily observed character as the presence or absence of anal gills or gill remnants is most important and useful when dealing with two species which look so much alike.

In 1937, I placed cuestae Ricker $(1935 b)$ in the synonymy of lycorias. This placement was in error and resulted

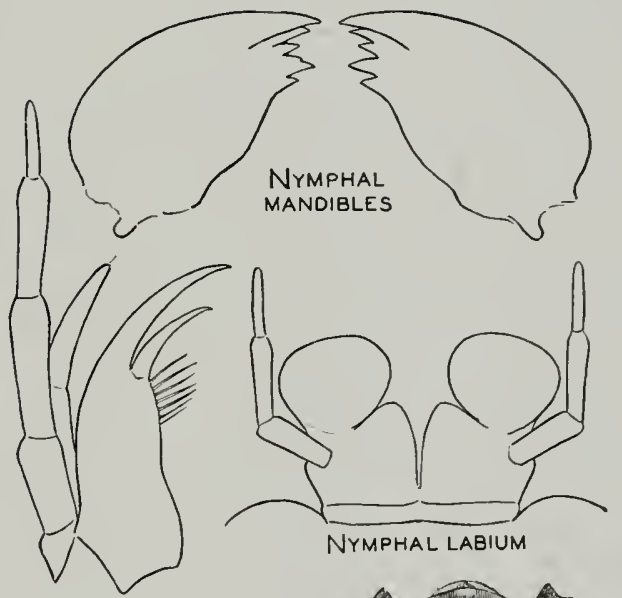

NYMPHAL MAXILLA

AOULT HEAD AND PRONOTUM

Fig. 48.-

Acroneuria

carolinensis.

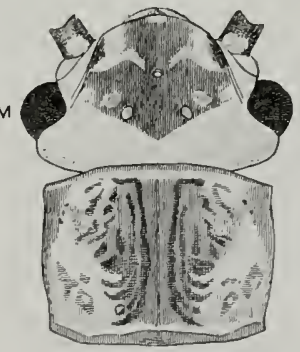

from the erroneous identification of reared male and female specimens from $\mathrm{New}$ York, sent to me by Dr. P. IV. Claassen as lycorias, and their association with exuviae which Dr. Claassen figured (1931) as lycorias. These adults, however, are without question carolinensis and are properly associated with exuriae without anal gill remnants. Correctness of this association of nymphs with adults is confirmed by rearing of an adult male of 
carolinensis from a nymph at Gatlinburg: Tenn., and the collection of a series of nymphs and adults from the Smoky

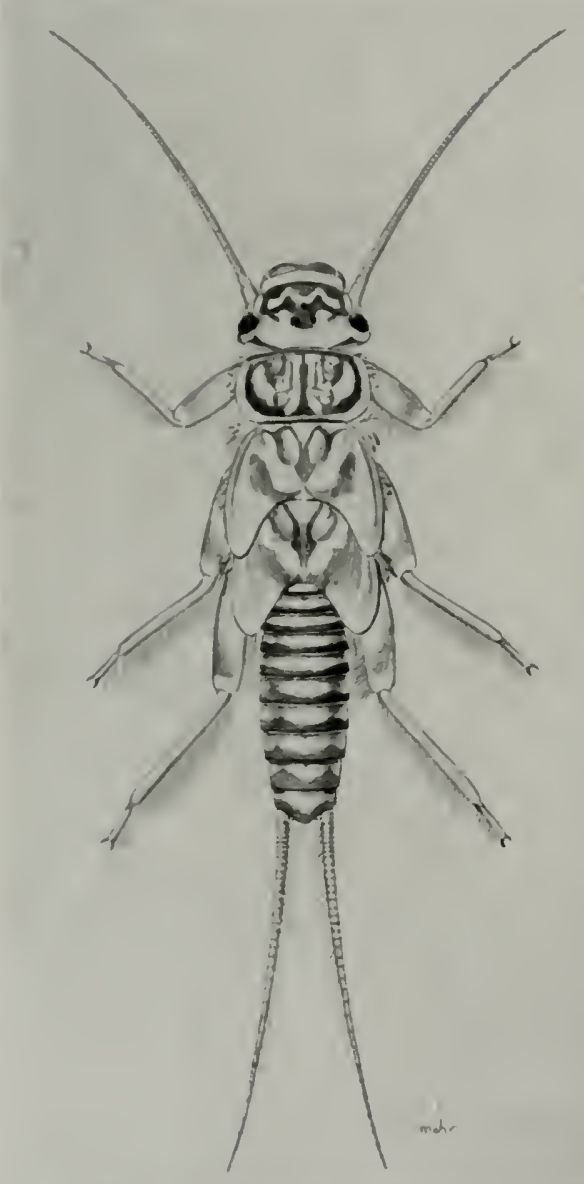

Fig. 49.-Nymph of Acroneuria carolinensis.

Mountains region, the adults of which agree perfectly with the types in the $\mathrm{Mu}$ seum of Comparative Zoology.

Because of a lack in the past of definite tangible characters for the separation of lycorias and carolinensis, the latter has appeared in literature as a species with a very restricted distribution. It is very probable that some of the adult records given by Needhan \& Claassen for lycorias apply to carolinensis, since Illinois Natural History Survey material slows carolinensis to be present in several of the states of the Appalachian region. Since the head pattern of Acroneuria adults, within certain limits, has some value when making determinations, an illustration of it is given, fig. +8 , to compare with similar illustrations which I have given for other species of the same genus.

NropH.-Although Claassen (1931) has given a photographic illustration of the nymph of carolinensis, under the name of lycorias, I think it highly desirable to include here the reproduction of a drawing of the nymph. A brief description of the nymph is as follows: General color of body and appendages yellow with brown or dark markings as in fig. 49 ; particularly important features of the color pattern are the arrangement of the light and dark areas on the dorsum of the head and the banding of the abdominal tergites; in color pattern the nymph is very similar to lycorias, but it differs from the nymph of lycorias in the lack of anal abdominal gills. No occipital transwerse ridge on the posterior part of the head. Maxilla, labium and mandibles as in fig. 48 .

The typic series of carolimensis consists of two females and one male, No. 11,320, from the "Black MIts. VI N.C." in the collection of the Museum of Comparative Zoology. Specimens in the Illinois Natural History Survey collection have been compared with these types. Through the kindness of Dr. Nathan Banks, I was permitted to clip off the apical abdominal segments of one of the typic females, relax it and study it in fluid, a procedure which enabled me to establish that these typic pinned specimens did not possess anal gill remnants on the subanal lobes.

It should be mentioned, at this time, that I believe Perla lurida Hagen (1861) is the same species as carolinensis, but hesitate to place carolinensis definitely as a synonym of lurida, which would have priority, until more information is available about the Acroneuria fauna of Georgia. Alabama and Louisiana. 'The type of lurida is a female, No. $2+6$, in the collection of the Museum of Comparative $\mathrm{Zo}$ ology, and bears the data "N. Orleans Pfeiffer 1858," which agree with statements in the original description. The apical abdominal segments of this type, by permission of Dr. Banks, were clipped off, softened in potassium hydroxide, and studied in fluid. The subgenital plate seems to be almost identical with that of carolimensis, and the lack of any anal gill remnants on the subanal lobes is a further 
very convincing bit of evidence that the two are identical.

Since the distributional pattern of carolinensis is so poorly known, the following records, based upon the Illinois Natural History Survey collection and an examination of material sent for study, are presented.

Maryland.-Keyser Ridge: Dec. 30, 193t, Frison \& Ross, 2 nymphs.

New Hampshire.-North WoOdstock, Bog Brook: June 21, 19+1, Frison \& Ross, 1 nymph.

NEW YORk.-Lloyd Cornell Wild Flower Preserve, Caroline: Aug. 16, 1928, T. H. Frison, 1 nymph. IтHACA: Sept t, 1936, Harvey Bowman, 39 nymphs; Coy Glen, under stones and in gravel of rapid waters, Oct. 6, 198 [1908?], nymphs. Downsville: Campbell Brook, Sept. $t, 1935$, nymphs; June 16, 19+0, H. Dietrich, 1 $\hat{\delta}$. McLean: May 29, 1927, $1 \hat{\alpha}, 1$ exuvia. Wild Life Preserve, SisterVILLE: June 9, 1927, 1 ㅇ, 1 exuvia. Schoharie: June 6, 1937, Flick, 1 웅 May 1t, 1938, P. Jennings, 1 nymph. KEENE, small creek 3 miles west, Adirondack State Park: June 20, 19+1, Frison \& Ross, 1 exuvia. Euba Mills, Adirondack State Park: June 20,1941, Frison \& Ross, 1 exuvia. Roscoe, Beaver Kill Creek: June $28,19+0$, P. Jennings, $1 \hat{\delta}$. Mount TremPER, Esopus Creek: July 31, 1938, P. Jennings, 1 9 . BeAver KILL, Beaver Kill River: July $24,19+0, \quad R$. B. Fischer, 1 nymph. UPPER Beaver KILl: June 21, 1936, Nottingham, 1 nymph. Catskill: June 20, 1936, J. B. N., 4 nymphs.

North Carolina.-Black Mountain, fork north of Swannanoa: May, $1 \hat{o} ;$ VI, 2 ㅇ.

Pennsylvania.-Poyntelle: June 17, 1904, M. Hebard, ô. Monroe County: Marshall's Creek, May 24, 1935, W. J. Harmer, 3 nymphs; Saw Creek, May 19, 1935, W. J. Harmer, 3 nymphs. Pike County, Saw Creek: May 19, 1935, WV. J. Harmer, 6 nymphs.

Tennessee.-Gatlinburg: Le Conte Creek, May 1t, 1939, Frison \& Ross, 1 exuvia; May 14, 1939, Frison \& Ross, $1 \hat{\delta}$ (reared); June 13, 19+0, Frison et al., many exuviae; June 14, 19+0, Frison et al., $1 \hat{\delta}, 359,1$ exuvia; June 1t, 19+0, T. H. Frison, 1 adult. KNoxville: June 13, 19+0, Frison et al., many exuviae; June 1t, 1940, Frison et al., 1 exuvia.

Virginia-StandardSVILle: Sept. 27, 1936, Frison, 1 nymph.

\section{Acroneuria lycorias (Newman)}

Perla lycorias Newman $(1839$, p. 35$)$. Original description.

Acroneuria lycorias Ricker (1938, p. 139). Designates lectotypic o.

Acroneuria perbranchiata Neave (1933, p. 237). New synonymy.

Newman in his original description does not give the sex of his typic specimens, but Ricker (1938) designates a female specimen in the Hope Collection, University Museum, Oxford, as the lectotype and states that it agrees with Needham \& Claassen's (1925) description of this spe- cies. Elsewhere in this article I have pointed out that there has been some mixing of species under the name of lycorias and that the nymph described as this species by Claassen (1931) is the nymph of carolinensis (Banks).

A study of paratypic male and female specimens of Acroneuria perbranchiata Neave sent to the Illinois Natural History Survey collection by Neave has revealed that this species is a synonym of lycorias. I suspect that Claassen's (1931) erroneous assignment of the nymph of carolinensis

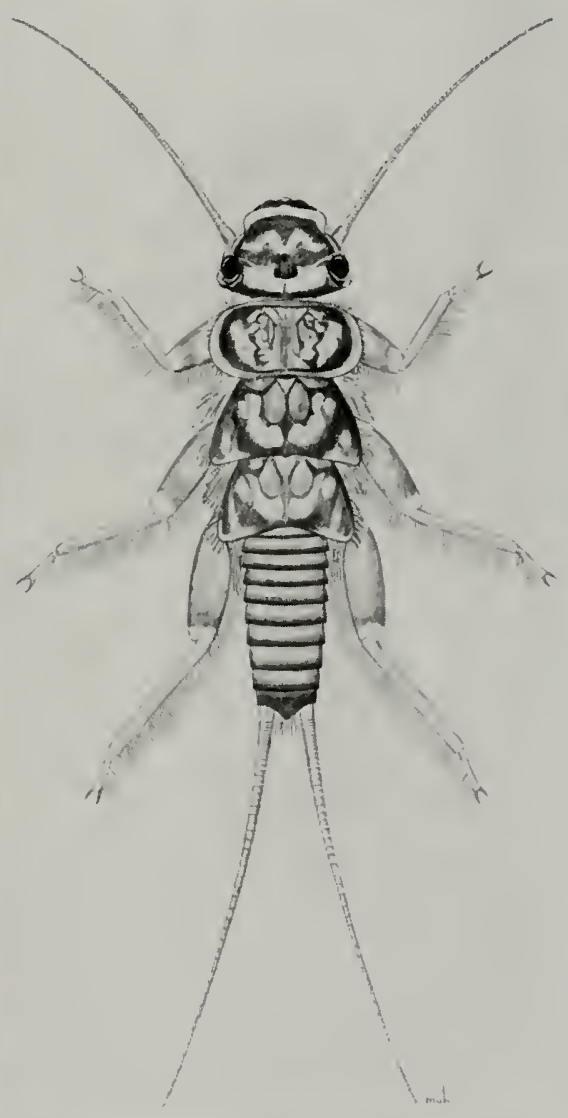

Fig. 50.-Nymph of Acroneuria lycorias.

to lycorias had some influence in leading to the description of perbranchiata since Neave describes the nymph of perbranchi$a t a$ and mentions its great similarity with lycorias as described by Claassen except for the presence in perbranchiata of anal abdominal gills. 
Neatle's (1933) description of the mymph of perluranchiota is a very good one and since it is identical with lycorias there is little need here for many further remarks. Neatve did not figure the nymph,
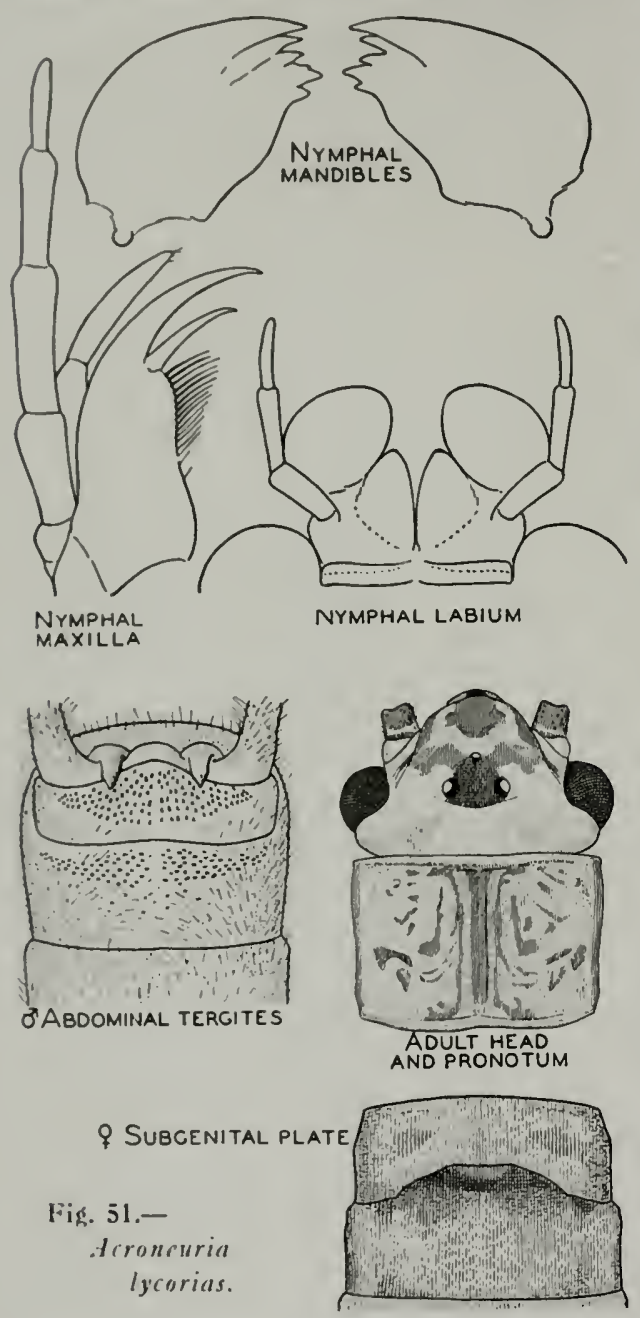

however, and since Claassen's figure is in error as to species I believe it well to include here an illustration of the nymph. The most important features of this nymph are the color pattern, fig. 50 , and the presence of the anal abdominal gills. 'The maxilla, labium and mandibles are as in fig. 51.

Since the adults of lycorias have been confused with those of other species, I am presenting here illustrations of the color pattern of the dorsum of head and pronotum, fig. 51, the subgenital plate of the female, fig. 51, and the dorsal apical segments of the male, all hased upon reared material. Klapálek's (1909) figure of the sulgenital plate of the female of lycorias does not agree with my figure, but Ricker has fixed a lectotype for lycorias which is similar to the illustration of Needham \& Claassen (1925) and this is comparable to iny material. Very likely Klapálek's material, at least in part, represents some other species.

In addition to reared male and female specimens obtained on Illinois Natural History Survey field trips to Michigan, Tennessee and Wisconsin, I have studied reared material from Minuesota sent to me for identification. A large series of adults and nymphs of this species in the Survey collection are from Florida, Maine, Manitoba, Maryland, Massachusetts, Michigan, Minnesota, New York Ohio, Ontario, Pennsylvania, Tennessee and W'isconsin.

\section{Acroneuria theodora \\ Needham \& Claassen}

Acroneuria theodora Needham \& Claassen (1922, p. 25t). Original description, $\hat{o}, \quad$ ․

Acroneuria theodora Claassen (1931, p. 90). Nymph.

This species has not been recorded in literature since its description, and because of its rarity the following notes, illustrations and records are presented.

The original description of the adults did not contain any illustrations of the structural features most important from the standpoint of identification. A few years later Needham \& Claassen (1925) published line drawings of the apical segments of the male and the subgenital plate of the female. Since these drawings are not very detailed, I think it worthwhile to present new drawings of these structures and also some additional ones, fig. 52, which should aid with the future recognition of this western species.

Comparisons of Illinois Natural History Survey material of theodora with that of californica (Banks) have revealed that the aedeagus of theodora is very distinctive and differs markedly from that of californica and other species of Acroneuria studied. Like californica, theodora belongs with the series of Acroneuria which do not possess anal abdominal gills in the nymphs or gill remnants on the subanal lobes of the adults. A. depressa Needham \& Claassen (1922) and parifica 
Banks have these anal gills in the nymphs or anal gill remnants in the adults.

Needham \& Claassen in the original description state that the males of theodora are "brachyterous," but give measurements of "length to tip of wings" for the males as "29-32 mm.," and "expanse 4850 mm." In their Monograph of a few years later, 1925, the "length to tip of wings" of the male is given as " $15 \mathrm{~mm}$.," and the "expanse-20 mm." Evidently the males vary from short-winged to longwinged forms. 'Two male specimens in the Illinois Natural History Survey collection from $W$ yoming have actual wing lengths of 15 and $20 \mathrm{~mm}$., and male specimens from Oregon have wings as long as $28 \mathrm{~mm}$. Wing lengths are poor criteria for separation of species in Plecoptera.

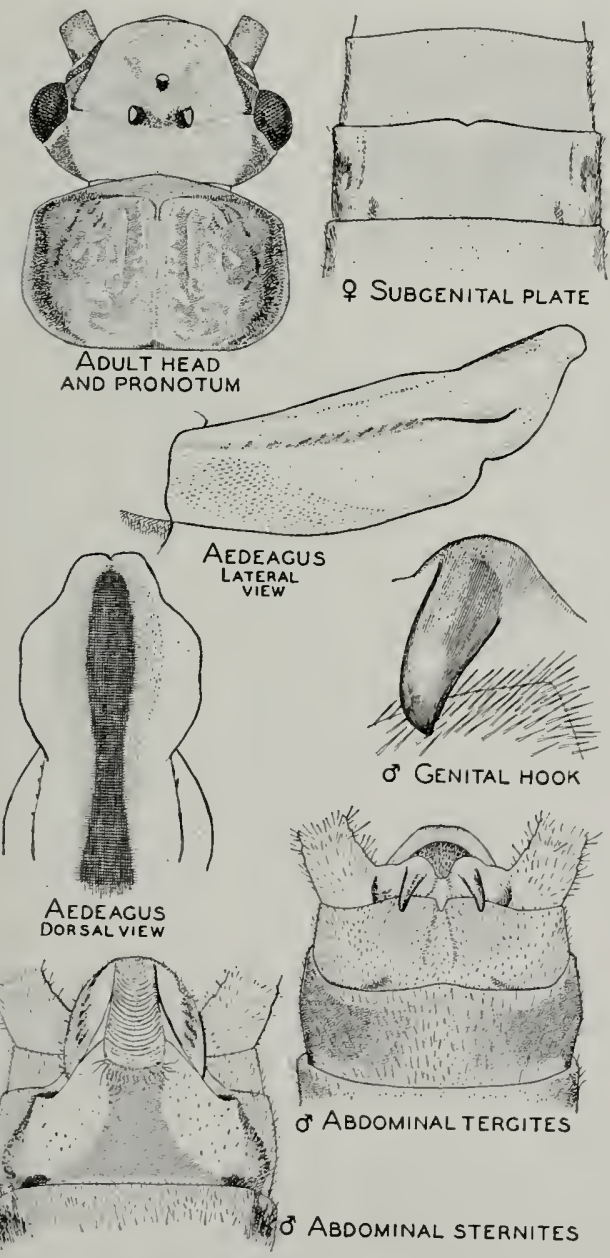

Fig. 52.-Acroneuria theodora.
Illinois Natural History Survey collection records for theodora are as follows.

California.-Monoc County: July 20, 1922, $1 \delta$.

OREGON,-MICKENZIE RIVER: south fork, 20 miles south from confluence, Sept. 4, 1932, R. Dimick, $1 \hat{\delta}$; Sept. 21, 1934, R. Dimick, $9 \hat{\delta}$, 8 ㅇ, 3 of exuviae, 8 우 exuviae. Camp Creek, Mount Hood National Forest: Aug. 2, 1933, R. Dimick, 1 i nymph. MCKENzIE BRIDGE: Sept. 21, 1934, R. Dimick, $5 \hat{\delta}, 5 q, 3 q$ exuviae. East Fork River, WillametTe National ForEST: Sept. 6, 1936, V. E. Storr, $1 \hat{\delta}$. BOYER, foot-log on Salmon River: Sept. 22, 1935, J. A. Macnab, 10 . McMinnville: Sept. 16, 1933, J. A. Macnab, $1 \hat{o}$. Summit Prairie, July 23, $1939,1 \hat{o}$.

WYOMING.-Shell Exit, BIg HORN MOUnTaINs: July 30, $19+0$, T. H. F. \& T. H. F., Jr., 1 $\hat{f}$. Bondi Camp, Big Horr National Forest, Tongue River: July 28, 1940, T. H. F. \& T. H. F., Jr., $1 \hat{\jmath}$.

\section{Acroneuria sabulosa (Banks)}

Perla sabulosa Banks (1900, p. 242). Original description, $q$.

Acroneuria depressa Needham \& Claassen (1922, p. 253). Original description, of, 우. New synonymy.

Pcrla sabulosa Needham \& Claassen 1925, p. 101). New synonymy.

By permission of Dr. Nathan Banks, I have had the privilege of studying critically the typic female, No. 11,317, of sabulosa and the holotype and allotype, No. 15,520, of depressa in the collection of the Museum of Comparative Zoology.

In order to study the typic female of sabulosa and a paratypic female of depressa in fluid, I relaxed the specimens and slightly softened the apical abdominal segments with potassium hydroxide. Both were found to be a species of Acroneuria which reveal traces or remnants of gills on the subanal lobes and hence must have nymphs with anal gills. No tangible differences were found to exist between the specimens; therefore, and because of priority of description, the specific name of depressa must fall into the synonymy of sabulosa.

It is interesting to note that the typic specimen of sabulosa came from "Yakima, IVash.". and the typic series of depressa came from "Yakima River, Lone Tree, June 30, '82, IV. T. [= Wash.]."

Under Claassenia arctica (Klapálek) in this article I have pointed out that Claassen (1931) erroneously described and illustrated the nymph of arctica under the name of Acroneuria depressa. 'The nymph 
of sabulosa (= depressa) still remains to be discovered, but when found will possess anal ahdominal gills.

\section{Claassenia arctica ( $\mathrm{K}$ lıpálek)}

didelungia arcrica Klapálek (1916, pp. 59, 78). Original description, ô, $\$$.

Perla languida Needham \& Claassen (1925, p. 100). New synonymy.

C.laassenia languida Ricker (1938, p. 1+0). Notes on type and generic transfer.

Acroneuria depressa (?) Claassen (1931, p. 86 and pl. 27, fig. 207). Misidentification of uImph.

This large western species of stonefly has had an interesting bibliographic history, considering the few times it has been mentioned in literature. It was originally described by Klapálek in his new genus Adelungia, with caudata from China as its genotype. In 1925, Needham \& Claassen in their Monograph described languida from specimens from Wyoming and Montana, but strangely made no mention of a species arctica from "Arctic America." Wu (193t) noted that Adelungia was a preoccupied name and proposed Claassenia as the name to replace Adelungia, without any reference to its occurrence in North America. Ricker (1938) noted the close relationship between arctica and languida and placed both for the first time in the genus Claassenia. Ricker's figures of the typic specimens in the British Museum and studies of specimens in the Illinois Natural History Survey collection convinced me that languida is a synonym of arctica. Many species occurring in the mountains of northwestern states range far into Canada.

Whether the species now included in Claassenin form a sufficiently distinct group to warrant generic status may be questioned, but at least for the present l am so recognizing them.

In August, 1940, while in Yellowstone National Park, Wyo., I had an excellent opportunity to rear series of arctica, both male and female, from nymphs and observe some of the habits of the adults. The adults are nocturnal and emerge at nightfall from nymphs which crawl out of the water on rocks or other objects near the shoreline of such turbulent mountain streans as the Yellowstone River. During the day the adults rest under stones and other objects close to the water's edge and when active at dusk or night have the ability to advance rapidly over the surface of the water somewhat like water-striders. Mating often takes place as soon as the females emerge from nymphal skins, and the males are able to recognize nymphs destined to be females as proved by attempts at mating and by waiting for a particular female to emerge.

Clanssen (1931) described and figured the nymph of arctica under the name of "Acroneuria depressa (?)." Certain characters of this nymph, particularly size, occipital ridge and anal gills, in addition to locality records, caused me to suspect its true identity before actually rearing it in 1940 .

Since records of the occurrence of this species are few, and confined to the references

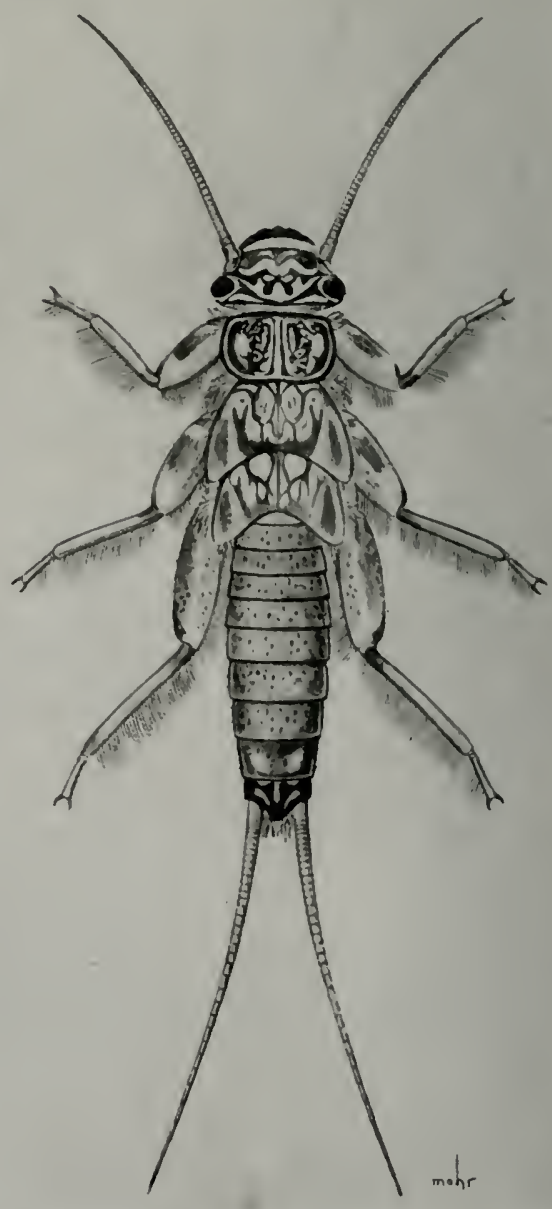

Fig. 53.-Nymph of Claassenia artica. 


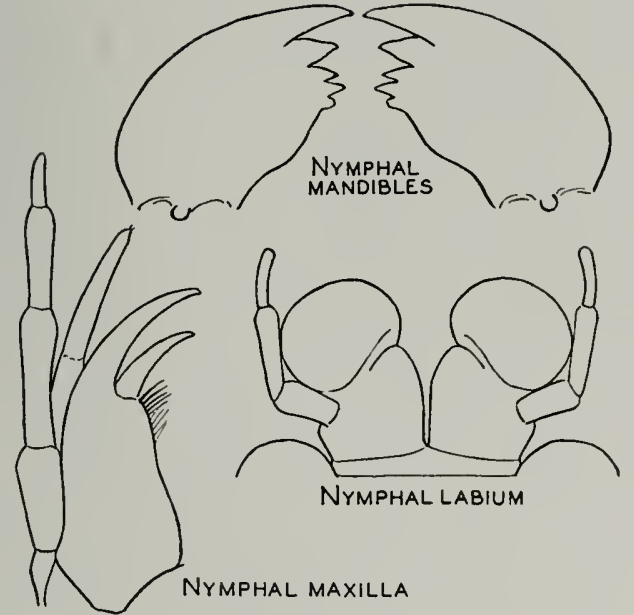

Fig. 54.-Claassenia arctica.

listed above, I present the following additional data from the Illinois Natural History Survey collection.

Montana.-Varney, Madison River: July 29, 1937, P. Jennings, 1 nymph. Glacier NATIONAL PARK, Logging Creek: July 11, 19+0, H. H. \& J. A. Ross, 2 nymphs, 1 exuvia. SOUTH Dakota.-SPEARFISH: July 25, 1924, 1 ô ; July 27, 1940, T. H. Frison \& T. H. Frison, Jr., 3 exuviae.

W.ashington--Seattle: C. V. Piper (collection of N. Banks), $1 \delta$; Cedar River, April 1, 1939, L. Lambuth, 2 nymphs.

Wyoming. - Yellowstone National Park, Gardiner River, Yellowstone River, Cascade Creek and Nez Perce Creek: July 30-Aug. 3, 1940, T. H. Frison \& T. H. Frison, Jr., many nymphs, $\hat{\delta} \hat{\delta}, \propto \wp$. Grand Teton National PARK, Taggart Creek: Aug. 7, 1940, T. H. Frison \& T. H. Frison, Jr., 3 nymphs, 1 exuvia. DANiel, Green River: Aug. 13, 19+0, T. H. Frison \& T. H. Frison, Jr., 1 exuvia. Moose, Snake River: Aug. 6, 1940, T. H. Frison \& T. H. Frison, Jr., 6 nymphs, 6 exuviae.

Colorado.-IDA: June 19,1934, 1 ㅇ. GunNisON: July 3, 193t, $3 \hat{\delta}$. Estes PARK, Big Thompson River: Aug. 4, 1940, T. H. Frison $\&$ T. H. Frison, Jr., 2 nymphs, 5 exuviae.

IDAHo.-Swan Valley, Caribou National. FOREST: Aug. 28, 1935, H. S. Telford, 1 ㅇ․

Although Claassen (1931) described and figured this nymph, but under the wrong name, it seems desirable here to present a new illustration of it, fig. 53, and add illustrations of the mouthparts, fig. $5+$.

\section{PERLODIDAE}

\section{Perlodes Banks}

It has been my good fortune to study in considerable detail the types, or what re- mains of them, of Arcynopteryx zagans Smith, Arcynopteryx aurea Smith, Arcymoptery x lineata Sinith, Protarcy's bradleyi Smith, Protarcy's dolobrata Smith (the neallotype only), Distyopteryx irregularis Banks, Dictyopteryx sigmata Hagen, Perlodes slossonae Banks, Perlodes yosemite Needham \& Claassen (allotype) and Perlodes tibialis Banks. All of these species were placed by Needham \& Claassen (1925) in the genus Perlodes, and while these authors sank Protarcy's Klapálek, Megarcys Klapálek and Arcynopteryx Klapálek as synonyms of the subgenus Perlodes, they proposed the new subgenus Perlinodes for the reception of Arcynoptery.x zagans.

I have studied too few specimens of adults and nymphs to permit me to come to definite conclusions regarding the proper appraisal of the names Arcynoptery, Megarcys, Protarcys, Perlinodes and Perlodes. For the present, at least, it seems that the safest procedure is to follow Needham \& Claassen (1925) in placing them all in the genus Perlodes and recognize as subgenera the other proposed units of classification above the rank of species in this family.

The studies have progressed far enough, however, to indicate that much synonymy exists in the genus and that fine distinctions of wing venation are not reliable for species determinations. One of the outstanding features of Perlodes (s.l.), as I recognize the genus, is the variety and character of gills. All species studied to date have the submental gills found in Isogenus and Hydroperla, and some species have additional pairs of gills in the cervical region and on the thorax. Needham (1933) has even described a new genus, Oroperla, with a new species called barbara, based upon the nymph, which has a row of gills on each side of the abdominal segments. The adult of barbara, when found, should show remnants of these gills.

My conclusions to date regarding valid species and synonymy are presented under the headings of the species concerned.

\section{Perlodes minor (Klapálek)}

Arcynopteryx minor Klapálek (1912, p. 22 ). Original description, $\hat{\delta}$.

Perlodes slossonae Banks (191t, p. 608). Original description, $q$. New synonymy. 
Arcynoferyx lineata Sinith (1917, p. 476). Original description, \&. New symonymy.

Pirlodes maryarila Alexander (1936, p. 26). Original description, o. New synonymy.

Appirenty every time a specimen of this species has fallen into a collector's hand it eventually has formed the basis for a description of a new species. The synonymy I have indicated above is based upon a study of the holotypic female of linina (C. U. No. 1,138) and the typic

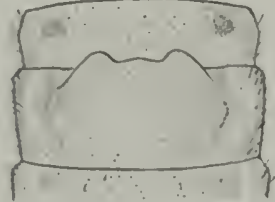

QSUBCENITAL PLATE
Fig. 55.-

Perlodes

minor. female of slossonae (M.C.Z. No. 11,308). Certainly both of these are identical as to species. Fig. 55 is an illustration of the subgenital plate of the holotypic female described by Smith (1917) as lineata.

Male and female specimens of minor determined by Klapálek are in the collection of the Museum of Comparative $\mathrm{Zo}$ ology: When these were compared with specimens of Perlodes from Mount WVashington, $\mathrm{N}$. H., previously determined as lineata, and with the type of slossonae, no tangihle differences could be found. Species of stoneflies have a much more general distribution within certain limits than literature records indicate. Although I have not examined the type of margarita I feel quite certain that it is the male of the species Banks described as slossonae-they even came from the same mountainwhich in turn is the same species as lineata from nearby New York. On the highest mountains in the East are a few species of stonclies found at lower levels farther nortl.

Klapálek's minor is a species of Perlodes having a pair of gill remnants in the adult only on the submentum. In western North America there is another species of Perlodes named americana (Klapálek) closely related on the basis of gills to minor but with a distinctive subgenital plate in the female and with different genitalia in the male. $P$. ignota (Sinith), described (1917) without locality data, is evidently another synonym of minor, but the type could not be found when my studies of the Perlodes types were made.

\section{Perlodes aurea (Smith)}

Aroynopieryx aurea Stnich (1917, p. 477). Original description, $q$.

Arcynopleryx zosgans Smith (1917, p. +78). Original description, o. New synonymy.

Arcynopteryx aurea was described from a single female (C.U. No. 1,1+1) from "San Diego, Calif., April 23, 1879," and ragans from a single male (C.U. No. 1,139) from "California."

I have studied the types of both aurea and ragans and as a result have come to the conclusion that the specimen described as zagans is the male of aurea, the name aurea having page priority. My reasons are as follows: Males and females agreeing with these two sexes occupy the same general territory, the opposite sex of each has not been previously located, and morphologically both are unique among North American species of stoneflies in having five pairs of gill remmants, fig. 56 .
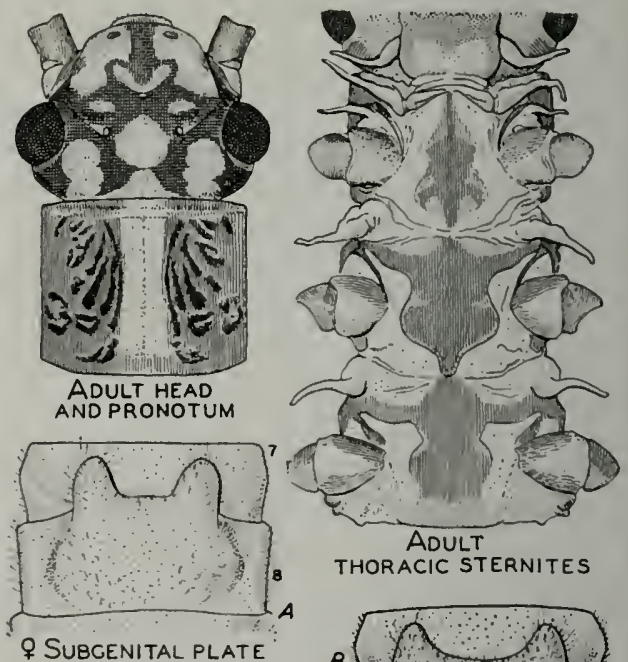

THORACIC STERNITES

Fig. 56.-

Perlodes aurea:

$A$, female holotype from California;

$B$, female specimen from Oregon.

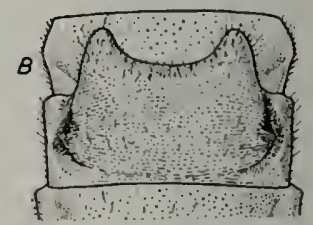

An illustration of the subgenital plate of the female holotype of aurea is presented in fig. $56 \%$. Fig. $56 B$ is an illustration of the subgenital plate of a female I consider to be aurea from Oregon. The head and pronotum of aurea, as observed in an Oregon specimen, has a pattern as in fig. 56. Although Needham \& Claassen (1925) mentioned the five pairs of gills in 
quoting Smith's original description of z'agans, reference to this feature was omitted when they quoted the original description of Smith for aurea, although the latter description contains such a statement. In the Illinois Natural History Survey collection are two nymphs from Rogue River, Ore., Sept. 29, 1932, collector, R. E. Dimick, which have five pairs of gills located as in the adult of aurea, and hence I consider them to be of this species.

Records for the distribution of this species based upon Illinois Natural History Survey material, or the identification of specimens for others, are as follows.

Oregon.-Corvallis, Alsea River: April 2, 1939, Davidson, 1 ㅇ. Near LAcomb, Roaring River: March 20, 1934, R. Dimick, 1 ó. PARKDALE, east fork of Mount Hood River: May 2, 1934, R. Dimick, $1 \hat{\delta}$. Rogue River, 1,780 feet elevation: Sept. 29, 1932, R. Dimick, 2 nymphs. Tillamook: March 20, 1934, Joe Schuh, $1 \hat{0}$.

Washington.-Easton: April 17, 1934, G. Hoppe, $8 \hat{\delta}, 2$; April 25, 1934, G. Hoppe, $7 \delta$.

\section{Perlodes dolobrata (Smith)}

Protarcys dolobrata Smith (1917, p. 469). Original description, 우

Perlodes dolobrata Needham \& Claassen (1925, p. 52). Description, ô.

I have not studied the typic female, in the Academy of Natural Sciences of Philadelphia, and described without locality data, and full information regarding actual number of pairs of gills is not given in the original description. The description does indicate, however, that thoracic gills are present, and it is a safe assumption that submental gills are present, thereby making Smith's key to Protarcy's indecisive.

Needham \& Claassen (1925), apparentIy on the basis of wing venation, described a male from "Glacier Peak and Lake Chelan Dist." as the "neallotype." This

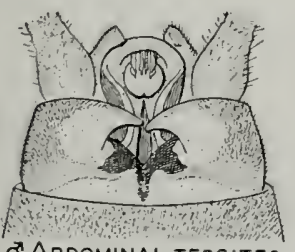

O'ABDOMINAL TERGITES

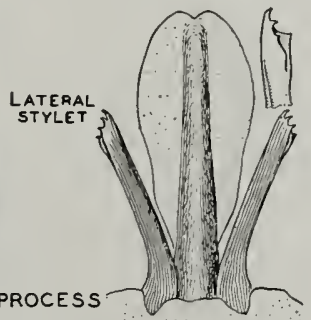

Fig. 57.-Perlodes dolobrata. specimen, in the Cornell University collection, has a pair of submental gills and at least one thoracic pair (number of pairs doubtful because of poor condition of specimen). Since these authors did not figure the important genital structures of this male, I am presenting illustrations of the terminal abdominal tergites, as viewed from above, and a view of the supra-anal process and flanking lateral stylets, fig. 57. Whether this male is correctly associated with its female remains to be established by future collections.

\section{Perlodes tibialis Banks}

Pcrlodes tiljalis Banks (1914, p. 608). Original description, $\hat{o}$.

Protarcys liradleyi Smith (1917, p. 470). Original description, $\hat{\delta}$, $q$. New synonymy.

'The type of tibialis is a male (M.C.Z. No. 11,309) and is from "Olympia Mts., Wash." A study of this male reveals it has a pair of submental gills and two pairs of gills on the sides of the thorax as Smith (1917) described for Protarcys bradleyi. For some reason, Smith (1917) in her account of the North American species

Fig. 58.-

Perlodes

tibialis.

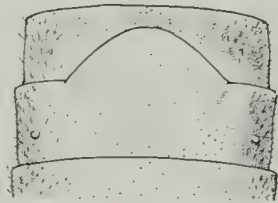

오 SUBGENITAL PLATE

of Perlodes failed to include any reference to the two species of Perlodes, tibialis and slossonae, described by Banks in 191t.

In the Illinois Natural History Survey collection is a male of tibialis from Fish Lake, British Columbia, July 23, 1908 , which agrees in structural details with the type, and a female with the same data which agrees with the male in gill arrangement. It is my belief that these two specimens of opposite sex are of the same species. A study of the holotypic male and allotypic female of Protarcys bradleyi Smith (C.U. No. 1,135) reveals that the allotype of bradleyi, fig. 58, from "Rogers Pass, B. C., August 7, 1908," is identical with the female in the Survey collection I consider to be the heretofore unknown female of tibialis. In general the holotypic specimen agrees with the allotype, and the gill arrangement is identical. Un- 
furtunately, the holotypic male of bradleyi has its abdomen missing, hut Sulth's drawing of a side view of the paragenital plate, lateral stylets and supra-anal process of the typic male are sufficient to indicate their likeness with tibialis. In view of (1) the distributional range involved, (2) the agreement in gill arrangement, (3) the similarity of a female evidently belonging ti) tibialis with the allotype of bradleyi, $(t)$ the general agreement of at drawing of certinin genitalic structures of the typic male of bradleyi with the male of tibialis and (5) the overlooking by Smith of the species tibialis when describing bradleyi, 1 propose that bradlesi be placed in the synonymy of tibialis.

\section{Perlodes signata (Hagen)}

Diclyopteryx signata Hagen (1874, p. 575). Original description, ô, $q$.

Dictyopleryx irregularis Banks (1900, p. $2+3)$. Original description, + . Synonym.

Perlodes yosemite Needham \& Claassen $(1925$, p. 56). Original description, $\hat{\delta}, \hat{q}$. New synonymy.

Smith (1917) placed irregularis in the syonymy of signata, but Needham \& Claassen (1925) have treated the two as distinct. I have studied the types of both irregularis (M.C.Z. No. 1,130, q) and signata (M.C.Z. No. 2tt, $\hat{\delta}, q)$ and can find no good characters for their separation. The types of both species have a distinctly cleft subgenital plate in the female, and both sexes have four pairs of gills: one pair attached to submentum and three pairs on sides of thorax. 'The difference that Needham \& Claassen (1925) mention in the shape of the tip of the genital hook of the males, in my opinion, is the result of individual variation. I have studied a male in the Cornell University collection from Paradise Valley, Wash., July 17, 1920, collected by E. P. $V$ an Duzee, which probably is the neallotype of irregularis, not one of the original typic series, fixed by Needham \& Claassen. This specimen was determined by Claassen as a male or irregularis and is in very poor condition. Enough remains to establish that it has a gill arrangement similar to that of signata, and therefore I believe it is of this species. The parts of the genitalia are missing.

Although the original description of yosemite states that the holotypic male and allotypic female are hoth in the collection of the California Academy of Sciences, only the allotypic female could be located by the present Curator of Insects, Dr. E. S. Ross, when I recently visited the Academy to study the stonefly types deposited there. The allotype of yosemite has a gill arrangement similar to that of signata, and the shape of the subgenital plate is of the same general type. 'The drawing of the subgenital plate hy Needham \& Claassen makes it appear that the two lobes of this plate are very angular or sharply pointed, whereas they are rounded. The characters mentioned in the original description to separate the male of yosemite from that of signata are ones which exhibit considerable variation in a series of specimens. I have no hesitancy in placing yosemite in the synonymy of signata.

Of the species of Perlodes, signata is most frequently collected, and specimens are in the Illinois Natural History Survey collection from Alberta, British Columbia, Colorado, Montana, Oregon, Utah and W ashington.

\section{Isogenus frontalis Newman}

Isogenus frontalis Newman (1838a, p. 178). Original description, $q$.

Isogenus colubrinus Hagen (187t, p. 576). New synonymy.

In the Museum of Comparative Zoology are the typic specimens of Isogenus colubrinus Hagen (1 male, No. 263), Isogemus elongarus Hagen (3 females, No. 262), Perla incesta Banks (3 females, No. 10.838) and Perla titusi Banks (1 male, No. 10,0+6). After a careful study of all these types and a large series of specimens of this genus in the Illinois Natural History Survey collection, I have come to the conclusion that Needham \& Claassen (1925) were correct in considering incesta and titusi as synonyms of frontalis. However, I dissent from Needham \& Claassen (1925) in holding colubrinus as a distinct species and propose that it he placed in the synonymy of frontalis. I cannot find any differences between the type of colubrinus and reared females which can be accepted as frontalis. Furthermore, males from western states associated with females of the fromtalis-colubrinus type are similar to reared specimens 


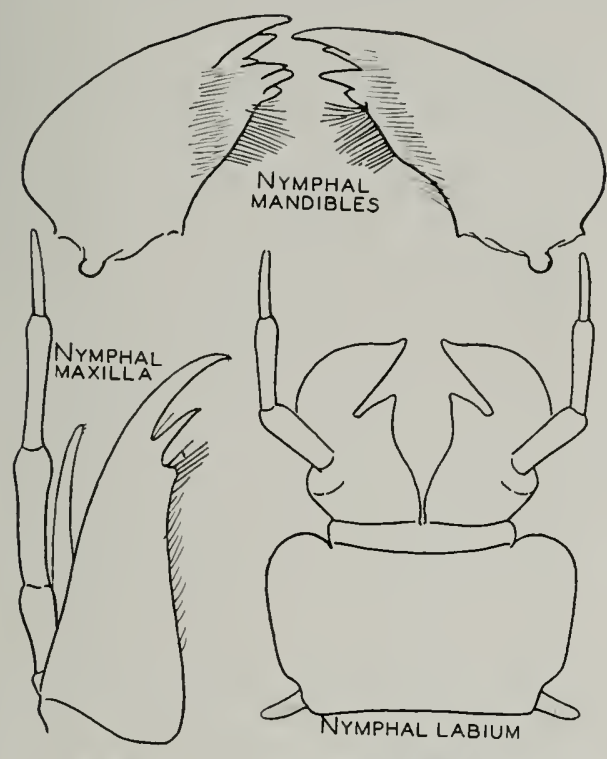

which can be accepted as frontalis. In this connection it should be noted that Needham \& Claassen (1925) were in doubt
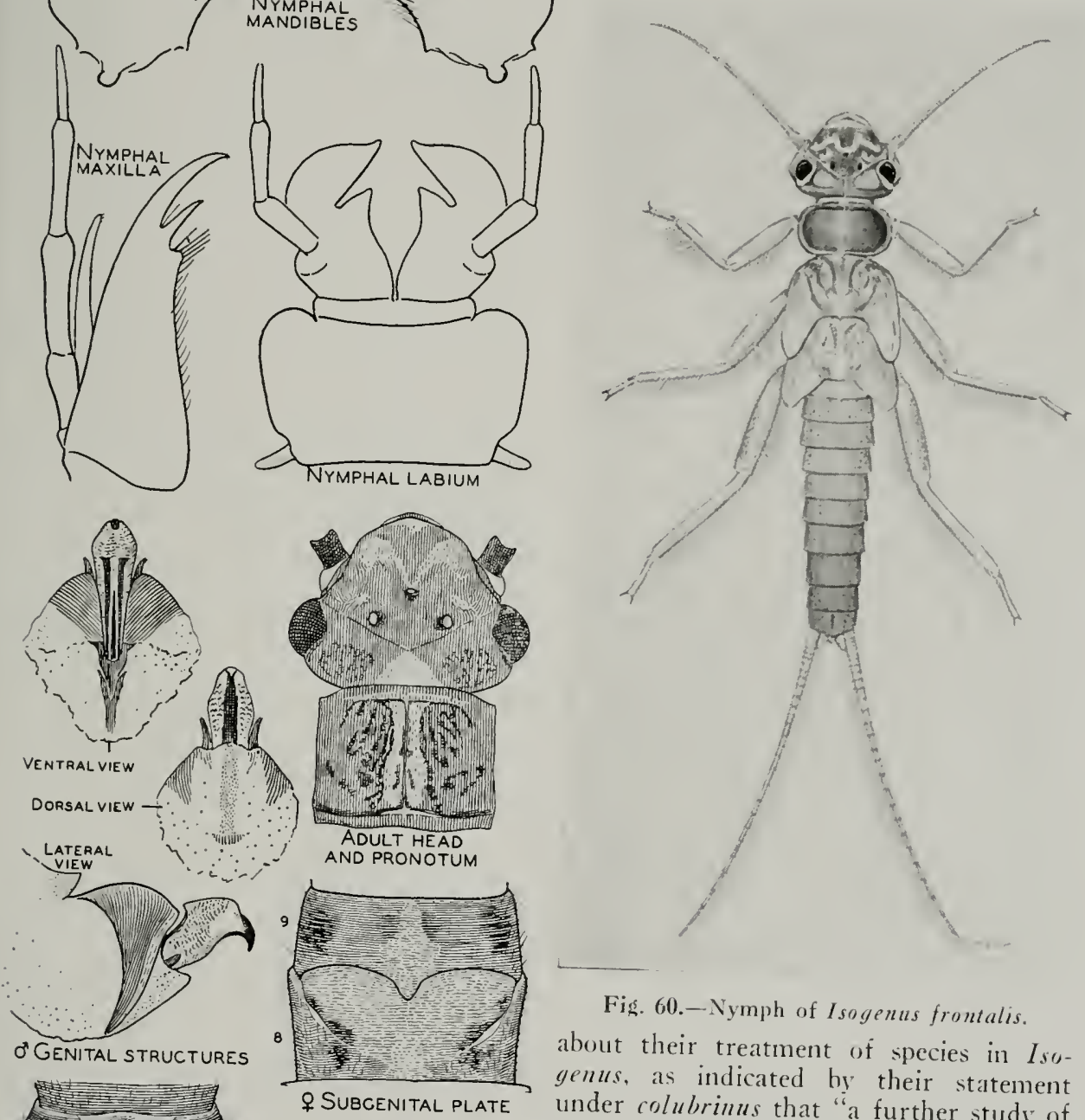

Fig. 60.-Nymph of Isogenus frontalis. about their treatment of species in Isogenus, as indicated by their statement under colubrinus that "a further study of the range of variability of the three preceding may determine that they constitute but one species" (frontalis).

Isogenus elongutus appears to be a valid species. It can be separated from frontalis on the hasis of the shape of the subgenital plate of its female and by the shorter headed supra-anal process of the male. All males which I can definitely assign to elongatus in the Illinois Natural History Survey collection have short wings, and this characteristic is true of all males assigned by Needham \& Claassen (1925) to elongatus.

All the types of Isogenus studied agree Fig. 59.-Isogenus frontalis. in having submental gill remnants and in 
this and other chanacters are closely related to Perlodes and Hydroperla.

"Fo aid with the future identification of adults of froutalis, I wish to present the illustrations in fig. 59 made from specimens reared from nymphs in northern Michigran: head and pronotum; seventh ahdominal sternite of male; dorsal and lateral views of terminal abdominal segments of male; three views of supra-anal process, lateral stylets and enveloping lobes: and the subgenital plate of the female.

Claassen (1931) does not describe the nympl of frontalis but questionably describes a nymph without locality label as "colubrinus (?)." His determination was based upon the fact that the nymph was a mature female about to produce the adult, and certain adult structures were visible. As I stated above, I consider colubrinus a synonym of frontalis. No illustration is given by Claassen of the dorsal view of the nymph, but the mouthparts are figured and agree in general with the mandibles, maxilla and labium, fig. 59, of a nymph, fig. 60 , whose association with frontalis has heen established by rearings. Claassen (1931) failed to note the submental gills, fig. 59, in his verbal description and drawing of the labium, but they are present and are a key, among other characters, to the close relationship of this genus with $H_{y}$ droperla and Perlodes.

Records of frontalis in the Illinois Natural History Survey collection and of specimens determined for others are as follows.

AiBertA.-MAligNe: July 20-21, 1926, F. Neare, 19.

British Columbih.-Big Thompson River: June $13,192 t, 3 \hat{\delta}, 3 \%$. Prince George, Nechaka River: July 13-15, 1938, W. E. Ricker, $1 \delta, 1 \%, 1$ exuria.

Manitoli.1-Churchill: July 9, 1936, H. E. McClure, $2 \hat{o}, 5$.

Micmian.-Pequaming: July 5, 1903, Morgan Hebard, $1 \hat{o}$. Montmorexcy County, Hunt Creek, near iower end of swamp above county road 612: April 1t, 1939, J. W. Leonard, 3 nymphs. GraYtixg, Manistee River near town: May 22, 1936, Frison \& Ross, 3 exuriae. Marquetre County, Yellow Dog River, llear Route M-35: Sept. 6, 1937, J. WT. Leonard, 8 nymphs. LAKE CoUnty, Pine River at Walker Bridge: May 31, 1938, J. W. Leonard, 18 . Montmorency County; Pigeon River, 18 miles east of VANDERBII.T: Oct. 2t, 1934, J. W. Leollard, 2 nymphs. Scilool.cr.AFT County, east branch of Fox River: Aug. 2, 1935, J. W. Leonard, 2 nymphs. Hoxor, Platte River: May 27, 1939, Frison \& Ross, 3 (reared), many exuviae. Nirvasi, San- born Creek: May 28, 1939, Frison \& Ross, t exuviae; Nay 10, 1940, Frison \& Ross, 11 nymphs. Mirfiet.d, Boardman River: May 28, 1939, Frison \& Ross, 1 exuvia. Pere Marquetle River near B.sLDw: Mas 19, 19+0, Frison \& Ross, 1 q and 1 exuvia (reared); May 9-10, 19+0, Frison \& Ross, + nymphs. Baldwis, Pere Marquette River: May 28, 1939, Frison \& Ross, 6 exuviae; May 23, 1940, Frison $d$ Ross, $1 q$ and exuria (reared). Mostmorexcy County, Hunt Creek: Aug. 30-Sept. 3, 19+0, J. W. Leonard, 1 \&.

Minnesota-Hexiepix County: May 11 , 1920, $1 \hat{\delta}$.

NeWfoundiand-West branch UPPER HuMBER River, between falls: July 8, 1938, E. Colohan, 1 \%

Oregon.-Corvallis: Feb. 25, 1934, H. A. Scullen, $1 \delta$; March 1t, 193t, K. Gray, $1 \delta$; March 19, 193t, H. A. Scullen, 1 o , 1 क; March 21, 193t, J. Roaf, 56,19 ; March 13, 1935, Gray \& Edwards, 19 ; March 28, 1933, J. Roaf, $1 \hat{\delta}$. Oregon State College campus, Corvallis: April 5, 1934, N. P. Larson, 19 ; March 28, 1935, J. Schuh, 1 \& ; April 9, 1935, Dimick, 18 ; Agriculture Building, April 10, 1935, 19; April 5, 1936, R. S. Rosenstiel, 1 ; ; April 11, 1935, K. Gray, 1 9 . Granger: April 28, 193t, A. O. Larson, 1 o.

Quebec.-Montre.1l, Lake St. Louis near St. Bernard lsland: June $30,19+1, \mathrm{~N}$. Lalumiere, tô. Laurextides National Park: G. Epaule Lake, Sept. 15-18, 1938, C. Gauthier, 3 nymphs; Noel Lake, Sept. 16, 1938, C. Gauthier, 2 nymphs; Big Rock Lake, July 29 , 1938, Gauthier \& Fournier, 2 nymphs, 2 exuviae.

Wiscoxsin. - Sfooner, Namakagon River: April 29, 1939, Frison \& Burks, $1 \delta, 2$ ㅇ․

\section{Hydroperla subvarians (Banks)}

Perla subzarians Banks (1920, p. 317$)$. Original description, $\delta$, + .

Needham \& Claassen (1925) placed subiarians as a synonym of Perla postica Walker, but in view of Ricker's (1938) notes regarding the type in the British Museum, it seems advisable to use the name subrarians for certain eastern and northeastern specimens of $H_{y} d r o p e r l a$ at least in part called P. postica since 1925. Ricker's statement that the abdomen of the type is missing indicates that postica can never be recognized with certainty on the basis of the typic specimen alone. It is possible, however, that collecting along the MacKenzie River in northwestern Canada may some day provide esoteric information which will establish its identity.

The typic series of subrarians, No. 10.817 , is in the Museum of Comparative Zoology, and consists of hoth males and females. One of the male cotypes bearing the labels "Great Falls, Va., 12-May," 
was relaxed, and the important genital characters studied in alcohol and compared with specimens in the Illinois Natural History Survey collection. It seems desirable to designate this specimen as the lectotype, and a female labeled "Great Falls, Va., 15-l V" as the lectoallotype. A male and a female of the original cotypic series, obtained by exchange, are now in the Survey collection.

Although Needham \& Claassen (1925) described the adult male and female of subiarians (by name of postica IValker), they gave no illustrations of the important abdominal characters. 'Therefore, illustrations of the head and pronotum, the basal segments of the anal cercus, the terminal

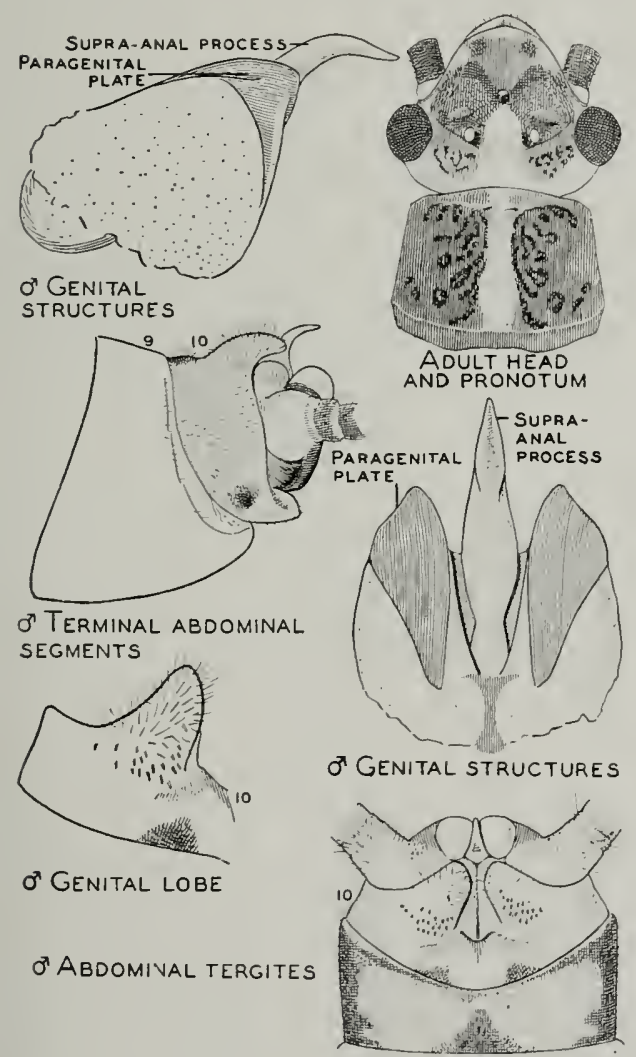

Fig. 61.-Hydroperla subvarians.

abdominal segments, one of the lobes on the tenth tergite, and two views of the supra-anal process and enveloping lobes are presented, figs. 61 and 62 , to aid future workers with the identification of this species. These drawings are based upon a male specimen from Calais, Me., and differ from the lectotype solely in having the extreme tip of the supra-anal process more recurved backwards.

Additional records for this species in the Illinois Natural History Survey collection are as follows.

MaIne.-CALais, St. Croix River: June 11, 1939, P. Jennings, $1 \hat{\jmath}$, 1 ㅇ․

ONTARIo. - Costello Lake, Algonquin Park, Ontario Fisheries $\mathrm{Re}$ search Laboratory: July 3, 1939, Wr. M. Sprules, $1 \hat{\delta}$.

VIRGIN1A.-GREAT FAl.LS: April 10, 1938, B. D. Burks, $1 \hat{o}, 2$ exuviae.

Fig. 62.-Anal cerci of IIydroperla subvarians and 11 . dorata.

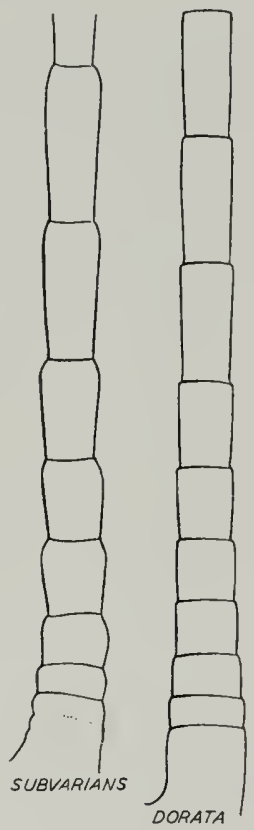

This species differs from z'arians (IValsh), crosbyi (Needham \& Claassen), parallela Frison, harti Frison and dorata Frison, the last described in this article, in lacking lateral stylets (paragenital plates). It differs from nalata Frison, also described in this paper, in the shape of supra-anal process and shape of lobes on tenth abdominal tergite.

\section{Hydroperla nalata new species}

MALE.-General body color black or dark brown with some yellow areas on head, thorax and abdomen. Dorsum of head and pronotum with dark and yellow areas, as in fig. 63. First abdominal tergite in part whitish, second through eighth tergites dominantly black or dark brown, ninth tergite with anterior portion dark and posterior portion vellow, tenth tergite yellow. Legs black or dark brown, with some yellow on middle part of femora. Antennate and anal cerci black or dark brown.

Head wider through compound eyes than width of pronotum; lateral ocelli about as far apart as each is distant from median ocellus, distance from inner margin 
of compound eve to lateral ocellus much shorter than distance between lateral ocelli. Submental gill remnant present.
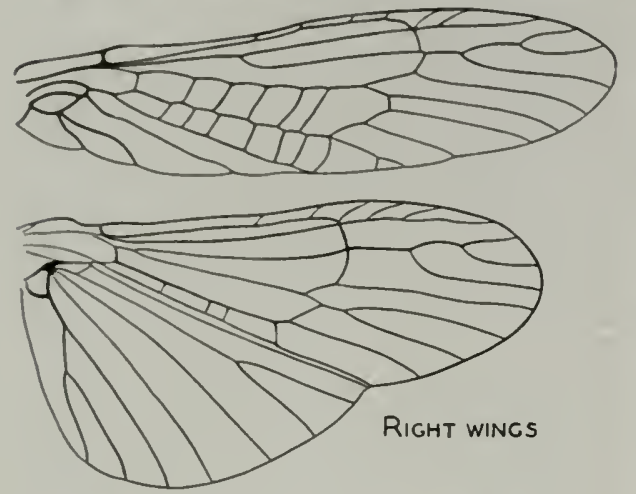

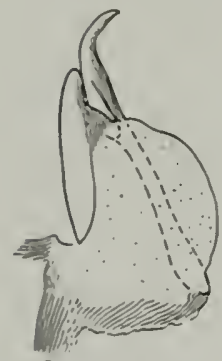

SUPRA-ANAL

PROCESS

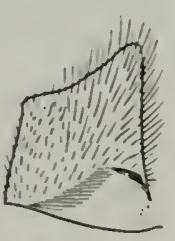

DORSAL LOBE OF TENTH SEGMENT
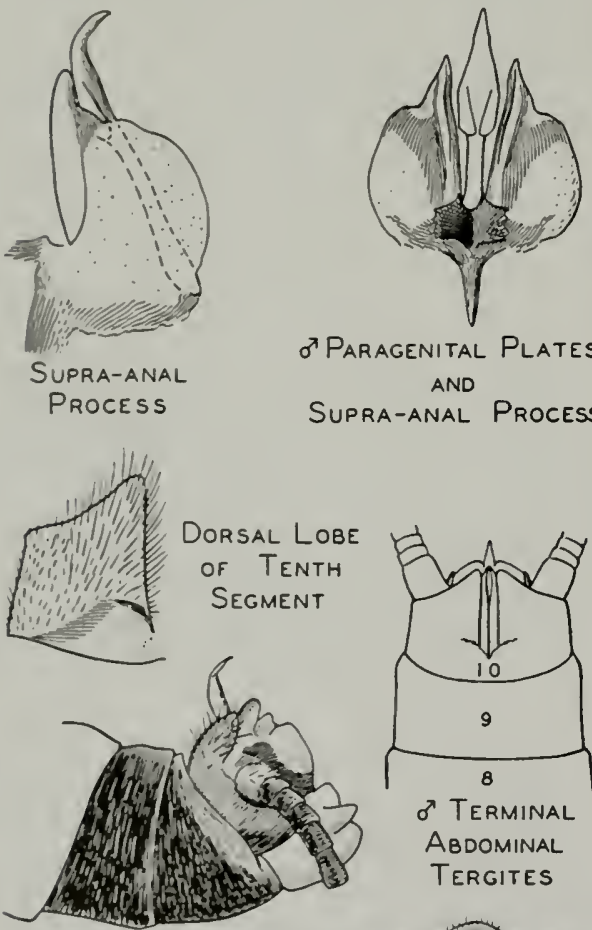

or Paragenital Plates AND

Supra-anal Process

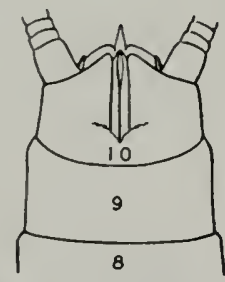

o TERMINAL AbDominal TERGITES o TERMINAL AbDominal SEGMENTS

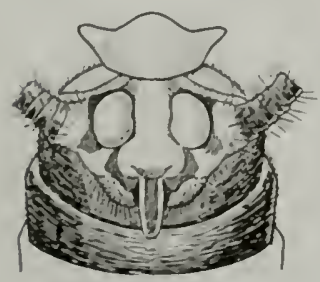

APEX OF O A BDOMEN

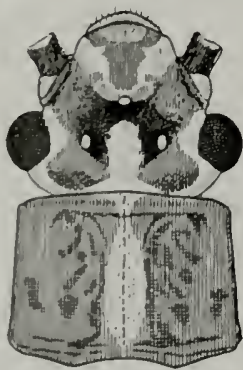

Fig. 63.-IIydroperla nalata.
Pronotum approximately quadrangular. hroader than long, a distinct pattern of raised rugosities on surface each side of yellow, median longitudinal stripe, as shown in fig. 63.

Wings with veins black or dark brown, and membranous interspaces hyaline; venation as in fig. 63.

Abdomen with tenth tergite cleft, the lobes formed by this cleft with sides adjacent to cleft almost parallel so that lobe is broad at base and not thumblike as in some species of the genus; supra-anal

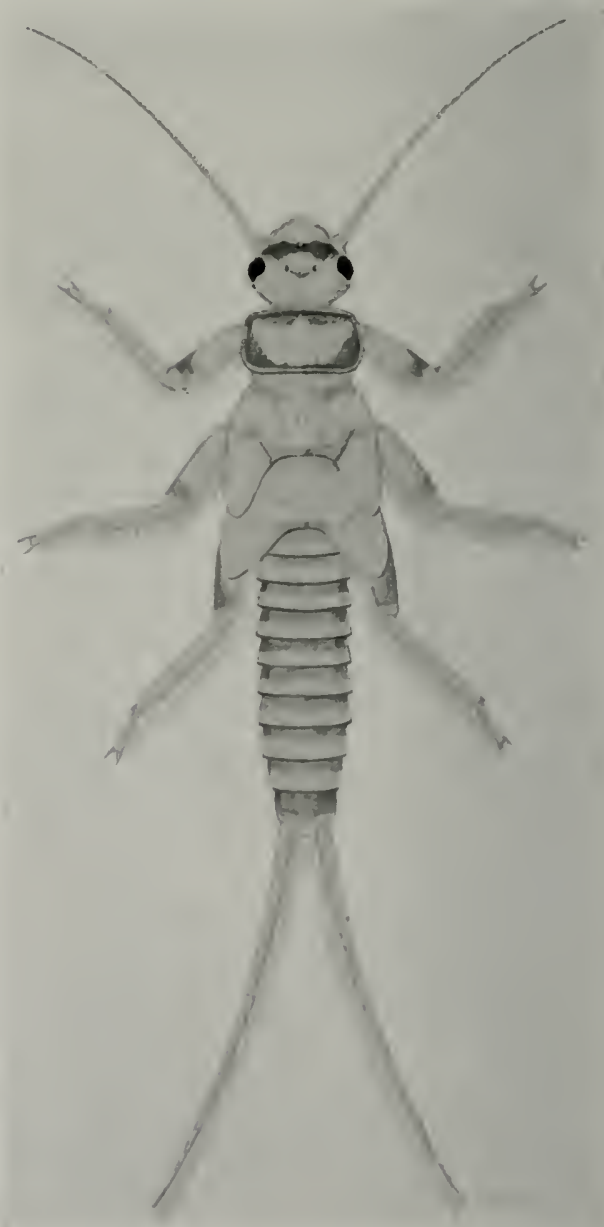

Fig. 64.-Nymph of Ilydroperla nalata.

process tapering to a point which is somewhat recurved backwards at tip, without lateral stylets (paragenital plates) flanking it, and enveloped by two lobes which are partly sclerotized, fig. 63 ; aedeagus as in fig. $6 \dot{3}$. 
Length to tip of wings $17 \mathrm{~mm}$.; length to tip of abdomen $14 \mathrm{~mm}$.

Holotype, male. - WASHTENaW County, Huron River, T25, R5E, Sec. 5, Mich.: May 31,1937, F. E. Lyman.

Paratypes. - Michigan. - Washtenaw County: Same data as for holotype, $6 \hat{o}$.

Nyмph.-General body color yellow with dark brown or black markings, as
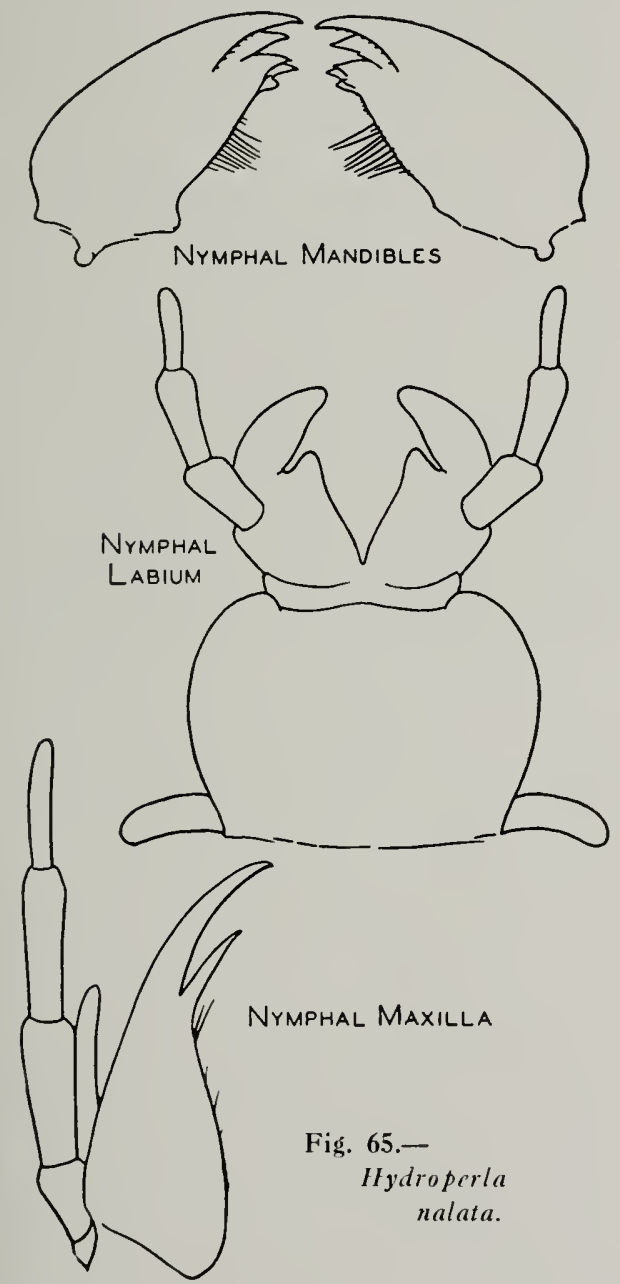

in fig. 64. Thoracic and abdominal gills absent. A small finger-like gill, fig. 65, at each outer posterior corner of submentum. Mandibles, labium and maxillae as in fig. 65. Occipital ridge lacking.

Approximately mature specimens with body length of $18 \mathrm{~mm}$.

Nymphal records: Same locality as for holotype with date records as follows: Jan. 29, 1937,1 nymph; Feb. +20, 1937, 3 nymphs:
April 4-9, 1937, 5 nymphs; May 6, 1937, 3 nymphs; April 10-28, 1938, 6 nymphs.

This species differs from varians (Walsh), crosbyi (Needham S Claassen), parallela Frison, harti Frison and dorata Frison, the last described in this paper, in lacking lateral stylets (paragenital plates). It differs from subiarians (Banks) in shape of supra-anal process and shape of lobes on tenth abdominal tergite.

\section{Hydroperla dorata new species}

MALE.-General features about as in nalata Frison, described in this paper. Head and pronotum with color pattern as in fig. 66. Important distinctive characters are as shown in figs. 62 and 66: Abdomen with tenth tergite cleft, the lobes formed by this cleft with sides adjacent to cleft not parallel and lobes somewhat thumblike; supra-anal process with tip strongly recurved backwards and shaped as in fig. 66; with lateral stylets (paragenital plates) flanking supra-anal process, both enveloped by two lobes which are partly sclerotized. Basal segments of anal cerci as in fig. 62 .

Length to tip of wings $18 \mathrm{~mm}$; length to tip of abdomen $16 \mathrm{~mm}$.

Female.-Head, thorax, basal abdominal segments and appendages in general similar to those of male but slightly larger in size. Important differences are as follows: eighth abdominal sternite with posterior portion forming a subgenital plate shaped as in fig. 66.

Holotype, male.-Near Baldwin, Pere Marquette River, Mich.: May 10, 1940, reared from nymph, T. H. Frison \& H. H. Ross.

Allotype, female.-Same data as for holotype.

Paratypes. - Michigan. - Near Baldwin: same data as for holotype, $1 \hat{o}$; same data as for holotype except not reared, 1 ㅇ.

PENNSYLVAN1A.-ANALOMINK, Brodhead Creek: April 15, 1939, 1 o ; April 23, 1939, $1 \delta, 19$; April 27, 1940, $1 \hat{\delta}$; all P. Jennings.

New York.-Mount Marcy: June 29, 19+0, H. Dietrich, $1 \hat{0}$. Phoenecia: May 5, 19+0, P. Jennings, $2 \hat{o}$. Schoharie: April 28, 1938, $1 \hat{\jmath}$.

NYmph (description based upon exuvia).-General body color yellow with dark brown on black markings as in fig. 67. Thoracic and abdominal gills lacking. A small finger-like gill at each outer posterior corner of submentum. Mandibles. labium and maxillae as in fig. 66. Occipital ridge lacking. 
Mature specimens with body length of approximately $21 \mathrm{~mm}$.

Nimphal and exuvial records: Near B.u.Dwis, Pere Marquette River, Mich., May 9-10, 1940, T. H. Frison \& H. H. Koss, 17 exuviae: 1 nyinph ready to produce adult, in poor con-

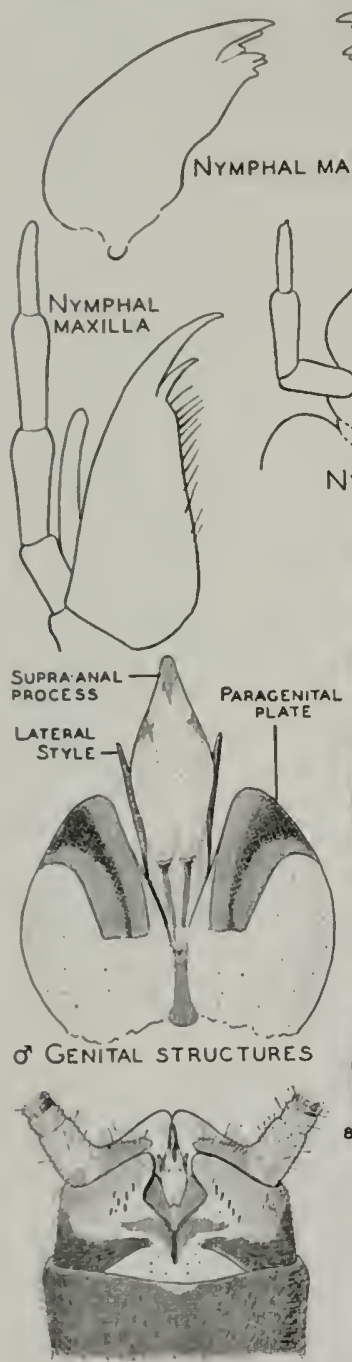

O"ABDOMINAL TERGITES
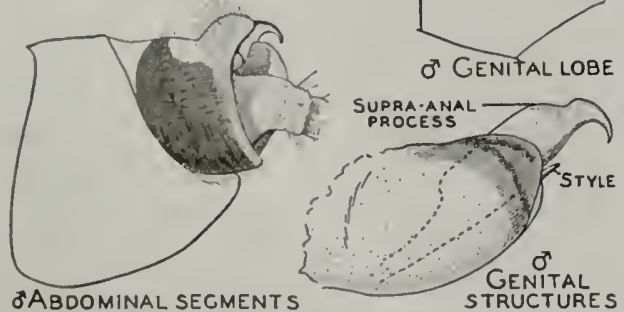

Fig. 66.-Hydroperla dorata.

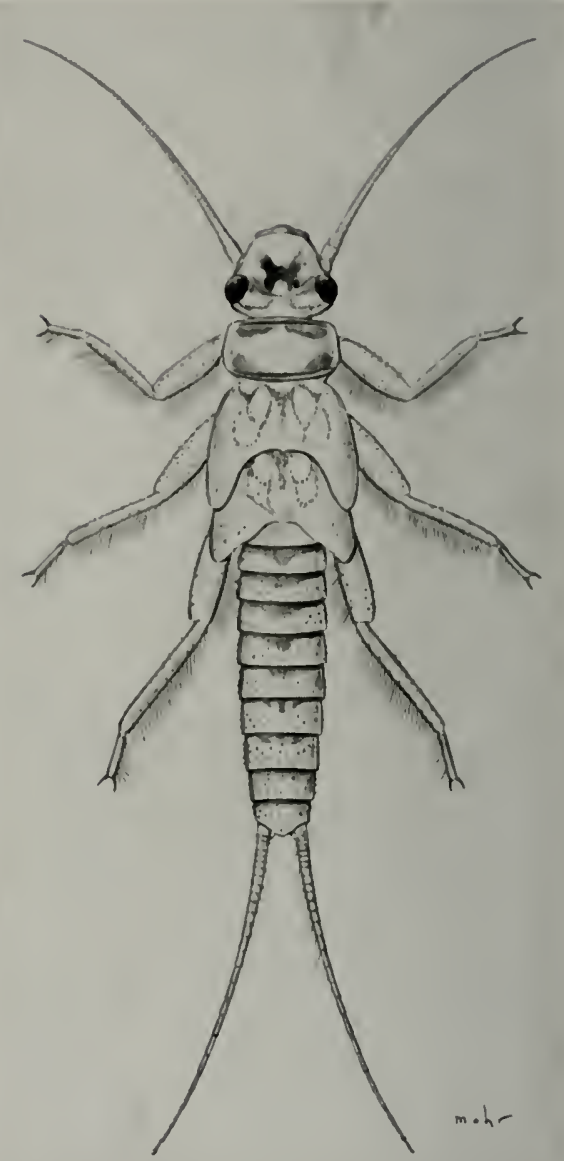

Fig. 67.-Nymph of IIydroperla dorata.

dition, taken in spider web, otherwise with same data as for exuviae.

This species differs from subvarians (Banks) and nalata Frison by having lateral stylets (paragenital plates). It differs from zarians (Walsh), crosbyi (Needham \& Claassen), parallela Frison and harti Frison in the shape of the supra-anal process and lobes formed by cleft tenth abdominal tergite. The nymph has a color pattern distinct from that of the nymphs of crosby $i$ and harti as illustrated by me $(1935 a)$, and from that of varians as illustrated by me (1937).

\section{Hydroperla olivacea (Walker)}

Perla olivacea Walker (1852, p. 144). Original description, $\hat{o}$.

Perla olivacea Ricker (1938, p. 142). Description of $q$. 
Hydroperla olizacea has rarely been recorded in literature, except in catalogs, since its original description and it was cntirely omitted by Needham \& Claassen (1925) in their Monograph. Walker's (1852) description was based upon a specimen from "St. Martin's Falls, Albany River, Hudson's Bay." Klapálek (1912) gave notes and an illustration of Walker's type in the British Museum. More recently Ricker (1938) redescribed and figured the typic male; in addition he described a female associated with the typic male as the "Neo-allotype," and recorded an additional male specimen from "Hudson's Bai, 1881," in the collection of the Vienna Museum.

In June, 1936, Dr. H. H. Ross and I collected at the Namakagon River, near Spooner, Wis., a single cast skin of a nymph easily distinguished from all other known North American stonefly nymphs by virtue of a peculiar curled process at apex of abdomen. In 1939, exuvial specimens of this same species were found at three places in northern Michigan; which suggested that an earlier trip the next year might result in the capture of adults. Accordingly, a trip to northern Michigan was made May 9-12, 1940, with the result that numerous exuviae, one dead adult male in a spider web, one dead adult male partially emerged from nymphal skin in a spider web and one perfect live specimen of a male adult were collected.

Previous to the collection of adult specimens in 1940, Ricker's (1938) illustration of the type of olivacea suggested that my exuviae with unique apical abdominal processes might be the cast skins of that species, since the adult male of olizacea has a most extraordinarily long supra-anal process. Finding adult males of olizacea in spider webs under bridges where exuviae were plentiful, and beating a fresh live male specimen from a bush where exuviae were present, afford sufficient evidence with such unique adults and nymphs to associate them definitely as the same species. Ricker's illustration of the typic male of oliracea is sufficient, too, to enable me to assign without question my northern Michigan specimens to the species olizacea. In many respects the stoneAy fauna of northern Michigan is similar to that of Ontario, Canada. As a further aid to the future recognition of this spe- cies, an illustration showing the color pattern of the dorsum of the head and thorax, and important structural features of the male, fig. 68 , is presented.

Based upon exuviae and one shriveled nymph found dead in a spider web beneath a bridge, the following description of the heretofore unknown nymph of olizacea is presented.

NYMPH. - General color yellowish brown with black or fuscous areas as in fig. 69 ; particularly noticeable are the dark transverse bands on the anterior and posterior margins of the abdominal tergites, the bands on the anterior margins broadest.

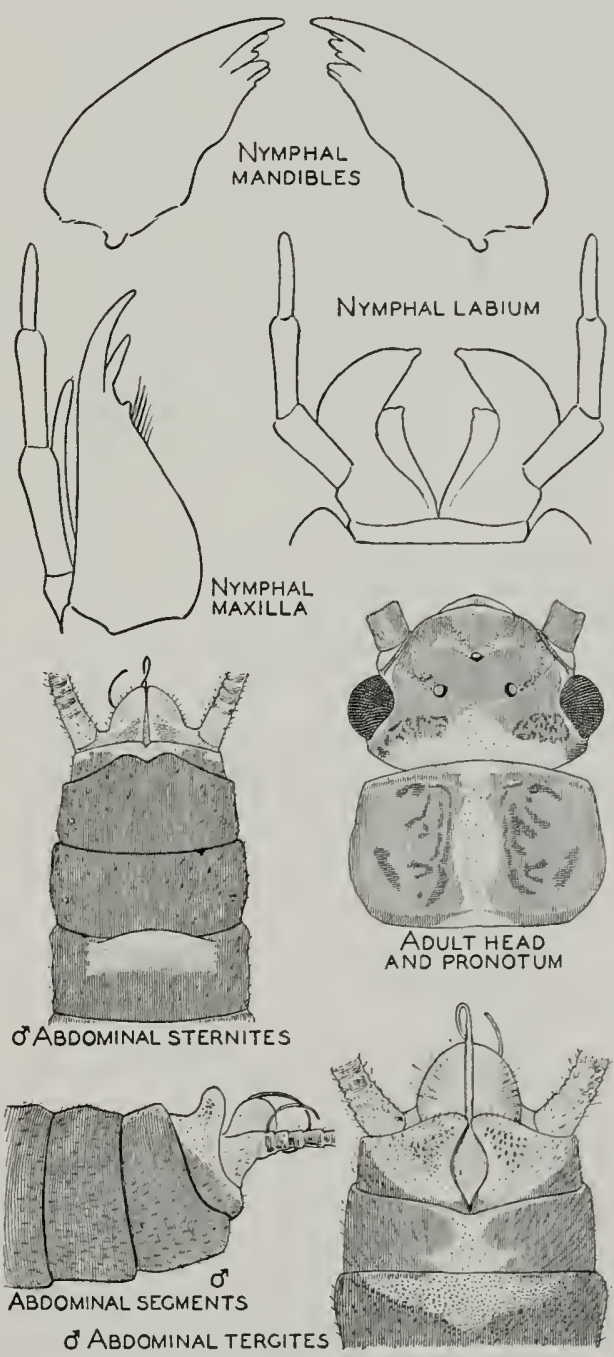

Fig. 68.-Hydroperla olivacea. 
Labium, maxillae and mandibles as in tig. $6 \$$.

Dorsum of abdonen terminating in a coiled tubular projection not heretofore

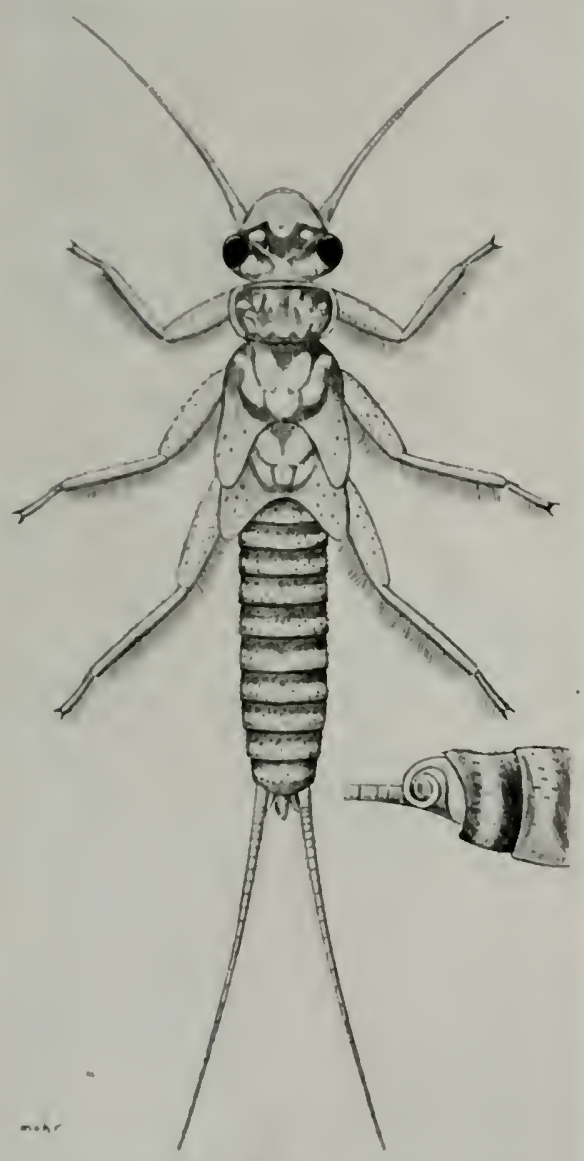

Fig. 69.-Nymph of Ilydroperla olizacea.

ubserved in any other described stonefly nymph, fig. 69.

No thoracic or anal gills; submental gills present as in all $H_{y} d r o p e r l a$.

Approximate body length of mature nymph $15 \mathrm{~mm}$.

Records of this species are as follows.

Miciligan.-Babdis, Pere Marquette River: May 28, 1939, + exuviae, and May 9-10, 1940,19 exuviae, 1 tnymp, 16 adult, T. H. Frison \& H. H. Ross. Howor, Platte River: May 27, 1939, 14 exuviae, and May 10, 1940, 22 exuriae, 1 partially emerged adult, T. H. Frison \& H. H. Ross. NiRvanA, Sanborn Creek: May 28, 1939, T. H. Frison \& H. H. Ross, 5 exuviae. PEAcock, Litle Manistee River: May
10, 1940, T. 11. Frisou \& H. H. Ross, 10 exuviae. Nalma Juscrion, Sturgeon River: May $12,19+0,8$ exuviae, $1 \hat{o}$ adult, 'T. H. Frison ¿ H. H. Ross. Like Coustr, Pine River Station 4: May 16, 1938, O. H. Clark, 1 ó adult.

Wisconsis: - SPOONER, Namakagon River: Jume 5-6, 1936, T. H. Frison \& H. H. Ross, 1 ó exuvia.

\section{Hydroperla parallela Frison}

IIydroperla parallela Frison (1936, p. 261). Original description, $\hat{o}$.

IIydroperla parallela Frison (1937, p. 90). Description, $ᄋ$.

Hydroperla parallela Ricker (1939, p. 23). Additional British Columbia records.

Since my original description of the male (1936), and subsequent description of the female (1937), I have examined nymphal specimens which I an certain are parallela, and the following description is presented.

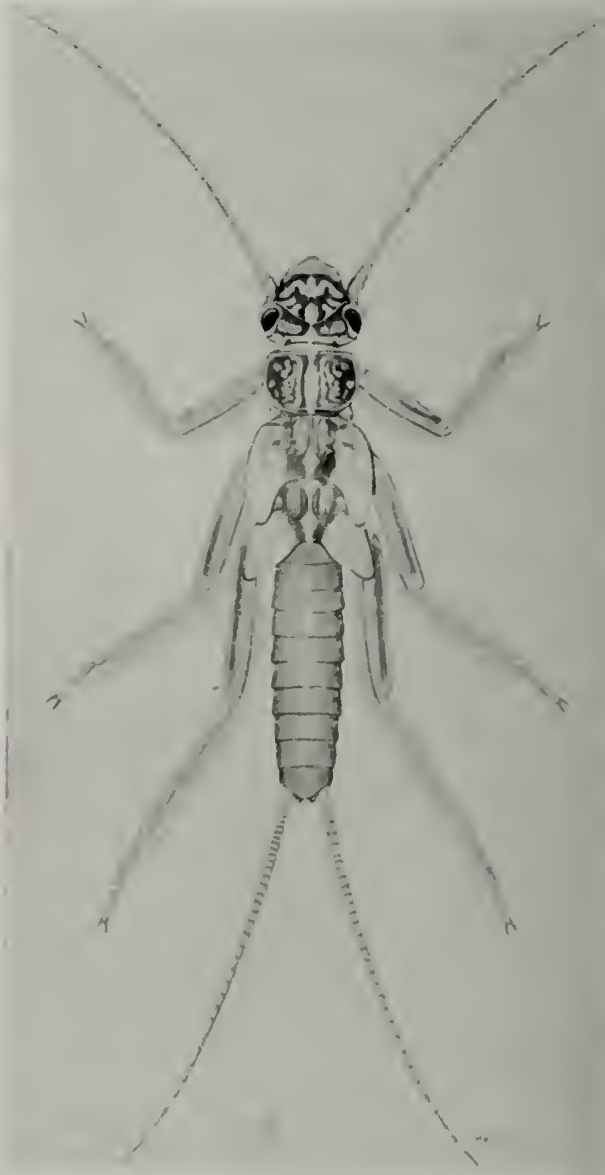

Fig. 70.-Nymph of IIydroperla parallela. 
NympH.-General color of head, thorax and abdomen brownish with paler spots and intersegmental areas as in fig. 70. Antennae, legs and anal cerci yellowish brown.

Head with three ocelli forming a nearly equilateral triangle, each lateral ocellus about as far apart as each is distant from

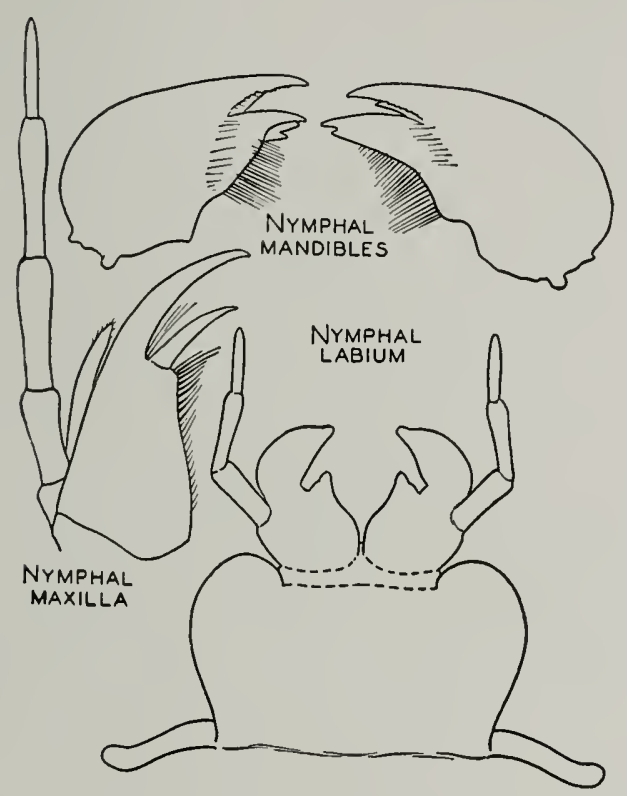

Fig. 71.-Hydroperla parallela.

inner edge of compound eye. A partial occipital ridge, interrupted in middle, accentuates posterior margin of each conspicuous eyelike spot adjacent to and between compound eyes and borders hind margin of compound eye. Labium, maxillae and mandibles as in fig. 71.

Pronotum about two-thirds as long as broad, all angles well rounded. Legs slender, not greatly flattened.

Abdominal tergites well covered with numerous conspicuous, short, stout setae. Cerci long, many segmented, segments progressively longer from base to apex, a longitudinal row of long, fine setae on dorsal surface in addition to smaller ones encircling segments.

Approximately mature specimens with a body length, exclusive of appendages, of about $23 \mathrm{~mm}$.

A finger-like submental gill at each outer posterior corner of submentum, fig. 71 ; thoracic and abdominal gills entirely lacking.
Nymphal and exuvial records are as follows.

British Columbia.-North of Ruskin, Stave Lake Dam: April 15, 1938, W. E. Ricker, 1 nymph, 2 exuviae. Cultus LAKE, Chilliwack River: April 26-27, 1937, W. E. Ricker, 2 nymphs. SARDIS, Vedder River: July 23, 1936, H. H. Ross, many exuviae.

IDAHO.-South central part of state: 1938,

L. H. Smith, 1 nymph.

Oregon.-Corvallis, Marks Creek: Feb. 26, 1938, B. White, 1 nymph. MCKenzie River: March 9, 1939, J. E. D., 1 exuvia.

WASHington.-Green and CeDAR RIVERS: April 1, 1939, L. Lambuth, 2 nymphs.

New adult records are as follows.

British Columbia.-Cultus Lake, Chilliwack River: May 9, 1937, W. E. Ricker, $4 \hat{\delta}$.

Oregon. - Mulitnomah Falis, Multnomah County: April 8, 1939, S. G. Jewett, Jr., $19 \hat{\text {, }}$ 3 q. Portland, Multnomah County: March 17, 1939, S. G. Jewett, Jr., 1 f . Clatsop County, Herman Creek, tributary of Mecanicum River, 6 miles south of SEAside: Feb. 18, 1939, S. G. Jewett, Jr., $2 \hat{\delta}$. Clackamas CounTY: Molalla River, Feb. 23, 1939, Rock Creek, tributary of Clackamas River, Feb. 20, 1939, and Wildcat Creek, tributary of Sandy River, March 31, 1939, S. G. Jewett, $1 \hat{\delta}, 2$ q. ColumBIA COUNTY: south of north fork of Scappoose Creek, Feb. 17, 1939, and Gnat Creek, Feb. 19,1939 , S. G. Jewett, Jr., $3 \hat{o}, 1$ ㅇ. ST Helens, Milton Creek, Columbia County: Feb. 19, 1939, S. G. Jewett, Jr. 1 ô. Herman, Oregon National Forest, 700 feet altitude: April 18, 1920, A. C. Burrill, $1 \hat{\delta}, 1$. .

Utah.-Logan Canyon: April 23, 1938, R. E. Nye, 1 ㅇ.

\section{Dictyopterygella knowltoni Frison}

Dictyopterygella knoweltoni Frison (1937, p. 89). Original description, $\hat{\delta}$.

The original description of knowltomi was based upon a single holotypic male from Logan, Utah. Since then I have examined additional males and recognized the females. A brief description of the heretofore undescribed female follows.

FeMale.-Similar in most morphological characters to the male (Frison 1937). Chief distinguishing characters are as follows: Subgenital plate, fig. 72, somewhat protruding over ninth sternite and inset on eighth sternite; baso-ventral, subanal plates heavily sclerotized, projecting backwards along median cleft where right and left plates meet to form a short, blunt lobe suggesting more modified subanal lobe projection in male; length $33 \mathrm{~mm}$. to tip of wings and $20 \mathrm{~mm}$. to tip of abdomen.

Allotype, female-Logan Canyon, Utah: April 23, 1938, R. E. Nye. Taken at same time and place as male of this species. 
Records for this species which have accumulated since the original description, in addition (1) those for the allotype, are as follows.

Colorido. - Estrs, Mill Creek: Jume 11, $1937,16,1$.

Oregos:-Ochoco CreEK: May 3, 1939, 1 \&.

['TAH.-Bic, Cottonwoons CANion: Apri] 24, 1937, G. F. Knowlton \& F. C. Harmston, 18. Logas Cisyon: June 18, 1937, Knowlwn \& Nye, 1 \&; April 23, 1938, W. P. Nye, 10,1 \% April 19, 19+0, R. E. Nye, $1 \delta, 1$ ․ East of DANiEls: June +1940 , Knowlton $\&$ Vansell, 19.

'The above specimens confirm the statement made when the type, a specimen relaved from a pin mount, was described, that the submental gill as it occurs in Hydroperla and Perlodes is lacking. However, there is a slight trace of a nipplelike projection at each outer posterior corner of the submentum suggestive of an atrophied submental gill. A similar situation is found in the case of Diploperla hastata (Banks) from eastern North Anerica and other species of Diploperla. I now believe that the genus Dictyopterygella, including knowltoni, should be placed in the family Perlodidae, which is

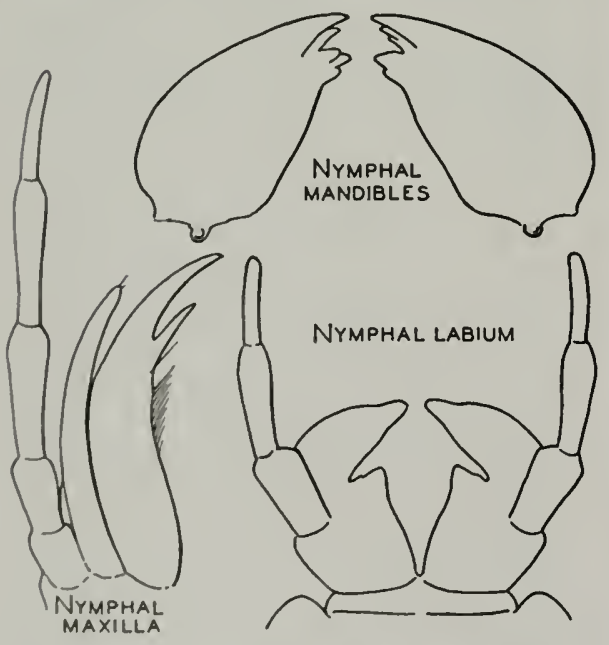

\& Subgenital Plate

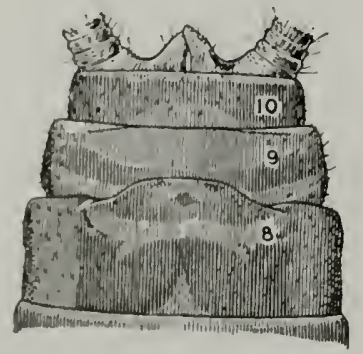

Fig. 72.-Dictyopterygella knowltoni. the family where this genus has been placed by recent European authors.

'The thoracic cervical sternites of knowltomi, and various species of Perlodes,

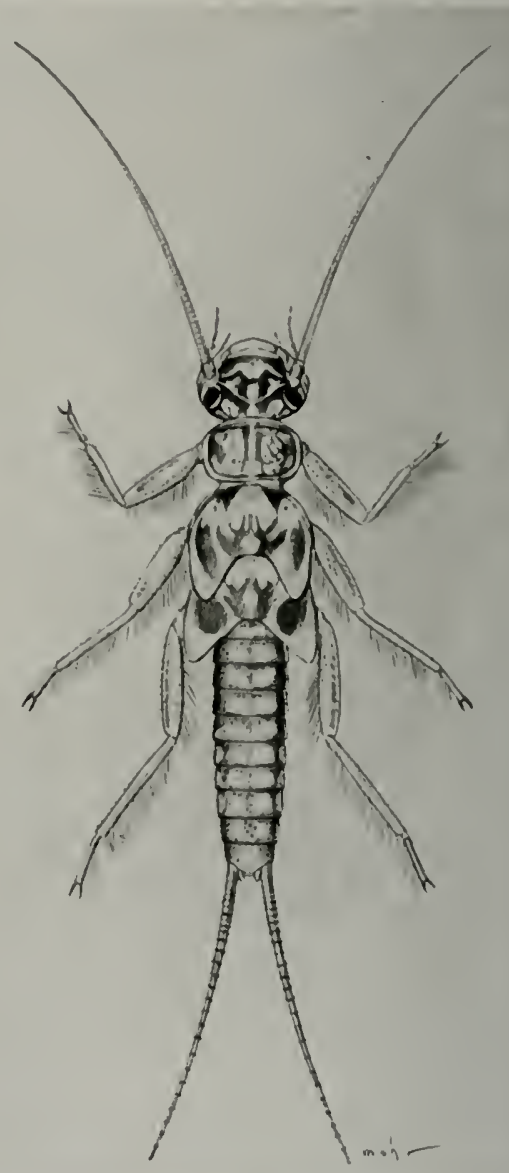

Fig. 73.-Nymph of Dictyopterygella knowltoni.

Hydroperla and Perla, possess weakly sclerotized folds or bulbous areas which probably play a part in respiration.

In the original description of the male of knowltomi (Frison 1937), an error occurs in regard to comparative lengths of tarsal segments. 'This statement should read: first and second tarsal segments together about one-half as long as third, first tarsal segment longer than the second.

Among a lot of stonefly specimens lent to Dr. IV. E. Ricker by the Canadian National Collection, Ottawa, Canada, and subsequently sent me for examination, are nymphs, adult females and an exuvia 
from British Columbia which certainly belong to the genus Dictyopterygella. Since the only known western species of this genus is knowltoni, and since I am unable to separate these British Columbian females from ones here considered and described as the species knowltoni, I am identifying these specimens as of this species. The description of this previously unknown nymph follows.

NyMPH. - General color yellowish brown with black or fuscous areas as in fig. 73; labium, maxillae and mandibles as in fig. 72 ; bases of maxillae somewhat extending out from sides of head and visible from above; subanal lobes prominent; no thoracic or anal gills; no distinct submental gills present but at the point where such gills are present in Hydroperla or Isogenus there is a small, nipple-like protuberance. Approximate length of mature nymph $18 \mathrm{~mm}$.

The nymphs upon which this description is based were collected at "Shingle Creek, Penticton, British Columbia, April 19, 1935, A. N. G.," and are associated with two adult females from the same place collected on April 19, 1935, together with one adult female reared from nymph on May 1, 1935, and associated with its exuvia.

lt is interesting to note that the first description of a nymph of Dictyopterygella, for the British species of bicaudata (Linnaeus), has only recently been published by Hynes (19+1). The nymph of knowltoni agrees very closely with the nymph of bicaudata as described and figured by Hynes.

\section{Diploperla Needham \& Claassen}

Diploperla Needham \& Claassen (1925, p. 286). New subgenus.

In my paper on the Stoneflies, or Plecoptera, of Illinois (1935a), I found it desirable to remove the genera Perlodes and Isogenus, and several species for which I proposed the generic name of $H_{y}$ droper$l a$, from the family Perlidae and to place them in the family Perlodidae. This left a residue of North American species in the genus Perla (in the sense of Needham \& Claassen 1925) which represented several distinct complexes of species, subgenera or genera. The problem of the correct use of the generic name of Perla and the status of certain North American genera were not considered further in my 1935 paper because that paper was primarily a study of the Illinois species, not a monograph of the North American species.

The description in this paper of new species of stoneflies from various parts of North America has now forced me to decide upon the use of certain generic names previously dodged. In my $1935 a$ paper, I wrote, "Although Needham and Claassen (1925) have placed several species of Perla (in the broad sense as used by them) in the subgenus Perla Geoffroy (s. str.) it is even doubtful whether the true Perla in the restricted sense as used by Klapálek (1923a) occurs in North America." To get further data regarding the status of Perla I wrote in 1936 to Mr. D. E. Kimmons of the British Museum requesting information about the genotype of Perla Geoffroy and its taxonomic characters. Mr. Kimmons' reply confirmed my previous suspicions and also added additional complicating data. Brief$\mathrm{l}$, his report indicated (1) that the genotype of Perla Geoffroy is Pliryganea bicaudata Linnaeus and not Perla bipunctata Pictet as selected by Klapálek (1923a) or Perla maxima (Scopoli) as stated by Needham \& Claassen (1925), and (2) that the name Perla probably should be associated with species now placed under another genus and family of stoneflies. Since this is a nomenclatorial problem primarily of concern to European entomologists, I am not assuming to settle the points involved at this time.

However, in view of the probably erroneous use of the generic name of Perla in European literature and the certainty that most, if not all, North American species placed in Perla in the past are not congeneric with the type of Perla, it is unwise to continue to describe new North American species under the generic name of Perla.

Needham \& Claassen (1925) listed 27 species under the genus Perla in their tabulation of the North American stoneflies. Since then the number of species left standing unchallenged in Perla (sense of Needham \& Claassen) has been reduced as follows: (1) a special genus Claassenia $\mathrm{Wu}(193+)$ has been erected for languida (Needham \& Claassen) notwithstanding that among the North American 
species languida is morphologically perhaps the closest representative of the genus Perla is now-but probably erroneouslyused in liurone (sense of Klapálek 1923a); (2) the recognition of Togoperla and Neophasganophora as valid North American genera (Frison 1935a) removed immargimata (Sily), media (Walker) and capitat (Pictet) from the list; (3) the erection of the genus $H_{y}$ droperla (Frison 1935a) removed the names of crosbyi (Needham \& Claassen) and rarians (Walsh); (t) the placement (Frison 1935a) of duplicata (Banks) in the genus Isoperla; and (5) the placement of kansensis (Banks) in Togoperla (Frison 1937 ) removed an additional species.

In this paper the list is further reduced as follows: (1) Perla sabulosa Banks is placed in the genus Acroneurin, and $A$. depressa Needham \& Claassen is shown to be a synonym of it; (2) Perla postica Walker is considered to be unrecognizable at present and subrarians (Banks), belonging to the genus $H_{y} d r o p e r l a$, is the name to he associated with some at least of the Needham \& Claassen records given under the name postica.

It is quite evident from my studies to date that the species now left in Perla, some of which may later fall in synonymy, constitute several complexes or species groups, represented by such divergent forms as modesta Banks, luctuosa Banks and bilobata Needham \& Claassen. It is highly probable also that one or two of these species will in the future be shifted to such genera as Isoperla or Hydroperla, since their generic relationships are somewhat obscured now because of the poor condition of the types and the lack of other material which can be definitely associated with these names. Until these species are better known, however, it seems advisable t) record them all under a single generic name.

In view of the fact that it now seems unwise to use the generic name of Perla for these species, and for the two new species described in this article, the problem of selecting at generic name is presented. It is now my belief that the species duplicata placed by Banks in Perla should not be included in Isoperla, as I proposed in 1935, and that it is more closely related to the species group represented by modesul Banks. This realignment of duplicata with such species as modesta, and my present belief that the species now under discussion should be grouped as a unit until they are better known, make possible the use of the name Diploperla Needham \& Claassen (1925) for these species, since Diploperla was proposed for the species duplicata and bilobata. 'This action is advantageous in that it makes possible the use of a name already in literature and removes the controversial name of Perla.

Therefore, until additional information warrants other generic treatment, I propose to group under the generic name of Diploperla Needham \& Claassen (s.l.) the species described under the following names: Perla imnubila Needham \& Claassen, Perla alameda N. \& C., Perla expansa Banks, Isogenus hastatus Banks, Perla fugitans N. \& C., Perla nona N. \& C., Perla aestizialis N. \& C., Perla modesta Banks, Perla verticalis Banks, Perla tinctata Claassen (nom. nov. for tincta N. \& C.), Perla sorpta N. \& C., Dictyogenus? phaleratus Smith, Perla misnoma Clsn. (nom. noz. for obscura N. \& C.), Perla errata Clsn. (nom. noz'. for z'enosa N. \& C.), Perla bilobata N. \& C., Perla duplicata Banks, Perla luctuosa Banks and Perla ramosa $\mathrm{N}$. \& C. I am also assigning to this genus three new species described in this article.

Since Needham \& Claassen (1925) did not select a genotype for Diploperla, I designate the species hitherto known as Perla bilobata Needham \& Claassen as the genotype because it is one of the two originally included species.

The proper family placing of this genus has many puzzling aspects. The cleft tenth abdominal tergite, supra-anal process and associated structures in the male, as well as the wing venation and other features of both sexes, suggest a close relationship with $H_{y} d r o p e r l a . ~ L a c k$ of distinct submental gills is annoying from the standpoint of a family key character, but there is a suggestion of these submental gills in the small nipple-like protuberance where a long submental gill is present in other genera of this family.

\section{Diploperla bilobata \\ (Needham \& Claassen)}

Perla bilobata Needham \& Claassen (1925, p. 95). Original description, $\delta, q$. 
Perla bilobata Claassen (1931, p. 54). Nymphal description.

Claassen's (1931) description of the nymph of this species was based upon nymphal skins from "Old Forge, New York," and, although the mouthparts were illustrated, no illustration of the entire nymph was presented.

During the course of field work near Gatlinburg, Tenn., in 1930, numerous nymphs of this species were collected and both males and females reared. Since no illustration of this nymph exists in literature, fig. $7 t$ is presented. The unusual

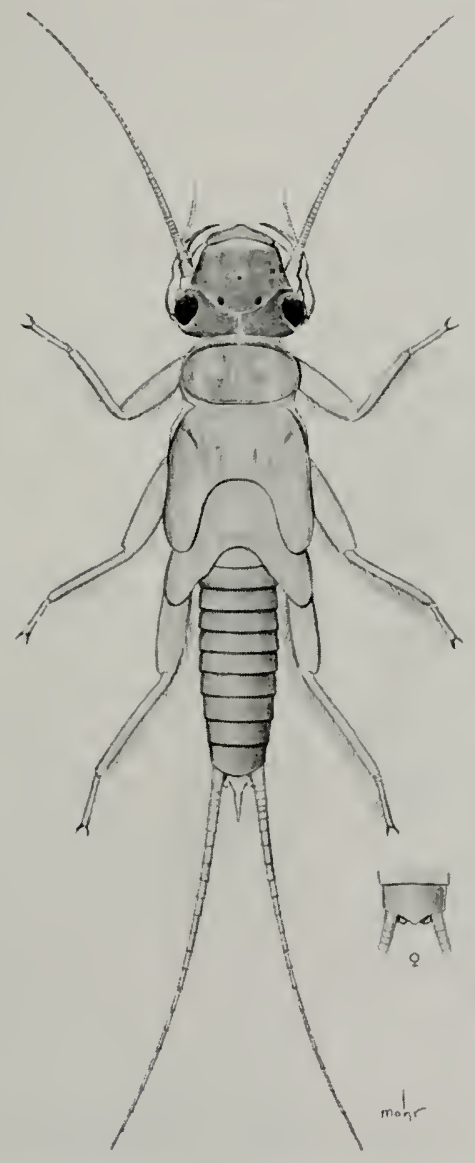

Fig. 74.-Nymph of Diploperla bilobata.

appendage at the end of the abdomen in the nymphal male, lacking in the female, was not noted by Claassen in his description. The mouthparts of the nymph are as in fig. 75 .

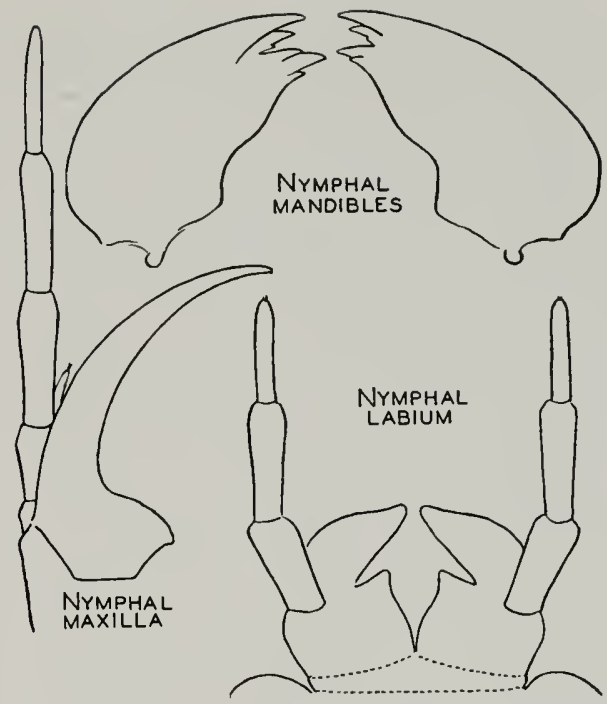

Fig. 75.-Diploperla bilobata.

Records for this species in the Illinois Natural History Survey collection are as follows.

Tennessee.-Great Smoky Mountains $\mathrm{Na}$ tional Park, Gatlinburg: June 1t, 1940, Frison et al., 2 , 1 exuvia, + nymphs; June 17, 1940, Frison et al., 1 \% ; June 18, 1940, Frison $c t$ al., 1 의 with exuvia (reared); June 19, 1940, Frison et al., 2 क with exuviae (reared), $1 \delta$; June 20, 1940, Frison et al., 1 ㅇ with exuvia (reared); June 21, 1940, Frison et al., 1 i with exuvia (reared); June 2t, 1940, Frison et al., 1 ㅇ with exuvia (reared), 2 q ; Le Conte Creek, May 14, 1939 , Frison \& Ross, 7 nymphs; Le Conte Creek, June 14, 1940, Frison et al., 20, 49 ; Cades Cove, June 13, 1940, Frison ot al., 1 ㅇ with exuvia and $1 \hat{\delta}$ with exuvia (reared), many nymphs; Fighting Creek Gap, May 15, 1939 , Frison \& Ross, 1 nymph.

North Carolina.-Smokemont, Oconaluftee Creek: May 28, 1934, T. H. Frison, 1 nymph. Macon Countr: Big Creek above Lake Randall, June 20, 1939, Thelma Howell, 1 nymph; Nantahala River, May 30, 1939, Thelma Howell, 1 nymph. BALsaM: April 24, 1938, Ross \& Burks, 9 nymphs.

\section{Diploperla modesta (Banks)}

Perla modesta Banks (1908a, p. 255). Original description, $\hat{\delta}, \hat{q}$.

It was my good fortune in August, 19+0, while in Wyoming, to rear several male and female specimens of modesta and thus definitely associate the nymph of this species with its adult. Since the nymph has not been previously described or illustrated, at least under the name modesta, I am presenting the following description. 
Nrupu.-General color yellow or yellowish brown with darker areas on head, thorax and abdomen, as in fig. 76. Antennae, legs and anal cerci mostly yellowish.

Head with three ocelli forming an almost equilateral triangle, the lateral ocelli about as far apart as each is distant from inner edge of compound eye; no occipital ridge; hasal segments of mouthparts conpicuously extending far out laterally from the side of head so that head appears much broader than thorax. Labium, maxillae and mandibles as in fig. 77 .

Pronotum much broader than long; margins darkly bordered and central areat light colored, rugosities very faint.

Abdominal tergites mostly yellowish with dark transverse markings on anterior and posterior margins, fig. 76; tergites with scattered, short, stout setae. Cerci

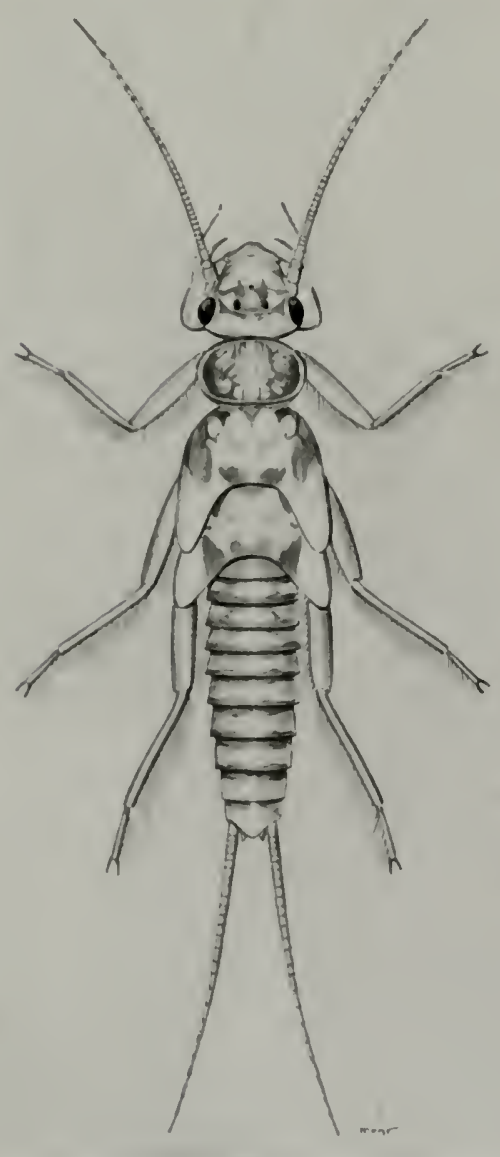

Fin. 76. -Nymph of Diploperla modesta. long, many segmented, segments progressively longer from base to apex, a longitudinal row of long, fine setae on dorsal

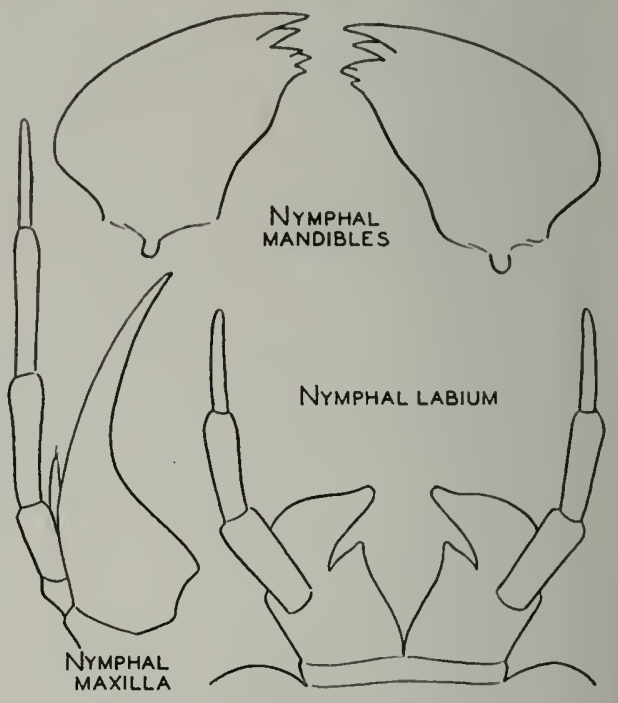

Fig. 77.-Diploperla modesta.

surface in addition to short, stout setae encircling apex of each segment.

Approximately mature specimens with a body length, exclusive of appendages, of $16 \mathrm{~mm}$.

A small nipple-like projection at each outer posterior corner of the submentum suggestive of an atrophied submental gill.

Since there are only a few records of this species in the literature, I present the following.

Colorado. - Pingree Park: Aug. 15-22, 1924, Drake \& Hottes, 19 . Rocky Mountain National. Park, Fall River and Glacier Creek: Aug. 15-17, 19+0, T. H. Frison \& T. H. Frison, Jr., $2 \delta, 3$ क (reared), 1 nymph, exuviae.

IDAHo.-Victor, Moose Creek: Aug. 12, 19+0, T. H. Frison \& T. H. Frison, Jr., $1 \hat{\text { ô, }}$ 19,4 exuviae.

Montana.-Saltese: July 9, 1936, H. H. Ross, $1 \hat{o}$ (reared). Silver Gate, Soda Butte Creek: Aug. 2, 19+0, T. H. Frison \& T. H. Frison, Jr., + nymphs.

OrEgon. - WaLiowa Countr, Lick Creek: Aug. 12, 1937, 19. Bexton Countr, Muddy Creek: April 12, 1938, S. G. Jewett, Jr., 1 \}ै.

Utan,-Logan Canyon: At light, July 29, 1937, Knowlton \& Harmston, 3 o , 3 \% ; Aug. 1, 1937, Smith \& Harmston, i 8,3 ; ; July 25, 1938, Knowlton \& Harmston, 5 of, 7 \% .

WASHINGTON-CASHMERE, Wenatchee River: July 10, 1936, H. H. Ross, $1 \hat{\delta}, 2$ ㅇ․

WYOMING. - PAHASKA TEPEE, north fork Shoshone River: July 29, 19+0, T. H. Frison \& T. H. Frison, Jr., 1 exuvia. Near WAPITI, north fork Shoshone River: July 30, 19+0, T. H. Frison \& 'T. H. Frison, Jr., $1 \hat{\delta}, 1$ \% (both 
reared), 4 nymphs. Iellowstone National PARK, Soda Butte Creek: Aug. 2, 1940, T. H. Frison \& T. H. Frison, Jr., $1 \hat{\delta}$. GRAND TETon National PARK, Beaver Creek and Cascade Canyon: Aug. 7-9, 1940, T. H. Frison \& T. H.

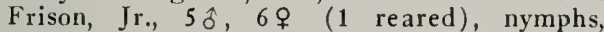
exuviae. Wilson, Coal Creek: Aug. 12, 1940, T. H. Frison \& T. H. Frison, Jr., 1 nymph.

I have studied a nymphal male in the collection of Cornell University collected at "Estes Park, Colo., Aug. 2, 1921," which was determined as "P. expansa" by Claassen. It is probable that this is one of the specimens he describes and records, with erroneous date citation, from "Estes Park, Col., Aug. 4, 1921," and states that "identification of this species was made possible by a study of the genitalia of both male and female nymphs." 'The genitalia of this male are well developed, but I cannot separate this specimen from similar well-developed nymphs which I am certain are modesta. It may be that expansa is a synonym of modesta.

It is possible that the nymph described, but not reared, by Claassen (1931) as Perla expansa Banks [now Diploperla expansa (Banks)] is of this species. This possibility is suggested because of the unidentate character of the lacinia.

\section{Diploperla pilata new species}

MALE. - General color yellowish to dark brown. Head and pronotum with dark and light areas forming a color pattern as in fig. 78 . Legs, antennae and anal cerci yellowish brown. No gill remnants.

Head wider through compound eyes than width of pronotum; lateral ocelli slightly more removed from one another than from anterior ocellus, distance between them about twice the distance each is removed from inner edge of compound eye.

Pronotum approximately quadrangular, somewhat broader than long, angles rounded, a distinct pattern of raised rugosities on surface each side of median longitudinal stripe, fig. 78 .

Legs with first and second tarsal segments together about one-third as long as third, first tarsal segment slightly longer than second.

Wings, fig. 78, essentially hyaline with venation dark brown; tip of wing with branches of radial sector slightly turned upwards; venation in general similar to that of wing figured for Dictyopterygella knowltoni Frison (1937).

Abdomen, fig. 78, with tenth tergite cleft for reception of narrow, elongate, supra-anal process, membranous on upper surface and sclerotized on lower surface, flanked on each side by a slender, sclerotized, lateral stylet (paragenital lobe); dorsal lobes on posterior margin of segment bordering cleft shaped as in fig. 78 , with some short, stout spines. Seventh sternite, fig. 78 , with a broad lobe extending slightly backwards, ninth sternite produced backwards over tenth sternite but not upturned over tenth sternite.

Length to tip of wings $16 \mathrm{~mm}$.; length to tip of abdomen $13 \mathrm{~mm}$.

Female.-Head, thorax, basal abdominal segments and appendages in general similar to those of male but slightly larger in size. Important differences are as follows: eighth abdominal sternite, fig. 78, with subgenital plate greatly produced so that it covers most of the ninth sternite, hind margin of plate not indented, sides somewhat rounded.

Holotype, male.-Vedder Crossing, B. C.: May 10-26, 1936, W. E. Ricker.

Allotype, female.-Same data as for holo. type.

Paratypes. - British Columbia. - Vedder Crossing: Same data as for holotype, $3 \hat{o}$. 17 연 Chilliwack River, April 24, 1937, S. Spencer, 16 ; May 9, 1937, Ricker \& Spencer, 7 ô, 3 o. Sumas River: May 4-6, 1937, IV. E. Ricker, 2 ㅇ․ Cultus LAKE: May 10-26, 1937, IV. E. Ricker, 1 $\delta, 1 \%$; Chilliwack River, May 8-22, 1938, S. Spencer, 2 ㅇ.

OREGON.-DODGE PARK, at confuence of Sandy and Bull Run rivers: June 22, 1933, R. Dimick, 1오. LAcome, Crabtres County: June 4,1935 , R. Dimick, $1 \delta$. ClacklMis County, Eagle Creek: June 20, 1935, S. G. Jewett, Jr., 89. FARMER's River: June 20, 1930, 1 ㅇ. Prospect: July 12, 1933, G. Hoppe, 1 오.

Washington.-Green River Gorge: May 27, 1933, G. Hoppe, $1 \delta$.

Nymph. - General color yellowish brown with darker areas on head, thorax and abdomen, as in fig. 79. Antennae. legs and anal cerci mostly yellowish.

Head with three ocelli forming an almost equilateral triangle, lateral ocelli about as far apart as each is distant from inner edge of compound eye; no occipital ridge; basal segments of mouthparts conspicuously extending out laterally from the sides of head so that head appears much broader than thorax. 
Labium, maxillae and mandibles as in lig. 78 .

A small, nipple-like projection at each outer posterior corner of the submentum suggrestive of an atrophied submental gill, fig. 7\$. No true submental gill.
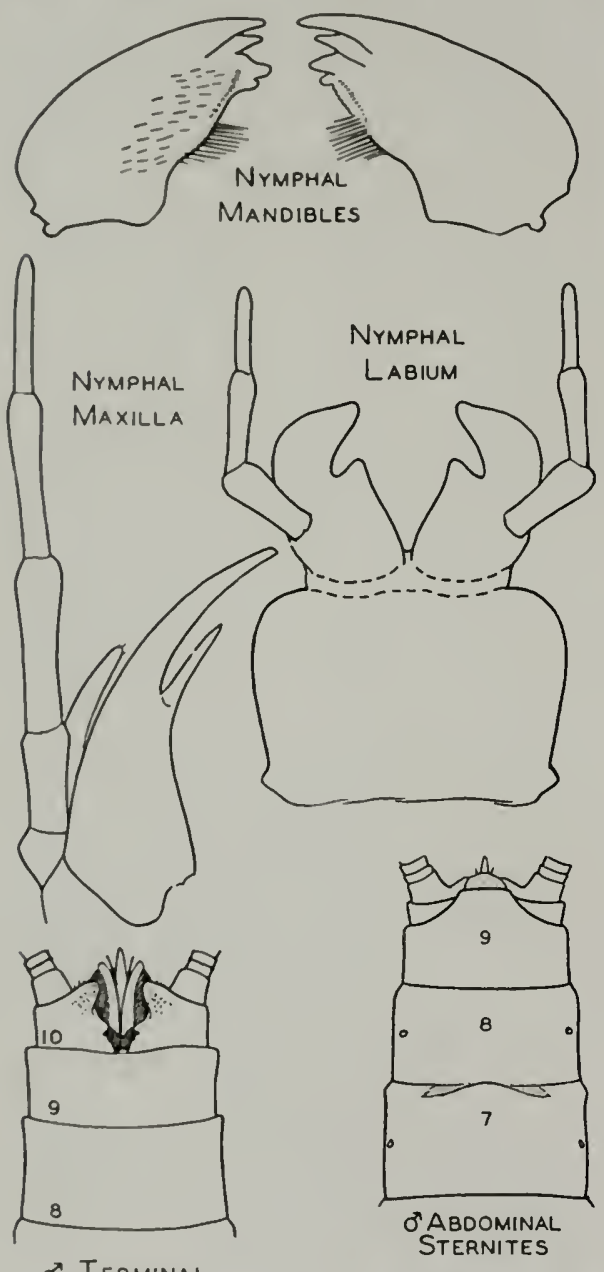

or TERMINAL

ABDOMINAL

TERGITES

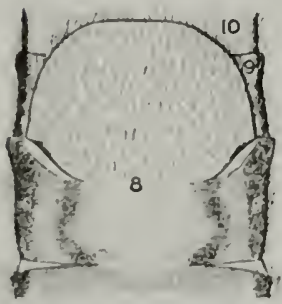

\& Subgenital Plate

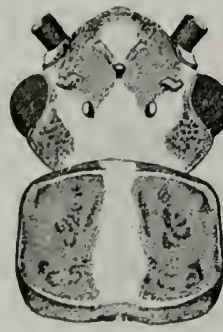

\& HEAD AND

PRONOTUM
Pronotum much broader than long; outer margins darkly outlined and central area mostly light colored, raised rugosities f:iint.

Abdominal tergites mostly yellowish brown with narrow, dark, transverse stripes prominent on anterior margins and weaker on posterior margins, fig. 79 ; tergites, except for posterior margins, mostly devoid of short, stout setae. Cerci long, many segmented, segments progressively longer from base to apex; a longitudinal row of long, fine setae on dorsal surface in addition to smaller spinelike ones encircling apex of each segment.
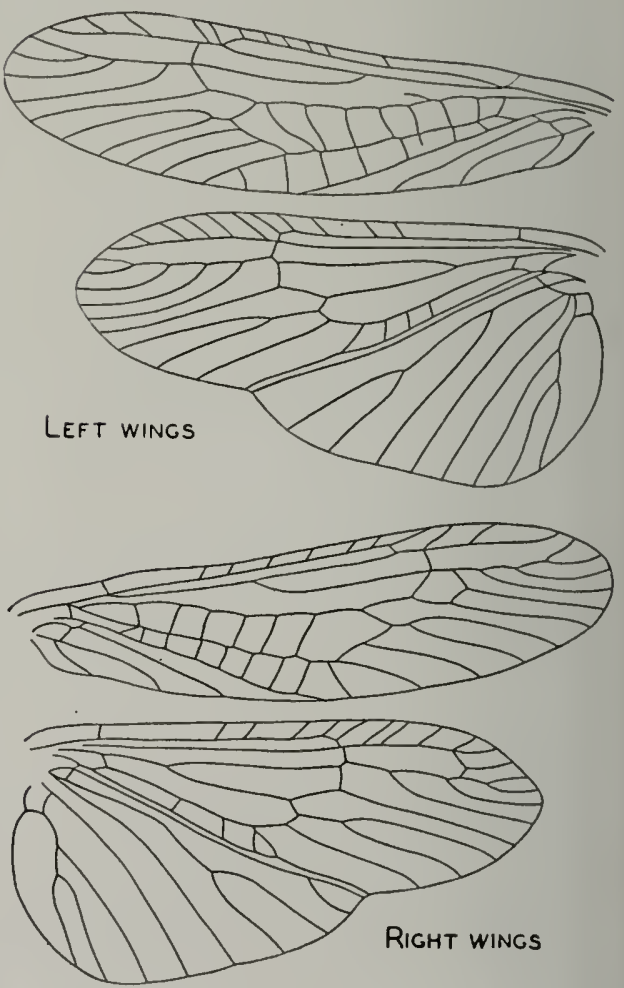

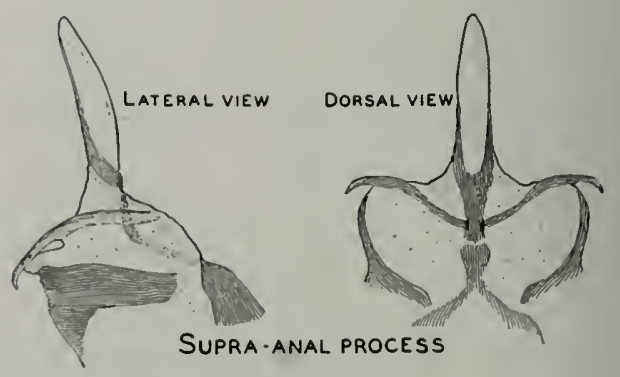

Fig. 78.-Diploperla pilata. 


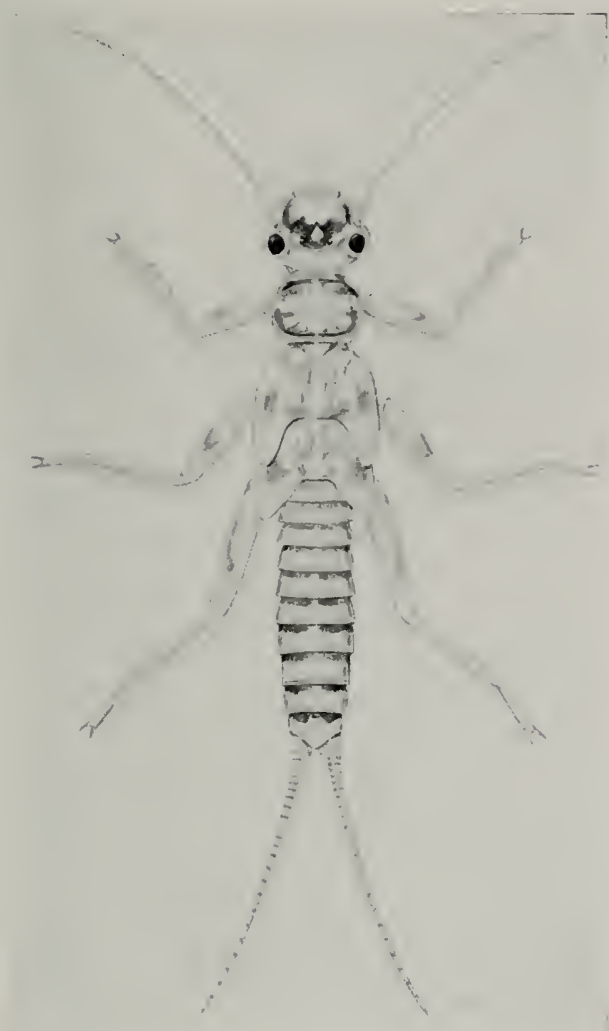

Fig. 79.-Nymph of Diploperla pilata.

Approximately mature specimens with a body length, exclusive of appendages, of $17 \mathrm{~mm}$.

Nymphal and exuvial records are as follows: Sumas River, British Columbia, May +-6, 1937, W. E. Ricker, 3 nymphs, 1 exuvia.

I am naming this species as new with considerable misgiving because of its close relationship with Diploperla expansa (Banks), described from Colorado; future collecting and studies may determine that they are synonymous. D. expansa is represented in the Illinois Natural History Survey collection by two females from separate localities in Colorado. These differ from the specimens here described as new in having a much larger and more quadrate subgenital plate; also, there are some differences in the color pattern on the head. Furthermore, Claassen (1931) described, but did not figure, the nymph of expansa as having the lacinia unidentate and similar to $D$. bilobata (Needham \& Claassen). The nymphs described here, and which I am certain go with the adults here described, have the lacinia bidentate. If Claassen's association of the nymph with expansa is correct, then this proposed new species is certainly distinct. There is a possibility, however, since Claassen did not actually rear any specimens of expansa from the nymphs he describes, that nymphs he called expansa are D. modesta (Banks) or some other closely related species.

\section{Diploperla bulbosa new species}

MaLE. - General color yellowish brown. Head and pronotum with dark and light areas forming an indistinct pattern, as in fig. 80. Legs and antennae in general concolorous with head and thorax; anal cerci with apical segments more yellowish. No gill remnants.

Head through compound eyes about as wide as pronotum; lateral ocelli slightly more removed from one another than from anterior ocellus, distance between each lateral ocellus and inner margin of compound eye about equal to distance between lateral ocelli.

Pronotum approximately quadrangular, somewhat broader than long, a pattern of raised rugosities on surface each side of rather indistinct, median, longitudinal, yellowish stripe, fig. 80 .

Legs with first and second tarsal segments together about one-half as long as third, first tarsal segment slightly longer than second.

Wings with membrane and veins heavily stained with brown; venation of holotype as in fig. 80 , but no doubt subject to some variation in a series of specimens.

Abdomen with segments normal through ninth; tenth tergite cleft, fig. 80 , the lobes formed by this cleft raised upwards; supra-anal process erect and protruding with tip bulbous, inclosed at base by two weakly sclerotized lobes or membranous folds; without lateral stylets flanking supra-anal process; subanal lobes elongated, somewhat bulbous at tip and forming a back support for supra-anal process. Seventh sternite with a broad lobe on posterior margin; eighth sternite with slight indications of a lobe, accentuated by the more numerous concentration of hairs, fig. 80 .

Length to tip of wings $1+\mathrm{mm}$. ; length to tip of abdomen $18 \mathrm{~mm}$. 

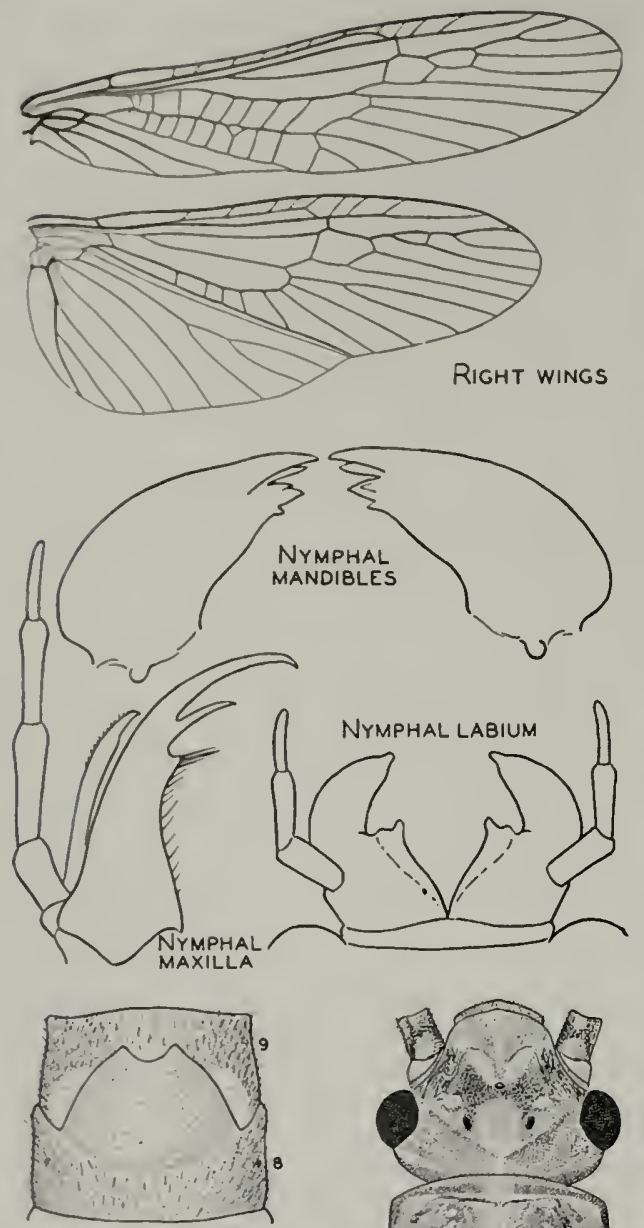

\& SUBCENITAL PLATE

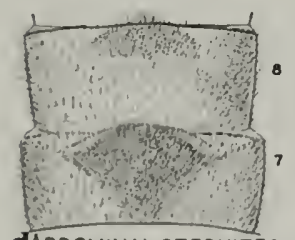

JABDOMINAL STERNITES

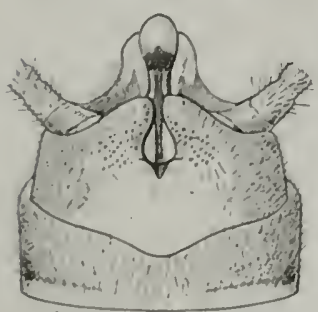

O'ABDOMINALTERCITES

ABDOMINAL O"

Fig. 80.-Diploperla buibosa.
Female.-Head, thorax, basal abdominal segments and appendages in general similar to those of male, but slightly larger in size. Important differences are as follows: Eighth abdominal sternite on posterior margin with at very large subgenital plate which covers most of the ninth sternite; median posterior margin of this plate is distinctly cleft, fig. 80 .

Holotype, male.-Great Smoky Mountains National Park, Greenbrier Cove, Tenn.: June t, 1939, A. C. Cole.

Allotype, female.-Same dala as for holotype.

Paratypes.-TenNessee.-Gatlinburg: June 27, 1940, reared from nymph, T. H. Frison cl al., 1 ㅇ.

NympH. - General color yellowish brown with dark brown or fuscous areas on head, thorax and abdomen, as in fig. 81 . Antennae, legs and anal cerci mostly yellowish brown.

Head with three ocelli forming an almost equilateral triangle, lateral ocelli slightly closer together than each ocellus is distant from inner margin of adjacent compound eye; no complete occipital ridge, but short, stout spinulae with conspicuous bases extend around posterior half of compound eye, and a row of them extends inwards part way to center from inner margin of each compound eye; basal segments of mouthparts extend out conspicuously from sides of head so that head appears much broader than pronotum. Labium, maxillae and mandibles as in fig. 80 ; glossae and paraglossae terminating in nipple-like structures.

Pronotum broader than long, posterior angles or corners more rounded than anterior angles, fig. 81 .

Abdominal tergites with prominent, pale-colored spots surrounded by dark brown or fuscous, fig. 81. Cerci long, many segmented, segments progressively longer from base to apex; a longitudinal row of long, fine setae on dorsal surface in addition to smaller spinelike ones encircling apex of each segment.

Approximately mature specimens with a body length, exclusive of appendages, of $1+\mathrm{mm}$.

A small nipple-like projection at each outer posterior corner of submentum is suggestive of an atrophied submental gill. No true submental gill. lows. 
NORTH CAROLINA.-Small stream near NEWFOUND GAP, 3,560 feet elevation: May 28, 1934, T. H. Frison, 1 nymph. SмокемоNт, Oconaluftee River: May 28, 1934, T. H. Frison, 2 exuviae. Macon County, Nantahala River: May 30, 1939, T. Howell, 1 nymph.

Tennessee.-Gationburg: June 13, 1940, T. H. Frison et al., 1 nymph, 6 exuviae.

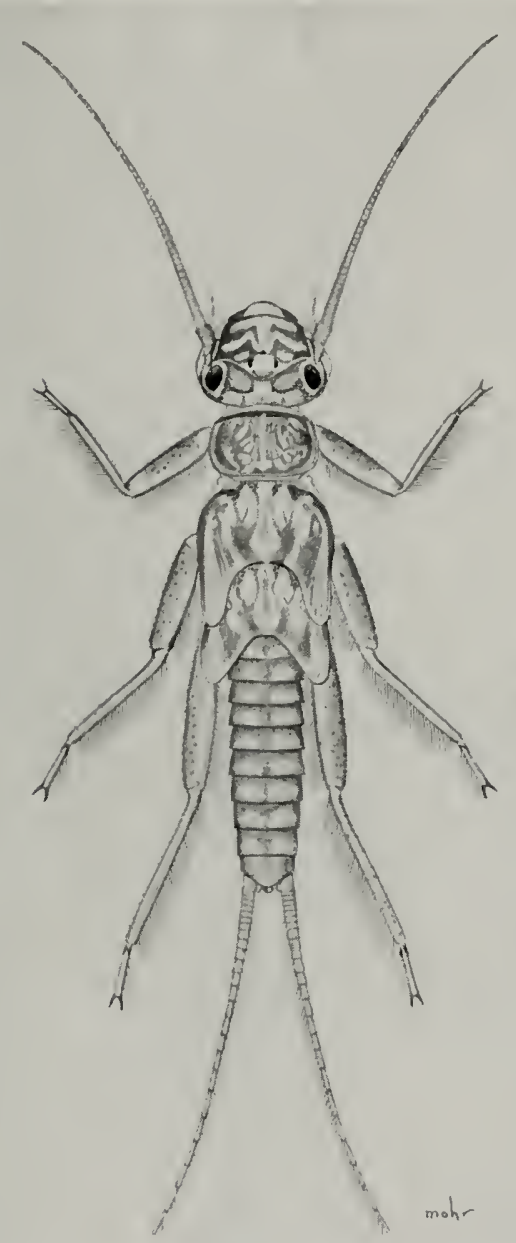

Fig. 81.-Nymph of Diploperla bulbosa.

'This new species is close to the complex of species typified by Diploperla hastata (Banks). It differs from hastata in the male in the shape of the supra-anal process and the lack of lateral stylets or paragenital plates and in the female in the shape of the subgenital plate. The nymph is apt to be confused with the nymph of hastata, but the large light-colored areas on the abdominal tergites present in this new species are lacking in hastata.

\section{Diploperla arina new species}

MaLE. - General color yellow and brown. Head and pronotum with brown and vellow areas forming a color pattern as in fig. 82. Legs yellow with brown markings; antennae and anal cerci yellowish brown. No gill remnants.

Head wider through compound eyes than width of pronotum; lateral ocelli slightly more removed from one another than from anterior ocellus, distance between them about the same as each is distant from inner margin of adjacent compound eye.

Pronotum approximately quadrangular,

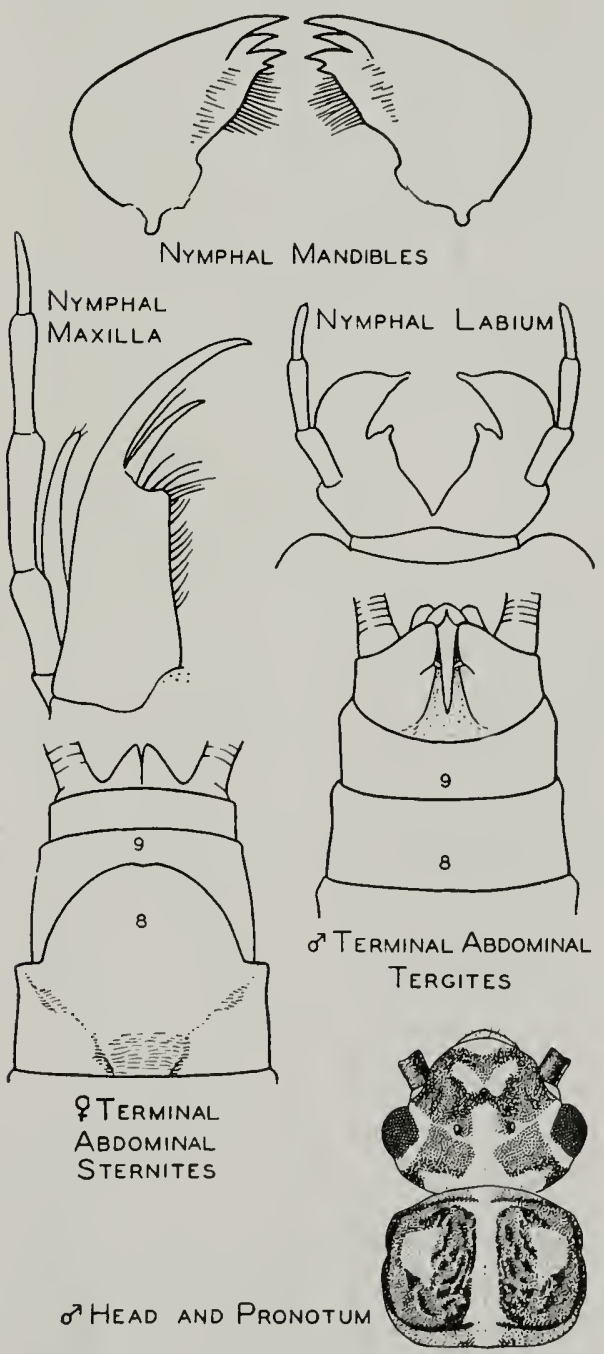

Fig. 82.-Diploperla arina. 
somewhat broader than long, angles rounded, a distinct pattern of raised rugosities on surface each side of median, longi-
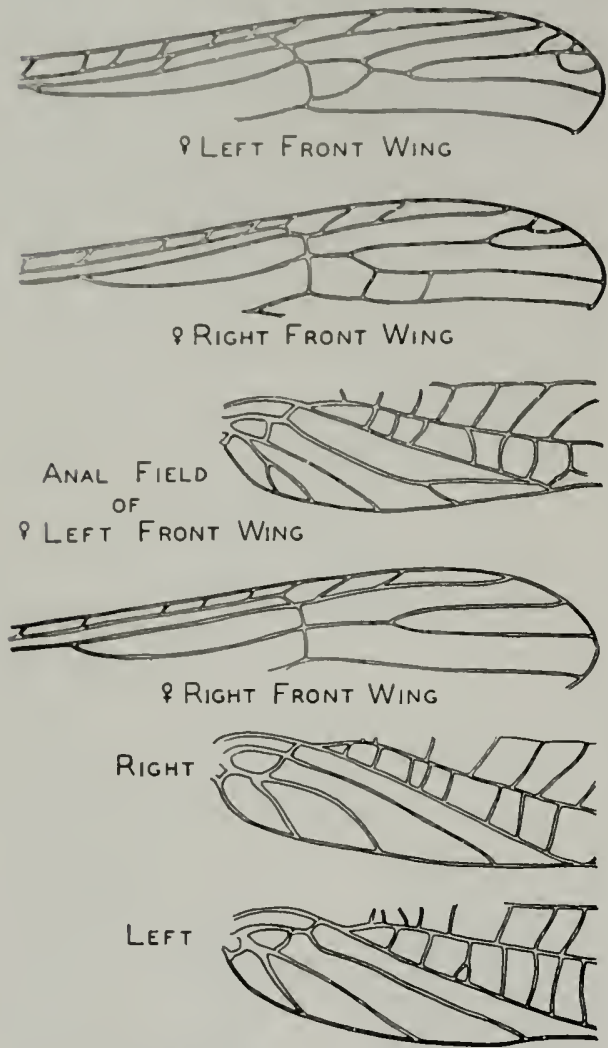

Anal Fielos of \& Front Wings

Fig. 83.-Diploperla arina.

tudinal, yellow stripe, stripe narrower at anterior margin than at posterior margin, fig. 82.

Legs with first and second tarsal segments together about one-half as long as third, first tarsal segment slightly longer than second.

Wings essentially hyaline with veins brown, venation variable as in fig. 83 ; slight suggestion of a brownish spot near inter-radial crossiein.

Abdomen, fig. 82, with segments normal through ninth; tenth tergite cleft, the lohes formed by this cleft broad and covered with numerous fine hairs and some sinall spinulate; inclosed within and beneath lobes is the supra-anal process, which i; enveloped by two hulbous, weakly sclerotized lobes which in turn surround the membranous area from which the supra- anal process arises; the supra-anal process is very long, slender and tapers to a point ; no lateral stylets are present; seventh and eighth sternites without well-developed lobes on posterior margins.

Length to tip of wings $21 \mathrm{~mm}$; length to tip of abdomen $17 \mathrm{~mm}$.

FEMALE.-Head, thorax, basal abdominal segments and appendages in general similar to those of male but slightly larger in size. Important differences are as follows: eighth abdominal sternite, fig. 82 . with subgenital plate broad and greatly produced so that it covers most of ninth sternite, posterior margin of plate in middle very slightly notched.

Holotype, male.-Balsam, N. C., April 24, 1938, H. H. Ross \& B. D. Burks.

Allotype, female.-Same data as for holotype.

Paratypes. - North Carolina. - Batsim: Same data as for holotype, 2 ㅇ.

Ten nessee.-Greenbrier Cove, Great SMOKY Mountains National. Park: May 7, 1939, A. C. Cole, $1 \hat{o}$.

NYмpH. - General color yellowish brown with dark brown or fuscous areas on head, thorax and abdomen, as in fig. 8t. Antennae, legs and anal cerci mostly yellowish brown.

Head with three ocelli forming an almost equilateral triangle, lateral ocelli about as far apart as each is distant from inner margin of adjacent compound eye; no complete occipital ridge, although there is an indication of such a ridge each side of head running to compound eye; basal segments of mouthparts conspicuously extending out laterally from sides of head so that head appears much broader than pronotum. Labium, maxillae and mandibles as in fig. 82; glossae and paraglossae terminating in a small nipple-like structure.

Pronotum broader than long, corners rounded, fig. 84 .

Abdominal tergites basically yellow with narrow, dark brown or fuscous transverse bands on anterior and posterior margins of tergites, fig. 84. Cerci long, many segmented, segments progressively longer from base to apex; a longitudinal row of long, fine setae on dorsal surface in addition to smaller spinelike ones encircling apex of each segment.

Mature specimens with a body length, exclusive of appendages, of $19 \mathrm{~mm}$.

A minute, nipple-like projection at each 
outer posterior corner of the submentum is suggestive of an atrophied submental gill. No true submental gill. lows.

Nymphal and exuvial records are as fol-

North Carolina.-Balsam: Same data as for holotype, + nymphs, 9 exuviae. WILLETTS: March 23, 1940, 'T. H. Frison, C. O. Mohr \& A. S. Hawkins, 6 nymphs.

Tennessee.-Elkmont, Little River: May 1t, 1939, T. H. Frison \& H. H. Ross, 9 exuviae. G.atlinbURG, Le Conte Creek: May 14, 1939, T. H. Frison \& H. H. Ross, 2 exuviae.

I have been able to associate the nymph of this species with its adult because of a mature male nymph which clearly shows the distinctive structural features of the adult about to emerge and which was collected at the same time and place as the holotype. The terminal abdominal structures of the male are much different from those of any other species of this genus known to me. Among the Diploperla (s.l.), as I am now recognizing this genus, this new species differs from duplicata (Banks) and bilobata (Needham \& Claas-

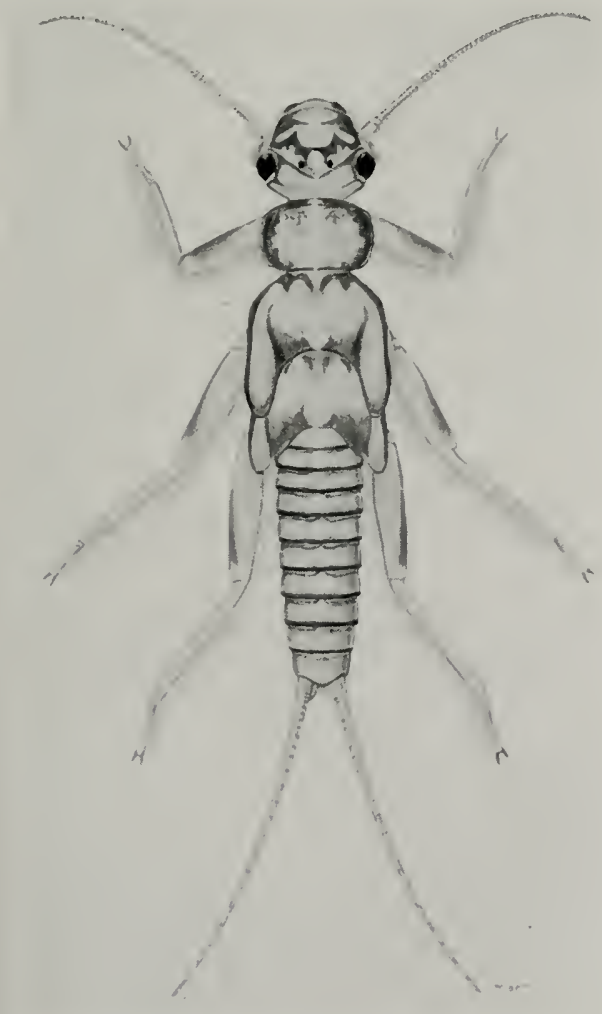

Fig. 84.-Nymph of Diploperla arina. sen) in the male in lacking the lobes on terminal abdominal sternites. It differs from another complex of species, including verticalis (Banks), in lacking the heavily sclerotized lateral stylets flanking the supra-anal process.

\section{ISOPERLIDAE}

The family placement of the genus Isoperla presents several problems. Needham \& Claassen (1925), following many other workers, have placed this genus in the family Perlidae, and there are several reasons for so doing. In my $1935 a$ paper on Illinois stoneflies, I placed Isoperla in the family Chloroperlidae, chiefly because of its lack of gills in nymphs or of gill remnants in adults. In addition to having characters in common with the Perlidae, the genus Isoperla (s.l.) has characters also in common with the Perlodidae.

It now seems desirable to me to erect a special family for this genus, rather than place it in existing families. Therefore, I propose the family name of Isoperlidae for the species now recorded under Isoperla (s.l.) and consider bilineata (Say), the type of the genus Isoperla Banks, as its most typical species.

\section{Isoperla holochlora (Klapálek)} 23).

Chloroperla holochlora Klapálek (1923b, p.

Probably because of its late date of description, holochlora was not included by Needham \& Claassen (1925) in their Monograph; it was omitted by Claassen (1928) when additions and corrections to the Monograph were published. It is listed, however, in Claassen's (19+0) posthumously published Catalogue.

Ricker (1938) in reporting upon his studies of the four cotypic series in the Musée Royal d'Histoire Naturelle, Brussels, Belgium, stated that one of these cotypic specimens is probably different from the others and selected a female as a lectotype. In 1938, through the kindness of Dr. Victor Van Straelen, Director of this Museum, one of the male cotypes, which Ricker assumed to be of the same species as the lectotypic female, was sent to me for study. This male agrees well with Ricker's description of the general features of the lectotypic female and was found to 
be identical with specimens in the Illinois Natural History Survey collection from Tennessec and North Carolina.

Fixcept for Ricker's drawing showing the triangular-shaped subgenital plate of
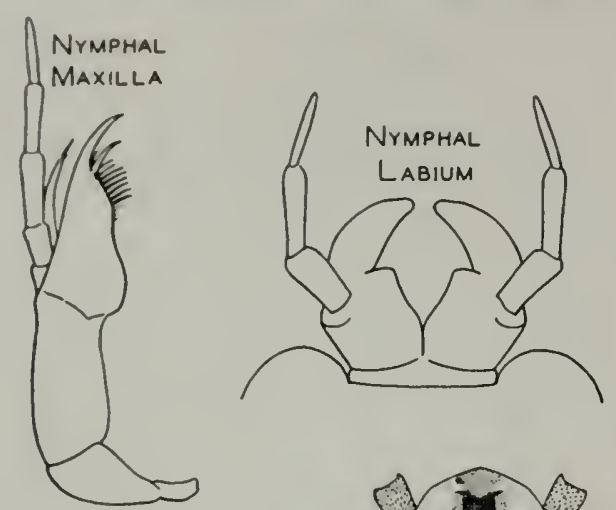

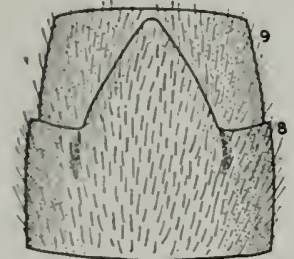

o SUBGENITAL PLATE

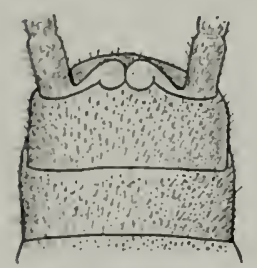

O' ABDOMINAL TERGITES
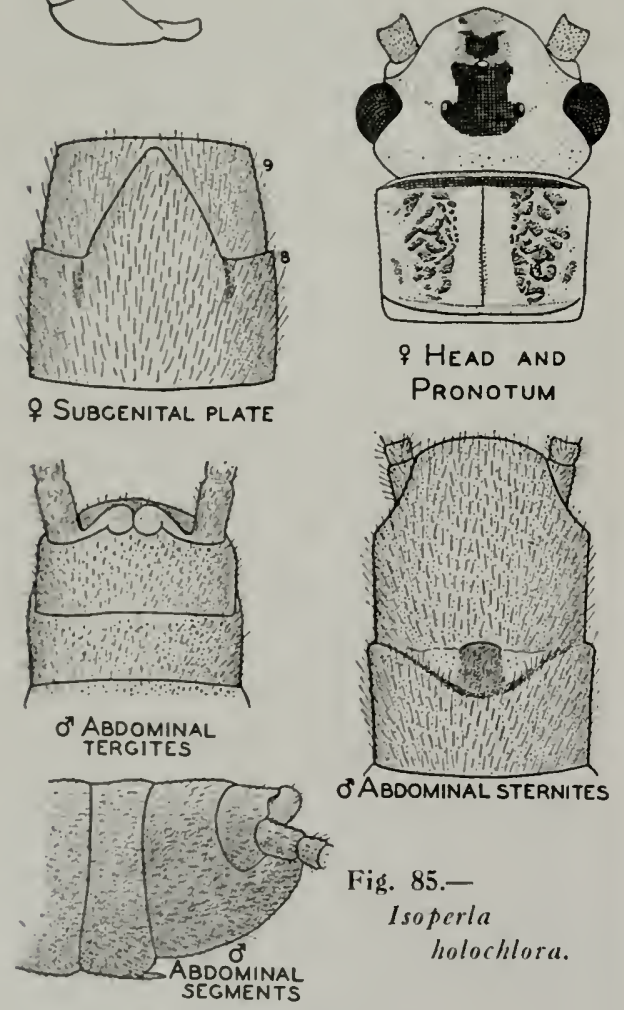

I HEAD AND

Pronotum

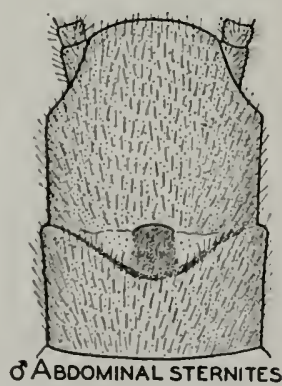

Fig. 85.-

Isoperla

holochlora. the lectotypic female, no illustrations of this species have been published, and no records other than that of "Georgia" associated with the types have heen introduced into literature.

lllinois Natural History Survey field work, as well as the study of some material submitted for identification, has revealed the presence of this species in several east- ern states. Rearings have enabled me to assuciate the previously unknown nymph with its adult and definitely to establish the correct association of males with females. To facilitate future identifications of this species, illustrations of the important characters of the adults, fig. 85 , are given and a description of the nymph is presented.

Nymph.-General structural features approximately the same as for nymph of Isoperla patricia, described in this paper. Labium and maxillae as in fig. 85. General color pattern as in fig. 86 , with tendency in some specimens for a broad, pale, longitudinal medial area on abdominal tergites to be more obscured.

Records for this species, based upon Illinois Natural History Survey field collecting and specimens submitted for identification, are as follows.

Mane.-MuUnt Kitahdi, Roaring Brooks: Aug. 26, 1939, T. H. Frison \& T. H. Frison, Jr., $9 \delta, 21$ \%.

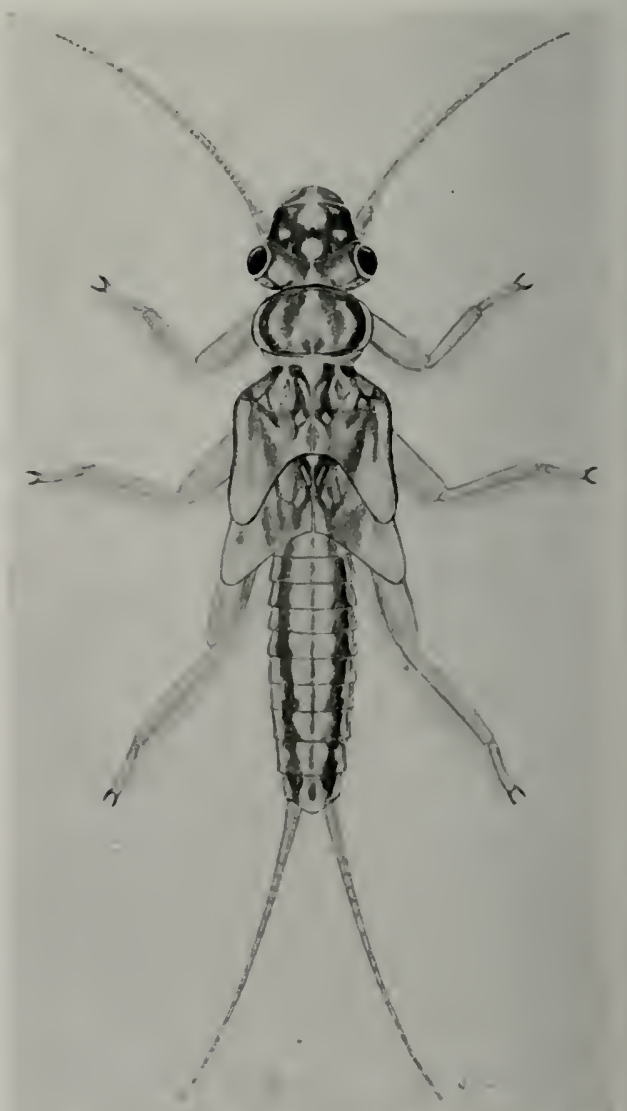

Fig. 86.-Nymph of Isoperla holochlora. 
New YORK-COLD Brook: June 30, 1940, H. Dietrich, $1 \hat{\delta}$.

North Carolina.-Balsam: April 2t, 1938, Ross \& Burks, + nymphs. CherokeE: June 26, 1938, W. Stehr, 1 $\hat{\delta}$. Dillsboro: April 24, 1938, Ross \& Burks, $1 \hat{\delta}$. Hazelwood: April 24, 1938, Ross \& Burks, $1 \hat{\delta}$. Newfound Gap, elevation 3,560 feet: May 28, 1934, T. H. Frison, $2 \hat{\delta}, 2$. SMOKEMONT, Oconaluftee Creek: May 28, 1934, T. H. Frison, 1 , nymphs.

Pennsyluania. - Monroe County, Marshall's Creek: June 1, 1935, W. J. Harmer, A.N.S. Lot 862,1 o with exuvia (reared). Swiftwater, Monroe County: 1928, F. R. Nevin, Lot 258, $1 \hat{\delta},+$ ㅇ․

Tennessee.-Cades Cove: June 13, 1940 , T. H. Frison et al., 2 \% with exuviae (reared),

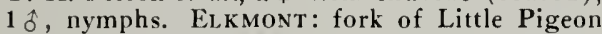
River, May 27, 1934, T. H. Frison, 1 nymph; June 12, 1935, H. H. Ross, $5 \hat{\sigma}, 5$ 울 Little River, June 12, 1938, T. H. Frison \& T. H. Frison, Jr., $1 \hat{\delta} ;$ same except June 17, 11 nymphs, 1 exuvia. Gatlinburg: Fighting Creek branch of Little Pigeon River, May 27, $193+$, T. H. Frison, tô, 39 , nymphs, exuviae; Little Pigeon River, June 12, 1935, H. H. Ross, $5 \hat{\delta}, 19,1$ with exuvia (reared); Le Conte Creek, June 13, 1938, T. H. Frison \& T. H. Frison, Jr., + nymphs, 1 exuvia; same except June 14, 10 with exuvia (reared); same except June $16,2 \hat{\sigma}, 1$ ㅇ, 3 nymphs; May 14 , 1939, Frison \& Ross, 8 nymphs; same except Le Conte Creek, 3 , nymphs; same except Fighting Creek Gap, May 15, $2 \delta, 1$; ; June 13, 1940, T. H. Frison et al., nymphs; same

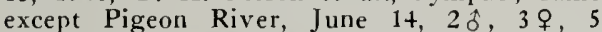
nymphs; June 14, 1940, T. H. Frison et al., $1 \hat{\delta}$ and $1 \%$ with exuviae (reared), $1 \hat{\delta}$;

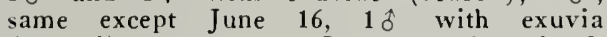
(reared); same except June 19, $1 \hat{\delta}$ and 1 \% with exuviae (reared); same except June 20, 1 ㅇ with exuvia (reared); same except June 25,2 with exuviae (reared). Monteagle: April 26, 1938, Ross \& Burks, 2 of (compared with paratype). Great SMOKY Mountains National Park: Greenbrier Cove, 2,400 feet elevation, July 19, 1939, A. C. Cole, 19; Chimneys Camp Grounds, July 13, 1939, A. C. Cole, 1 o.

Virginia.-Big Meadows, SHenandoah N.1TIONAL PARK: April 20, 1938, Ross \& Burks, 5 nymphs.

\section{Isoperla patricia new species}

Male. - Basic color light yellowish brown, with darker markings forming a distinct pattern on head and pronotum, fig. 87 ; posterior half of mesothorax and metathorax dark brown; in life, and sometimes in fresh material, the abdomen is colored vermilion. Legs, antennae and anal cerci pale yellowish brown. No gill remnants.

Head slightly wider through compound eyes than width of pronotum; lateral and median ocelli forming an approximately
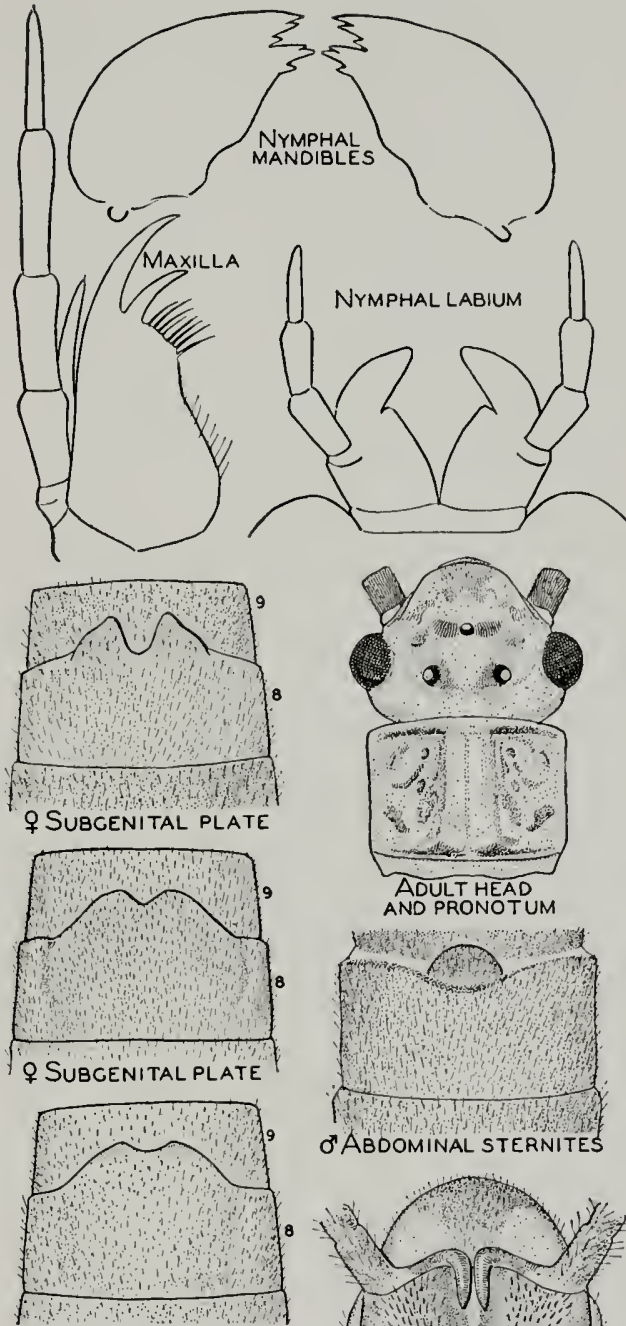

q SUBGENITAL PLATE
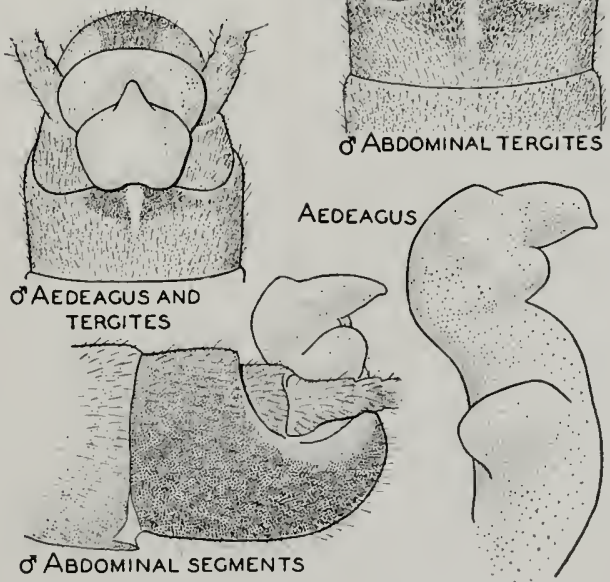

OTABDOMINAL STERNITES

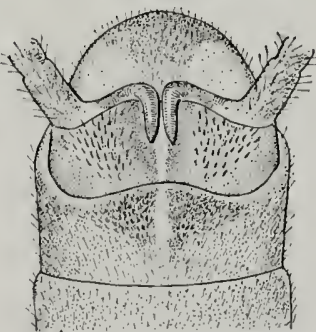

O' ABDOMINAL TERGITES

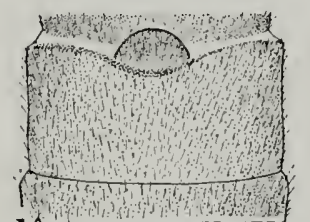

Fig. 87.-Isoperla patricia. 
ecpuilateral triangle, distance between ocelli about the same as each lateral ocellus is removed from compound eye.

Prunotum approximately cuadrangular, hroader than long, a distinct pattern of raised rugosities on surface each side of pille, median, longitudinal stripe, witls posterior end of stripe broader than anterior end, fig. 87.

Legs with first and second tarsal segments together shorter than third, first tarsal segment longer than second.

Wings hyaline with costal margins pale vellowish, venation light brown.

Abdomen, fig. 87, with tenth tergite not cleft but with a distinct, depressed, median, longitudinal trough almost free of stout setae and separating flanking patches of numerous short, stout setae; subanal lobes recurved upwards over tenth tergite and with prominent, slender, long, sharply pointed tips; aedeagus membranous with distinctive shape, fig. 87 ; ninth sternite produced much beyond tip of ahdomen and rounded behind; eighth sternite with a prominent median lobe on pusterior margin, fig. 87.

Length to tip of wings $10 \mathrm{~mm}$; length to tip of abdomen $9 \mathrm{~mm}$.

Fe.rale.-Head, thorax, basal abdominal segments and appendages in general similar to those of male but slightly larger in size. Important differences are as follows: eighth abdominal sternite, fig. 87, with subgenital plate partly produced over ninth sternite and deeply notched in most specimens but occasionally only slightly indented.

Holotype, male.-Spearfish, Spearfish River, 5. 1).: July 27,1940, T. H. Frison \& T. H. Frison, Jr.

Allotype, female.-Same data as for holoiype.

Paratypes. - SoUth D.sKotA. - SPEARFISH: Same llata as for holotype, $+5 \hat{\delta}, 20 \%$.

British Columbia.-VANicouver: July 25 , 1936, H. H. Ross, 1 ㅇ.

Californi.1-Mlono County; Convict Creek: July 3, 1938, H. J. Rayner, 2 ㅇ.

COI.ORADO.-HARTZEL: July 22, 1938, H. H. \& J. A. Ross, 1 . IOLA: June 22, 1934, elevation $7,+50$ feet, H. Pratt, $2 \hat{\delta}$. ECKERT, Surface Creek: Jume 28, 1938, Lanham \& Bauer, 2 \%. Gr.ABY, Colorado River: July 24, 1938, H. H. \& J. A. Ross, 3ô. LAKF. (jEORGE, South Platte River: July 22, 1938 , H. H. \& J. A. Ross, 1 \%.

IDAllo.-ST: ANTHoNY: June 28, 1938, H. S. T'elford, 1 ․

Moxtana-Harrison: July 8, 1936, H. H. Ross, 1 . Toston, Missouri River: June 22,
1940 , H. H. \& J. A. Ross, $15 \hat{\delta}, 15 \%$ Noxon, Clark Fork River: June 23, 1940, H. H. \& J. A. Ross, 1 d.

Oregox. - Frexchigles, Harney County, Blitzen River: July 11, 1935, S. G. Jewett, Jr., 1 $\delta$. Five miles south of UNioN CREEK on Mill Creek: June 2t, 1937, S. G. Jewett, Jr., 16 . Fort KLAMATH: June 26, 1937, S. G. Jewett, Jr., 3o, 1 \%. Will.AMETTE RIVER: May 26, 1938, C. Jensen, $1 \hat{\delta}, 1$ ㅇ. Near mouth of Williamon River, July 8, 1938, R. Dimick, 1 ㅇ․

Utih.-Ogden Canyon: June 21, 1937, O. E. Hardy, 1 우 ; June 23, 1938, Hardy \& Stains, 16. BLACKSMITH FORK CANYoN: June 20, 1937, Harmston \& Smith, 8\%, 6\%. Hustsville; June 23, 1938, Hardy \& Stains, $1 q$; June 27, 1937, G. F. Knowlton, 19. SUNSET: July 26, 1933, G. F. Knowiton, 1 \%. PARADISE: June 1t, 1938, Hardy \& Stains, $1+\delta, 12 q$. Kixosh Cixyox: May 27, 1939, Knowlton \& Harmston, 16, 3ㅇ. EDEx: July 15, 1938, G. F. Knowiton, 1\%. Uista: June 18, 1937, G. F. Knowlton, $2 \delta, 2 q$. Logax CANYox: July 11,1938 , D. E. \& A. T. Hardy, 1 \%. SMithfield: May 13, 1939, Knowlton \& Harmston, 2 \%

Wroming. - Boulder, Tributary of Pine Branch: July 6, 1936, H. H. Ross, 3ô, 2 ㅇ. Pinedale, Green River: July 6, 1936, H. H. Ross, 1 ㅇ. CentenNial: July 2, 1938, D. J. \& J. N. Knull, 1 \%.

Nymph.-General color pale yellowish with darker areas on head, thorax and abdomen, as in figs. 88 and 89 ; specimens exhibit color variation from a light, fig. 88 , to dark, fig. 89 , phase ; nymphal male in life sometimes show's reddish abdominal coloring as in adult. Antennae, legs and anal cerci mostly yellowish.

Head with three ocelli forming an almost equilateral triangle, lateral ocelli about as far apart as each is distant from inner edge of compound eye; no occipital ridge; basal segments of mouthparts not extending out from side of head. Labium, maxillae and mandibles as in fig. 87.

Pronotum broader than long, with markings as in figs. 88 and 89.

Abdominal tergites with general background yellowish and with dark longitudinal stripes as in figs. 88 and 89 ; some scattered, stout, short setae on abdominal tergites in addition to row on posterior margin of each tergite. Cerci long, many segmented, segments progressively longer from base to apex; a longitudinal row of long, fine setae on dorsal surface of apical segments in addition to smaller spinelike ones encircling apex of each segment.

Approximately mature specimens with body lengths, exclusive of appendages, in males $11 \mathrm{~mm}$. and in females $12 \mathrm{~mm}$. 
No thoracic, anal or submental gills.

Nymphal and exuvial records: same data as for holotype, 22 nymphs, 13 exuviae.

I am naming this species in honor of my daughter, Patricia Ann, who takes great delight in assisting with the collection of stonefly adults and nymphs whenever opportunity presents itself and who

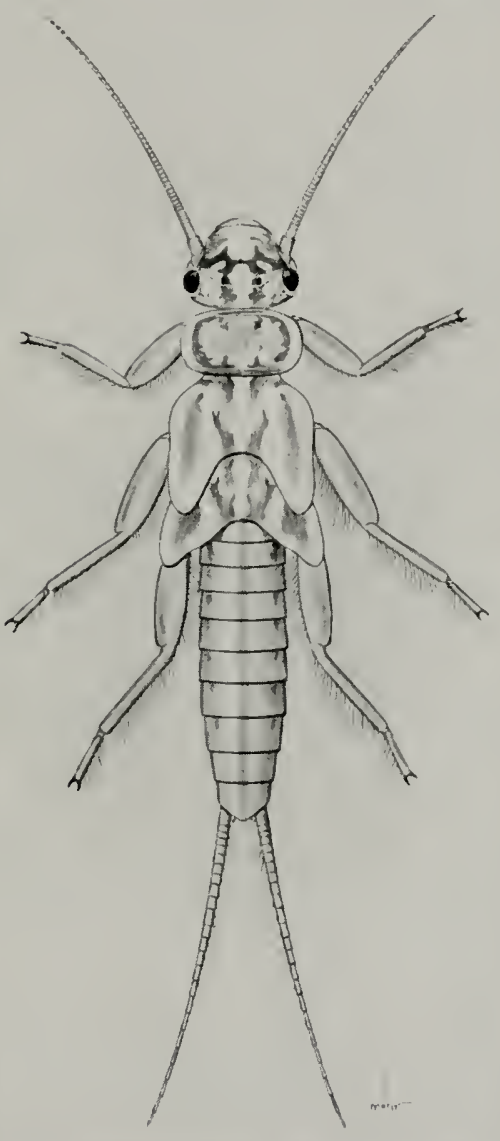

Fig. 88.-Nymph of Isoperla patricia, light form.

helped with the collection of the nymph and adult specimens from Spearfish, S. D.

This widely distributed western species is easily recognized in the female among species of Isoperla, because of its usually distinctly notched subgenital plate and the peculiar darkening of the posterior part of the mesothorax and metathorax. Isoperla fulva Claassen (1937d) has somewhat the same general color appearance, but the subgenital plate of the female is quite different, and the subanal lobes of the male are much shorter and stouter.

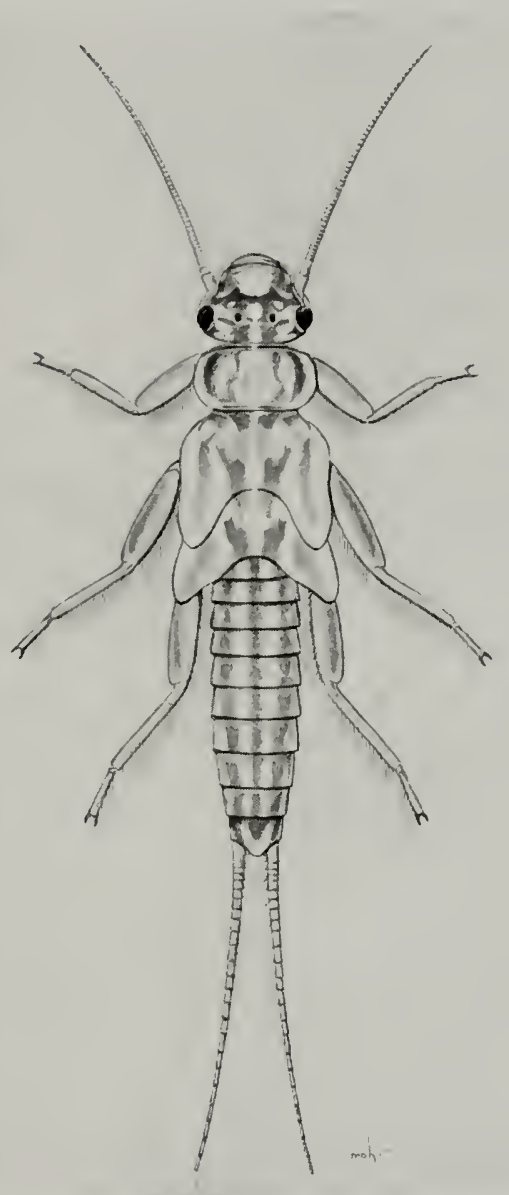

Fig. 89.-Nymph of Isoperla patricia, dark form.

I. extensa Claassen (1937d) has a subgenital plate suggestive of patricia, but in extensa this structure is broader at base and its general make-up is more similar to that of bilineata (Say).

Although the adult was not actually reared from the nymph, the circumstances under which nymphs, exuviae and adults were taken at Spearfish, S. D., on July 27, 1940 , have enabled me with certainty to associate immature and adult forms. The vermilion coloring of the abdomen of some adult males and indications of this coloring in some nymphal males are most unusual in this order of insects. 


\section{Isoperla transmarina (Newman)}

Chloroperla transmarina Newman (1838b, p. 499). Original description, 9.

Isoperla sentralis Bauks (1908b, p. 66). Original descripriou, $\delta$. + . New synonymy.

Isoperla transmarina was synonymized by Hagen in 1861 as the same as bilimeata (Sily), but Ricker (1938) has clearly shown that it is not bilineata. Ricker's drawings of the color pattern of the head and of the subgenital plate are so characteristic of aentralis that I have no hesitancy in placing r'entralis as a synonym of transmarina.

Newman's original description is not clear as to sexes involved, but according to Ricker the typic specimen now in the British Museum is a female. "Inhabits Canada, etc." and "Trenton Falls" indicate in the original description the source of the typic specimen, and the specimen considered as the type by Ricker is from

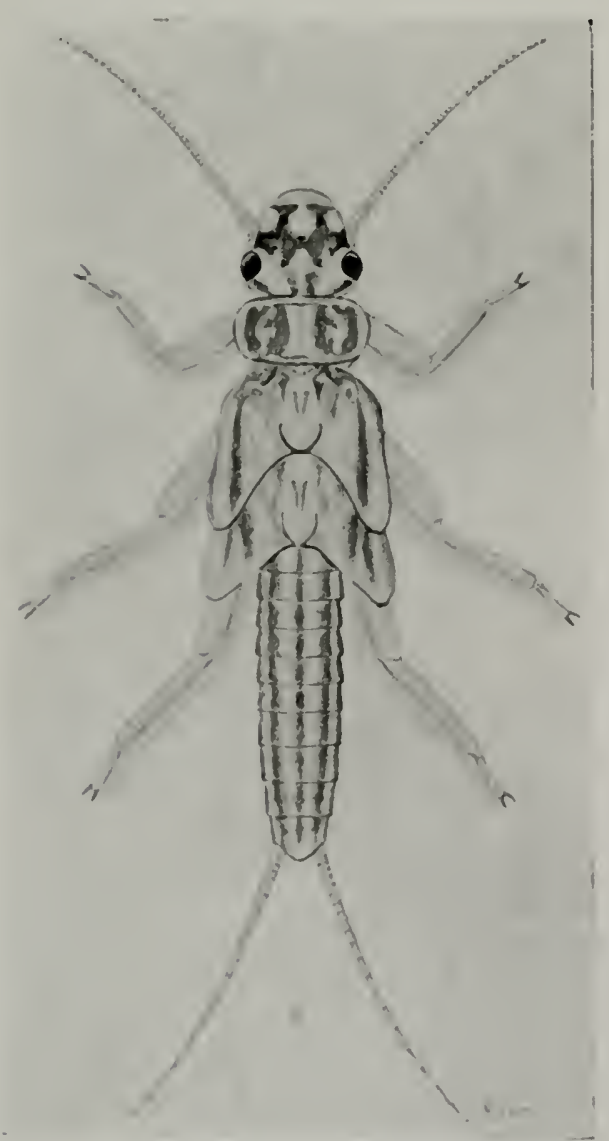

Fig. 90.-Nymph of Isoperla transmarina.
"North America." 'The statements regatrding locality of typic specimen fit the general northeastern range of the species described by Banks (1908b) as zentralis and now synonymized as transmarima.

Isoperla rentralis was described from specimens collected at "Grand Lake, Newfoundland," and the typic series is now in the collection of the Museum of Comparative Zoology (No. 11,333). In the original description, reference is made to both males and females, but the typic series
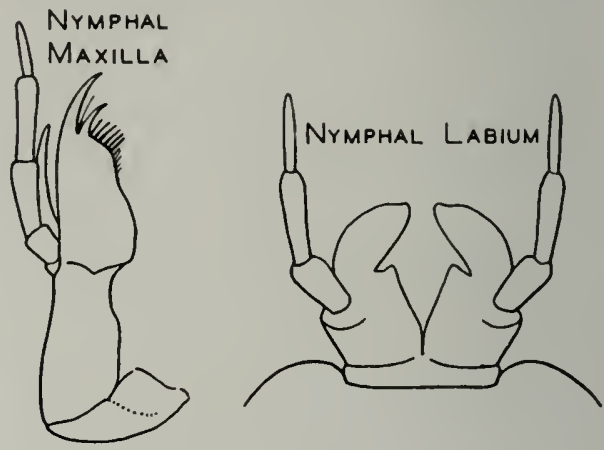

Fig. 91.-Isoperla transmarina.

now contains only males. Evidently a similar situation existed when Claassen studied the types, because Needham \& Claassen (1925) omit any reference to the female.

Through the kindness of Dr. Nathan Banks, I was permitted to relax one of the typic males and study it closely in comparison with reared specimens. It seems advisable to designate this particular specimen as the lectotype and I so do.

The rearing of adult males and females has enabled me to associate conclusively the heretofore undescribed nymph of this species, and the description of the nymph is therefore presented.

NyupH.-General color yellowish with darker areas forming a conspicuous pattern on dorsum of head, thorax and abdomen, fig. 90. Antennae, legs and anal cerci mostly yellowish.

Head with three ocelli forming an almost equilateral triangle, lateral ocelli about as far apart as each is distant from inner edge of compound eye; no occipital ridge; basal segments of mouthparts not extending out from sides of head. Labium and maxillae as in fig. 91 .

Pronotum much hroader than long with 
markings as in fig. 90, corners rounded.

Abdominal tergites with alternating longitudinal stripes of yellow and brown, fig. 90. Cerci long, many segmented, segments progressively longer from base to apex; a longitudinal row of long, fine setae on apical segments in addition to smaller spinelike ones encircling apex of each segment.

Mature specimens with a body length, exclusive of appendages, up to $1+\mathrm{mm}$.

No gills present.

Since this species has been previously recorded only in the original descriptions already noted, I present the following records, which show it has a wide northeastern distribution in North America.

Manitoba.-Churchill: July 5-9, 1936, H. E. McClure, 5ô, $\hat{\jmath}$ 우 ; July 23, 1936, H. E. McClure, 10 . Swan River, Swan River: June 5, 1936, H. E. McClure, $1 \hat{\delta}, 2$, + nymphs.

Michigan.-Baldwin, Pere Marquette River: May 28, 1939, Frison \& Ross, 18 ; May 9, 1940, Frison \& Ross, $1 \hat{\delta}, 5$ with exuviae (reared); same except May $9-10, \hat{\delta} \hat{\delta}$, 우 우, nymphs, exuviae; same except May 10, $1 \hat{\delta}$, 1 if with exuviae (reared). Boardman River, 3 miles above Traverse City power dam: March 7, 1935, J. W. Leonard, nymphs and 1 exuvia. Germfask, Manistique River: May 11, 1940, Frison \& Ross, 4 nymphs. GRAND Traverse County, Boardman River: May 7, 1935, J. W. Leonard, ô $\hat{o}$, 우 ㅇ․ HonOR, Platte River: May 27, 1939, Frison \& Ross, $3 \hat{\delta}, 4$, 2 nymphs with exuviae and $1 \hat{o}$ with exuvia (reared); May 10, 1940, Frison \& Ross, $2 \hat{\delta}$, 6 nymphs, 1 exuvia. LAke County, Pine River: May 1t, 1938, O. H. Clark, 1 \% ; May 16, 1938, O. H. Clark, 2 \% ; Walker Bridge Camp, May 29, 1938, J. W. Leonard, 1 ô, 2 ; May 30, 1938, O. H. Clark, 19; Walker Bridge Camp, at light, May 31,1938 , O. H. Clark, $3 \hat{\delta}, 1$; ; June 4, 1938, J. Blue, $1 \hat{\delta}$, 1 우 ; June 11, 1938, R. Love, 1 여 ; June 12, 1938 , J. Blue, 3 \%. Luzerne, east branch of Big Creek: J. W. Leonard, 1 exuvia. MAYFIELD, Boardman River: May 28, 1939, Frison \& Ross, 1\%. Montmorency County, Hunt Creek: April 17, 1939, J. W. Leonard, 2 nymphs. Route 46 between Muskegon and KENT CITY, tributary of Black Creek: May

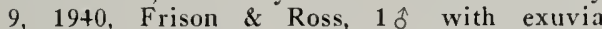
(reared), 5 nymphs. Nahma Junction, Sturgeon River: May 12, 1940, Frison \& Ross, nymphs; same data except May $15,2 q$ with exuviae (reared); same data except May 17 , 1 ㅇ (reared); same data except May 20, 2 ㅇ with exuviae (reared). NiRvana, Sanborn Creek: May 10, 1940, Frison \& Ross, 4 nymphs. OTsEgo County, west branch of Sturgeon River: March 15, 1935, J. W. Leonard, 3 nymphs. PEAcock, Little Manistee River near town: May 10, 19+0, Frison \& Ross, $3 \hat{o}, 2$, nymphs, 1 exuvia. Sturgeon River, west branch between Vinderbilt and Wolverine: March 15 , 1935, J. W. Leonard, 1 nymph. Thомpson, creek near town: May 12, 1940, Frison \& Ross, 2 nymphs.
Minnesota. - Winona County: May 20, 1938, Page Nicholson, 1 ㅇ.

Ontario.-Algonquin Park, Costello Lake, Ontario Fisheries Research Laboratory: June 14, 1938, W. M. Sprules, 1 ㅇ. Kenora: June $16,1908,1$ ㅇ.

IVIsconsin.-Boulder Junction: 'Trout River, July 3-4, 1933, Frison \& Mohr, exuviae: Trout River, June 20, 1934, Frison \& Mohr, + exuviae; Trout River, April 8-9, 1937, Frison \& Mohr, 1 nymph; May 6-17, 1937, Frison \& Mohr, 5 nymphs; May 7-17, 1937, Frison \& Mohr, 12, 15우 (reared) ; May 20, 1937, Frison \& Mohr, 2 nymphs. SPOONER, Namakagon River: June 6, 1936, Frison \& Ross, 2 exuviae.

\section{Isoperla fusca Needham \& Claassen}

Isoperla fusca Needham \& Claassen (1925, p. 1+6). Original description, $\hat{o}, \quad$.

Specimens of this species, recorded only once (Neave 1929) since it was first described from specimens collected at Waterton Lakes, Alberta, Canada, were found

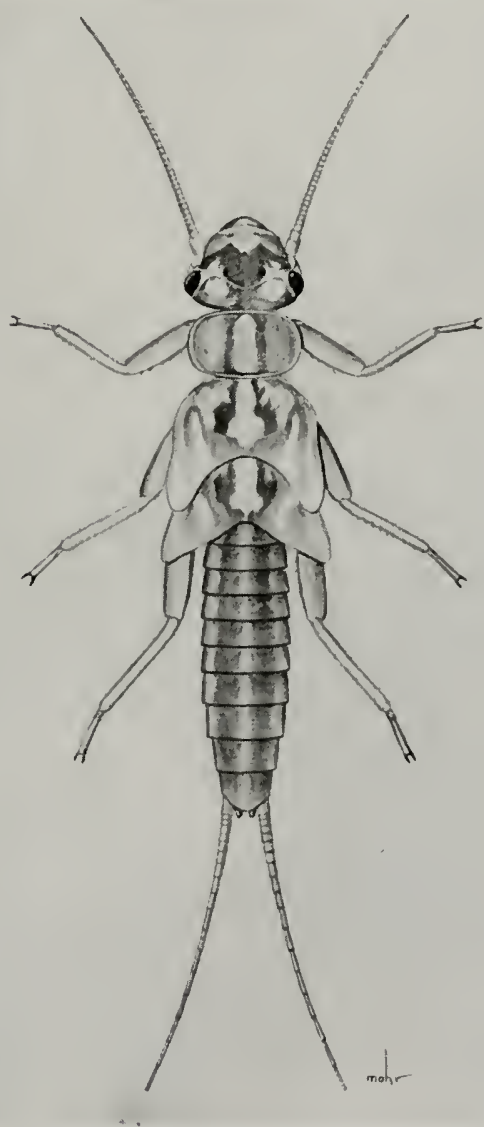

Fig. 92.-Nymph of Isoperla fusca. 
by the writer in a small stream at Dunraven Pass, Mount Wasliburn, Y'ellowstone National Park, Wyo., Aug. 2, $19+0$. In addition to five male and two female adults, two nymphs and one exuvia were collected under such conditions that I am certain these immature forms belong with the adults. A nymph is shown in fig. 92.

'The adults agree very well with the original description and a dissection of the apical ahdominal sternite of one male revealed the forked chitinous process of the aedeagus which is so characteristic of this species and was illustrated by Needham \& Claassen. Several illustrations of important structures of the male and female are presented to aid future recognition of this little known species, fig. 93.

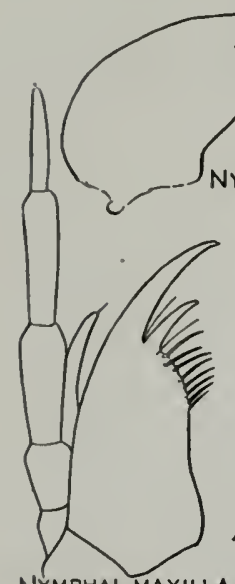

NYMPHAL MAXILLA

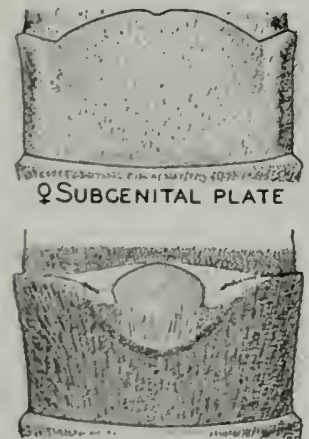

O'ABDOMINAL STERNITES

O ABDOMINAL TERGITES

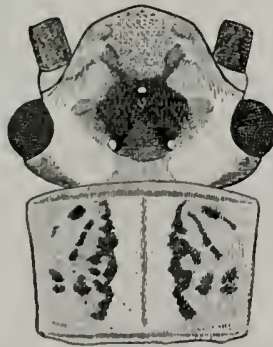

ADULT HEAD AND PRONOTUM

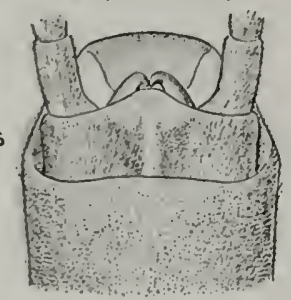

Fig. 93.-Isoperla fusca.
Since the nymph has not been previously recognized, a description and illustration of it are presented here.

Nympu. - General color hrown with lighter areas as in fig. 92. Legs, antennae, anal cerci and ventral parts of body pale yellow: Short, stout, spinelike setae, in addition to longer hairs, present on body and particularly femora. Ocelli in same relative position as in adult. Basal segments of mouthparts not extending noticeably from the sides of the head. Labium, maxillae and mandibles as in fig. 93.

Pronotum broader than long with a pale yellow longitudinal stripe in middle, fig. 93.

Abdominal tergites mostly dark brown, but a pale median longitudinal stripe is present, and a lateral Hanking stripe on each side is slightly in evidence.

Cerci long, many segmented, segments progressively longer from base to apex; small, stout, spinelike setae encircling apex of each segment, but with no evidence of long, fine setae on dorsal surface of apical segments as in some species.

Approximately mature specimens with a body length of $10 \mathrm{~mm}$.

No thoracic, anal or submental gills.

Nymphal specimens collected at same time and place as adults.

\section{Isoperla longiseta Banks}

Isoperla longiseta Banks (1906c, p. 337). Original description, $\$$.

Isoperla longiseta is a species apparently associated with the prairie and plain states mostly west of the Mississippi River and partially replaced in the Rocky Mountain and perhaps entirely in the IVest Coast states by mormona Banks. 'The collection of specimens of this species in Missouri by Dr. H. H. Ross in 1937 and the determination as this species of material from Ames, Iowa, in 1935, indicated it might some day be found in western lllinois. This supposition was confirmed in 1939 by the capture in extreme western Illinois, on the Mississippi River at Quincy, of a single female of this species. I am inclined to believe that the record of longiseta from "Indiana" by Needham \& Claassen (1925) was in error.

The two typic females, No. 11,336, in the collection of the Museum of Comparative Zoology, have been studied and com- 


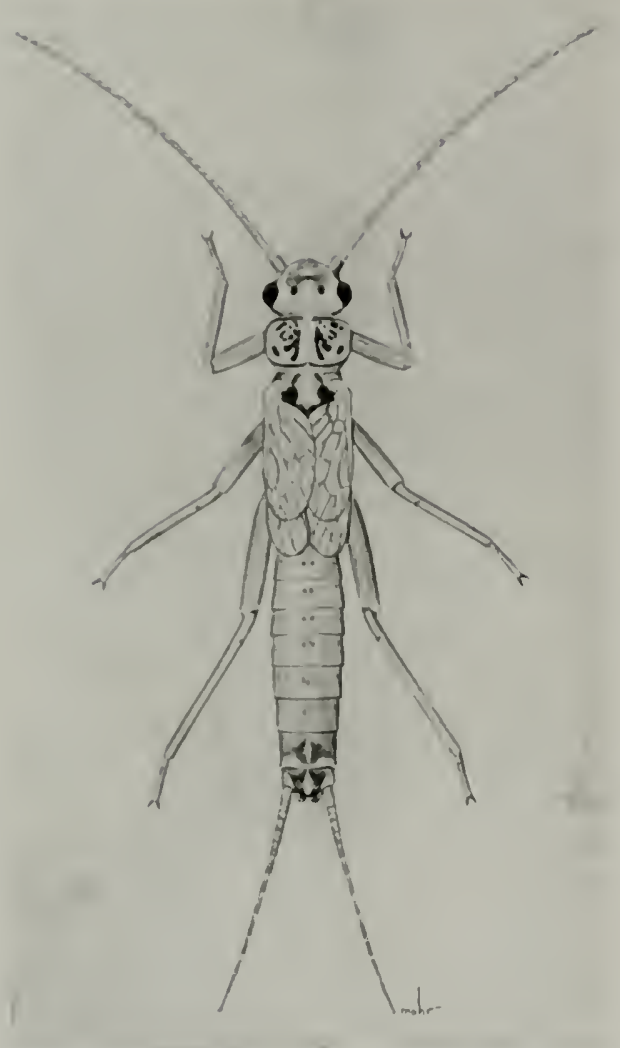

Fig. 96.-Isoperla longiscta, adult male from Texas.

more like mormona. 'The other characters of these 'I'exas specimens, and, particularly, the shape of the subgenital plate of the female, strongly support, however, their specific identity with longiseta. The Illinois Natural History Survey collection also contains a single male from "La Veta Piss, Colorado," which apparently agrees with the Texas specimens in every way.

'The nymph of this 'lexas race, as I now consider it, of longiseta is typical of the Isoperla group or complex containing the species bilineata (Say). Fig. 9t shows the shape of the mandibles, maxillac and labium, and fig. 97 is a dorsal view of the mymph, all drawn from exuviae. 'The nimph of typical longiseta from other states has not been described or illustrated, and when found it should help clear up the status of these Texas specimens.

Distributional records for longiscta based upon specimens in the Illinois Natural History survey collection, or submitted for identification, are as follows.
It.1.1015.-Quincy: June 8, 1939, Burks \& Riegel, 1 오.

Colorabo.-Lat Vetat P.iss: July 21, 1938, D. J. \& J. N. Kinull, 1 ô (brachypterous). [owA.-Ames: May 30, 1929, $1 \hat{\delta}, 1$; J June 1, 1929, $2 \circ$; June $3,1929,3 \hat{\circ}, 1 \uparrow ;$ June 10 , 1931, P. A. Moore, 3 오.

Minnesota.-St. Paui, University Farm at light: June 16, 1933, A. A. Granorsky, 1 . Missourt.-Jefferson CirY: May 29, 1937, H. H. Ross, $1 \hat{\delta}, 1$.

Montina. - Glendive, Yellowstone River: July 14,1940, J. A. \& II. II. Ross, $3 \hat{\delta}, 7$.

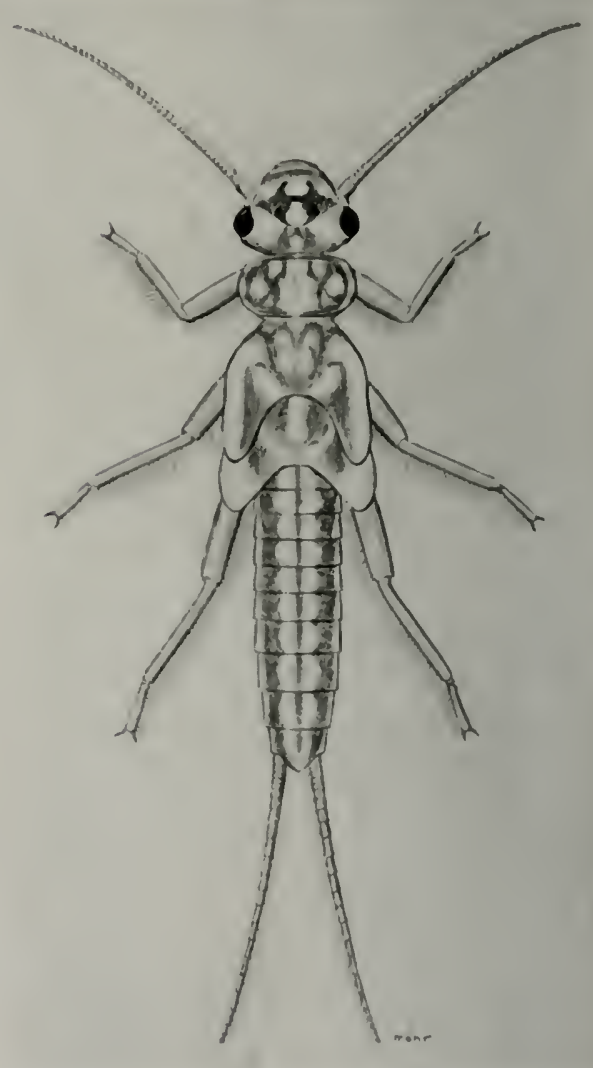

Fig. 97.-Isoperla longiscta nymph, drawn from exuviae collected in Texas.

Lonman, Milk River: July 13, 1940, J. A. \& H. H. Ross, 2 \%. Wot.F Point, Missouri River: July 14, 1940, J. A. \& H. H. Ross, 28,9 ․

Soutil Dakota.-Brookings: 19 ; June 6, 1919, H. C. Severin, $1 \hat{\delta}$. Buffalo: June 19, 1925, H. C. Severin, $1 \hat{\delta}, 1$. ChamberLain, Missouri River: June 19, 1940, J. A. \& H. H.

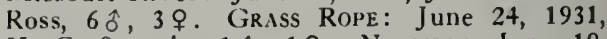
H. C. Severin, $1 \hat{\delta}, 1 \%$. Newell: June 19, 1923, H. C. Severin, $1 \hat{\delta}$. SPRINGFIELD: June 15,1928, H. C. Severin, 1 \%. YANkTON: June 18,1930, G. I. Gilbertson, $2 \hat{\delta}, 4+$; June 25, 1934, H. C. Severin, 2 오. 
Texas.-El Paso: April 22, 1939, J. A. \& H. H. Ross, $8 \hat{\delta}$ (brachypterous), $q$ \&, 3 exuviae.

Wroming. - Madison Junction, IELLowstone National Park, Gibbons River: July 8, 1936, H. H. Ross, 1 ․ Pinedale, Green River north of town: July 6, 1936, H. H. Ross, 1 $\delta$. Upton: June 20, 1940, J. A. \& H. H. Ross, $2 \hat{\delta}, 1$ ㅇ․

\section{Isoperla mormona Banks}

Isoperla mormona Banks (1920, p. 322). Original description, 오.

Isoperla insipida Hoppe (1938, p. 157). Original description, $\hat{\delta}$, $q$. New synonymy.

This species is apparently closely related to longiseta Banks, as mentioned in the discussion of that species. The type, a single female, No. 10,822, from "Vineyard, Ut.," in the collection of the $\mathrm{Mu}$ seum of Comparative Zoology, has been studied and compared with specimens in the Illinois Natural History Survey collection. Also, through the kindness of Professor Trevor Kincaid of the University of $W$ ashington, I have had the opportunity of studying the holotype and allotype of insipida, as well as most of the paratypic specimens. I find them all to be synonymous with mormona, which is apparently a Rocky Mountain and West Coast species, meeting with longiseta in such states as Wyoming and Montana.

Records for this little-known species contained in the collection of the Illinois Natural History Survey or identified for others are as follows.

ArizonA.-Coconino County, Oak Creek at Indian Garden: June 13, 1937, Leonora K. (iloyd, $+\delta, 3 q$.

Montana.-Toston, Missouri River: June 22, 19+0, H. H. \& J. A. Ross, 3 ô, 7 \%.

Oregon.-Benton County, Oak Creek: R. E. Rieder, 16,1 o. Convallis: April 18, 1939, S. E. Crumb, Jr., $1 \delta$; April 21, 1938, W. M. W., 1 f. Freschales, Harney County, Blitzen River: July 7, 1935, S. G. Jewett, Jr., $1 \hat{\delta}$, 6 영 July 11, 1935, 9ô, 6q ; Aug. 2, 1935, 1 $q$. Granger Station, near Convallis: April, 1938, N. A. Ramsdell, 6ô, 2 q. KLAMATH County, Crooked Creek: July 8, 19+0, F. Glover, $8 \hat{o}$, $q q$. Malheur County, Trout Creek: July 30, 1937, S. G. Jewett, Jr., 3 d, 3\%. Moldila, Clackamas County, Molalla River: July 1, 1935, S. G. Jewett, Jr., 1 \%. Pendefton: June 5, 1934, R. E. Dimick, 1 ㅇ. SUTTLE LAKE, $3,+35$ feet elevation: Aug. 6, 1935, H. A. Scullen, 1 \%

UTAH.-AMERICAN FORK: July 6, 1939, G. F. Knowlton, $1 \delta, 2 \%$. ElsinORE: July 22, 1937, G. F. Knowlton, $+\hat{o}, 2$. 2 . HeBer: July 25, 19+0, G. F. Knowlton, 1 ㅇ. LEHI: July 2, 1939, G. F. Knowlton, +q. Logax CANYoN: May 17, 1933, G. F. Knowlion, 1 \%. Milford:
July 2, 19+1, Knowlton \& Hardy, 18 . Orton: July 5, D. J. \& J. N. Knull, 1 . . Sunset: July 26, 1933, G. F. Knowlton, $3 q$.

Wyoming. - Boulder, tributary of Pine Branch River: July 6, 1936, H. H. Ross, 2 . Madison Junction, Yellowstone National Park, Gibbons River: July 8, 1936, H. H. Ross, $1 \hat{o}, 2$ ㅇ․

Since insipida is a synonym of mormona, the Washington and Oregon records associated with ins!pida must now be referred to mormona.

\section{Isoperla dicala new species}

MaLe.-General color creamy yellow with fuscous or brownish areas. General type of coloration similar to that of the Isoperla bilineata (Say) complex. Dorsum of head dominantly creamy yellow without a dark $V$-shaped area uniting lateral and median ocelli, a few small dusky or brownish spots adjacent to ocelli, fig. 98. Pronotum with margins and a wide, median, longitudinal stripe creamy yellow; area each side of stripe with raised rugosities dusky or brownish, fig. 98. Mesonotum and metanotum mostly creamy yellow but each with a dusky or brownish spot on central posterior area, fig. 98. Abdomen entirely creamy yellow. Legs, except for brownish tarsi, essentially creamy yellow. Antennae with basal segments creamy yellow and succeeding segments fuscous or brown. Anal cerci creamy yellow.

Head slightly wider through compound eyes than width of pronotum; lateral ocelli farther distant from one another than each is distant from median ocellus, distance between each lateral ocellus and inner margin of compound eye about onehalf the distance between lateral ocelli.

Pronotum approximately quadrangular, broader than long, a distinct pattern of raised rugosities on surface each side of yellow, median, longitudinal stripe, fig. 98.

Legs with first and second tarsal segments together much shorter than third, first tarsal segment longer than second.

Wings mostly very pale or hyaline, with stigmal areas milky; veins mostly pale, but costal and some in middle area of wing brown.

Abdomen, fig. 98, with tenth tergite not cleft; subanal lobes weakly developed and scarcely visible from above; ninth sternite, fig. 98, produced backwards so that apical tergites are not visible in ventral view, eighth sternite with a prominent long, 

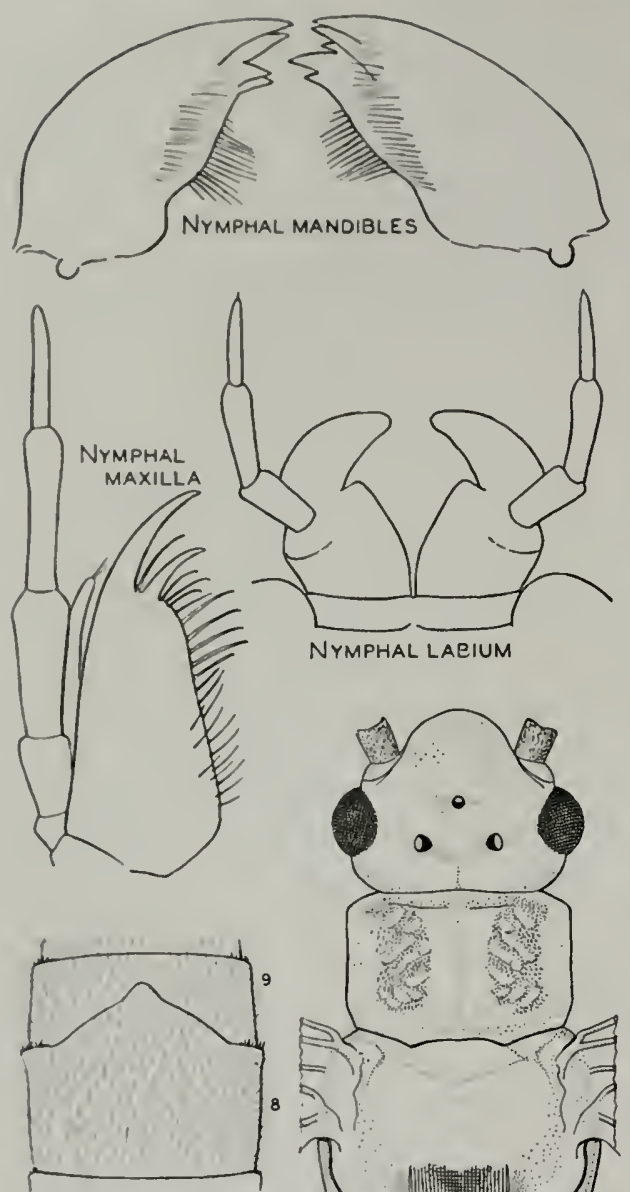

NYMPHAL LABIUM

O SUBGENITAL PLATE
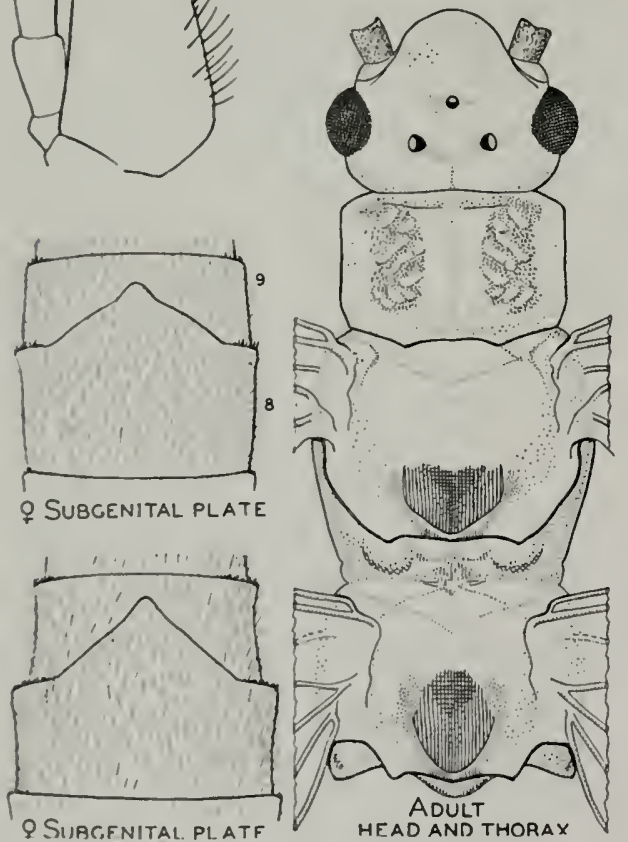

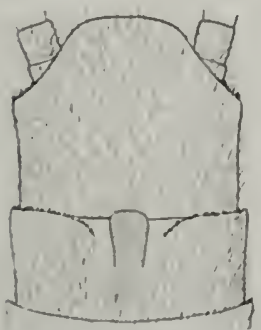

O TERMINAL ABDOMINAL STERNITES
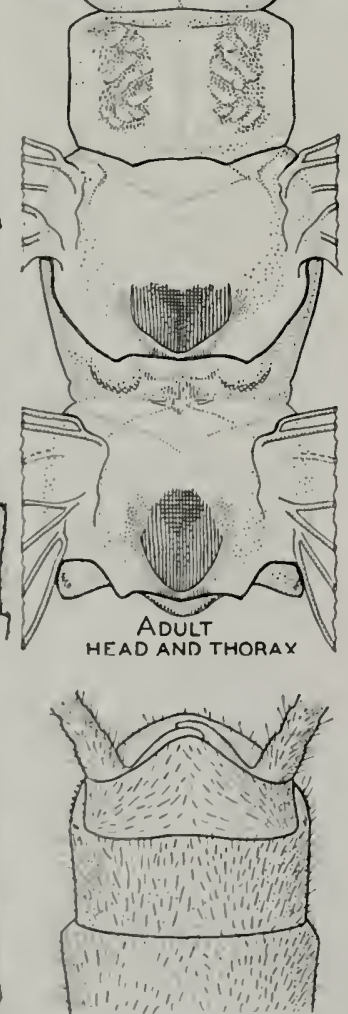

O’ TERMINAL ABDOMINAL TERGITES
Fig. 98.-Isoporla dicala. deeply recessed lobe in middle of posterior margin.

Length to tip of wings $11 \mathrm{~mm}$; length to tip of abdomen 8 mm.

Finale. - Head, thorax and basal abdominal segments and appendages in general similar to those of male, but slightly larger in size. Important differences are as follows: eighth abdominal sternite, fig. 98 , triangularly produced over ninth sternite and with sides slightly curved inwards on each side just before extreme tip.

Holotype, male.-Free Soil, Great Sable River, Mich.: reared from nymph, May 26, 1939, T. H. Frison \& H. H. Ross.

Allotype, female.-Same data as for holotype.

Paratypes.-Michigas. - FreE Soll: Same data as for holotype, $1+\hat{o}, 8 \%$. Osceola County, Pine River near LuTher: June 27, 1936, 2 \%. LAkE County, Pine River: June 3, 1938, R. P. Bohlard, 5ô, 2 ..

Other specimens which I am identifying as this species but which I do not want to include as paratypes because of lack of nymphs from same general area are as follows.

Tennessee.-Sevierville, at light: June 11, 1938, T. H. Frison \& T. H. Frison, Jr., $1 \hat{o}$, 13 + . Gatlinburg: Little Pigeon River, June 12,1935 , H. H. Ross, 1 ; at light, June 11, 1938 , T. H. Frison \& T. H. Frison, Jr., 1 ; June 1t, 19+0, T. H. Frison et al., 2 ㅇ.

Missouri.-Greer Springs: June 7, 1937, H. II. Ross, 2 \%

Minnesota.-Pine County, Snake River: May 26, 1939, P. H. Harden, $1 \hat{o}$.

IndANA.KNox, Yellow River: May 24 , 1937, H. H. Ross, 1 oิ.

NYMPH. - General color of dorsum brown with small pale areas, fig. 99; venter, except for conspicuous, short, brown, spinelike setae on apical abdominal segments, creamy yellow. Legs, antennae and anal cerci dominantly pale yellow, with short, stout, spinelike setae on femora very numerous and conspicuous. Ocelli in same relative position as in adult. Basal segments of mouthparts not extending out from sides of head. Numerous conspicuous, short, stout, spinelike setae on dorsum, particularly prominent on back of head, anterior part of mesonotum and metanotum and on abdominal tergites. Labium, maxillae and mandibles as in fig. 98.

Pronotum broader than long, with markings as in fig. 99.

Abdominal tergites dark with a series of pale spots which tend to set off a series of longitudinal dark and somewhat lighter colored stripes, the median and two lateral stripes darkest, fig. 99. Cerci long, with many segments, progressively longer from 


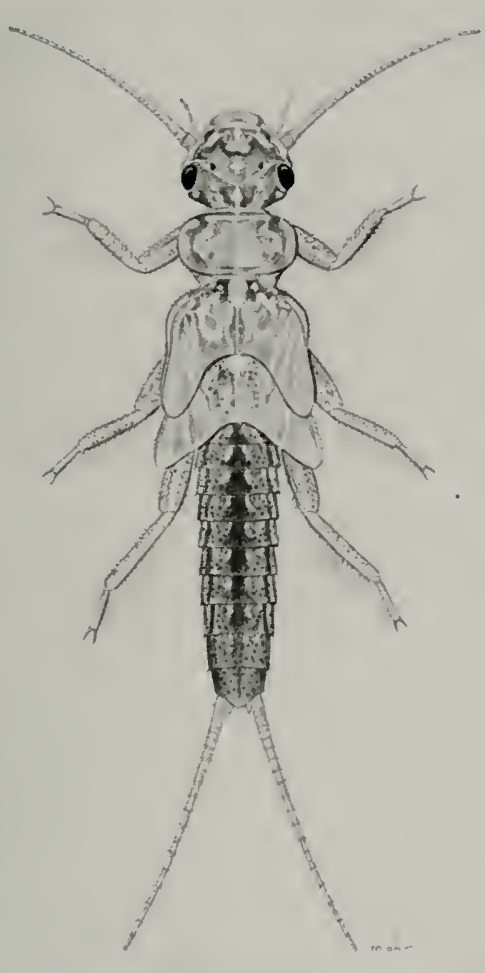

Fig. 99.-Nymph of Isoperla dicala.

base to apex, a longitudinal row of long, fine setae on dorsal surface of apical segments in addition to smaller spinelike ones encircling apex of each segment.

Approximately mature specimens with a body length of $10 \mathrm{~mm}$.

No thoracic, anal or submental gills.

Nymphal records are as follows.

Michigan.-FreE Soll, Great Sable River: May 26, 1939, T. H. Frison \& H. H. Ross, numerous nymphs. RAPID RIVER, Rapid River: May 12, 19+0, T. H. Frison \& H. H. Ross, 4 nymphs. Baldwin, Pere Marquette River: May 9-10, 19+0, T. H. Frison \& H. H. Ross, 8 nymphs. PEAcock, Little Manistee River: May 10, 19+0, T. H. Frison \& H. H. Ross, 15 nymphs. Irons, Little Manistee River: May 28, 1939, T. H. Frison \& H. H. Ross, many nymphs. Howor, Platte River: May 27, 1939, T. H. Frison \& H. H. Ross, 1 exuvia Brunswick, Brooks Creek: May 29, 1939, T. H. Frison \& H. H. Ross, 1 exuvia. CraWFord Countr, near branch of Au Sable River: May 18,1936, J. N. Leonard, 1 nymph.

Minnesota.-Ery, 12 miles southeast, Kawishiwi River: June 21, 1939, R. H. Daggy, 1 nymph.

New Brunswick. - Penobsquis: Aug. 20, 1939, T. H. Frison \& T. H. Frison, Jr., 1 exuvia.
This species, on the basis of habitus, belongs in the Isoperla group or complex containing bilineata. The long, deeply recessed lobe in the middle of the posterior margin of the eighth abdominal sternite in the male easily separates it from bilineata, as does also the lack of a $V$ shaped line connecting ocelli on the head. The nymph is very dark, with numerous conspicuous, short, stout setae; in this respect reminding one of minuta (Banks), but the head pattern is quite different, and maxillae have two large teeth at apex instead of one.

Adults were observed at Free Soil, Mich., to be emerging during the daytime from nymphs clinging to logs on the sides of the river bank. This habit of emerging during the day has been noted in the case of another species, decepta Frison, in Illinois.

\section{Isoperla orata new species}

Female.-General color creamy yellow with fuscous or brown markings. General type of coloration similar to that of the Isoperla bilineata (Say) complex. Dorsum of head, fig. 100, mostly creamy yellow; compound eyes and area immediately surrounding ocelli black; lateral ocelli connected with median ocellus by short, dark stripes which connect with a large, solid, transverse, graduate, dark patch adjacent to median ocellus. Pronotum mostly creamy yellow except for fuscous or brownish area associated with raised rugosities, fig. 100. Mesonotum and metanotum mostly creamy yellow with some fuscous or brownish areas. Abdomen essentially creamy yellow witl slight traces of fuscous longitudinal stripe on tergites. Antennae, legs and anal cerci practically concolorous with body.

Head wider through compound eyes than pronotum; ocelli forming an almost equilateral triangle, lateral ocelli somewhat farther apart than each is distant from inner margin of compound eye.

Pronotum broader than long, approximately quadrangular in shape, a distinct pattern of raised rugosities on disk each side of median pale-colored stripe.

Legs with first and second tarsal segments together much shorter than third. first tarsal segment longer than second.

IVings very pale or hyaline with stigmal 
areas milk! ; reins pale and almost concolorous with connecting membrane.

Abdomen, fig. 100, with no distinctive features except for shape of subgenital plate on posterior margin of eighth sternite: subgenital plate extends somewhat wer nintl sternite, is broadly rounded on posterior margin, slightly indented at tip. and with a concave, transwerse valley at

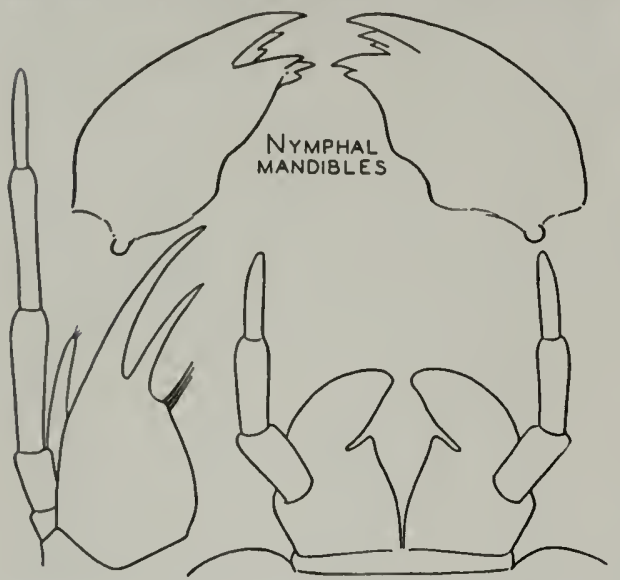

NYMPHAL MAXILLA

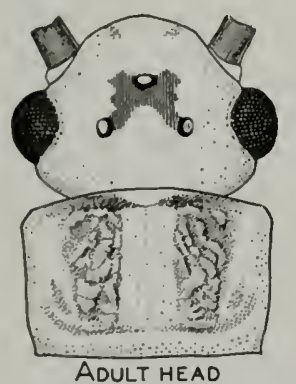

AND PRONOTUM

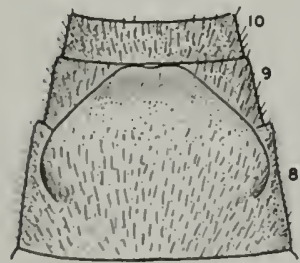

\& SUBCENITAL PLATE

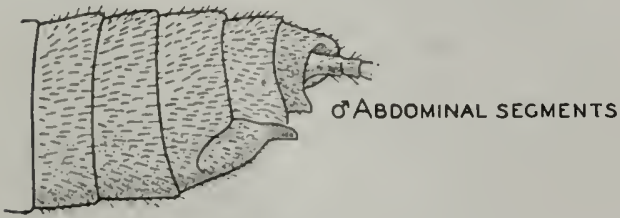

Fig. 100.-Isoperla orata. its hase; subgenital plate, as viewed from side, tends to extend away from abdomen much as in truncata frison.

Length to tip of wings $11 \mathrm{~mm}$. ; length to tip of abdomen $7 \mathrm{~mm}$.

MAle.-Head, thorax and basal abdominal segments in general similar to those of female, but slightly smaller in size. Important differences or structures are as follows: tenth tergite not cleft, fig. 100, subanal lobes weakly developed and but slightly visible from above; ninth sternite, fig. 100, produced backwards so that apical tergites are not visible in ventral view; eighth sternite with a shallowly recessed but distinct lobe in middle of posterior margin.

Holotype, female. - Gatlinburg, Le Conte Creek, Tenn.: reared from nymph, May 14 , 1939. I. H. Frison \& H. H. Ross.

Allotype, male.-Same data as for holotype.

Paratypes.-Tennessee.-Gatilinurg: Same lata as for holotype, $5 \%$; same data as for holotype except not reared, $5 \hat{\delta}, 18 \%$; June 14, 1940, T. H. Frison $\mathrm{ct}$ al., 1 \%, reared from nymph; same data except not reared, 16 ; fork of Little Pigeon River, May 27, 1934, T. H. Frison, $1 \hat{\delta},+q$; Fighting Creek Gap, May 15, 1939, T. H. Frison \& H. H. Ross, 1 o, 2․ Elkmont, June 13, 19+0, T. H. Frison et al., 1 ㅇ․

NEW YORK.-Keene, tributary of Sable River: June 20, 1941, T. H. Frison \& H. H. Ross, $3 \hat{\delta},+9$. EUna Mir.s, Adirondack Park: June 20, 19+1, T. H. Frison \& H. H. Ross, 1 $\delta, 19$. Hawkinsvit.te, Black River: June 19, 1941, T. H. Frison \& H. H. Ross.

New HAMPsiliRe. - Bentos, Witcherville Brook: June 21, 19+1, T. H. Frison \& H. H. Ross, 12 f , 3 \%.

Nortil Carol.1na.-SMOKEMont, Oconaluftee River: May 28, 193t, 'T. H. Frison.

Pennsyivinia. - Swiftwater, Montoe County: 1928, F. R. Nevin, 2 ㅇ (A.N.S.).

VERMONT. - Topsilim, Waits River: June 21, 19+1, T. H. Frison \& H. H. Ross, $3 \hat{o}$.

NympH.-General color yellow with dark markings on dorsum of head, thorax and abdomen, fig. 101. Legs, antennae and anal cerci dominanty pale yellow. Short, stout, spinelike setae, in addition to longer hairs, present on body and legs but bases not conspicuous as in such species as decepta Frison and dicala Frison, the latter described in this paper. Ocelli in same relative position as in adult. Basal segments of mouthparts not extending out from sides of head. Labium, maxillae and mandibles as in fig. 100.

Pronotum broader than long with dark markings on disk, as in fig. 101.

Longitudinal dark stripes on abdominal 
tergites tend to be connected on hind margin of segments by narrow transverse line which gives tergites somewhat the appearance of having cell-like light spots each side of median, longitudinal stripe.

Cerci long, many segments, progressively longer from base to apex, a longitudinal row of long, fine setae on dorsal surface of apical segments in addition to smaller, stout, spinelike ones encircling apex of each segment.

Approximately mature specimens with a body length of $8 \mathrm{~mm}$.

No thoracic, anal or submental gills.

Nymphal records are as follows.

Tennessee.-Gatlinburg, Le Conte Creek: May $1+, 1939$, 'T. H. Frison \& H. H. Ross, 2 nymphs, numerous exuviae. West of OzONE:

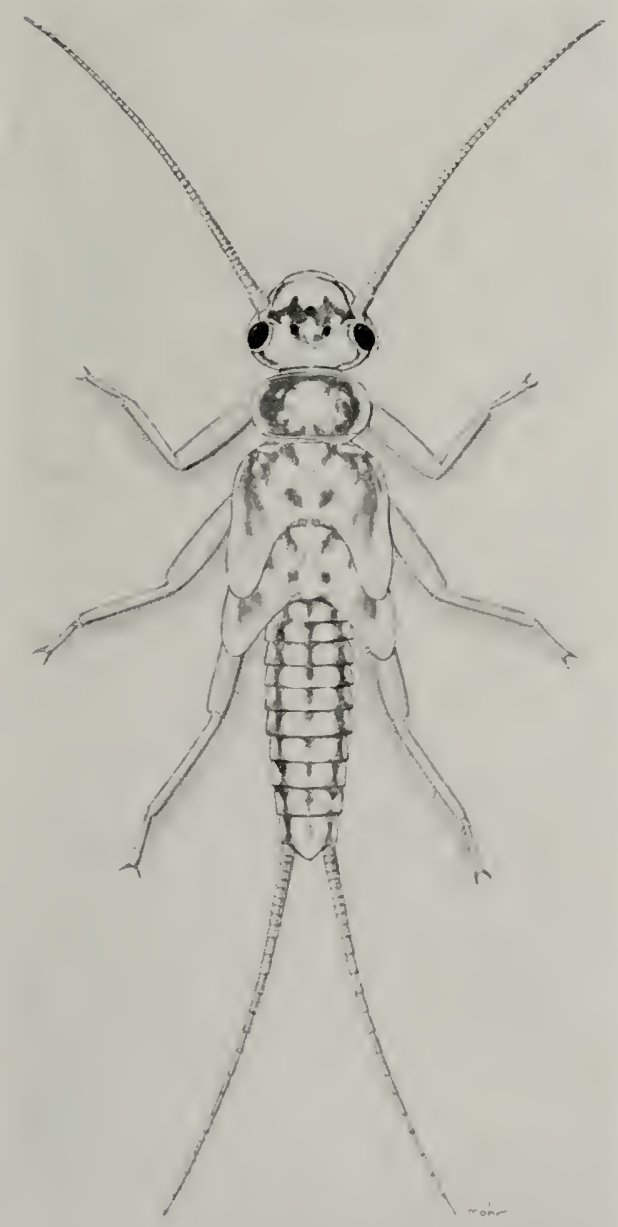

Fig. 101.-Nymph of Isoperla orata.
May 15, 1939, T. H. Frison \& H. H. Ross, + exuviae. Elkmont, Little River: May 14, 1939, T. H. Frison \& H. H. Ross, 9 exuviae. North Carolina.-Smokemont, Oconaluftee River: May 28, 193t, 10 nymphs.

This is another species belonging to the group or complex of Isoperla species containing bilineata (Say). The shape of the dark area connecting the lateral and median ocelli is very suggestive of truncata Frison, but the color pattern of the nymph and the much broader subgenital plate of the adult female indicate it is a distinct species. 'That the two species may occur in the same territory, at least in northern states, is shown by the collection of adult females of both truncata and this new species at Hawkinsville, Black River, N. Y.. June 19, $19+1$ ('T. H. Frison \& H. H. Ross). Apparently truncata is most abundant in the north central states region and this new species in mountainous areas of the eastern states.

\section{Isoperla similis (Hagen)}

Perla similis Hagen (1861, p. 26). Original description, + .

This species was originally described from the female and recorded from "Pennsylvania and Maryland." A single female typic specimen from "PennsylvaniaUhler-1858" is in the collection of the Museum of Comparative Zoology ('Type No. 250) and has been compared with reared material in the Illinois Natural History Survey collection. Needham \& Claassen (1925) gave additional distributional records from New Hampshire and New York and described the previously unknown male, but did not figure any of the important structural features of the adults.

Claassen (1931) gave a brief verbal description of the nymph based upon a male nymphal skin from which the adult was reared. Evidently this nymphal skin did not show the distinctive color pattern of the nymph, which is somewhat suggestive of Diploperla hastata (Banks); at least it was not noted. The pale, longitudinal stripe down the middle of the otherwise brownish abdominal tergites, coupled with the color pattern of the head, helps to recognize this species, fig. 102. The maxillae, mandibles and labium of the nymph are as in fig. 103.

To aid with the future identification 


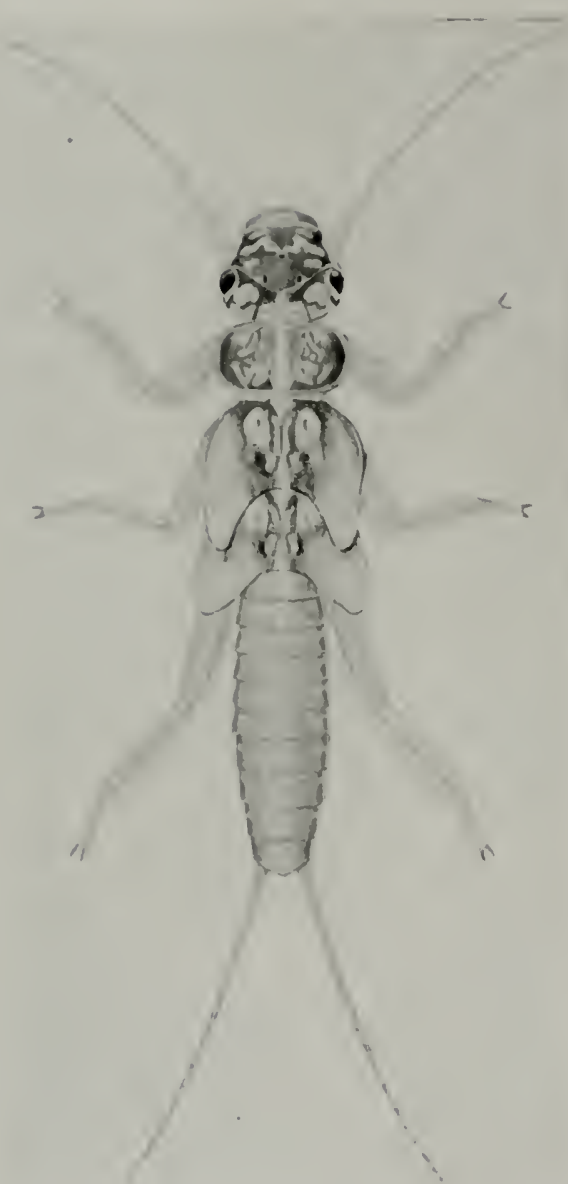

193t, T. H. Frison, $1 \hat{\delta}, 1$ nymph; Litule Pigeon River, June 13, 1935, H. H. Ross, $1 \delta^{\hat{\delta}}$.

Pexisylvania.-Swiftwater, Monroe CounIy: 1928, F. R. Nevin, Lot 258, 1 ㅇ.

Tennessee.-Gatlinburg: Le Conte Creek, May It, 1939, Frison \& Ross, 9 exuviae; March 2t, 19+0, Frison, Mohr \& Hawkins, 1 nymph; June 13, 1940, T. H. Frison ot al., $+\hat{b}, 39$; Le Conte Creek, June 14, 1940, T. H. Frison ot al, exuviae. Newfound Gsp, Little Pigeon River: May 1t, 1939, Frison \& Ross, 19 (reared), $\hat{\jmath} \hat{\delta}, 6 q,+$ nymphs,
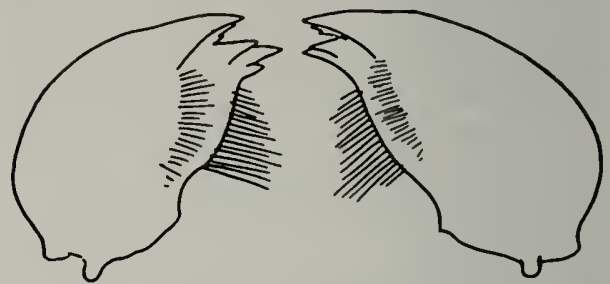

Nymphal Mandibles

Fig. 102.-Nymph of Isoperla similis.

of the adults of this species, I present illustrations of the terminal abdominal sternites of the male showing lobe on posterior margin of eighth sternite, fig. 103, the terminal abdominal sternites of the female showing shape of subgenital plate (eighth sternite), fig. 103, and the color pattern of the dorsum of the head and pronotum, fig. 103.

Additional distributional records based upon Illinois Natural History Survey collections and material submitted for identification are as follows.

Consecticut. - Waterbury, Bristol Park: March 2t, 1937, H. H. Ross, 8 nymphs.

NeW Himpsinire. - Nelson, Silver Lake Stream: Aug., 1930, C. N. Hardy, 2 nymphs.

NEW YORK.-RINGWOOD: April 30, 1937, Lot 770,1 nymph.

Northi Carolina. - Blowing Rock, near Grandfather Mountain, west of town: March 23, 1940, Frison, Mohr \& Hawkins, 7 nymphs. Newfound Gap: 3,560 feet altitude, May 28,

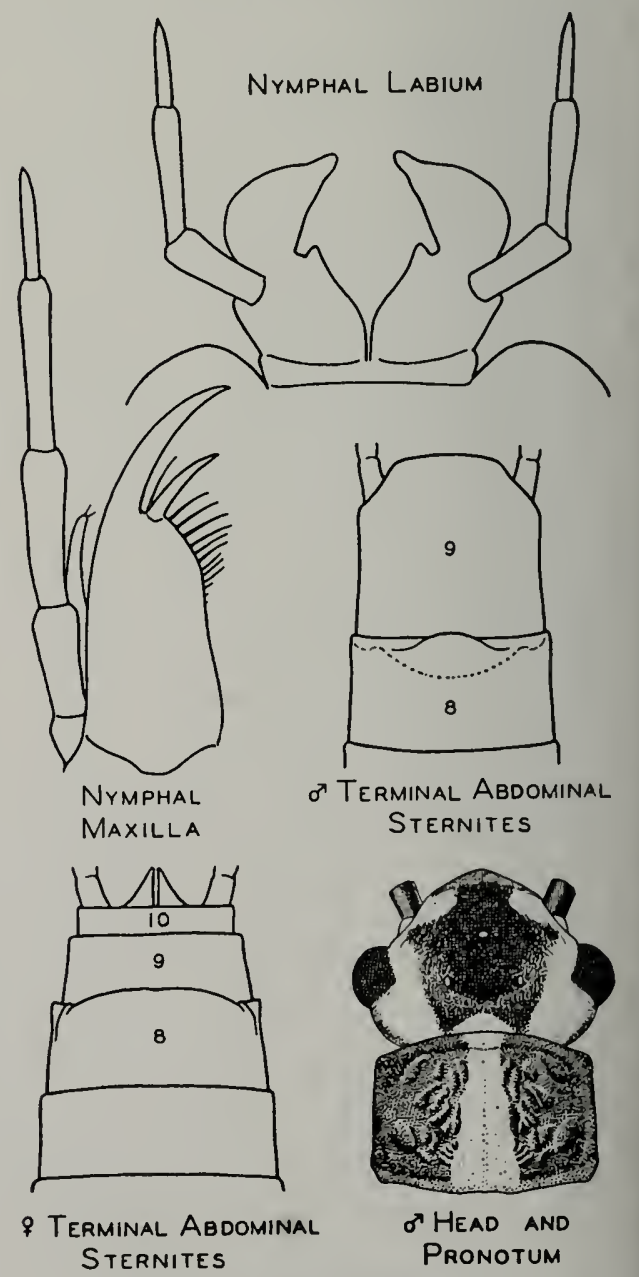

Fig. 103.-Isoperla similis. 
exuviae. Great Smoky Mountains NationAL PARk, Greenbrier Cove: March 18, 1939, A. C. Cole, $1 \hat{\delta}$.

Virginia.-Elkton, Elk River: Jan. 1, 1939, Frison \& Burks, 1 nymph. Falls CHurch: +22 (collection of N. Banks), 1 ㅇ․ Great FALls: Potomac River, March 26, 1938, B. D. Burks, $1 \hat{o}$; Potomac River, April 3, 1938, B. D. Burks, 1 o, 2 exuviae; April 10, 1938, B. D. Burks, 2 exuviae. LydiA: April 20, 1938, Ross \& Burks, 2 ô, 1 exuvia. ShenandoAH NaTional PARK, Big Meadows: April 20, 1938, Ross \& Burks, nymphs; April 30, 1940, T. H. Frison et al., $\hat{\delta}$ with exuvia (reared). Skyline Drive, south of Front Royal: March 17, 1940, T. H. Frison et al., 2 nymphs. STANDARDSville: March 21, 1940, Frison, Mohr \& Hawkins, 2 nymphs.

\section{Isoperla namata new species}

MALE.-General color in life bright yellow with dusky or fuscous areas. Dorsum of head yellow with dark or dusky markings as follows: a $V$-shaped mark connecting median and lateral ocelli, portion of head anterior to median ocellus and several patches on posterior margin of head behind eyes, fig. 10t. Pronotum with a broad, median, longitudinal, yellow stripe somewhat constricted in the middle, and with fuscous raised rugosities each side of stripe, fig. 10t. Mesonotum and metanotum with medial and posterior portions yellow and remainder of dorsum and most of sides dark brown or fuscous. Abdomen on dorsum with a narrow, dark, median, longitudinal stripe and a broader, dark, longitudinal stripe on each lateral margin extending to about the ninth tergite, the ninth and tenth tergites mostly yellow. Legs with trochanters, coxae and tips of femora yellow, tibiae and most of femora dark or fuscous. Antennae and anal cerci with all segments black. In specimens which have been preserved in fluid, the bright yellow color tends to become cream colored and the fuscous or dark areas tend to become dark brown.

Head slightly wider through compound eyes than width of pronotum; lateral ocelli farther distant from one another than each is distant from median ocellus; distance between compound eye and lateral ocellus about the same as between lateral ocellus and median ocellus.

Pronotum approximately quadrangular, broader than long, a distinct pattern of raised rugosities on surface each side of yellow, median, longitudinal stripe, fig. 104.
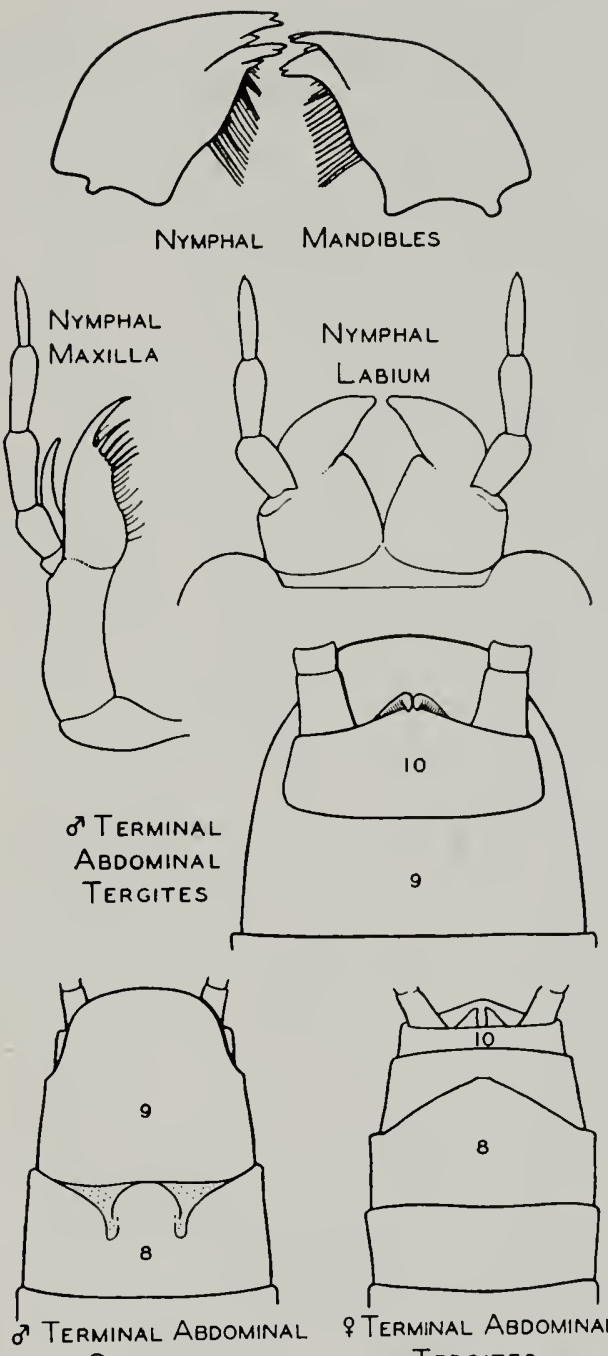

STERNITES

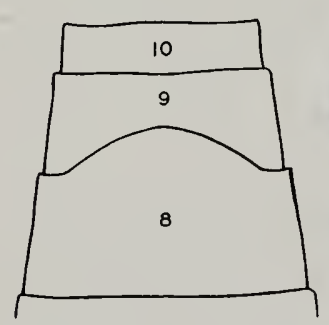

\& Subgenital Plate o Head and

TERGITES

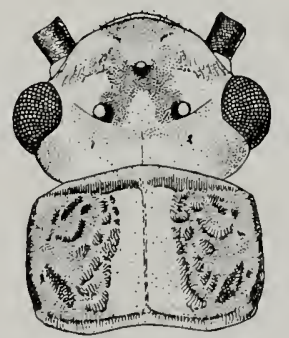

Fig. 104.-Isoperla namata.

Abdomen, fig. 10t, with tenth tergite not cleft; subanal lobes weakly developed into short finger-like processes; ninth sternite, fig. 104, produced backwards so that 
apical tergites are not visible in ventral view, eighth sternite with a prominent rounded lobe in middle of posterior margin.

Legs with first and second tarsal segments together shorter than third; first tarsal segment slightly longer than second.

Wings slightly suffused with brown; veins uniformly dark brown.

Length to tip of wings $11 \mathrm{~mm}$.; length to tip) of abdomen $S \mathrm{~mm}$.

FEMAlE.-Head, thorax and basal abdominal segments and appendages in general similar to those of male but slightly larger in size. Important differences are as follows: eighth abdominal sternite, fig. $10 t$, with subgenital plate slightly produced over ninth sternite and rounded.

Holotype, male. - Silva, Wayne County, Mo.: reared April 8, 1938, from nymph collected April 7, 1938, T. H. Frison \& Carl O. Mohr.

Allotype, female.-Same data as for holotype.

Paratypes.-Missouri.-Sir.vit: Same data as for holotype, $11 \hat{\delta}, 1+q$. Same data as for holorype except date (all 1938): April 7, 1 \% ; April 12, 29 ; April 16, $1 \hat{\delta},+q$. Zion, Madison County: reared April 15, $1 \delta, 2 q$; April 18, 1 $\delta, 20$; April 20,1 $\delta$; April 21, $1 \hat{\alpha}, 1$; April 22, 1 ; ; April 24, 1 우 ; all collected as nymphs, April 7, 1938, by T. H. Frison \& Carl 0 . Mohr, and reared.

INDIMNA-MCCORMick's CreEk State PARK: April 16, 1938, 2\&, 1 우; April 23, 1938, 1 \& ; all reared from nymphs collected April 16 by T. H. Frison.

Nymph. - General color pale yellow with fuscous areas on head, thorax and ahdomen, as in fig. 105. Legs, antennae and anal cerci pale yellow. Head with ocelli forming an almost equilateral triangle; basal segments of mouthparts not conspicuously extending out from sides of head. Labium, mandibles and maxillae as in fig. $10 t$.

Pronotum broader than long with markings as in fig. 105.

Abdominal tergites having general background creamy yellow with fine, longitudinal, dark stripes, one in middle and one on each side, a series of prominent, small, dark spots associated with dark stripes, fig. 105; some scattered, stout, short, pale setae on tergites in addition to row on posterior margin of each segment. Cerci long, many segmented, segments progressively longer from hase to apex; a longitudinal row of long, fine setae on dorsal surface of apical segments in addition to smaller spinelike ones encircling apex of each segment.

Approximately mature specimens with body length of $9 \mathrm{~mm}$.

No thoracic, anal or submental gills.

Nymphal records are as follows.

INdina-McCormick's Creek State PARK: April 16, 1938, T. H. Frison, 6 nymphs.

Missourt.-Sil.vi, Wayne County: April, 7, 1938, T. H. Frison \& C. O. Mohr, 17 nymphs; March 27, 1937, T. H. Frison, 3 nymphs.

The general shape of the subgenital plate of the female, the lobe on eighth sternite of male and subanal lobes of male, as well as general pattern of fuscous markings on dorsum of adult, approach very closely those of signata (Banks). That the species here described as new is not signat $a$ is definitely proved by the marked differences in color patterns of the nymphs; in fact, it was the distinctiveness of the nymphal color pattern observed in

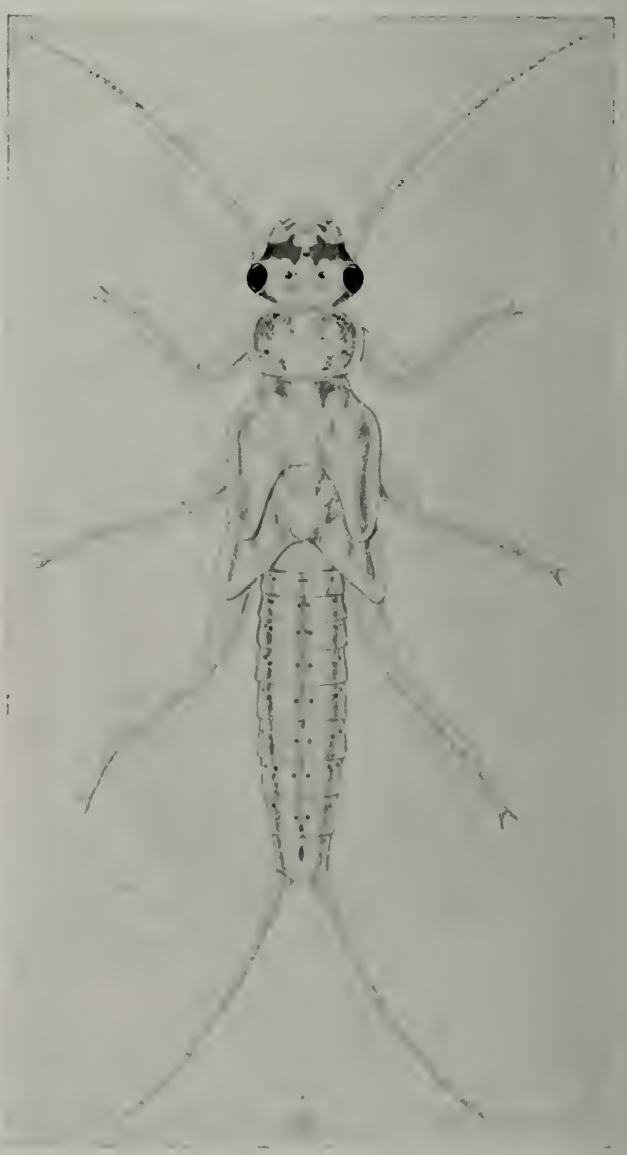

Fig. 105.-Nymph of Isoperla namata. 
1937 which led to additional collections of nymphs in 1938 and the rearing of the adults. The adults of signata are much larger than those of this new species and the body integument is heavily suffused with brown, whereas in this new species the body integument is very pale colored. The apical segments of the anal cerci in the adults of signaia are much longer than comparable segments of this new species.

\section{Isoperla slossonae (Banks)}

Perla slossonae Banks (1911, p. 335). Original description, $\hat{o}, \hat{q}$.

Clioperla annecta Needham \& Claassen $(1925$, p. 140$)$. Original description, + . New synonymy.

Studies of the single female type of slossonae in the collection of the Museum
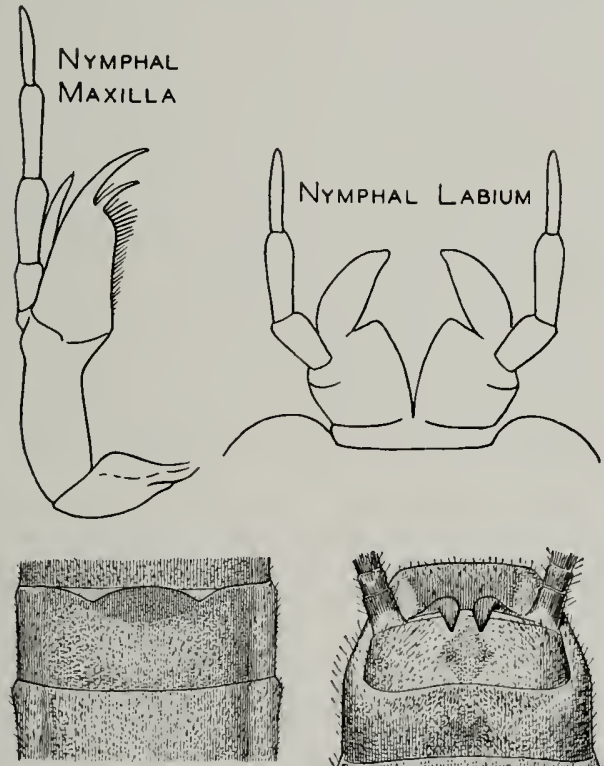

OABDOMINAL STERNITES

o" AboOMINAL TERGITES

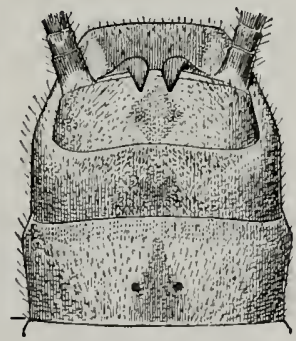

Fig. 106.-Isoperla slossonae.

of Comparative Zoology (Type No. 11,327 ), and the typic female series of annecta, in the collection of Cornell University, have revealed that these specimens are of the same species and hence the more recent name of annecta falls in synonymy. For the sake of exactness in record, it may be stated that the type of slossonae is somewhat darker in coloration than the typic series of annecta and most specimens in the Illinois Natural History Survey collection, but such a difference in degree of coloring often occurs in stonefly species.

The original description of slossonae mentions both the male and female, but only a single female type is now in the collection at Cambridge. The original description of annecta is based upon females only, collected in New York and Quebec.

Since neither Banks (1911) or Needham \& Claassen (1925) have figured the male or described certain important characters useful in identifying it, I present the following brief description of certain structures.

MALE.-Agrees in general with description of annecta as given for female by Needham \& Claassen (1925). Important structural differences are as follows: Subanal lobes developed into prominent sturdy hooks; ninth abdominal sternite much produced, fig. 106 ; eighth abdominal sternite with a broad, shallow lobe on posterior margin, fig. 106. Very suggestive of and closely related to pinta Frison (1937).

As a result of field work in several states, which enabled me to rear males and females from nymphs, I am now able to present the following description of the nymph.

NyMPH.-General color pale yellowish, with darker areas on dorsum of head, thorax and abdomen, as in fig. 107. Antennae, legs and anal cerci mostly yellowish, with dark bands at apex of femur and base of tibia especially prominent.

Head with three ocelli forming an almost equilateral triangle, each lateral ocellus about as far apart as each is distant from inner edge of compound eye; no occipital ridge; basal segments of mouthparts but slightly extending out from sides of head. Labium and maxillae as in fig. 106.

Pronotum much broader than long, with markings as in fig. 107, corners very much rounded.

Abdominal tergites with a general dark brown to black background, with rows of light spots, fig. 107, posterior margin of tenth or last tergite yellowish. Cerci long, many segmented, segments progressively longer from base to apex; a longitudinal row of long, fine setae on apical segments in addition to smaller, spinelike ones encircling apex of each segment. 


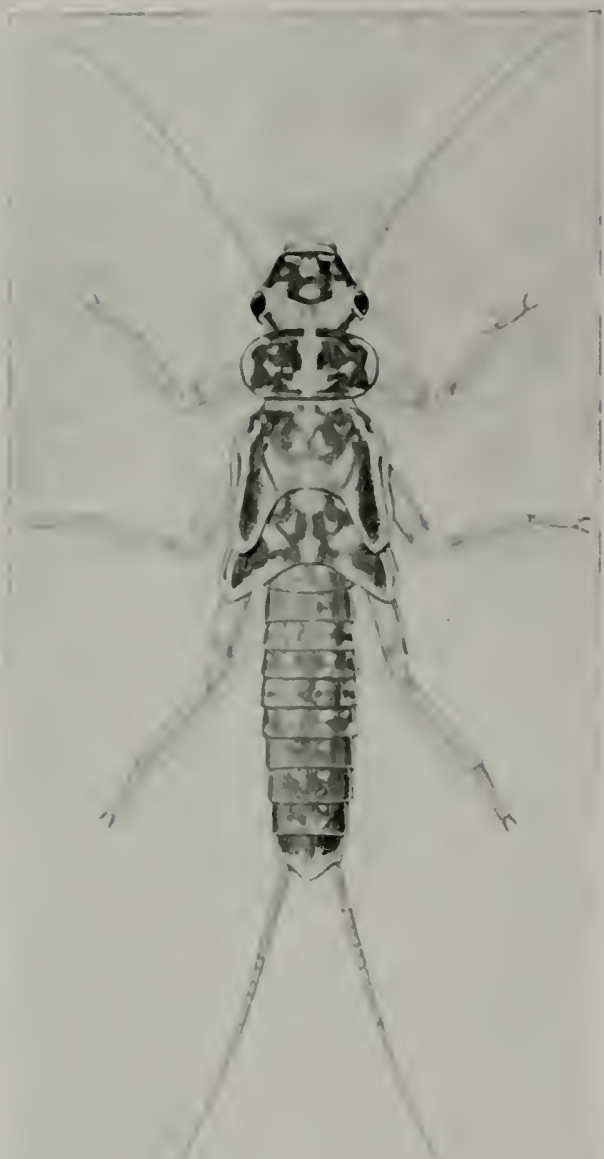

Fig. I07.-Nymph of Isoperla slossonae.

Mature specimens with body length, exclusive of appendages, up to $14 \mathrm{~mm}$.

No gills present.

New records for this species based upon specimens submitted for identification and lllinois Natural History Survey collecting are as follows.

Mane.- Double Top Mountain, Sourdnahunk River: Aug. 27, 1939, T. H. Frison \& T. H. Frison, Jr., 2 exuviae.

Michigin.-BAldwix, Pere Marquette River: May 28, 1939, Frison \& Ross, 2 ㅇ, 2 exuivae; May 9-10, 1940, Frison \& Ross, $3 \hat{o}$, 9 ․, 1 nymph, exuviae, 2 q with exuviae (reared). Crawford County, Au Sable River: Feb. 23, 1936, J. WV. Leonard, 1 nymph. Near Lovel.1.S: March 23, 1936, J. W. Leonard, 10 nymphs. Fife LAKE, near Canada Creek: Oct., 1935, 5 nymphs. Grand T'raverse County, Boardman River, 3 miles above Traverse City Power Company dam, T. 26N., R. 9VV., Sec. 18: May 7, 1935, J. W. Leonard, 83, 6 \%. GalYhisg, Manistee River: May 22, 1936, Frison \& Ross, 59 . Howor, Platte River: May
27. 1939. Frison \& Ross, + exuriae; May 10 , $19+0$, Frison \& Ross, ôे ô, 6 q, 2 nymphs, 6 exuviae. KLACKING CREEK, northwest branch: Oct. 14, 1935, 5 uymphs. LAkE Couxtr: middle branch of Pere Marquette River, south of Nirvana, Nov. 5, 1936, J. W. Leonard, 4 nymphs; Pine River, Walker Bridge Camp, May 29, 1938, J. WV. Leonard, 1 \% ; Pine River, Walker Bridge Camp, May 30, 1938, O. H. Clark, 1 f . Lewiston, Hunt Creek: Oct. 28, 1935, 7 nymphs. Lovel.Ls, Au Sable River: May 22, 1936, Frison \& Ross, +o, 2 \% 2 exuviae. Near Lovells, north branch of Au Sable River: May 24, 1936, J. IV. Leonard, 2 . Oscodi County, Perry Creek: Oct. 29, 1936, J. WV. Leonard, 2 nymphs. PEAcock, Little Manistee River: Oct., 1935, + nymphs; Oct. 24, 1935, 2 nymphs; May 10, 1940, Frison \& Ross, 2 , 2 nymphs, exuviae. Rose CiTY, Houghton Creek: Oct. 15, 1936, 6 nymphs. Wolverine, Maple River: Sept. and Oct., 1935, 2 nymphs.

Minnesota. - Bloomington, Nine Mile Creek: March 31, 1935, L. L. Smith, 10 nymphs; April 5, 1935, L. L. Smith, 1\%, 1 exuvia; April 9, 1935, L. L. Smith, 2 \% (reared); April 10, 1935, L. L. Smith, $1 \hat{\delta}$ and 1 \& (reared) ; April 13, 1935, L. L. Smith, 2 (reared) ; April 17, 1935, L. L. Smith, $1 \hat{\text { ô }, ~} 3$ nymphs. COON CREEK: April 20, 1935, H. B. Welshonse, 1 nymph. Hexiepin CounTY: Nine Mile Creek, May 5, 1933, C. E. Mickel, 1 \% ; May 2, 1936, C. E. Mickel, 2 \% May 1, 1937, R. du Toit, 1 ô, 1 웅 May 1, 1937, H. S. Telford, 1 우 ; May 3, 1937, M. 'T. Jen, 1 \% .

New Hampshire. - Glen House, Mount Washington: June 22, 1941, T. H. Frison \& H. H. Ross, $1 \%$ (compared with type of slossonac in M.C.Z.).

Novi Scotia.-SPRinghill Junction: Aug. 21, 1939, T. H. Frison \& T. H. Frison, Jr., 1 exuvia.

Wisconsin.-Boulder Junction: April 9, 1937, Frison \& Mohr, 1 क nymph; April 29, 1937, Frison \& Mohr, $1 \hat{\delta}$ (reared); May 10, 1937, Frison \& Mohr, 1 i (reared).

\section{Isoperla marlynia Needham \& Claassen}

Isoperla marlynia Needham \& Claassen $(1925$, p. 148$)$. Original description, $\hat{o}, \hat{q}$. Chloroperla montana Banks (1898, p. 199). In part, $\hat{\sigma}$ paratypic specimen.

Isoperla clio Needham \& Claassen (1925, p. 139). In part, misidentification.

Isoperla clio Claassen (1931, p. 69). Erroneous nymphal association.

Isoperla clio Frison (1935a, p. 439). Nymph.

Numerous rearings of North American species of Isoperla have revealed considerable confusion in identification of species under the specific names of clio (Newman), marlynia Needham $\&$ Claassen and confusa Frison. In the first place, there is very great uncertainty in regard to which North American species the name clio applies. Until this uncertainty is 
definitely eliminated by a restudy of the typic specimens, and they are carefully compared with all North American species of Isoperla likely to be the true clio, the use of this specific name means continual confusion. I plan to follow the course, therefore, of not using the name clio for the time being. Ricker's recent comments regarding the typic specimens of clio do not clear up the points at issue; the specimens he accepts as types in the British Museum are stated to be from "Canada," whereas, the original description is based upon material which "inhabits Georgia." Newman's clio may prove to be marlynia, confusa or some other species.

Through the kindness of Dr. Henry Dietrich of Cornell University, I have had the privilege of studying all material determined by Needham \& Claassen, or Claassen, as clio and also the typic series of marlynia. I find that some of the adults recorded as clio belong to the species which I have reared and described as confusa $(1935 a)$, and some are identical with marlynia, as follows: 2 male and 1 female adults from "Raleigh, N. C., March 22, 1907," are confusa, and 1 female adult from "Elkhart, Ind., June 18, 1902," and the nymph from "Elkhart, Ind., April," figured by Claassen (1931) are marlynia.

In the Museum of Comparative $\mathrm{Zo}$ ology there are two specimens belonging to the typic series, No. 11,339, of Chloroperla (=Isoperla) montana Banks. One of these specimens, from "Mt. Wash'n," I relaxed and placed in alcohol when I studied it in 1939; Dr. Nathan Banks has recently informed me that it has been marked "type." 'The second specimen, from "Franconia, N. H.," is a pinned specimen of another species and has been marked as "paratype." This paratypic specimen, which I studied in $19+1$, proves to be of the same species as marlynia but montana does not fall in synonymy because the "type" specimen is another species of Isoperla for which the name montana is available. The original description of montana does not refer to a "type" and a "paratype," but the specimens are now so marked by Dr. Banks. It is fortunate from a nomenclatorial standpoint that the "type" specimen is the "Mt. Wash'n" specimen now in alcohol. Specimens of Isoperla montana considered by Needham
\& Claassen (1925) are, at least in part, of the same species as the specimen now in alcohol and labeled as "type." I. montana has a much lighter colored head pattern than marlynia.

The rearing of numerous specimens of adults of marlynia from nymphs collected in Indiana and Michigan has revealed that the nymph described by Claassen (1931) as clio is in reality marlynia. As

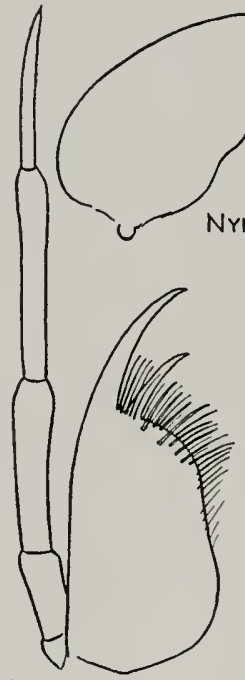

NYMPHAL MAXILLA

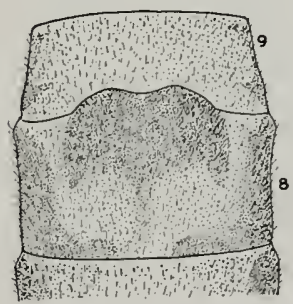

q SubGenitAL PLATE

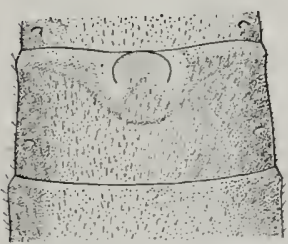

O'ABDOMINAL STERNITES

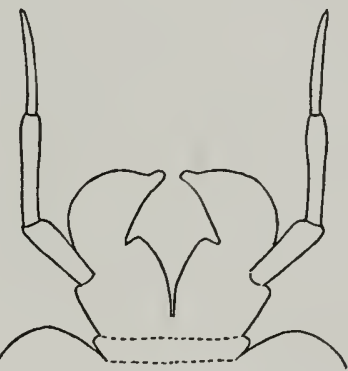

NYMPHAL LABIUM

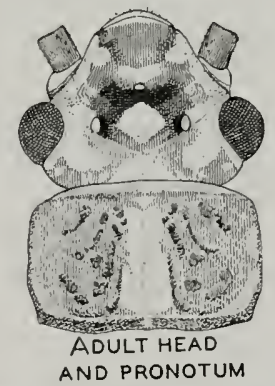

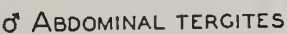

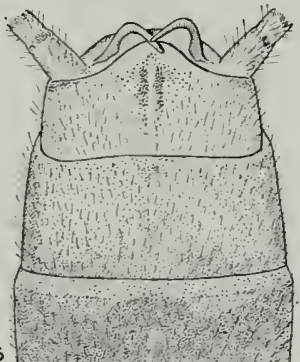

O'ABDOMINAL TERGITES

Fig. 108.-Isoperla marlynia. 
alreads stated, I feel that until the true identity of clio is definitely established the name clio should not be used. My

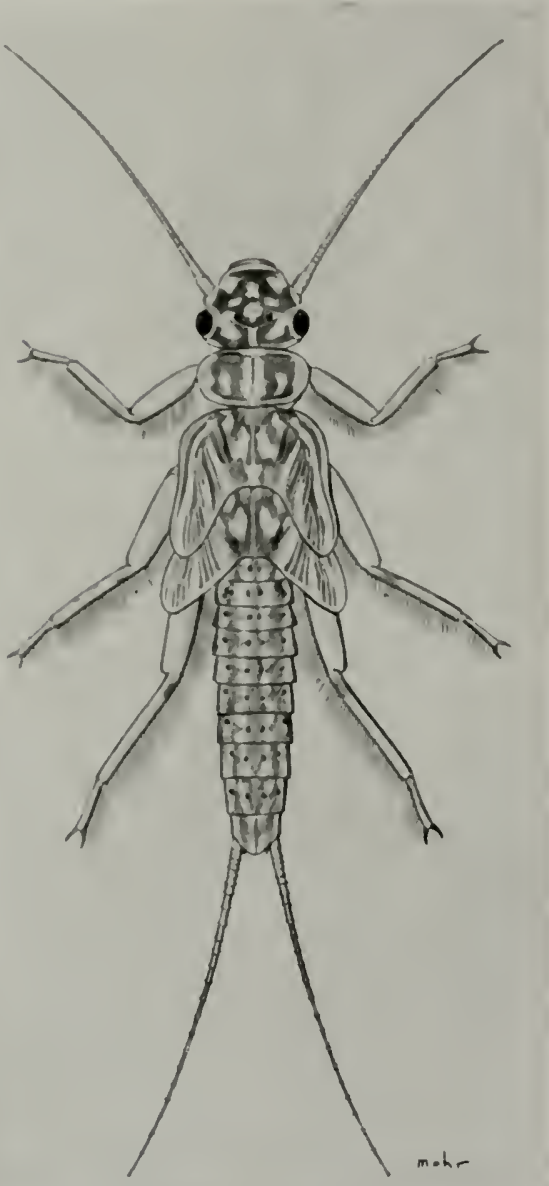

Fig. 109.-Nymph of Isoperla bilineata, dark phase.

1935 listing of certain nymphs from 11linois ats clio followed Claassen, and therefore these records should now be associated with the name marlynia.

As an aid to the recognition of marlynin, l am presenting new illustrations, fig. 108, of the adults secured by the rearing of nymphs, and also illustrations of the mouthparts of nymphs, fig. 108, and total dorsal views of three nymphs, frontispiece.

The three nymphs exhibit variations in color patterns displayed by nymphs collected at the same time and place and which, based upon reared adult material, are unquestionably of the same species. These nymphs should serve as a warning in placing too great reliance on color patterns alone when making specific determinations of Isoperla nymplis. The general color patterns in this genus are a good guide to species, but consideration must be given to variation in the extension or diminishment of markings. 'The light nymphal form of bilineata (Say) was figured in my 1935a paper, and this seems an opportune time to present an illustration of a dark phase of the same species, fig. 109.

Isoperla marlynia has not been recorded since its original description. In addition to the records previously listed under clio which should be associated with this name, and which are specifically mentioned in a preceding paragraph, I can now add the following records.

Illinols.-RockFord, Rock River: April 3, 1928, Frison \& Ross, 1 of nymph. Rock IsLAnd, Rock River: April 2, 1928, Frison \& Ross, 1 ㅇ nymph; April 27, 1932, Frison \& Mohr, 1 exuvia. (Listed by Frison $1935 a$ as clio.)

INDIANA.-Rogers, White River: March 14, 1936, Frison \& Ross, 7 nymphs; April 16, 1936, Ross \& Mohr, 1 exuvia; April 19, 1936, Ross \& Mohr, 1 \% with exuvia (reared); April 24, 1936, Frison \& Mohr, 19; April, 1940, Mohr \& Burks, 1 exuvia; April 10, 1940, Mohr \& Burks, 1 nymph, 2 \% with exuviae (reared); April 20, 1940, Mohr \& Burks, 1 oे with exuvia (reared); April 21, 1940, Mohr \& Burks, 1 ô (reared).

Manitoba.-Churchili: July 23, 1936, H. E. McClure (19CH73), $1 \delta$.

Michigan. - Nahma Junction, Sturgeon River: May 12, 1940, Frison \& Ross, 9 nymphs; same except May 14, $2 \hat{\delta}$ and 2 ? with exuviae (reared); same except May 15, $7 \delta$ and 9 o with exuviae (reared); same except May 16, $1 \delta$ and $1 \%$ with exuviae (reared); same except May $17,+q$ with exuviae, $1 \delta$ (reared); same except May 20, $2 \hat{\delta}$ and $4+9$ with exuviae (reared). Ontollagon County, between Silver City and Ontonagon, shore of Lake Superior: May 15, 1935, J. W. Leonard, 1 \%. RAPID RIVER: May 12, 1940, Frison \& Ross, 1 nymph.

VIRGINIA,-REMINGTON, Rappahannock River: March 21, 1940, Frison, Mohr \& Hawkins, 3 nymphs; same except April 2, 2 \% with exuviae (reared); same except April 3, 1 \% (reared).

Wisconsin.-Edgerton: June 5, 1936, Frison \& Ross, 1 ㅇ.

\section{Isoperla burksi new species}

Male. - General body color yellow with brown to fuscous markings. Dorsum of head with dark brown V-shaped area connecting ocelli and then extending forward to tip of head, fig. 110. Pro- 
notum with a broad, median, longitudinal, yellow stripe, fig. 110; areas each side of stripe with brown to fuscous raised rugosities. Mesonotum and metanotum brown with median dorsal area palest. Abdomen creamy yellow with sides brown to fuscous. Legs, antennae and anal cerci brown to fuscous.

Head wider through compound eyes than pronotum; ocelli forming an almost equilateral triangle, lateral ocelli much farther distant from one another than each is from inner margin of compound eye.

Pronotum broader than long, approximately quadrangular in shape, a distinct pattern of raised rugosities each side of median stripe, fig. 110.

Legs with first and second tarsal segments together shorter than third; first tarsal segment longer than second.

Wings faintly tinged with brown; veins uniformly dark brown in forewings but some veins in anal area of hindwing very pale.

Abdomen, fig. 110, with tenth tergite not cleft; subanal lobes weakly developed and not recurved over tenth tergite; ninth sternite produced backwards; eighth sternite with a prominent, rather broad lobe on middle of posterior margin, fig. 110 .

Length to tip of wings $11 \mathrm{~mm}$.; length to tip of abdomen $9 \mathrm{~mm}$.

Fenale.-Head, thorax, basal abdominal segments and appendages in general similar to those of male but slightly larger in size. Important differences are as follows: eighth abdominal sternite, fig. 110 , with subgenital plate well produced backwards over ninth sternite and with tip slightly indented; as viewed from the side the subgenital plate tends to extend downwards away from abdomen.

Holotype, male. - Eddyville, Lusk Creek, Pope County, Ill.: May 1, 19+0, reared from nymph, B. D. Burks \& C. O. Mohr.

Allotype, female.-Same data as for holotype.

Paratypes. - Illinois. - Eddrville: Same data as for holotype, $1 \hat{\delta}$. Same data as for holotype except dates of rearing as follows: May 5, 19+0, $1 \delta$; May 7, 19+0, $2 \delta, 1 \%$; May $13,1940,1 q ;$ May 15, 19+0, $1 q$; May 14, $19+0,1 \delta, 3$ \%

Nraph.-General color pale creamy yellow with some pale brownish markings as in fig. 111. Legs, antennae and anal cerci pale yellow.

Head with ocelli forming an almost equilateral triangle, basal segments of mouthparts somewhat extending out beyond sides of head. Labium, mandibles and maxillae as in fig. 110 ; second hooklike tooth at tip of each maxilla very strongly developed and extending at least two-thirds as far as primary or first tooth.

Pronotum broader than long, with markings as in fig. 111.

Abdominal tergites mostly pale creamy yellow with a narrow, fuscous, transverse band on posterior margin of each tergite
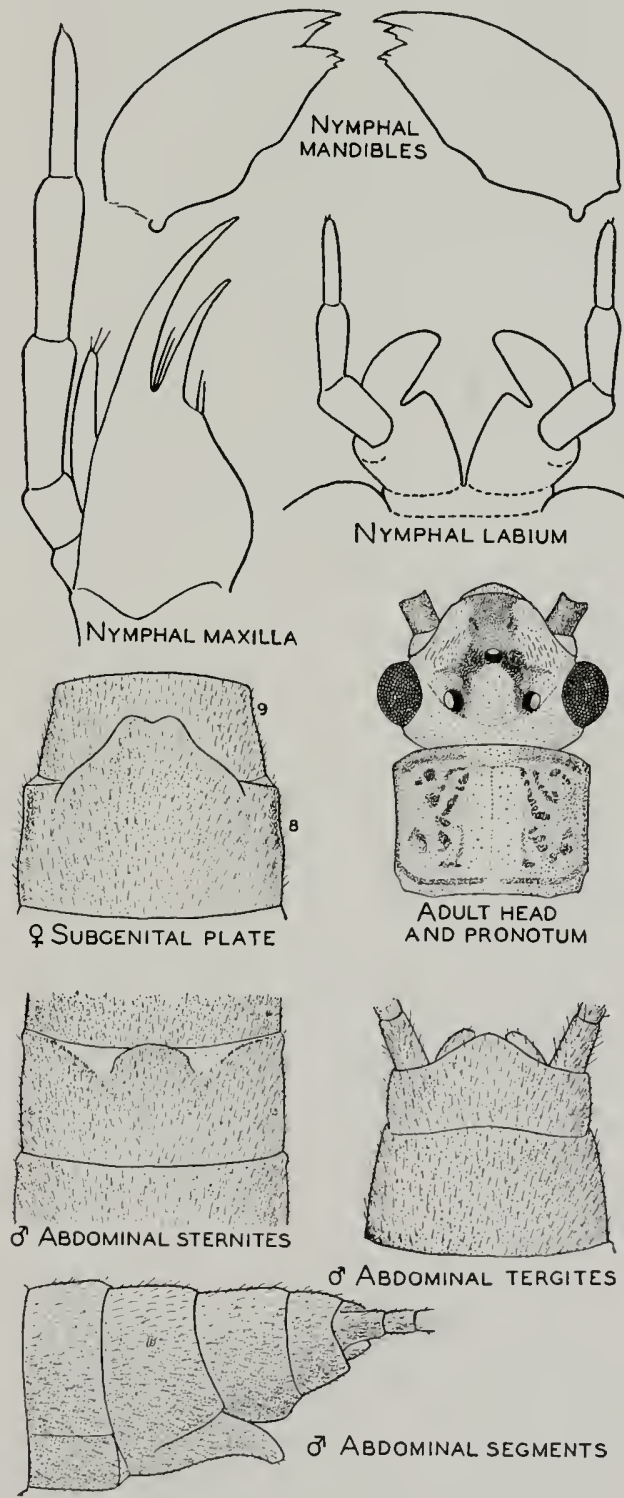

Fig. 110.-Isoperla burksi. 


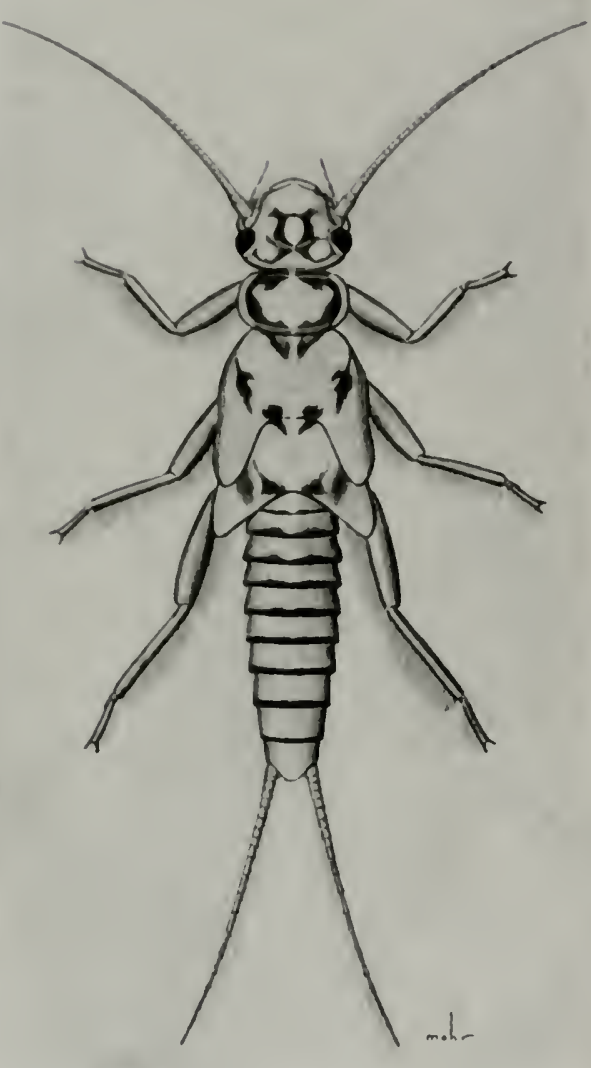

Fig. 111.-Nymph of Isoperla burksi.

except tenth; posterior margin of each tergite with numerous short, stout, pale setae; some scattered short, stout setae together with fine hairs on central area of tergites. Cerci long, many segmented, seginents progressively longer from base to apex; a longitudinal row of long fine setae on dorsal surface of apical segments in addition to smaller spinelike ones encircling apex of each segment.

Approximately mature specimens with body length of $11 \mathrm{~mm}$.

No thoracic, anal or subinental gills. lows.

Nymphal and exuvial records are as fol-

II.LNOIS,-Heron, Gibbons Creek: April 19, 1937. H. H. Ross \& C. O. Mohr, 1 nymph. Gol.cond.1: May 13, 1939, B. 1). Burks \& G. 'I. Riegel, 1 exuvia. Eddrvitce, Lusk Creek, Pope Counly: April 30, 19+0, 2 nymphs; May 1, 19+0, 1 nymph; May 9, 19+0, 2 nymphs; May $2+$ and June 1, 19+0, many exuviae; all collected by B. D. Burks \& C. O. Mohr.

'This is another new species first found ats a nympl and, because of distinctive features of nymph, recognized as new to the Illinois faunal list before adult was reared. Rearings and collection of material prove it to be a previously undescribed species. The combination of nymphal and adult characters separates it from all other species of Isoperla. Although much smaller than ientralis (Banks), it somewhat resembles this species in general color pattern of adult. In the nymph, the transverse bands on abdominal tergites place it with such species as marlynia Needham \& Claassen (= clio of American authors).

I take pleasure in naming this species for Dr. B. D. Burks, Assistant Entomologist on the staff of the Illinois Natural History Survey, who has assisted with the collection and rearing of stonefly material in Illinois and elsewhere.

\section{Isoperla lata new species}

MaLE.-Basic color brownish to black. Dorsum of head with a small yellowish spot anterior to median ocellus, another yellowish spot in ocellar triangle, and with a large yellowish area on posterior part of head running forward on each side between compound eyes and lateral ocelli, fig. 112. Pronotum with a broad, median, longitudinal, yellowish stripe, much narrower at anterior end than posterior end, fig. 112 ; areas each side of stripe brown to black. Mesonotum and metanotum essentially brown to black. Abdomen brown to black, with two short, pale, longitudinal stripes on the two basal tergites. Legs, antennae and anal cerci brownish.

Head slightly wider through compound eyes than width of pronotum; lateral ocelli farther distant from one another than each is from median ocellus; distance between each compound eye and lateral ocellus about the same as between lateral ocellus and median ocellus.

Pronotum approximately quadrangular, broader than long, a distinct pattern of raised rugosities on surface each side of pale, median, longitudinal stripe, fig. 112.

Legs with first and second tarsal segments together shorter than third, first tarsal segment much longer than second.

Wings slightly suffused with brownish, veins uniformly dark brown. 
Abdomen, fig. 112, with tenth tergite not cleft; subanal lobes recurved upwards and over tenth tergite and with prominent, long, sharply pointed tips; ninth sternite produced much beyond tip of abdomen and rounded behind; eighth sternite with a stubby lohe on posterior margin, fig. 112.

Length to tip of wings $13 \mathrm{~mm}$; length to tip of abdomen $10 \mathrm{~mm}$.
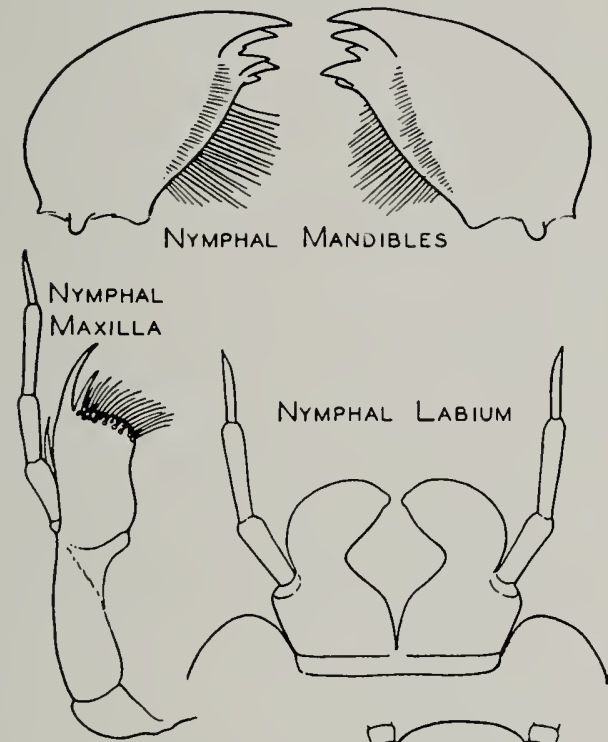

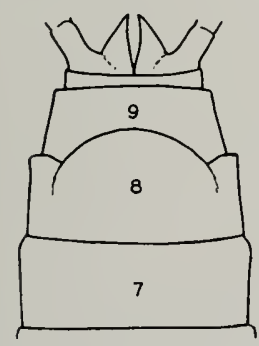

\& Terminal Abdominal STERNITES

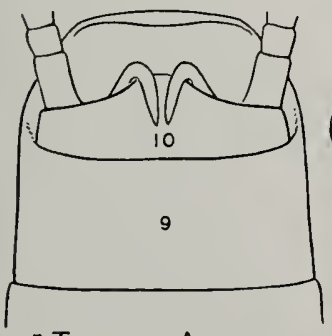

TERGITES
Fenale.-Head, thorax, basal abdominal segments and appendages in general similar to those of male but slightly larger

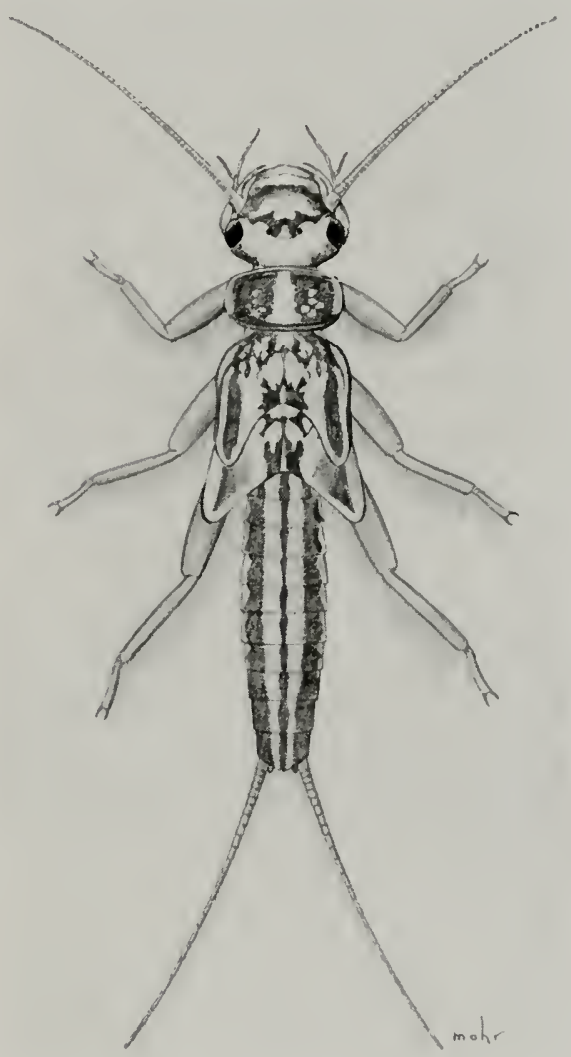

Fig. 113.-Nymph of Isoperla lata.

in size. Important differences are as follows: eighth abdominal sternite, fig. 112 , with subgenital plate slightly produced over ninth sternite and broadly rounded.

Holotype, male-Boulder Junction, Wis.: reared April 20, 1937, from nymph taken in small stream April 9, 1937, T. H. Frison \& C. O. Mohr

Allotype, female.-Same data as for holotype.

Paratypes. - Wisconsin. - Boulder JuncTron: Same data as for holotype except reared April 30, 1937, 1 오.

Michigan.-Lovelis, north branch of $\mathrm{Au}$ Sable River: June 16, 1935, J. W. Leonard, 2 ㅇ. North of ST. Ignace: May 11, 1940, T. H. Frison \& H. H. Ross, $1 \hat{0}$.

Quebec. - Laurentides National Park, Pikauba River: July 7, 1938, Charles Gauthier, 1 ㅇ․

NYMPH.-General color bright yellow witl sharply contrasting black areas on

Fig. 112.-Isoperla lata. 
head, thorax and abdomen, as illustrated in fig. 113. Legs, antennae and anal cerci velluwislt.

Head with ocelli forming an almost equilateral triangle, median ocellus very indistinct; basial segments of mouthparts extending out from side of head. Labium, mandibles and maxillate as in fig. 112; mavilla is particularly distinctive with its broad apical end and dense brush of stout setae in addition to the long, stout, curved outer process and much smaller, adjacent, inner spinelike process.

Pronotum hroader than long with markings as in fig. 113.

Abdominal tergites having general background bright yellow with dark longitudinal stripes, as in fig. 113; some scattered, stout, shurt setae on tergites in addition to row on posterior margin of each segment. Cerci long, many segmented, segments progressively longer from base to apex; a longitudinal row of long, fine setae on dorsal surface of apical segments in addition to smaller spinelike ones encircling apex of each segment.

Approximately mature specimens with body length of $13 \mathrm{~mm}$.

No thoracic, anal or submental gills. lows.

Nymphal and exuvial records are as fol-

Michig.ı.-PEAcock, Little Manistee River: Nay $10,19+0$, T. H. Frison \& H. H. Ross, 1 exuvia. North of ST. IGNAce: May 11, 1940, 'T. H. Frison \& H. H. Ross, 3 exuviae. HoNoR, Platte River: May 10, 19+0, T. H. Frison \& 11. H. Ross, 3 exuviae; May 27, 1939, T. H. Frison \& H. H. Ross, 2 exuviae. Rapid River, Rapid River: May 12, 19+0, T. H. Frison \& II. H. Ross, 1 nymph.

Novi Scotil.-Moose River: Aug. 21, 1939, T. H. Frison \& T. H. Frison, Jr., 1 exuria.

Tennessee.-Ciatlinburg, Le Conte Creek: May 1t, 1939, T. H. Frison \& H. H. Ross, 1 exuvia.

'The maxillae of the nymph and general features of the adult show that this new species belongs in that group or subgenus of Isoperla (s.l.) which includes marlynia Needham \& Claassen (= clio of Ameri(an authors) ; for clio, Needham \& Claassen (1925) proposed the generic name of Clioperla. The nymph in life has a particularly strong contrasting pattern of dark markings on a bright yellow background which, coupled with the peculiar construction of the maxilla, makes lata a species that is easily recognized in this stage.

\section{Isoperla trictura (Hoppe)}

Perla trictura Hoppe (1938, p. 151). Original description, $\delta$, $q$.

This aberrant species was placed in Perla when originally described by Hoppe, but it probably is best placed in Isoperla (s.l.) and probably eventually will be given subgeneric status. Although Hoppe has given illustrations of the dorsal terminal abdominal segments of the male and ventral terminal abdominal segments of the female, 1 feel warranted in presenting new illustrations of these structures together with additional drawings to aid future identifications of this species, fig. 114. At one time, I had planned to describe this species as new, but fortunately discovered in time the description of Hoppe.

The typic series of Hoppe came from Washington. To these typic records I can now add the following records, based mostly upon material sent to me by Dr. William E. Ricker.

Oregon.-Aisen River, May 24, 1939, Pillow, 19. Lacomb: Crabtree Creek, June $t$,

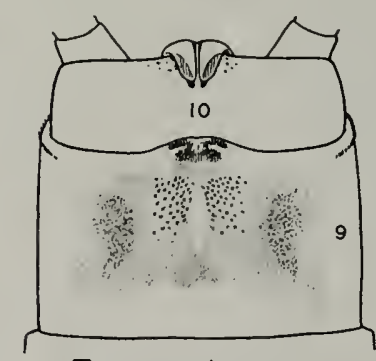

or Terminal Abdominal TERGITES
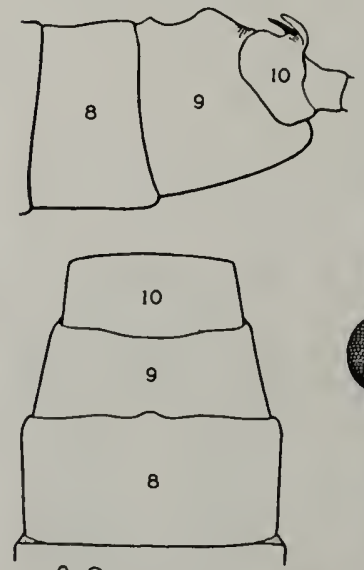

SUBGENITAL

PLATE

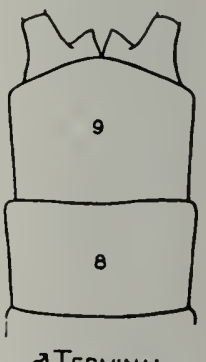

OTERminal ABDOMINAL StERNITES
Fig. 114.-Isoperla trictura.

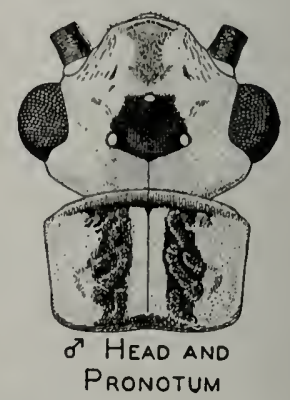
SEGMENTS 
1935, R. Dimick, 1 क ; Molalla River, June 13, 1938 , S. G. Jewett, Jr., 1 fं ; Willamette River, May 26, 1938, C. Jensen, 1 .

BRitish Columbia.-Cultus LAKE: lower Sweltzer Creek, May 12, 1937, IV. E. Ricker, 5 ô, 2 우; Sweltzer Creek, June +, 1937, Ricker, 30 , 19 ; Chilliwack River, April 24, 1938, Ricker \& Spencer, $2 \hat{o}, 2$; Chilliwack River, May 22, 1938, S. Spencer, $3 \hat{\delta}$. Vedder CrossING: May 5, 1937, W. E. Ricker, 1 ; ; May 19, 1937, WV. E. Ricker, $3 \hat{o}$.

\section{Isoperla pinta Frison}

Isoperla pinta Frison (1937, p. 92). Original description, $\hat{\delta}, \mathcal{f}$, nymph.

Isoperla tokula Hoppe (1938, p. 157). Original description, $\delta$, $q$. New synonymy.

Through the kindness of Professor Trevor Kincaid of the University of Washington, I have had the privilege of studying the holotype, allotype and paratypes of tokula. This is the same species as pinta, and hence tokula must be placed in the synonymy of pinta on the basis of date priority.

\section{Isoperla fulva Claassen}

Isoperla fulva Claassen (1937a, p. 80). Original description, $\hat{\delta}, q$.

Isoperla chrysannula Hoppe (1938, p. 156). Original description, $\delta$. New synonymy.

Isoperla cascadensis Hoppe (1938, p. 158). Original description, $\delta$, + . New synonymy.

A study of the types of fulva, chrysannula and cascadensis has convinced me that only one species of Isoperla is involved, which will take the name of fulva on the basis of date priority. The types of fulr'a have been studied through the courtesy of Dr. Henry Dietrich of Cornell University, and the types of chrysanmula and cascadensis through the courtesy of Professor Trevor Kincaid of the University of Washington.

The typic specimen of chrysannula differs from the types of ful $\tau^{\prime} a$ and cascadensis in that the costal vein of the forewing is not connected with the radial vein. In view of agreement in all other respects, the frequency of variation in details of wing venation in general, and variation existing within the same species, it is my opinion that the absence of part of the tip of the costal vein in chrysannula is an instance of variation.

The description by Hoppe of cascadensis as a new species can be explained by the probability that Claassen's description of fulv'a was overlooked. 'This probability is indicated by the lack of any citation of this particular article in the bibliography given by Hoppe and by the lack of recognition of fulv' from IVashington, where it occurs. Claassen's paper appeared several months before Hoppe's paper was published and therefore has priority.

A study of the types of cascadensis has failed to reveal any characters which definitely separate the species from fulz' $a$. The lobe on the posterior margin of the eighth abdominal sternite is subject to variation in size, depending upon age of specimen and other factors. Hoppe's figures of the male eighth abdominal sternites of chrysammula and cascadensis would seem to indicate a wide difference in respect to size of the lobe on the posterior margin of this sternite, but such a great difference does not exist because of reasons just mentioned.

\section{CHLOROPERLIDAE}

Considerable confusion has resulted in stonefly literature, both in Europe and North America, because of the erroneous interpretation of the genotype of Chloroperla Newman (1836). Banks (1906b) was first to point out that Isopteryx Pictet $(18+1)$ was synonymous with Chloroperla Newman (1836) and to recognize that the Chloroperla of Pictet contained two previously unnamed genera for which he proposed the names of Alloperla and Isoperla. Kimmins (1936), in a recent study of the British species of Chloroperla, has confirmed the work of Banks in regard to synonymizing Isopieryx with Chloroperla and in proposing the new generic names of Alloperla and Isoperle. In addition, Kimmins has shown that the genotype of Chloroperla was established by IVestwood (1840) as C. tripunctata (Scopoli) $[=$ C. lutea (Latreille) $]$.

Another source of trouble in North American literature has been an erroneous conception of the species described from Georgia by Newman (1839) under the name of Chloroperla cydippe. Ricker's (1938) comments and drawings, and additional information furnished to me through the kindness of D. E. Kimmins of the British Museum, prove that the typic specimens of cydippe are not of the species assigned to this name by Hagen (1861), Needham \& Claassen (1925) 
and others, and that cydippe belongs to the genus alloperla.

The establishment of the fact that cydippe (Newman) belongs to the genus tlloperla makes breqis (Banks 1895) an available name for the species erroneously called cydippe by Hagen, Needham it Claassen and other north American writers since then. The possibility of such a usage I suggested in 1937, but no definite stand was taken in regard to this use of names at that time because the status of cydippe had not been definitely determined. Furthermore, the name of Hastaperla Ricker (1935a) now becomes available as the generic name for brezis (Banks), since the genotype of Hastaperla is an outright synonym of brevis (Frison 1937); and Chloroperla, on the hasis of its genotype, must be associated with another group of closely related species. Along with brevis, the species orpha (Frison 1937) should now be placed in Hastaperla.

Ricker (1938) suggested the possibility that Alloperla Banks is synonymous with Chloroperla Newman. Basing my conclusions upon comparative studies of true specimens of Chloroperla from Europe named by Kimmins with North American specimens of Alloperla, I find that Alloperla should be accepted as a valid generic name for certain North American species, and probably some Asiatic species, now going by this name. My reasons for the recognition of Alloperla Banks as generically distinct from Chloroperla Newman are as follows: (1) in Chloroperla the hooked supra-anal process (see Kimmins 1936) of the male is not mounted on a large membranous base deeply recessed in the broadly cleft tenth abdominal tergite as is the case in Alloperla, and (2) the second anal vein of the forewing in Chloroperla does not appear branched as a result of fusion with base of third anal vein as is the case in Alloperla.

'There is, however, a North American species of Chloroperlidae, recognized and described for the first time in succeeding pages of this article, which seems best placed generically in the genus Chloroperla Newman, as defined and used by Kimmins (1936). It is true that the male of this new species differs from the genotype of Chloroperla [tripunctata (Scopoli)] by the presence of a small projec- tion on the seventh abdominal sternite, but its general habitus, small size, color pattern, wing shape and renation, and structure of terminal dorsal abdominal segments otherwise place it with or very near to Chloroperla (s.s.).

What has just been stated, when practically interpreted, results as follows: (1) Isoperla Banks is the valid generic name for a group of species [genotype bilineata (Say)] in North American literature now going under this name, and also for certain Eurasian species, many of which have been going under the generic name of Chloroperla (i.e. Chloroperla in the sense of Despax 1936); (2) Chloroperla is a valid generic name for certain European, and possibly Asiatic, species which have gone under the names of Chloroperla and Isoptery: $x$, and for a new species from eastern North America described in this paper; (3) Hastaperla Ricker (1935a), as I suggested in 1937, becomes the generic name for two North American species, orpha (Frison) and brevis (Banks), the latter misidentified in most North American literature under the name cydippe (Newman); and (t) Alloperla is a valid generic name for certain North American species, and possibly some Asiatic species, now going by this name.

Admittedly, Chloroperla, Hastaperla and Alloperla are closely related, but from the standpoint of comparing the world fauna, there are advantages at present in considering them as distinct genera, at least until the Chloroperlidae of the world are better known. Kathroperla and Paraperla, belonging to this same family, are much more distantly related.

The removal of Isoperla from the Chloroperlidae, as done elsewhere in this paper, and the recognition in North America of the genus Chloroperla as defined by Kimmins (1936), warrants a new key for the separation of the genera of Chloroperlidae as follows.

\section{KEY TO ADULTS, NORTH AMERICAN GENERA OF CHLOROPERLIDAE}

1. Hindwing without a distinct folded anal lobe, fig. $115 \ldots \ldots \ldots \ldots \ldots$............

Hindwing with a distinct folded anal lobe, figs. $116-118 \ldots \ldots \ldots \ldots \ldots \ldots \ldots 2$

2. Head much longer than pronotum; compound eyes situated far forward on sides of head so that the distance between each compound eye and front 


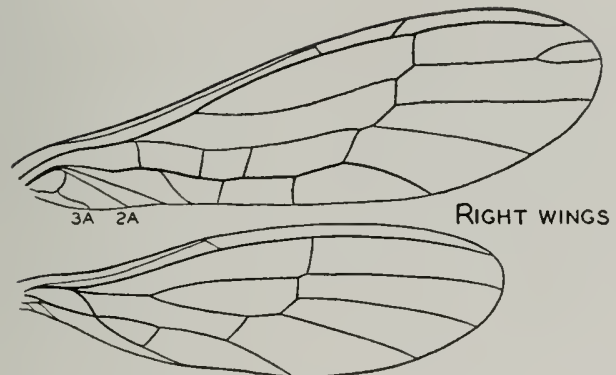

Fig. 115.-Hastaperla brezis.
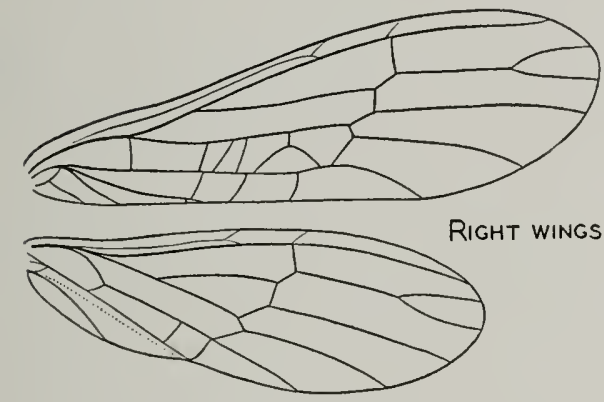

Fig. 116.-Chloroperla terna.

margin of pronotum is at least twice as great as diameter of eye. Kathroperla Head shorter than in Kathroperla, but slightly longer than pronotum; compound eyes situated on sides of head about their diameter from front margin of pronotum.

3. Third anal vein of forewing not present or, if present, not fused with second anal vein so that second anal vein appears branched, fig. 116 ..... Chloroperla

Third anal vein of forewing with basal portion fused with second anal vein so that second anal vein appears branched, figs. $117-118$

4. Anal lobe of hindwing small, in length extending about to middle point of wing, fig. 117 ; small, pale-colored species.

Alloperla

Anal lobe of hindwing large, in length extending well beyond middle point of wing, fig. 118; medium-sized, darkcolored species

Paraperla

In The Stomeflies, or Plecoptera, of Illinois (Frison 1935a), the generic key for Chloroperlidae included the genera Hastaperla $(=$ Chloroperla of North American authors) and Isoperla. Isoperla was inincluded in the key on the hasis of actual records of numerous species from Illinois. Hastaperla was included because of the occurrence of the species brezis (Banks) (= cydippe of North American authors) in Indiana at a locality a few miles from

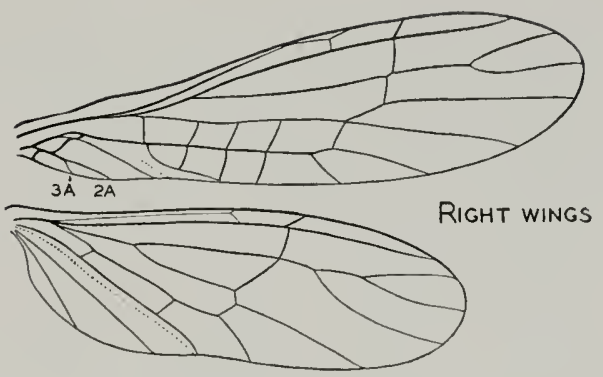

Fig. 117.-Alloperla caudata.
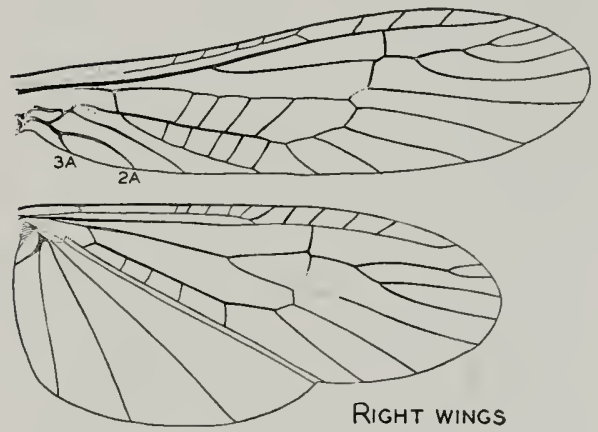

Fig. 118.-Paraperla frontalis.

the Illinois boundary line, and also hecause of the probability of its eventual capture in Illinois. In a later article (Frison 1937), giving additions to the Illinois stonefly faunal list, no new records of Chloroperlidae for Illinois were available, but a new species of Hastaperla was described from IVisconsin as Chloroperla orpha.

Since 1937, continued field work in Illinois in restricted local habitats has revealed actual Illinois material of the genera Hastaperla and Alloperla. Records of the Illinois specimens of Alloperla caudata Frison, A. banksi Frison and Hastaperla brezis (Banks) are given under my notes and descriptions of these species in following pages.

\section{Chloroperla terna new species}

MALE.-Head, thorax, abdomen, cerci, basal segments of antennae and most of legs dominantly a pale yellowish green; apical segiments of antennae fuscous; localized black or fuscous markings on thorax and abdomen. Ocelli and compound eyes black. No gill remnants.

Head slightly wider through compound 
eles than width of pronotum; median crellus located ahout on al line with anteriur margins of compound eyes, lateral ocelli located well anterior to a line connecting posterior margins of compound
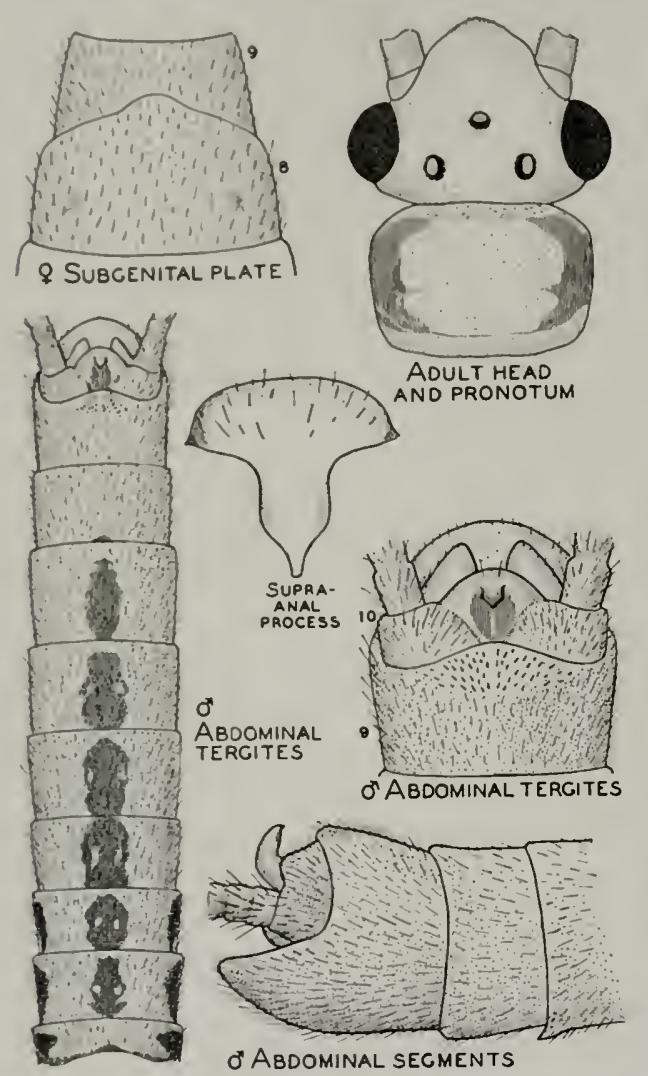

Fig. 119.-Chloroperla terna.

eyes, distance between lateral ocelli greater than distance between lateral ocellus and adjacent compound eve.

Pronotum much wider than long; lateral margins bordered with a wide black or a fuscous line, fig. 119. Legs yellowish green, except for fuscous tarsal segments.

Dorsum of abdomen with a median longitudinal series of fuscous spots forming a line from first to eighth tergite and with a shorter fuscous line on the lateral margins of the first three hasal segments, fig. 119; supra-anal process or hook very small, dark colored at tip, shaped as in frg. 119, and but slightly inset or recessed on tenth tergite; seventh sternite with a small lobe in middle of posterior margin, fig. 119. Cerci short, composed of
7 to 8 segments several times longer than wide.

Wings extending well beyond tip of abdomen; with membrane and veins pale; a small anal lohe on hindwing, fig. 116; forewing with venation as in fig. 116.

Length to tip of wings $6 \mathrm{~mm}$; length to tip of abdomen $+\mathrm{mm}$.

Fenale. - Head, thorax, basal segments of abdomen and appendages in general similar to those of male but slightly larger in size. Differs in having eighth abdominal sternite with a slightly produced, rounded subgenital plate, fig. 119.

Holotype, male.-West Topsham, Waits River, Vt.: June 21, 1941, T. H. Frison \& H. H. Ross.

Allotype, female.-Same data as for holotype.

Paratypes.-New YoRk.-Small creek 3 miles west of KEENE: June 20, 1941, T. H. Frison \& H. H. Ross, 1 ô. Euba Mir.is, Adirondack State Park: June 20, 1941, T. H. Frison \& H. H. Ross, 1 ㅇ․

Tennessee.-El.kmont, Little Pigeon River: May 14, 1939, T. H. Frison \& H. H. Ross, 1 ơ.

This minute species is particularly interesting since it resembles in color Hastaperla orpha (Frison) but structurally is best placed in the genus Chloroperla as defined by Kimmins (1936). The chief difference that I note between this new species in the male and Chloroperla tripunctata (Scopoli), the genotype, is the small lobe on the posterior margin of the seventh abdominal sternite. It differs from species of Hastaperla and Alloperla as indicated in the key to the adults of Chloroperlidae.

\section{Hastaperla brevis (Banks)}

Chloroperla brevis Banks (1895, p. 314). Original description.

Isopteryx cydippe Hagen (1861, p. 31). Misidentification.

Cluloroperla cydippe Needham \& Claassen (1925, p. 128).

Chloroperla cydippe Frison (1935a, p. 431).

In 1935, I included brezis under the name Chloroperla cydippe Newman, as a species likely to be found in Illinois because of its occurrence in Indiana just a few miles from the boundary line between these two states. In 1938, this species was first actually collected in Illinois and therefore is now to be definitely included in the faunal list of this state.

The illustration of the nymph (Frison 

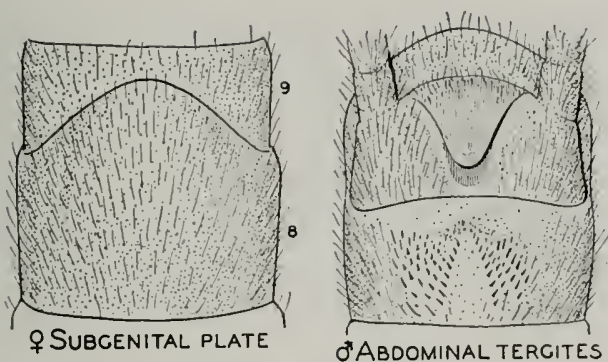

O'ABDOMINAL TERGITES

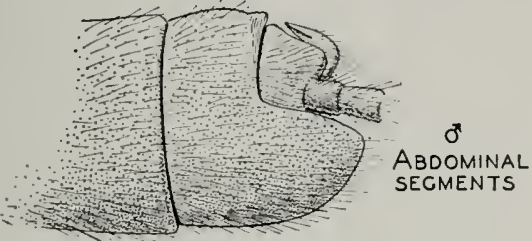

Fig. 120.-Hastaperla brevis.

$1935 a$, fig. 331 ) is quite satisfactory, but the illustrations of the most important structural details of the adults are poor, and new ones, figs. 115 and 120 , are herewith presented.

Specimens of this species, and records associated with them, have been studied as follows.

Arkansas.-Benton, Salt Creek: April 15, 1939 , H. H. \& J. A. Ross, 1 nymph, 1 \%. MAI, VERN, southwest of town: April 15, 1939, H. H. \& J. A. Ross, 1 f. Mountainburg, Clear Creek: May 1, 1939, H. H. \& J. A. Ross, 1 ․ Mountain Pine: June 5, 1937, H. H. Ross, $\delta \hat{\delta}$, 우. WAshington County: May 3, 1939, $1 \delta$. WinsLow: May 1, 1939, H. H. \& J. A. Ross, $1 \hat{\jmath}, 2$ ㅇ.

Illinols.-Shawnee National Forest, Union County, Hutchin's Creek: April 8, 1938, Frison \& Mohr, 10 nymphs. Mountain GLEN, Union County, Hutchin's Creek, near town: Apri] 24,1938 , C. O. Mohr, 7 fo, 10 오, 1 nymph, 2 exuviae, 39 (reared). SERENA, Indian Creek: May 19, 1938, Ross \& Burks, 2 ㅇ. WoLF LAKE, Union County, Hutchin's Creek: May 2, 19+0, Mohr \& Burks, 1 nymph; May 7. 1940, Mohr \& Burks, 16 with 1 exuvia (reared); May 12, 1939, Burks \& Riegel, 1 오, 1 nymph, + exuviae; May 1+-15, 1940, Mohr \& Burks, ô $\hat{o}$, 우우 May 25, 19+0, Mohr \& Burks, 1 오.

Indiana.-Turkey Run State Park: May 30,1930 , Frison \& Ross, 1 우 ; in gorge, May 22 , 1932, T. H. Frison, 1 \% ; Newby Gulch, May 6, 1933, Mohr \& Townsend, nymphs; May 11, 1933, Frison \& Mohr, $6 \hat{f}$ (reared), of $\hat{o}$, 오 오; Newby Gulch, May 11, 1933, Frison \& Mohr, nymphs, $\hat{\delta} \hat{\delta}$, 우 $q$; reared at Charleston, 1ll., May 12, 1933, Frison \& Mohr, $1 \hat{\delta}$, 19 ; Newby Gulch, May 12, 1933, Mohr \& Frison, nymphs; Sugar Creek, May 7, 1939. G. T. Riegel, 3 nymphs; small tributary stream, May 7, 1939, G. T. Riegel, + nymphs; Newby Gulch, April 9, 19+0, Frison \& Ross, 5 nymphs.
Kentucky. - Cumberland Falls State PARK: May 12, 1939, Frison \& Ross, 1 ㅇ․

Manitoba.-Churchill: Aug. 3, 1937, D. Denning, 1 우 ; Churchill River, 20 miles south of town, Aug. 5-6, 1937, D. G. Denning, 3 d, 2 웅 Aug. 2-9, 1937, D, G. Denning, 1 \%; July 29, 1936, H. E. McClure, 1 of . PIGEON River: June 10, 1932, F. Neave, + specimens. Swan River, Swan River: June 5, 1936, H. E. McClure, 3 nymphs.

MARYland,-Baltimore: May 16, 1938, E. G. Fisher, 1 f, 3 ㅇ․ Piney Grove: April 19, 1938, H. H. Ross, 2 nymphs.

Michigan. - Benzonia: May 27, 1939, Frison \& Ross, 1 $\delta, 8$ ․ Free Soll, Great Sable River: May 26, 1939, Frison \& Ross, $5 \delta, 3$ ㅇ, 1 nymph, + exuviae. HaLe, Au Sable River: May 21, 1936, Frison \& Ross, $3 \hat{\jmath}$. Near Hale, Au Gres River: May 21, 1936 , Frison \& Ross, 1 오 3 nymphs. IroNs, Little Manistee River, near town: May 28, 1939, Frison \& Ross, 4 nymphs. IsLE Royale: Aug. 3-7, 1936, C. Sabrosky, 1 오. MAYfiel.D, Boardman River: May 28, 1939, Frison \& Ross, 2 .

Minnesota. - Enchanted Isle, Lake MinNETONKA: June 25, 1932, H. H. Shepard, 1 오. Grand MaraIs: Little Devils Track Creek, Aug. 8, 1929, C. T. Schmidt, 9웅 Devils Track Creek, Aug. 7, 1929, C. T. Schmidt, 1 영 Kadunce Creek, in spider web on rock cliff, Aug. 8, 1929, C. T. Schmidt, 1 ․ . No. $1,95+$, O. Wr. Oestlund collection, 1 오.

Missouri. - Springfield, Pickerel Creek: May 20, 1937, H. H. Ross, 19. ZION, Madison County: April 7, 1938, Frison \& Mohr, 1 nymph.

New York.-ITHACA: Coy Glen, July 7, 1908, 2 specimens; Wild Flower Preserve, July, 1929, 1 ㅇ. SPRAKERS, Flat Creek: July 3, 1934, 1․ Tompkixs County, Six Mile Creek: July 8, 1927, P. R. Needham, 1 o, 5 ㅇ. Euba Mrlis, Adirondack State Park: June 20, 19+1, Frison \& Ross, $1 \hat{\delta}, 1$ ㅇ․ BLuE MounTAIN LAKE, Bear Brook near town, Adirondack State Park: June 19, 19+1, Frison \& Ross, $1 \delta$.

North Carolina.-Marion: April 23, 1939 , Ross \& Burks, +千, 2 우. SMOKEMONT, Oconaluftee River: May 29, 1934, T. H. Frison, 36,3 ㅇ. Statesville, April 23, 1938, Ross \& Burks, 1 o, 1 \%, 1 nymph.

Nova Scotia.-Moser River: Lower Goldmine Brook (A1), June 22, 1939, J. A. C. Nicol, $10 \delta, 10$ 우 ; Goldmine Brook (B), June 23, 1939, J. A. C. Nicol, 5 ô, 13 우; Goldmine Brook (A2), June 26, 1939, J. A. C. Nicol,

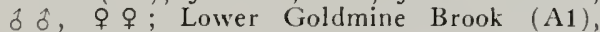
July 9, 1939, J. A. C. Nicol, 1 o ; Lower Goldmine Brook (A2), June 19, 1939, J. A. C. Nicol, $1 \hat{o}$.

Ohlo.-Hocking County: May 1, 1938, D. J. \& J. N. Knull, 1 오

OklahomA.-Albion, Clear Creek: June 4, 1937, H. H. Ross, 11 \%. Flint: June 6, 1934, 16 ; June 8,1934, 26, 1 q ; June 19, 1937 , Standish-Kaiser, 20,1 . Locust Grove: May 5, 1937, 1ô, 2 o . PAGE: June 23, 1937, Standish-Kaiser, $1 \hat{\delta}, 1$ ㅇ․ WILBurton: June 4, $193+, 1$ 우 ; July $10,193+, 10$.

OrEgon,-Horsetall FAlls, Columbia River Highway: Aug. 6, 1922, G. Hoppe, $2 \hat{\delta}, 3 q$. 
["lhese specimens were originally recorded hy Hoppe (1938) under the name Chloroperla ijlippe Newman.]

ONtirio,-Costello Lake, Aigonquix PArk, ()urario Pisheries Research Laboratory: Sta(ion 3, June 2, 1938, W. M. Sprules, 39 ; Sralion 3. June 17, 1939, 1 क ; June 6, 1939, $1 \hat{\sigma}$; June $8,1939,1$ \% ; Station $t$, June 12, 1939, 18 : Sration 6, June 7, 1939, 1 오 ; June 15, 1939, 1우 ; June 6, 1939, $2 \delta$; Station 7, June 9, 1939,1 1 .

Texingsee.-Gitrixburs: Fighting Creek, branch of Litlle Pigeon River, May 27, 1934, I. H. Frison, $\delta$ o. $q$ 우 ; Litsle Pigeon River, June 12, 1935, H. H. Ross, 19 ; Le Conte Creek, May 1t, 1939, Frison \& Ross, 7 ô, 우 우 ; Le Conte Creek, June 1t, 1940, T. H. Frison et al., 6o, 39 ; Pigeon River, June 14, 1940, 1. H. Frison of al., 1 \% ; June 1t, 1940, T. H. Frison et al., 1 $q$. Parksville: April 25, 1938, Ross \& Burks, of ô, 우 $q$. PIgeon FORGe: May 13, 1939, Frison \& Ross, $1 \hat{\delta}$. T'OWNSEN, Lynncamp Prong, Little River: May 15, 1939, Frison \& Ross, 10.

VirgixiA.-Curley's Neck Bridge: April 19, 1938, M. E. Davis \& D. T. Ries, $5 \hat{o}, 2$..

WIScossix,-BI.OOMER: June 5, 1936, Frison \& Ross, 26,7 ㅇ. Himward, Teal Creek: Aug. 5, 1932, T. H. Frison, $1 \hat{\delta}$. SPooner, Namakagon River: June 5, 1936, Frison \& Ross, 2 exuviae. Trout Like: July 22, 1937, Frison s. Ross, $1 \hat{\delta}, 7 q$.

\section{Alloperla caudata Frison}

Alloperla caudata Frison (1934, p. 27). Original description, $\hat{\delta}, \hat{q}$.

It is a source of satisfaction now to add to the Illinois list of stoneflies the species caudata, originally described from material collected in Oklahoma. Specimens of this species were first found in Illinois in 1939, after persistent field work in a small stream in southwestern Illinois long suspected of harboring some aquatic insects of rare occurrence in this state. In 1940 , more thorough collecting and better seasonal timing produced numerous additional specimens of this species.

Although candata is new to the Illinois list of stoneflies, there is no need to redescribe it. I do, however, wish to present is an aid to identification new and better illustrations, based mostly upon Illinois specimens, of the terminal abdominal segments of the male showing the supraanal process and the subgenital plate of the female, fig. 121. Fig. 117 shows the wing.

The nymphs of the different species of Alloperla described to date, and others collected by me, are homogeneous in appearance, and caudata is no exception to this statement. Perhaps careful studies of reared material will eventually reveal some minute characters which will serve to distinguish some or all of the species of this genus. As in the case of Allocapnia, Nemoura, Leuctra and other genera which have homogeneous nymphs, it is sometimes possible to identify last stage nymphs because the color patterns and important genitalic features of the adults about to emerge are visible and recognizable through the nymphal skin.

A brief description of the nymph of coudata is as follows.

NYuPH.-General color of head, thorax, abdomen and appendages pale brown, without conspicuous bands, spots or stripes of contrasting colors, fig. 122.

Head with three ocelli forming a nearly equilateral triangle; distance between

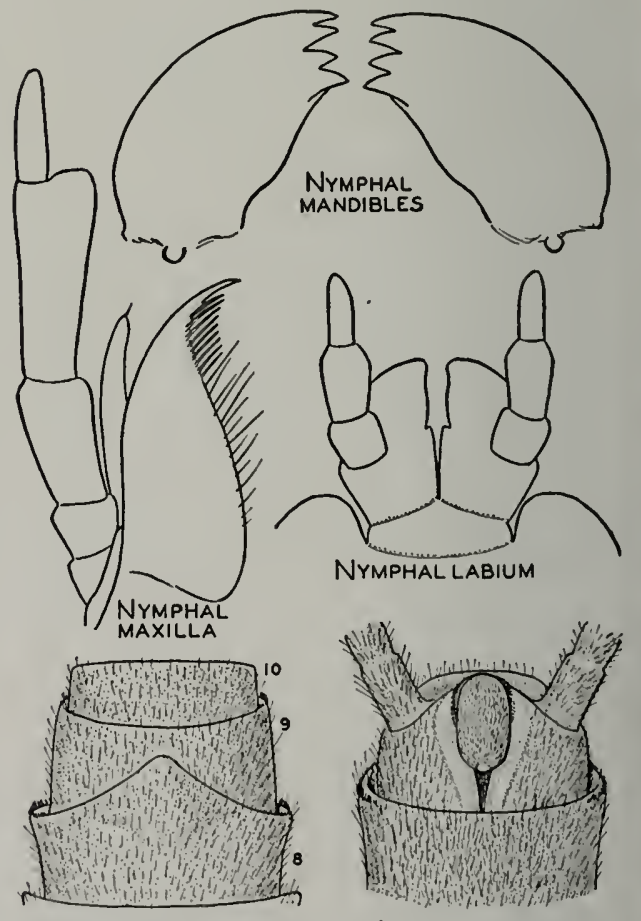

\& SubGenital plate ơABdominal tergites

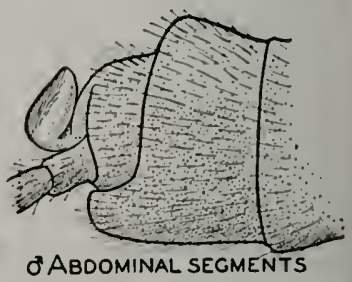

Fig. 121.-Alloperla caudata. 
ocelli about the same as distance from a lateral ocellus to inner margin of compound eye; no occipital ridge; labium. maxillae and mandibles as in fig. 121.

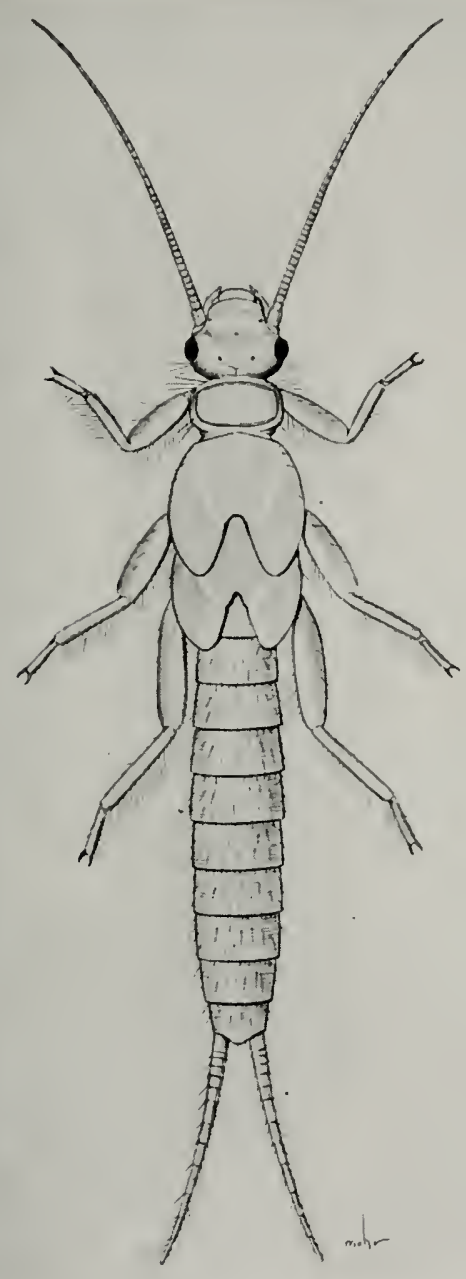

Fig. 122.-Nymph of Alloperla caudata.

Pronotum suboval, much wider than long. IVing pads on mesonotum and metanotum with lateral margins broadly rounded.

Gills entirely lacking.

New distributional records for this species, represented by material in the Illinois Natural History Survey collection, are as follows.

Illinols.-LA RUE, near McCann School: May 26, 1938, B. D. Burks \& G. T. Riegel, 1 ô. Hutchin's Creek, near Wolf LAKE: May 12,1939 , B. D. Burks \& G. T. Riegel, 1 exuvia;
May 18, 25, 31, 1940, C. O. Mohr \& B. D. Burks, of $\delta$, 우 ㅇ, nymphs and exuviae.

Arkansas.-Mountain Pine: June 5, 1937, H. II. Ross, $3 \hat{\delta}, 6 q$. Kings River, Eureki SPRINGS: May 8, 1938, M. W. S., 1 .

OKLAHOMA.-Flint: June $6,8,193+$, $\delta$ of , 우 우 ; June 19, 1937, Standish-Kaiser, $3 \hat{\delta}, 2$ ․․

\section{Alloperla banksi new species}

Alloperla nanina Needham \& Claassen (1925, p. 126). Misidentification.

dlloperla nanina Frison (1935b, p. 3+1). Misidentification of Needham \& Claassen suggested.

Under the discussion of namina Banks attention is directed to the fact that Needham \& Claassen (1925) misidentified nanina. This I first suggested (1935a) when I stated, "That there is another unnamed species without a dark dorsal abdominal stripe now going under the name of nanina is evident from the description of Needham and Claassen (1925) and the collection of such a female specimen by the author at Caroline, New York, in August, 1928." At that time, I further stated, "Action in proposing a name for these specimens without a dark dorsal abdominal stripe, now confused with namina, is delayed pending the study of further material." Additional material of this species has now been collected and studied, and the time has arrived for actual naming and recognition of this species.

Male.-Head, thorax, abdomen, cerci, hasal segments of antennae and legs in general a pale yellowish green. Ocelli and compound eyes black. No gill remnants present.

Head slightly wider through compound eyes than width of pronotum; median ocellus located about on line with anterior margins of compound eyes, lateral ocelli located well anterior to line connecting posterior margins of compound eyes, distance between lateral ocelli greater than distance between a lateral ocellus and adjacent compound eye.

Pronotum much wider than long, angles rounded.

Dorsum of abdomen without a dark, dorsal, median stripe. Supra-anal process small, inset in cleft of tenth tergite, fig. 123; basal portion membranous and pale colored; small recurved tip, fig. 123, more sclerotized and brownish in color. Eighth and ninth tergites without raised ridges. 
[These specimens were originally recorded hy Hoppe (1938) under the name Chloroperla ijlippe Newinan.]

()NTIRII.-Cosiello Lake, MI.conquix PARK, ()ntario Fisheries Research Laboratory: Station 3, June 2, 1938, W. M. Sprules, $3 q$; Station 3, June 17, 1939, 1 \% ; June $6,1939,1$; June 8, 1939, 19; Station $t$, June 12, 1939 , 16 : Sialion 6 , June $7,1939,1$ 의 June 15 , 1939, 19 : June 6, 1939, $2 \delta$; Station 7, June 9, $1939,1 \%$.

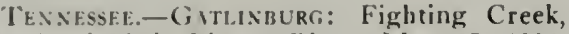
hranch of Litule Pigeon River, May 27, 1937, 'T. H. Frisoll, of o, \& \&: Little Pigeon River, June 12, 1935, H. H. Ross, 1\%; Le Conte Creek, May 14, 1939, Frison \& Ross, $7 \hat{0}$, $q$ 우 Le Conte Creek, June 1t, 19+0, T. H. Frison of al., $6 \delta, 39$; Pigeon River, June 14, 1940, T. H. Frison et al., 1 \% ; June 1t, 1940, T. H. Frison el al., 19 . Parksville: April 25, 1938, Koss $\alpha$ Burks, of of, $q$ \%. Pigeon Forge: May 13, 1939, Frison \& Ross, 18 . Townsend, Lynncamp Prong. Little River: May 15, 1939 , Frison \& Ross, $1 \hat{o}$.

Virginia.-Curley's Neck Bridge: April 19, 1938, M. E. Davis \& 1). T. Ries, $5 \hat{\delta}, 2$.

W'Isconsin.-13inomer: June 5, 1936, Frison s Ross, $2 \delta^{\circ}, 7$ \% . H.IYWard, 'Teal Creek: Aug. 5, 1932, T. H. Frison, $1 \hat{\delta}$. SpooNer, Namakagon River: June 5, 1936, Frison \& Ross, 2 exuriae. Trout Like: July 22, 1937, Frison ¿ Ross, 1 ô, 7 ㅇ․

\section{Alloperla caudata Frison}

Alloperla caudala Frison (193t, p. 27). Original description, $\hat{\delta}$, $q$.

It is a source of satisfaction now to add to the Illinois list of stoneflies the species caudata, originally described from material collected in Oklahoma. Specimens of this species were first found in Illinois in 1939, after persistent field work in a small stream in southwestern Illinois long suspected of harboring some aquatic insects of rare occurrence in this state. In 1940 , more thorough collecting and better seasonal timing produced numerous additional specimens of this species.

Although candata is new to the Illinois list of stoneflies, there is no need to redescribe it. I do, however, wish to present as an aid to identification new and better illustrations, based mostly upon Illinois specimens, of the terminal abolominal segments of the male showing the supraanal process and the subgenital plate of the female, fig. 121. Fig. 117 shows the wing.

'The nymplss of the different species of Alloperla described to date, and others collected by me, are homogeneous in appearance, and caudata is no exception to this statement. Perhaps careful studies of reared material will eventually reveal some minute characters which will serve to distinguish some or all of the species of this genus. As in the case of Allocapnia, Nemoura, Leuctra and other generat which have homogeneous nymphs, it is sometimes possible to identify last stage nymplis because the color patterns and inportant genitalic features of the adults about to emerge are visible and recogniz. able through the nymphal skin.

A brief description of the nymph of caudata is as follows.

NyMPH.-General color of head, thorax, abdomen and appendages pale brown, without conspicuous bands, spots or stripes of contrasting colors, fig. 122 .

Head with three ocelli forming a nearly equilateral triangle; distance between

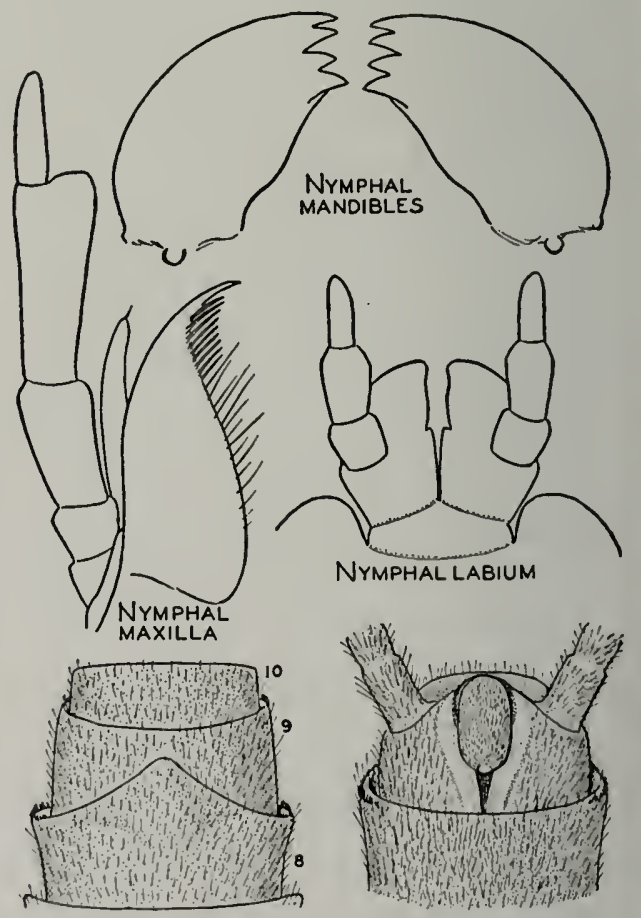

\& SubGenital PLATE

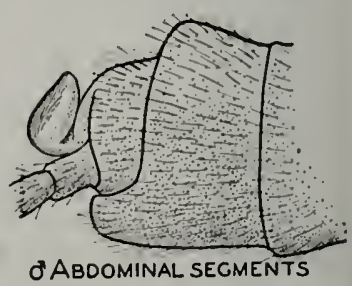

Fig. 121.-Alloperla caudata. 
ocelli about the same as distance from a lateral ocellus to inner margin of compound eye; no occipital ridge; labium, maxillae and mandibles as in fig. 121.

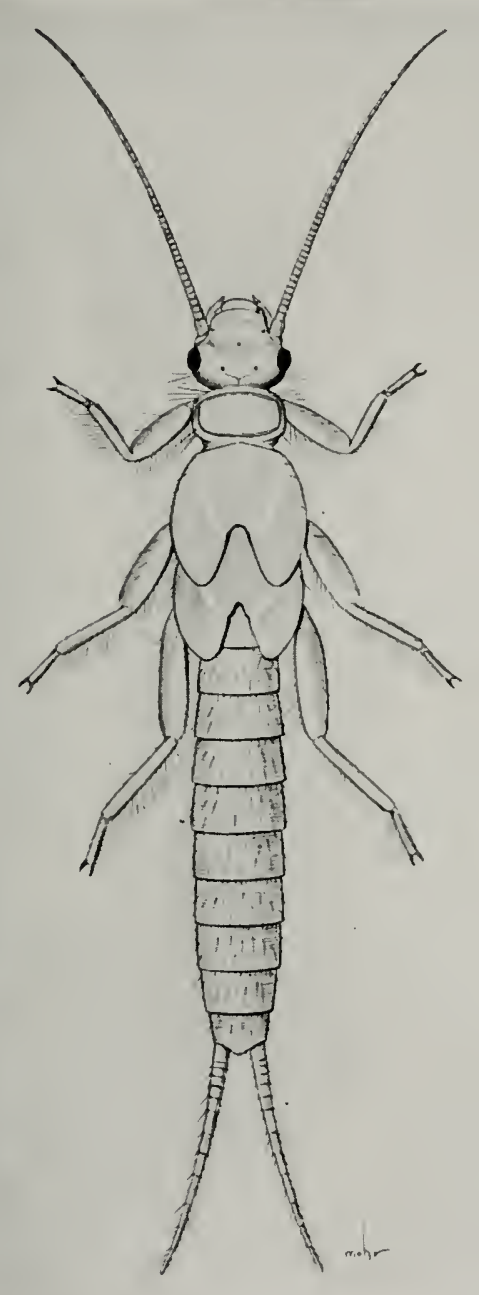

Fig. 122.- Nymph of Alloperla caudata.

Pronotum suboval, much wider than long. Wing pads on mesonotum and metanotum with lateral margins broadly rounded.

Gills entirely lacking.

New distributional records for this species, represented by material in the Illinois Natural History Survey collection, are as follows.

Illinois.-LA RUE, near McCann School: May 26, 1938, B. D. Burks \& G. T. Riegel, 1 d. Hutchin's Creek, near WoLf LAKE: May 12, 1939, B. D. Burks \& G. T. Riegel, 1 exuvia;
May 18, 25, 31, 1940, C. O. Mohr \& B. D. Burks, $\delta \hat{\delta}$, $ᄋ+q$, nymphs and exuviae.

Arkansas.-Mountain Pine: June 5, 1937, H. I. Ross, $3 \delta, 6$. Kings River, EurekA SPRINGS: May 8, 1938, M. W. S., 1 ㅇ․

OKLAномA.-FLiNT: June $6,8,1934$, of o , 우 오 ; June 19, 1937, Standish-Kaiser, $3 \hat{\delta}, 2$ 오.

\section{Alloperla banksi new species}

Hlloperla nanina Needham \& Claassen (1925, p. 126). Misidentification.

Alloperla nanina Frison (1935b, p. 341). Misidentification of Needham \& Claassen suggested.

Under the discussion of nanina Banks attention is directed to the fact that Needham \& Claassen (1925) misidentified namina. This I first suggested (1935a) when I stated, "That there is another unnamed species without a dark dorsal abdominal stripe now going under the name of namina is evident from the description of Needham and Claassen (1925) and the collection of such a female specimen by the author at Caroline, New York, in August, 1928." At that time, I further stated, "Action in proposing a name for these specimens without a dark dorsal abdominal stripe, now confused with nanina, is delayed pending the study of further material." Additional material of this species has now been collected and studied, and the time has arrived for actual naming and recognition of this species.

MALE.-Head, thorax, abdomen, cerci, basal segments of antennae and legs in general a pale yellowish green. Ocelli and compound eyes black. No gill remnants present.

Head slightly wider through compound eyes than width of pronotum; median ocellus located about on line with anterior margins of compound eyes, lateral ocelli located well anterior to line connecting posterior margins of compound eyes, distance between lateral ocelli greater than distance between a lateral ocellus and adjacent compound eye.

Pronotum much wider than long, angles rounded.

Dorsum of abdomen without a dark, dorsal, median stripe. Supra-anal process small, inset in cleft of tenth tergite, fig. 123; basal portion membranous and pale colored; small recurved tip, fig. 123 , more sclerotized and brownish in color. Eighth and ninth tergites without raised ridges. 
Finale. - Head, thorax, basal segments of abdomen and appendages in general similar to those as described for the male (Needham \& Claassen 1925), except general color is more brownish. Important differences are as follows: eighth abdominal sternite, fig. 125, with posterior mar-

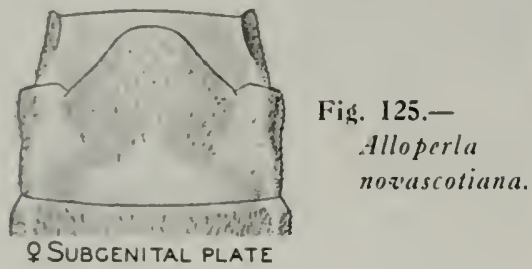

gin produced backwards over ninth sternite, its tip somewhat truncate.

Allotype, female.-Essex County, Artist's Brook, N. Y.: June 23, 19+0, H. D. Dietrich.

New records for this species are as follows.

NEW YORK.-COLd Brook: June 30, 19+0, H. Dietrich, 1ㅇ. Essex County, Artist's Brook: June 23, 19+0, H. Dietrich, 3 o , 10 9. Mount Marcy: June 29, 19+0, H. Dietrich, $1 \delta, 1$ ㅇ․

Pexnsylvania,-Swiftwater, Monroe County: 1928, F. R. Nevin, Lot 258, 2 ㅇ․

\section{Alloperla fidelis Banks}

Alloperla fidelis Banks (1920, p. 323). Original description, ㅇ.

It seems desirable to record here a series of adults with brachypterous wings, both males and females, which are apparently of the species fidelis. 'The only differences noted between the typical fidelis and these specimens are the smaller average size, the short wings in both sexes, a slight difference in shape of the indention on the posterior margin of the subgenital plate in the female, and the somewhat narrower supra-anal process of the male. These are the first specimens of Alloperla I have ever seen which were brachypterous, but Ricker (1939) has recorded brachypterous forms of the same species from small creeks at high elevations in British Columbia. It is of interest to note that both sexes in these specimens are short winged, whereas in many species of stoneflies this condition occurs or is reported to occur only in the males.

The specimens have the following data.

WYoming.-DUNRIVEx PAss, Mount Washburu, Yellowstone National Park: Aug. 2,
1940, T. H. Frison \& T. H. Frison, Jr., 5 d, 32 우.

In fig. 126 are illustrations of these specimens as follows: dorsum of male abdomen, lateral view of male terminal

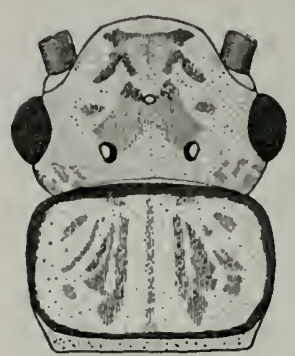

ADULT HEAD AND PRONOTUM

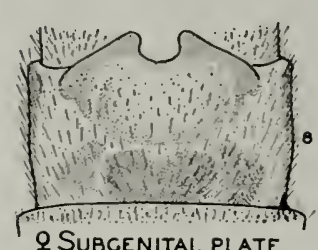

Q SUBGENITAL PLATE

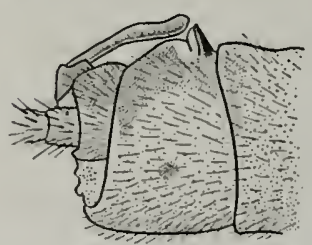

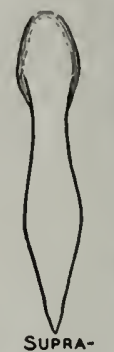
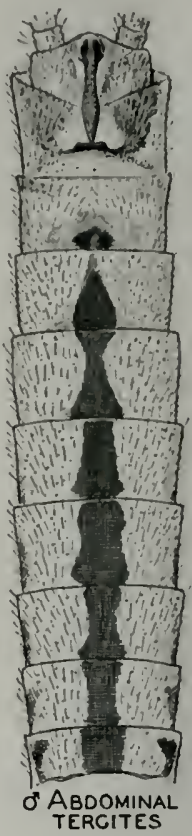

Fig. 126.-Alloperla fidclis.

abdominal segments, supra-anal process of male, subgenital plate of female, and head and pronotum.

\section{Alloperla pallidula (Banks)}

Chloroperla pallidula Banks (1904, p. 99). Original description, 오.

Alloperla dubia Frison (19356, p. 338). Original description, $\hat{\jmath}$, $q$. New synonymy.

In 1935, I described dubia as a new species closely related to pallidula and differing from it in having a median, longitudinal, dorsal, dark stripe on the abdomen. Although Needham \& Claassen (1925) had treated pallidula as a species with this dark stripe, I had disregarded their concept of this species becaluse of information from Dr. Nathan Banks that pallidula did not have such a stripe, and there was no indication in the original description of such a stripe on the typic specimen. 
A recent study of the typic female of pallidula in the collection of the Museum of Comparative Zoology has revealed that, although faded and barely distinguishable, the type of pallidula does have the dorsal, longitudinal, dark stripe on the abdomen, as Needham \& Claassen (1925) stated. Although females of Alloperla are not as satisfactory as males for purposes of specific recognition, I have come to the conclusion that pallidula and dubia are the same species and therefore the name $d u b i a$ should fall in synonymy upon the basis of priority.

This paper is also the proper place to correct another statement made by me in my $1935 b$ paper involving dubia. At that time, I recorded that three specimens of the "Aug., Estes Park, Colo." material recorded by Needham \& Claassen (1925) were without a dark dorsal stripe on the abdomen "and hence agree with the true pallidula Banks," as I then accepted it. A restudy of these specimens reveals that this stripe was originally present but is now barely distinguishable because of fading or bleaching in preservative. Recently; Hoppe (1938) recorded both pallidula and dubia from $W$ ashington, but a check of her material named as these two species reveals that only one species-dubia-is involved. In other words, there is now no evidence that a western species exists which is structurally like pallidula but that differs in lacking the dark dorsal abdominal stripe.

\section{Alloperla diversa Frison}

Alloperla diversa Frison (1935b, p. 333). Original description, $\hat{\jmath}$, $q$.

Alloperla nimbilis Hoppe (1938, p. 155). Original description, $\hat{\delta}$. New synonymy.

A study of the male type of nimbilis, through the courtesy of Professor Trevor Kincaid of the University of Washington, has revealed that it is practically identical with the male type of dizersa, described from Oregon. The supra-anal process may differ slightly, but certainly no differences exist to warrant separate specific recognition, in the absence of other characters. Hoppe did not record diversa from Washington, and no mention is made in the original description of nimbilis of differences from or similarities to diz'ersa.

\section{Alloperla chloris Frison}

Alloperla chloris Frison (1934, p. 27). Original description, $\hat{\delta}$, + .

Chloroperla milnei Ricker (1935, p. 198). Original description, $\hat{\delta}$, + . New synonymy.

A restudy of a paratypic specimen of milnei in the Illinois Natural History Survey collection and the cleared terminal abdominal segments of another paratypic specimen sent to me by Dr. IV. E. Ricker on loan from the Royal Ontario Museum of Zoology, Toronto, Canada, has revealed that milnei is a synonym of chloris. Dr. Ricker states in a letter to me that he concurs with my opinion regarding this synonymy. 


\section{I.ITERATURE CITED}

Alevander, C. P.

1936. A new species of Perlodes from the White Mountains. New Hanpshire. Brouklyu Ent. Soc. Bul. $31: 24-7$.

lianks, Nathan

1895. New neuropteroid insects. Am. Ent. Soc. Trans. 22:313-6.

1898. Descriptions of new North American neuropteroid insects. Am. Ent. Soc. 'rrans. 25 :199-201.

1900. New genera and species of Nearctic neuropteroid insects. Am. Ent. Soc. Trans. 26:239-59. June.

1904. Neuropteroid insects from New Mexico. Am. Ent. Soc. Trans. 30:97-110.

1905. Descriptions of new species of neuropterous insects from the Black Mountains, N. C. Am. Mus. Nat. Hist. 13ul. $21: 215-8$.

1906a. Descriptions of new Nearctic neuropteroid insects. Am. Ent. Soc. Trans. 32:1-51. Pls. 1-5. Nov.-Dec., 1905.

1906h. On the perlid genus Chloroperla. Ent. News $17(5): 17+-5$. May.

1906c. New species of Perlidae. Can. Ent. $38: 335-8$.

1907. A list of Perlidae from British Columbia and Alberta. Can. Ent. 39: 325-30.

1908a. Neuropteroid insects-notes and descriptions. Am. Ent. Soc. Trans. 34: 255-67.

1908b. Trichoptera, and allied insects, from Newfoundland. Psyche 15:66.

1911. Descriptions of new species of North American neuropteroid insects. Am. Ent. Soc. Trans. $37: 335-7$.

1914. New neuropteroid insects, native and exotic. Acad. Nat. Sci. Phila. Proc. 66:608-11.

1918. New neuropteroid insects. Mus. Comp. Zool. Bul. 62(1):3-22. 2 pls. March.

1920. New neuropteroid insects. Mus. Comp. Zool. Bul. 64:31t-25.

1938. New native neuropteroid insects. Psyche 45:73-5.

Hurmeister, $\mathrm{H}$.

1839. Plecoptera. Handbuch der Entomologie, land II, part 2, pp. 863-81. T. C. F. Ensliu, Berlin.

\section{Claassen, Peter W.}

1923. New species of North American Plecoptera. Can. Ent. 55(12):257-63. 281-92. 1 pl. Dec.

1924. New species of North American Capniidae (Plecoptera). Can. Ent. 56 (2) $:+3-8$. Feb.

1928. Additions and corrections to the monograph on the Plecoptera of
North America. Ent. Soc. Aın. Ann. $21(4): 667-8$. Dec

1931. Plecoptera nymphs of America (north of Mexico). Thomas Say Found. Pub. 3. 199 pp., 35 pls.

1937a. New species of stoneflies (Plecop. tera). Can. Ent. 69:79-82. 1 pl. April.

1937b. New species of stoneflies (Plecoptera). Kans. Ent. Soc. Jour. 10(2): +2-51. 1 pl. April.

1940. A catalogue of the Plecoptera of the world. Cornell Univ. Ag. Exp. Sta. Memoir 232:1-235. June.

Clark, Robert L.

1934. The external morphology of Acroneuria evoluta Klapálek (Perlidae, Plecoptera). Ohio Jour. Sci. $34(2)$ : 121-8. 17 figs. March.

Despax, R.

1936. Contribution a l'étude du genre Chloroperla [Pictet] (Isoperla Banks) [Plecoptera]. Toulouse Société d'Histoire Naturelle Bulletin 69(3):337-98.

Fitch, Asa

18+7. Winter insects of eastern New York. Am. Jour. Ag. Sci. 5 (13) :27+-8t. May.

Frison, Theodore $\mathrm{H}$.

1929. Fall and winter stonetlies, or Plecoptera, of Illinois. 1ll. Nat. Hist. Surv. Bul. 18(2) :3+0-409. 77 figs. May.

1934. Four new species of stoneflies from North America (Plecoptera). Can. Ent. 66(2):25-30. 16 figs. Feb.

1935a. The stoneflies, or Plecoptera, of 11linois. III. Nat. Hist. Surv. Bul. 20(4): 281-471. Frontis. + 3+t tigs., bibliog., index.

1935l. New North American species of the genus Alloperla. Am. Ent. Soc. Trans. $61: 331-4+$.

1936. Some new species of stoneflies from Oregon (Plecoptera). Ent. Soc. Am. Ann. 29 (2) :256-65. June.

1937. Studies of Nearctic aquatic insects: Descriptions of Plecoptera. Ill. Nat. Hist. Surv. Bul. 2l(3):78-99. Figs. 65-86. Sept.

1942. Descriptions, records and systematic notes concerning western North American stoneflies (Plecoptera). Pan-Pacific Ent. 18(1):9-16; (2):6173. 19 figs. Jan., April.

Garman, H.

1912. A preliminary study of Kentucky localities in which pellagra is prevalent. Ky. Ag. Exp. Sta. Bul. 159: 58-60. Figs. 47, 48. Jan. 


\section{Gerstaecker, A.}

1873. Ueber Pteronarcys Newm. und eine zweite, in Imago-Stadium mit Tracheenkiemen versehene PerlarienGattung. Festschrift zür Feier des 100-jährigen Bestehens der Gesellschaft Naturforschender Freunde zu Berlin, pp. 39-7t.

\section{Hagen, Hermann}

1861. Synopsis of the Neuroptera of North America. Smithsn. Inst. Misc. Collect. $\mathrm{xx}+3+7 \mathrm{pp}$. Washington, D. C. July.

1873. Perlina. Boston Soc. Nat. Hist. Proc. I5:281-90.

1874. Family Perlina. U. S. Geol. and Geog. Surv. Terr. Ann. Rep. 1873: 573-7.

Hanson, John F.

1938. Studies on the Plecoptera of North America 1. Brooklyn Ent. Soc. Bul. $33: 79-83$.

19+1. Studies of the Plecoptera of North America II. Brooklyn Ent. Soc. Bul. 36:57-66. 15 figs.

Hoppe, Gertrude N.

1938. Plecoptera of Washington. Wash. [State] Univ. Pubs. Biol. 4(2) :13974. 25 figs.

Hynes, H. B. N.

19+1. The taxonomy and ecology of the nymphs of British Plecoptera with notes on the adults and eggs. Roy. Ent. Soc. London Trans. 91(10): 459 557. $2+$ figs., 1 map. Dec.

Kimmins, D. E.

1936. Synonymic notes on the genera Chloroperla, Isopteryx and Isoperla (Plecoptera). Soc. Brit. Ent. Jour. 2:121-4. March.

\section{Klapálek, Franz}

1902. Zur Kenntniss der Neuropteroiden von Ungarn, Bosnien und Herzegovina. Termeszetrajzi Füzetek, Budapest, $25: 178-80$.

1907. Beitrag zur Kenntnis der Gattung Pteronarcys Newman. Bulletin International, Académie des Sciences de l'Empereur François Joseph I, 12: 150-62. 10 figs.

1909. Revision der Gattung Acroneuria Pict. Bulletin International, Académie des Sciences de l'Empereur François Joseph I, 14:23+-47. 10 figs. Nov.

1912. Collections zoologiques du Baron Edm. de Selys Longchamps, Catalogue systématique et descriptif. Fasc. IV (Plécoptères). I. F am. Perlodidae. 66 pp., 58 figs. June 25.

1916. Subfamilia Acroneuriinae Klp. Ceské Spolecnosti Entomologécké Casopis $13: 45-84$.

1917. Ceské Spolecnosti Entomologécké Casopis $14: 40-57$.

1923a. Collections zoologiques du Baron
Edm. de Selys Longchamps, Catalogue systématique et descriptif. Fisc. IV 2 (Plécoptères). II. F am. Perlidae, subfam. Perlinae, Neoperlinae. 193 pp., $85+61$ figs. March 1.

1923b. Plécoptères nouveaux. Soc. Ent. Belgique Ann. 63:21-9.

Neave, Ferris

1929. Reports of the Jasper Park Lakes Investigations 1925-26. II. Plecoptera. Contributions to Can. Biol. and Fish. 4(13):159-68. 21 figs.

1933. Some new stoneflies from western Canada. Can. Ent. 65(10):235-8. Figs. 1-5. Oct.

1934. Stoneflies from the Purcell Range, B. C. Can. Ent. 66(1):1-6. 1 fig.

Needham, James G.

1905. New genera and species of Perlidae. Biol. Soc. Wash. Proc. 18:107-10. March 31.

1933. A stonefly nymph with paired lateral abdominal appendages. Jour. Ent. and Zool. 25:17-9. 1 fig.

Needham, J. H., and P. W. Claassen

1922. The North American species of the genus Acroneuria (Order Plecoptera). Can. Ent. 54(11):249-55. Nov.

1925. A monograph of the Plecoptera or stoneflies of America north of Mexico. Thomas Say Found. Ent. Soc. Am. 2. 397 pp., 50 pls., 29 figs.

Newman, Edward

1836. Entomological notes. Ent. Mag. 3: +99-501.

1838a. Entomological notes. Ent. Mag. 5: 175-8.

1838b. Entomological notes. Ent. Mag. 5: 483-500.

1839. On the synonymy of the Perlites, together with brief characters of the old, and of a few new, species. Mag. Nat. Hist. n.s. (ser. 2) 3:32-7, 8t-90.

Newport, George

1851. On the anatomy and affinities of Pteronarcys regalis Newm.: with a postscript, containing descriptions of some American Perlidae, together with notes on their habits. Linn. Soc. Lond. Trans. 20 (3) : $+47-52$. Pl. 21.

Pictet, F. J.

18+1. Histoire naturelle générale et particulière des insectes Névroptères. Premiere Monographie: Famille des Perlides. +23 pp., 53 colored pls. J. Kessman, Genève.

Provancher, Abbé L.

1876. Petite faune entomologique du Canada, Fam. II, Perlides, Gen. 1, Ptéronarcys. Nat. Can. 8:188-91. June.

Rambur, M. P.

18+2. Histoire naturelle des insectes- $-\mathrm{Nev}$ roptères. xvii $+53+$ pp., 12 colored pls. Roret, Paris. 
Ricker, William E.

1935a. Descriptions of three new Canadian perlids. Can. Ent. 67(9):197-201. Sept.

19356. New Canadian perlids (part 11). Can. Ent. 67 (12) :256-64. 1 pl. Dec.

1938. Notes on specimens of American Plecoptera in European collections. Roy. Can. Inst. Trans, 22:129-56. 38 figs. Oct.

1939. A preliminary list of stoneflies (Plecoptera) from the vicinity of Cultus Lake, British Columbia. Ent. Soc. Brit. Columbia Proc. 35:19-23.

Say, Thomas

1823. Descriptions of insects belonging to the order Neuroptera Lin., Latr. Collected by the expedition authorized by J. C. Calhoun, Secretary of War, under the command of Major S. H. Long. West. Quart. Rep. 2:160-5. April-May-June.

Smith, I. W.

1917. Studies of North American Plecoptera (Pteronarcinae and Perlodini). An. Ent. Soc. Trans. 63:433-89. Dec. 28. Pls. XXIX-XXXIV, figs. A-E.
Stephens, J. Ii.

1835. Illustrations of British entomology, 6: Mandibulata, $13+-45$. Pl. XXXI. Baldwin \& Cradock, London.

Walker, F.

1852. Catalogue of the specimens of neuropterous insects in the collection of the British Museum. Part 1, pp. 1192. London, by order of the Trustees.

Walsh, B. D.

1862. List of the Pseudoneuroptera of Illinois contained in the cabinet of the writer, with descriptions of over 40 new species, and notes on their structural affinities. Acad. Nat. Sci. Phila. Proc., Sept., 362-7.

1863. Perlina. Notes by Benj. D. Walsh. Ent. Soc. Phila. Proc. 2(3):186-8. Oct.

Westwood, J. O.

1840. Synopsis of the genera of British insects-Perlidae Leach. P. +7 .

Wu, Chenfu F.

1934. A homonym of a Plecopterous genus. Ent. Soc. Am. Ann. 27 (2) :256. June. 


\section{$I N D E X$}

Bold face type indicates a principal reference. Both principal and subsidiary references may occur on the same page. A species name appeuring in the heading or billiouraphic subleading of a description is indexed for the page on which it first occurs and not again in that description.

Acroneuria, 237, 240, 241

abnormis, 241

arenosa, 272, 275

areta, 240

arida, 241, 272, 273, 274, 277, 278

brevicauda, 277

californica, 284

carolinensis, 281, 283

clara, 275

cuestae, 281

depressa, 284, 285, 302

depressa (?), 286

evoluta, 241, 272, 273, 274, 277

filicis, 275

georgiana, 280

internata, 241

lycorias, 281,283

mela, 241, 274, 277

pacifica, 284

pennsylvanica, 275,276

perbranchiata, 281, 283

perplexa, 241, 277

prolonga, 272, 273

ruralis, $2+1$

sabulosa, 285, 302

sp. a, $241,27 t$

theodora, 284

valida, 273,274

xanthenes, 277

abnormis, Acroneuria, 241

Adelungia

arctica, 286

caudata, 286

aestivalis, Diploperla, 302

aestivalis, Perla, 302

alameda, Diploperla, 302

alameda, Perla, 302

alex, Taeniopteryx (Oemopteryx), 251

Allocapnia, 237, 241, 262,265, $3+2$

curiosa, 268, 269, 270

forbesi, 241, 269

cornuta, 241

granulata, $2+1$

illinoensis, 241,269

incisura, 266

mystica, 241, 262

pygmaea, $241,265,269$

recta, $2+1$

rickeri, $241,267,269$

sp., 266

torontonensis, 265

virginiana, 269

vivipara, $2+1,265$

Alloperla, 237, 242, 337, 338, 339, 340,34t banksi, $242,339,343$

caudata, $242,339,342$

chloris, 347

concolor, 345

cydippe, 338

diversa, 347

dubia, $3+6$

fidelis, 346

lodgei, $3+4$ nanina, 343,344

neglecta, 345

nimbilis, 347

novascotiana, 345

pallidula, 346

americana, Perlodes, 288

annecta, Clioperla, 329

arctica, Adelungia, 286

arctica, Claassenia, 285, 286

arcuata, Peltoperla, 246, 247

Arcynopteryx, 287

aurea, 287,288

lineata, 287, 288

minor, 287

vagans, 287,288

arenosa, Acroneuria, 272, 275

areta, Acroneuria, 240

arida, Acroneuria, 241, 272, 273, 274, 277, 278

arida, Perla, 272

arina, Diploperla, 309

Atoperla, 237, 241

ephyre, 241

aurea, Arcynopteryx, 287, 288

aurea, Perlodes, 288

banksi, Alloperla, 242, 339, 343

Banksiella kansensis, 278

barbara, Oroperla, 287

bicaudata, Dictyopterygella, 301

bicaudata, Phryganea, 301

biline ata, Isoperla, $242,311,315,316,320,321$, $323,325,332,338$

biloba, Pteronarcys, 245

bilobata, Diploperla, 239, 302, 307, 311

bilobata, Perla, 302

bipunctata, Perla, 301

Brachyptera, 237, 238, 241, 248, 250

contorta, 253

fasciata, 241,248,250,254, 256

glacialis, 251

limata, 255

nigripennis, 256

oregonensis, 251

pacifica, 251, 256

rossi, 254

trifasciata, 248

vanduzee, 253

(Brachyptera) glacialis, Nemoura, 251

bradleyi, Protarcys, 287, 289

brevicauda, Acroneuria, 277

brevis, Hastaperla, 242,338, 339, 341

brevis, Chloroperla, 338, 340

brevis, Peltoperla, 245,246

bulbosa, Diploperla, 307

burksi, Isoperla, 242, 332

californica, Acroneuria, $28+$

californica, Nemoura, 261

capitata, Neophasganophora, 241, 302

capitata, Perla, 302

Capnella

pygmaea, 265

vivipara, 265 
Capnia, 237, 2+1, 262

minima (?), 265

opis, $2+1,262,264,266$

sp., 262

verualis (?), $240,2+1,262,264$

Capuiilae, 237, 238, 239, 241, 262

Capnura, 237

carolina, Nemocapnia, 2+1, 262

carolineusis, Acroneuria, 281, 283

carolinensis, Perla, 281

cascadensis, Isoperla, 337

caudata, Adelungia, 286

caudata, Alloperla, 242,339, 342

chloris, Alloperla, $3+7$

Chloroperla, 237, 337, 338, 339

brevis, $338,3+0$

crelippe, $337,338,339,340$

holochlora, 311

lutea, 337

milnei, $3+7$

inoutana, 330, 331

uana, $3+4$

orpha, 338, 339, 3+0

opis, $26 t$

pallidula, $3+6$

terna, 339

iransmarina, 316

tripunctata, $337,338,340$

Chloroperlidae, 237, 238, 239, 2+0, 242, 337

chrysannula, Isoperla, 337

claasseni, Leuctra, 2+1, 256, 258, 259

claasseni, Paraleuctra, 256, 257

Claassenia, 237, 238, 286, 301

arctica, 285,286

languida, 286, 301, 30 ?

clara, Acroneuria, 275

clio, Clioperla, 336

clio, Isoperla, 2+2,330,334, 336

Clioperla

annecta, 329

clio, 336

clymene, Neoperla, $2+1$

colubrinus, lsogenus, 290

comstocki, Pteronarcys, $2+5$

concolor, Alloperla, $3+5$

confusa, I soperla, 242,330,331

conspicua, Isoperla, $2+2$

contorta, Brachyptera, 253

contorta, Taeniopteryx, 253

cornelia, Peltoperla, $2+7$

cornuta, Allocapnia forbesi, $2+1$

crosbyi, Hydroperla, 241, 293, 295, 296, 302

crosbyi, Perla, 302

cuestae, Acroneuria, 281

curiosa, Allocapnia, 268

cydippe, Alloperla, 338

cydippe, Chloroperla, 337, 338, 339, 340

cydippe, Hastaperla, 2+2, 339

cydippe, Isopertyx, $3+0$

decepta, Isoperla, $2+2,323,32 t$

decepta, Leuctra, 241, 256, 257, 258, 259

depressa, Acroneuria, 28t, 285, 302

depressa (?), Acroneuria, 286

dicala, Isoperla, $240,2+1,321,32+$

Dictyogenus (?) phaleratus, 302

Dictyopterygella, 237, 238, 239, 240

bicaudata, 301

knowltoni, 299, 305

Dictyopteryx

irregularis, 287,290

sigriata, 287,290
Diploperla, 237, 238, 239,240,301, 302

aestivalis, 302

alameda, 302

a rina, 309

bilobata, 239, 302, 307, 311

bulbosa, 307

duplicara, 239, 302, 311

errata, 302

expansa, 302, 305, 307

fugitans, 302

hastata, 300, 302, 309, 325

innubila, 302

luctuosa, 239, 302

misuoma, 302

modesta, 302, 303, 307

nona, 302

phalerata, 302

pilata, 305

ramosa, 302

sorpta, 302

tinctata, 302

verticalis, 302, 311

diversa, Alloperla, 347

dolobrata, Perlodes, 289

dolobrata, Protarcys, 287, 289

dorata, Hydroperla, 293, 295

dorsata, Pteronarcys, 242, $2+4$

dorsata, Sialis, $2+2$

drymo, Perlinella, $2+1$

dubia, Alloperla, $3+6$

duplicata, Isoperla, 2+1, 302

duplicata, Perla, 302

duplicata, Diploperla, 239, 302, 311

duplicata, Perla, 302

Eccoptura xanthenes, 277

elongatus, I sogenus, 290, 291

ephyre, Atoperla, 2+1

errata, Diploperla, 302

errata, Perla, 302

Eucapnopsis, 237, 238

evoluta, Acroneuria, 2+1, 272, 273, 274, 277

expansa, Diploperla, 302, 305, 307

expansa, Perla, 302, 305

extensa, Isoperla, 315

fasciata, Brachyptera, 241,248, 250,25+, 256

fasciata, Semblis, 250

fasciata, Strophopteryx, 250

fidelis, Alloperla, 346

filicis, Acroneuria, 275

Filipalpia, 23\%, 239

flavicornis, Pteronarcys, 242

forbesi, Allocapnia, 2+1, 269

cornuta, $2+1$

forcipata, Leuctra, 259

frigida, Pteronarcys, $2+2$

frontalis, Isogenus, 290

frontalis, Paraperla, 339

fugitans, Diploperla, 302

fugitans, Perla, 302

fulva, Isoperla, 315, 337

fusca, Isoperla, 317

Garman, Larva No. 1, 273

georgiana, Acroneuria, 280

georgiana, Perla, 280

glacialis, Brachyptera, 251

glacialis, Nemoura (Brachyptera), 251

glacialis, Taeniopteryx, 251

granulata, Allocapnia, $2+1$

harti, Hyclroperla, 241, 293, 295, 296 
Hastaperla, 237, 238, 239, 242, 338, 339, 340 brevis, $2+2,338,339,340$

cydippe, $2+2,339$

orpha, 338,340

hastata, Diploperla, 300, 302,309, 325

hastatus, Isogenus, 302

holochlora, Chloroperla, 311

holochlora, lsoperla, 311

Holognatha, 237

Hydroperla, 237, 239, 240,241, 287, 292, 300 , 301,302

crosbyi, 241, 293,295, 296, 302

dorata, 293, 295

harti, 241, 293, 295, 296

nalata, 293, 295, 296

olivacea, 296

parallela, 293, 295, 296, 298

subvarians, 292, 295, 296, 302

varians, $241,293,295,296,302$

ignota, Perlodes, 288

illinoensis, Allocapnia, 241, 269

immarginata, Perla, 302

immarginata, Togoperla, 302

incesta, Perla, 290

incisura, Allocapnia, 266

innubila, Diploperla, 302

innubila, Perla, 302

insignis, Kollaria, $2+2$

insipida, Isoperla, 321

internata, Acroneuria, $2+1$

irregularis, Dictyopteryx, 287, 290

Isocapnia, 237

Isogenus, 237, 239, 240,287, 291, 301

colubrinus, 290

elongatus, 290, 291

frontalis, 290

hastatus, 302

I soperla, 235,237,238,240,242,302, 311, 337, 338,339

bilineata, $2+2,311,315,316,320,321,323$, $325,332,338$

burksi, 2+2, 332

cascadensis, 337

chrysannula, 337

clio, $242,330,337,336$

confusa, $2+2,330,331$

conspicua, $2+2$

decepta, 242, 323, 32t

dicala, $2+0,2+1,321,32 t$

duplicata, 2+1, 302

extensa, 315

fulva, 315,337

fusca, 317

holochlora, 311

insipida, 321

lata, 334

longiseta, 242, 318, 321

marlynia, frontispiece, $2+2,330,33+, 336$

minuta, $242,323,3+4$

mohri, $2+2$

montana, 331

mormona, $318,319,320,321$

namata, 240,327

orata, 323

patricia, 312, 313

pinta, 329,337

richardsoni, $2+2$

signata, 328, 329

similis, 325

slossonae, 329

tokula, 337 transmarina, 316

trictura, 336

truncata, $32 t, 325$

ventralis, 316,334

Isoperlidae, 237, 239, 240,242, 311

Isopteryx, 337, 338

cydippe, $3+0$

kansensis, Banksiella, 278

kansensis, Perla, 302

karisensis, Togoperla, 2+1, 27j, 302

Kathroperla, 237, 239, 338, 339

kincaidi, Taeniopteryx, 251

knowltoni, Dictyopterygella, 299, 305

Kollaria insignis, $2+2$

languida, Claassenia, 286, 301, 302

languida, Perla, 286, 301, 302

lata, Isoperla, 334

Leuctra, 237, 2+1, 256, 260, $3+2$

claasseni, 241,256, 258, 259

decepta, 241, 256, 257, 258, 259

forcipata, 259

occidentalis, 259, 260

projecta, 260

purcellana, 259

sara, $2+1,259$

tenuis, $2+1,256,257,258,261$

Leuctridae, 237, 238, 239, 241, 256

limata, Brachyptera, 255

lineata, Arcynopteryx, 287, 288

lita, Taeniopteryx, 241, 249

lobata, Nemoura, 261

lodgei, Alloperla, $34+$

longiseta, Isoperla, 242, 318, 321

luctuosa, Diploperla, 239, 302

luctuosa, Perla, 302

lurida, Perla, 282

lutea, Chloroperla, 337

lycorias, Acroneuria, 281, 283

lycorias, Perla, 283

margarita, Perlodes, 288

marlynia, Isoperla, frontispiece, 242, 330, 33t, 336

maura, Nemoura, 248

maura, Taeniopteryx, 241, 248, 253

maxima, Perla, 301

media, Perla, 302

media, Togoperla, 241, 302

Megaleuctra, 237

Megarcys, 287

mela, Acroneuria, 241, 274, 277

milnei, Chloroperla, 347

minima (?), Capnia, 265

minor, Arcynopteryx, 287

minor, Perlodes, 287

minuta, Isoperla, 242,323, 3t+

misnoma, Diploperla, 302

misnoma, Perla, 302

modesta, Diploperla, 302, 303, 307

modesta, Perla, 302, 303

mohri, Isoperla, $2+2$

montana, Chloroperla, 330, 331

montana, Isoperla, 331

mormona, Isoperla, 318, 319, 320, 321

mystica, Allocapnia, 241, 262

nalata, Hydroperla, 293, 295, 296

namata, Isoperla, $2+0,327$

nana, Chloroperla, $3+t$

manina, Alloperla, $3+3,344$ 
nebulosa, 'l'aeniopteryx, 248

ueglecta, Alloperla, 345

Vemocapnia, 237, 238, 241, 262

caroliua, 2+1, 262

Vemoura, 237, 238, 2+1, 260, $3+2$

(Brachyptera) glacialis, 251

californica, 261

lobata, 261

inaura, $2+8$

nivalis, 248

tenuis, 258

trispinosa, 241,260,261

venosa, $241,260,261$

Nemouridae, 237, 238, 239, 2+1, 260

Neoperla, 237, 2+1

clymene, $2+1$

Neophasganophora, 237, 240,241, 302

capitata, 2+1, 302

Nephelopteryx, 248

Nephopteryx, 238

nigripennis, Brachyptera, 256

nimbilis, Alloperla, $3+7$

nivalis, Nemoura, $2+8$

nivalis, Taeniopteryx, 241, 248,250, 253

nivicola, Perla, 265

nobilis, Pteronarcys, $2+1,2+2,2+t$

nona, Diploperla, 302

nona, Perla, 302

novascotiana, Alloperla, 345

Obipteryx, 238

obscura, Perla, 302

occidentalis, Leuctra, 259, 260

Oemopteryx, 238, 250

(Oemopteryx) alex, Taeniopteryx, 251

olivacea, Hydroperla, 296

olivacea, Perla, 296

opis, Capnia, 241,262, 264, 266

opis, Chloroperla, 264

orata, Isoperla, 323

oregonensis, Brachyptera, 251

oregonensis, Taeniopteryx, 251

Oroperla, 237, 238

barbara, 287

orpha, Chloroperla, $339,3+0$

orpha, Hastaperla, 338,340

pacifica, Acroneuria, 284

pacifica, Brachyptera, 251, 256

pacifica, Taeniopteryx, 251

pallida, Taeniopteryx, 252

pallidula, Alloperla, 346

pallidula, Chloroperla, $3+6$

Paraleuctra, 256, 257, 260

claasseni, 256, 257

projecta, 260

parallela, Hydroperla, 293, 295, 296, 298

Paraperla, 237, 338, 339

frontalis, 339

parvula, 'Taeniopteryx, 241,249, 250

patricia, Isoperla, 312,313

Peltoperla, 237

a rcuata, $246,2+7$

brevis, $2+5,2+6$

cornelia, 247

zipha, 247

Peltoperliclae, 237, 238, 239, 245

pennsylvanica, Acroneuria, 275

perbranchiata, Acroneuria, 281, 283

Perla, 238, 300, 301, 302

aestivalis, 302

alaneda, 302 arida, 272

hilohata, 302

bipunctata, 301

carolinensis, 281

capitata, 302

crosbyi, 302

duplicata, 302

errata, 302

expansa, 302, 305

fugitans, 302

georgiana, 280

immarginata, 302

incesta, 290

innubila, 302

kansensis, 302

languida, 286, 301, 302

luctuosa, 302

lurida, 282

lycorias, 283

maxima, 301

media, 302

misnoma, 302

modesta, 302, 303

nivicola, 265

nona, 302

obscura, 302

olivacea, 296

placida, 271

postica, 292, 293, 302

ramosa, 302

sabulosa, 285, 302

similis, 325

slossonae, 329

sorpta, 302

subvarians, 292

tincta, 302

tinctata, 302

titusi, 290

trictura, 336

valida, 272

varians, 302

venosa, 302

verticalis, 302

xanthenes, 277

Perlesta, 237, 2+1

placida, 241, 271

Perlidae, 237, 238, 239, 241, 271, 301, 311

Perlinella, 237, 241

drymo, 241

Perlinodes, 287

Perlodes, 237, 238, 239, 240, 287, 292, 300, 301 americana, 288

aurea, 288

dolobrata, 289

ignota, 288

margarita, 288

minor, 287

signata, 290

slossonae, 287, 289

tibialis, 287, 289

yosemite, 287, 290

Perlodidae, 237, 238, 239, 240, 241, 287, 300 , 301,311

Perlomyia, 237

perplexa, Acroneuria, 241, 277

phalerata, Diploperla, 302

phaleratus, Dictyogenus (?), 302

Phryganea bicaudata, 301

pictetii, Pteronarcys, 2+1, 2+2, 244

pilata, Diploperla, 305

pinta, Isoperla, 329, 337

placida, Perla, 271 
placida, Perlesta, 241, 271

Plecoptera, List of the Illinois, $2+1$

Plecoptera, Revised classification, 237

Plecoptera, Revised key to families, 238 postica, Perla, 292, 293, 302

projecta, Leuctra, 260

projecta, Paraleuctra, 260

prolonga, Acroneuria, 272, 273

Protarcys, 287, 289

bradleyi, 287, 289

dolobrata, 287, 289

proteus, Pteronarcys, 242, 24t, 245

Pteronarcella, 237

Pteronarcidae, 237, 238, 239, 241, 242

Pteronarcys, $237,240,2+1,2+2$

biloba, $2+5$

comstocki, $2+5$

dorsata, 242, $2+4$

flavicornis, $2+2$

frigida, $2+2$

nobilis, $2+1,2+2,2+4$

pictetii, $241,242,244$

proteus, $2+2,2+4,2+5$

rectus, $2+2$

regalis, $242,2+4$

shelfordi, $2+2$

species, 245

purcellana, Leuctra, 259

pygmaea, Allocapnia, 241, 265, 269

pygmaea, Capnella, 265

pygmaea, Semblis, 265

ramosa, Diploperla, 302

ramosa, Perla, 302

raynoria, Taeniopteryx, 251

recta, Allocapnia, $2+1$

rectus, Pteronarcys, $2+2$

regalis, Pteronarcys, 242,244

Rhabdiopteryx, 238, 250

richardsoni, Isoperla, $2+2$

rickeri, Allocapnia, 241, 267, 269

rossi, Brachyptera, $25+$

ruralis, Acroneuria, $2+1$

sabulosa, Acroneuria, 285, 302

sabulosa, Perla, 285, 302

sara, Leuctra, 2+1, 259

Semblis

fasciata, 250

pygmaea, 265

Setipalpia, 237

shelfordi, Pteronarcys, 242

Sialis dorsata, $2+2$

signata, Dictyopteryx, 287, 290

signata, Isoperla, 328, 329

signata, Perlodes, 290

similis, Isoperla, 325

similis, Perla, 325

slossonae, Isoperla, 329

slossonae, Perla, 329

slossonae, Perlodes, 287, 289

sorpta, Diploperla, 302

sorpta, Perla, 302

Strophopteryx, 238, 248, 250

fasciata, 250

Subulipalpia, 237, 239

subvarians, Hydroperla, 292, 295, 296, 302 subvarians, Perla, 292

Systellognatha, 237

Taeniopterygidae, 237, 238, 239,241, 247, 250

Taeniopteryx, 237, 241, 248, 250

contorta, 253

glacialis, 251

kincaidi, 251

lita, 241, 249

maura, 241, 248, 253

nebulosa, 248

nivalis, $2+1,248,250,253$

(Oemopteryx) alex, 251

oregonensis, 251

pacifica, 251

pallida, 252

parvula, $241,249,250$

raynoria, 251

vanduzee, 253

tenuis, Leuctra, 241, 256, 257, 258, 261

tenuis, Nemoura, 258

terna, Chloroperla, 339

theodora, Acroneuria, 284

tibialis, Perlodes, 287, 289

tincta, Perla, 302

tinctata, Diploperla, 302

tinctata, Perla, 302

titusi, Perla, 290

Togoperla, 237, 241, 302

immarginata, 302

kansensis, 241,277, 302

media, 241, 302

sp. a, 241

tokula, Isoperla, 337

torontonensis, Allocapnia, 265

transmarina, Chloroperla, 316

transmarina, Isoperla, 316

trictura, Isoperla, 336

trictura, Perla, 336

trifasciata, Brachyptera, $2+8$

tripunctata, Chloroperla, 337, 338, 3+0

trispinosa, Nemoura, 241, 260, 26I

truncata, Isoperla, 324, 325

vagans, Arcynopteryx, 287, 288

valida, Acroneuria, 273, 274

valida, Perla, 272

vanduzee, Brachyptera, 253

vanduzee, Taeniopteryx, 253

varians, Hydroperla, 241, 293, 295, 296, 302

varians, Perla, 302

venosa, Nemoura, 241, 260, 261

venosa, Perla, 302

ventralis, Isoperla, 316, 334

vernalis (?), Capnia, $240,2+1,262,26+$

verticalis, Diploperla, 302, 311

verticalis, Perla, 302

virginiana, Allocapnia, 269

vivipara, Allocapnia, 241, 265

vivipara, Capnella, 265

xanthenes, Acroneuria, 277

xanthenes, Eccoptura, 277

xanthenes, Perla, 277

yosemite, Perlodes, 287, 290

zipha, Peltoperla, 247 




\section{Recent Publications}

\section{of the Illinois Natural History Survey}

\section{A.-ILLINOIS NATURAL HISTORY SUIVEY BULLETIN.}

Volume 21, Article 3.-Studies of Nearctic Aquatic Insects. By H. H. Ross and T. H. Frison. September, 1937. 52 pp., frontis. +86 figs., bibliog. 50 cents.

Volume 21, Article 4.-Descriptions of Nearctic Caddis Flies (Trichoptera), with special reference to the Illinois species. By Herbert H. Ross. March, 1938. 84 pp., frontis. + 123 figs., foreword, index. $\$ 1.00$.

Volume 21, Article 5.- Preliminary Studies on Parasites of Upland Game Birds and Fur-Bearing Mammals in Illinois. By W. Henry Leigh. August, 1940. 10 pp, frontis. +2 maps.

Volume 21, Article 6.-Preliminary Investigation of Oak Diseases in Illinois. By J. Cedric Carter. June, 1941. 36 pp., frontis. + 51 figs., bibliog. (Bound with Article 7.)

Volume 21, Article 7.-A Needle Blight of Austrian Pine. By Robert L. Hulbary. June, 1941. 6 pp., frontis. +3 figs., bibliog. (Bound with Article 6.)

Volume 21, Article 8.-Duck Food Plants of the Illinois River Valley. By Frank C. Bellrose, Jr. August, 1941. 44 pp., frontis. + 35 figs., bibliog., appendix.

Volume 22, Article 1. -The Plant Bugs, or Miridae, of Illinois. By Harry $\mathrm{H}$. Knight. September, 1941. 234 pp., frontis. + 181 figs., bibliog., index. $\$ 1.25$.

\section{B.-ILLINOIS NATURAL HISTORY SURVEY CIRCULAR.}

32.-Pleasure With Plants. By L. R. Tehon. April, 1939. 32 pp., frontis. + 9 figs. Coutents: What is botanizing? Ways to botanize; Where to botanize; When to botanize; How to botanize; Studying plants; Equipment for atudying plants; The herbarlum; Useful books; Maps; Couclusion.

33.-Controlling Peach Insects in Illinois. By S. C. Chandler and W. P. Flint. Auguat, 1939. 40 pp., frontis. +32 figs.

Contents: Part I. Insects attacking bark and trunk of the peach tree; Part II. Insects attacking twitgs, foliage and fruit of the peach tree.

34.-Rout the Weeds! Why, When and How. By L. R. Tehon. January, 1940. (Second printing.) $47 \mathrm{pp}$., color frontis. + 13 figs.

Contents: The importance of weeds; Weeds as economic factors; Weeds as harborers of insects; Weeds as harborers of plant diseases; Relation of weeds to public health; Control methods; Thirteen noxious and pernicious weeds of Illinois.

35.-Diseases of Small Grain Crops in Illinois. By G. H. Boewe. September, 1939. 130 pp., frontis. +47 figs.

Contents: Nature of cereal diseases; Wheat disesses; Oats diseases; Barley diseases; Rye discases; Cereal dlsease control.

36.-Planting and Care of Shade Trees. By J. E. Davis. March, 1941. 23 pp., fronti. +16 figs.

Contents: Introduction; Planning for shade; Planting shade trees; Care of newly plantad trees; Care of older trees; Some common trees used for ghade.

37.-Outwitting Termites in Illinois. By W. E. McCauley and W. P. Flint. Auguat, 1942. (Seeond printing.) 23 pp., frontis. +19 figs.

Contents: Termites and their habits; Structural control of termites; Control of termites with

38. - Windbreaks for Illinois Farmsteads. By J. E. Davis. February, 1942. (Secol printing.) 24 pp., frontis. +19 figs.

Contents: Introduction; Planning the windbreak; Planting the windbreak; Care of the windbreak; What the windbreak trees are like; windbreals and wildilfe.

39.-How to Collect and Preserve Insects. By H. H. Ross. June, 1941. 48 pp., frontis. +53 figs.

Contents: Where to collect; What to use; Special collecting equipment; Sending insects for Identification; How to handle unmonnted gpecimens; How to mount and preserve ap j. mens; How to label the specimens; Housing the collection permanently; Pdentifying to specimens; Useful books; How to ship a collection; Where to buy supplies.

40.-Control of Roundheaded Apple Tree Borer. By S. C. Chandler and W. P. Flint April, 1942. 8 pp., 6 figs.

\section{C.-ILLINOIS NATURAL HISTORY SURVEY MANUAL.}

1.-Fieldbook of Illinois Wild Flowers. By the staff. March, 1936. $406 \mathrm{pp}$, color frontis. +349 figs., index. $\$ 1.50$.

Contents: Introduction; Key to familles; Description of species (650).

2.-Fieldbook of Illinois Land Snails. By Frank Collins Baker. August, 1939. 166 pp., color frontis. +170 figs., 8 pls. $\$ 1.00$.

Contents: Land snulls, what they are and where they live; Land analls native to Illinols; Lant salls introduced from foreign countries; Land snalis of uncertain presence in Iilinols; Hibliography; Check list of Illinols species; Index.

List of available publications, over 300 titles, mailed on request.

Address orders and correspondence to the Chief

ILliNOIS NATURAL HISTORY SURVEY

Natural Resources Building, Urbana, Illinois

Payment in the form of U. S. Post Offes money order made out to

State Treasurer of Inlnols, Springfield, IIInnols,

must accompany requesto for those publications on which a price is sot. 